FINAL TECHNICAL REPORT

Award No. DE-FC36-04GO14045

Project Period: January 1, 2004 through December 31, 2006

\title{
Low Temperature Surface Carburization of Stainless Steels
}

\author{
Sunniva R. Collins \\ Swagelok Company \\ 31500 Aurora Road \\ Solon, Ohio 44139-3492 \\ (440) 349-5934 ext. 4128 \\ Sunniva.collins@,swagelok.com \\ Arthur H. Heuer \\ Case Western Reserve University \\ Department of Materials Science \& Engineering \\ 10900 Euclid Avenue \\ 526 White Building \\ Cleveland, Ohio 44106-7204 \\ (216) 368-3868 \\ heuer@cwru.edu \\ Vinod K. Sikka \\ Oak Ridge National Laboratory \\ P.O. Box 2008 \\ Oak Ridge, Tennessee 37831-6083 \\ (865) 574-5112 \\ sikkavk@ornl.gov
}

Prepared jointly by:

Swagelok Company

Case Western Reserve University

Oak Ridge National Laboratory

December 2007 


\section{Acknowledgments and Disclaimer}

\section{Acknowledgments}

This report is based upon work supported by the U.S. Department of Energy, Energy Efficiency and Renewable Energy, Industrial Technologies Program, Industrial Materials for the Future, under Award No. DE-FC36-04GO14045.

Research at the Oak Ridge National Laboratory was sponsored by the U.S. Department of Energy, Office of Energy Efficiency and Renewable Energy, Industrial Technologies Program, under contract DE-AC05-00OR22725 with UT-Battelle, LLC. The authors wish to thank Dr. James Hemrick for reviewing the document and Ms. Millie Atchley for preparation of documents.

\section{Disclaimer}

This report was prepared as an account of work sponsored by an agency of the U.S. Government. Neither the U.S. Government nor any agency thereof, nor any of their employees, makes any warranty, express or implied, or assumes any legal liability or responsibility for the accuracy, completeness, or usefulness of any information, apparatus, product, or process disclosed, or represents that its use would not infringe privately owned rights. Reference herein to any specific commercial product, process, or service by trade name, trademark, manufacturer, or otherwise, does not necessarily constitute or imply its endorsement, recommendation, or favoring by the U.S. Government or any agency thereof. Any findings, opinions, and conclusions or recommendations expressed in this report are those of the author(s) and do not necessarily reflect the views of the Department of Energy. 


\section{Table of Contents}

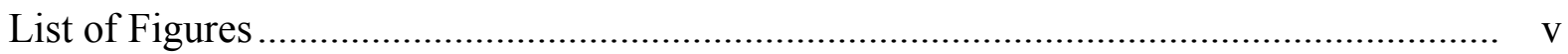

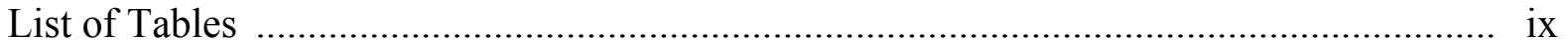

Abbreviations and Acronyms ...................................................................................... xi

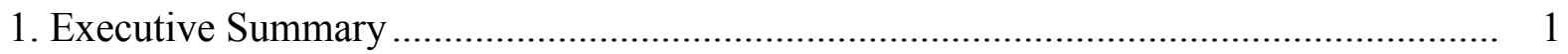

1.1 Purpose

1.2 Scope

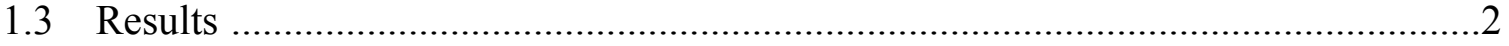

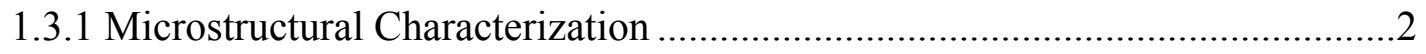

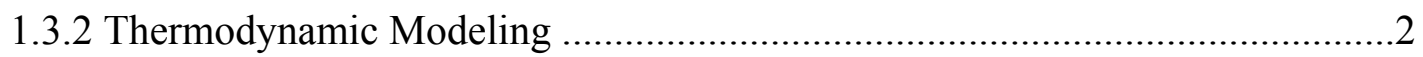

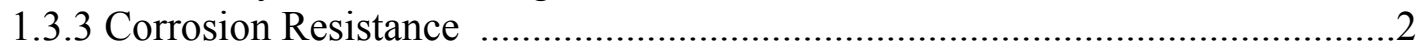

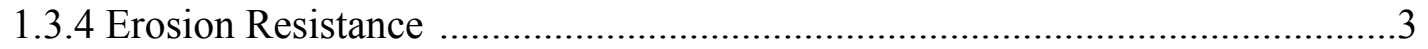

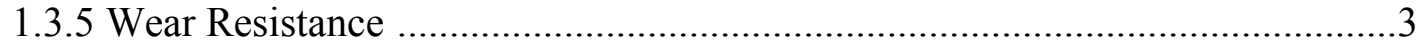

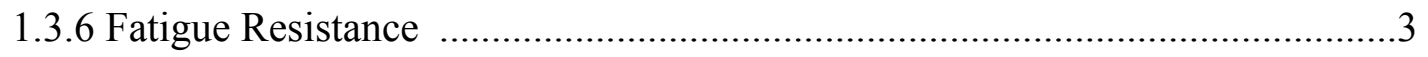

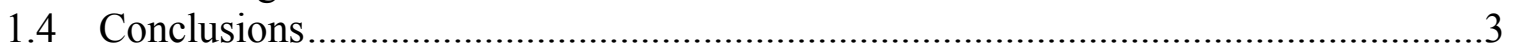

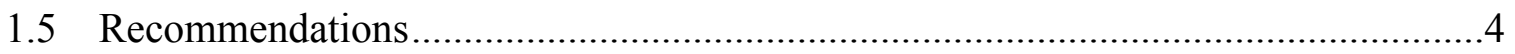

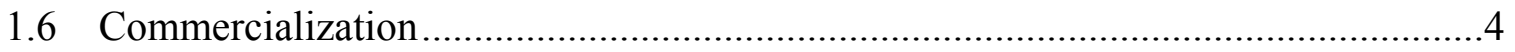

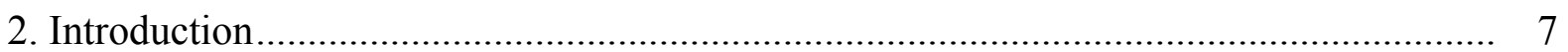

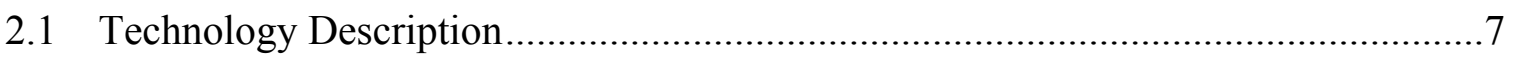

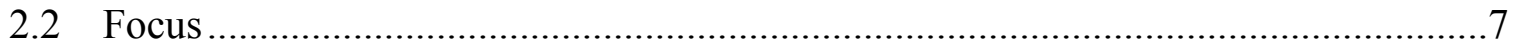

2.3 Potential Applications and Energy Savings .............................................................

2.4 Commercialization Status and Plans.....................................................................

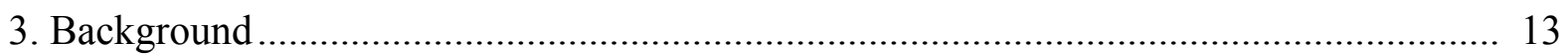

3.1 Domestic Technology Status Including Emerging Technologies.............................13

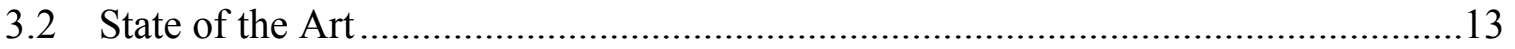

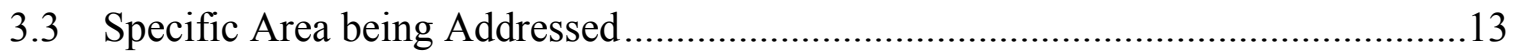

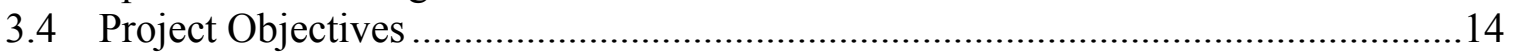

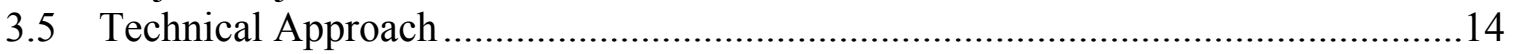

3.6 Relevant Qualifications and Experience of Team Members …………………….....16

3.6.1 Resumes of Key Personnel ......................................................................16

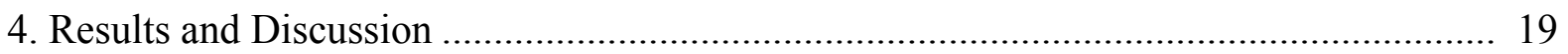

4.1 Project Approach .........................................................................................19

4.1.1 Manufacture/Procure Alloys and Specimens, Process Alloys, and Perform Initial Evaluations (Swagelok)................................................................ 19

4.1.2 Microstructural Characterization (CWRU),............................................... 19

4.1.2.1 Optical and Scanning Electron Microscopy ……............................. 19

4.1.2.2 Transmission Electron Microscopy ……………………………...... 22

4.1.2.3 Hardness Testing ..................................................................... 25

4.1.2.4 Microchemical Analysis ............................................................ 26

4.1.2.5 X-ray Diffraction .......................................................................... 28

4.1.2.6 Magnetic Force Microscopy of Carburized 301 Stainless Steels ...... 32 
4.1.2.7 Local Electrode Atom Probe Microscopy........................................... 32

4.1.3 Thermodynamic Modeling......................................................................... 35

4.1.3.1 Carbon Solubility in FCC Steels................................................... 35

4.1.3.2 TTT Diagrams .............................................................................. 37

4.1.3.3 Carbon Solubility in Other Alloys ..................................................... 37

4.1.3.4 Ferrite/Austenite Stability ............................................................ 38

4.1.4 Corrosion Testing .................................................................................. 39

4.1.4.1 Polarization Measurements ............................................................... 39

4.1.4.2 Critical Pitting Temperature and Electrical Pitting Potential of

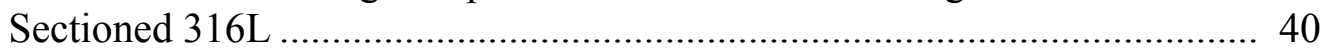

4.1.4.3 Cavitation Erosion ........................................................................ 43

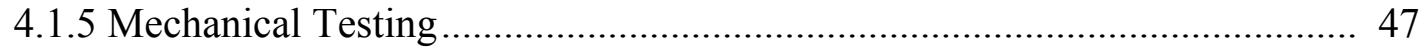

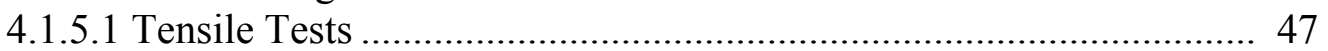

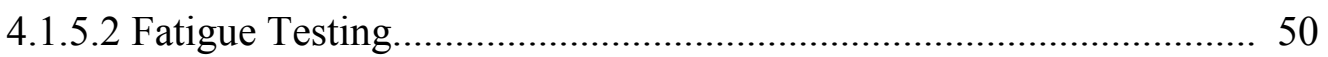

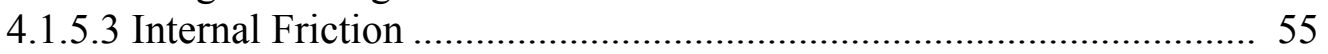

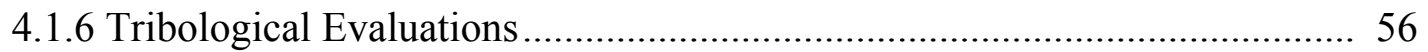

4.1.6.1 Pin-on-Disk Friction and Wear Tests ............................................. 56

4.1.6.2 Elevated Temperature Wear Tests ................................................... 58

4.1.6.3 Sliding Friction and Wear Tests ..................................................... 59

4.1.6.3.1 Dry Sliding at Room Temperature ...................................... 60

4.1.6.3.2 Sliding in Salt Water......................................................... 60

4.1.6.3.3 Sliding at Elevated Temperatures ........................................ 61

4.1.6.3.3.1 Effects of Temperature on Friction ........................ 61

4.1.6.3.3.2 Effects of Temperature on Wear ............................ 61

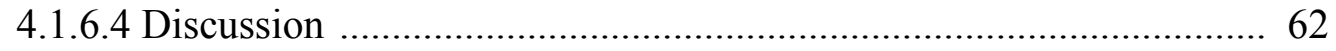

4.1.6.4.1 Work Hardening ......................................................... 62

4.1.6.4.2 Stability of the Carburized Surface at Elevated

Temperatures .................................................................... 64

4.1.6.4.3 Frictional Behavior ………………………....................... 64

4.1.6.4.4 Wear Mechanisms .......................................................... 67

4.1.6.5 Conclusion of Tribological Evaluation ............................................ 68

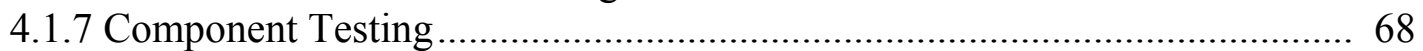

4.1.7.1 Sonoco Pulp and Paper Facility in Tennessee ...................................... 68

4.1.7.2 Other Components ...................................................................... 71

4.1.8 Manufacture of Experimental Alloy .............................................................. 71

4.1.9 Meetings and Reports ............................................................................ 74

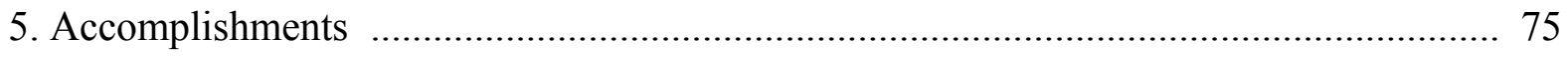

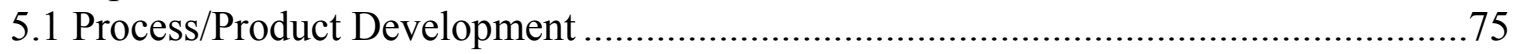

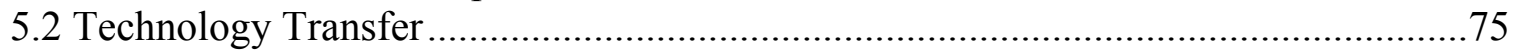

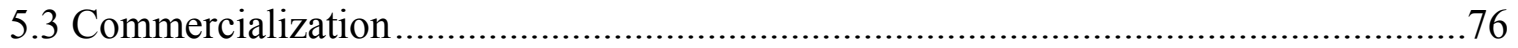

5.4 Publications, Presentations, Conference Proceedings, Patents, and Theses .................78

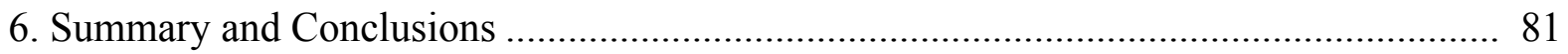

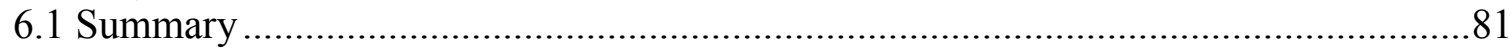

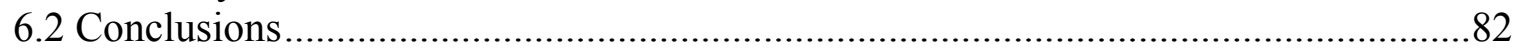




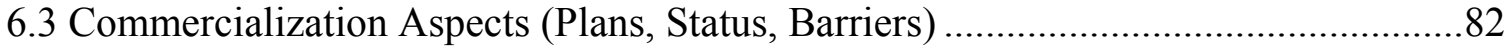

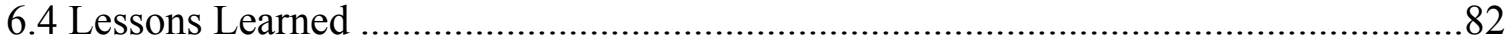

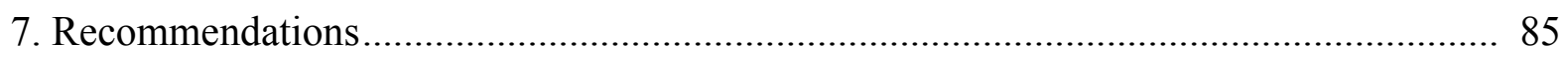

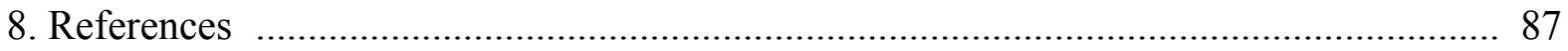

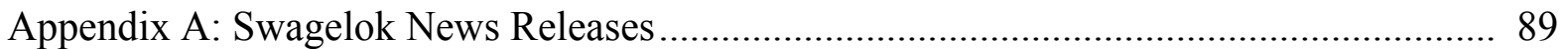

Appendix B: Results of Field Testing ...................................................................... 97 


\section{List of Figures}

2.1 Low-temperature carburization of stainless steels: project milestones and stage gates .. 10 4.1 Optical microscope images of the treated surfaces: (a) 254 SMO and (b) 316 alloys. The deformation of the deformation following the carburization treatment may be seen in the images.

4.2 Scanning electron microscopy micrographs of: (a) non-treated and (b) treated 316 alloy showing the surface deformation at a higher magnification, and (c) non-treated and (d) treated 254 SMO alloy showing the surface deformation at a higher magnification. 4.3 (a) and (b) Scanning electron microscopy images showing secondary phase found in 4xcarburized 304 stainless steel samples. (c) and (c) Optical microscopy images of 304 stainless steel samples; (c) 1x carburized and etched with Marble's reagent; and (d) 4x carburized and chemo-mechanically polished with a $\mathrm{SiO}_{2}$ suspension.

4.4 (a) Carburized 301 polished with $0.05 \mu \mathrm{m} \mathrm{Al}{ }_{2} \mathrm{O}_{3}$ powder, (b) 301 etched by Glyceregia etchant, and (c) 301 after etching 30 seconds with $\mathrm{HNO}: \mathrm{HCl}: \mathrm{H} 2 \mathrm{O}=1: 1: 1$

4.5 Orientation image microscopy micrographs of the non-treated alloy surface of: (a) 254 and (b) 316.

4.6 High resolution transmission electron microscopy image of the interface between Hägg carbide and austenite in carburized $316 \mathrm{~L}$ austenitic stainless steel.

4.7 Energy filtered convergent beam electron diffraction (CBED) images taken from [323] zone axis of the austenite phase in the 254 SMO sample: (a) a raw CBED image, and (b) the same image with an overlay of the best fit higher order low zone lines simulation indicating a lattice parameter of $3.618 \pm 0.0005 \mathrm{~nm}$.

4.8 Hardness versus depth for a carburized 316L sample using both micro-indentation and nano-indentation

4.9 Calibration of the Auger measurement performed by using five different standards with known carbon compositions. Every measurement consists of at least six times. The red and blue lines represent the upper and lower boundary of the fit with 95\% confidence level.... 27 4.10 Compositional profile obtained by line-scan using Auger electron spectroscope, taken from (a) 316 and (b) $254 \mathrm{SMO}$ alloys. The measurements were performed under a continuous sputtering at a minimal dose to prevent carbon contamination during the measuring.

4.11 (a) Hardness and carbon concentration data for carburized 316L, and (b) the same data as hardness versus carbon concentration. The solid line is a linear extrapolation...... 28 4.12 (a) X-ray diffraction results for a carburized 316L sample, which was serially sectioned by electropolishing, and (b) the lattice parameters determined by the peak positions in (a). 29 4.13 X-ray diffraction patterns of $1 \mathrm{x}$-treated and non-treated 301 specimens. .................. 31 4.14 Magnetic force microscopy cross-sectional image of carburized 301 stainless steel, near the surface. The area shown is 50 by $50 \mu \mathrm{m}$. The sample mount is on the left side of the imag

4.15 Scanning electron microscopy micrographs of a 1x-carburized 316 sample prepared for local electrode atom probe analysis by focused ion beam: (a) is a low-magnification image showing the tip and the opening on both sides (allowing the approach of the electrode) and (b) is a higher magnification image of the tip. 
4.16 Reconstructed atom images obtained by the local electrode atom probe analysis. The images are a projection of a 2-nm slice taken through the central area of the tip. In some of the images a light-shaded line can be seen going from the top to the bottom; this is due to an artifact of the multi-channel detector and is not a bona fide structural feature. The values presented as a percent are the ratio of the atoms present in the figure to the total number of atoms recorded in the same area x 100: (a) $\mathrm{Ni}^{+2} 100 \%$; (b) $\mathrm{Cr}^{+2} 77 \%$; (c) $\mathrm{C}^{+}, \mathrm{C}^{+2}, 2 \mathrm{C}^{+}, 3 \mathrm{C}^{+2}$, $3 \mathrm{C}^{+}, 100 \%$; (d) All Mo \& C, 100\%; (e) $\mathrm{Mo}^{+2}, \mathrm{Mo}^{+3}, \mathrm{MoC}^{+2}, 100 \%$; and (f) $\mathrm{MoC}^{+2}$, $100 \%$.

4.17 Reconstructed atom images obtained by the local electrode atom probe analysis based on the main matrix elements, $\mathrm{Fe}-\mathrm{Ni}-\mathrm{Cr}$. The results are presented at two different magnifications: (a) $3 \mathrm{~nm}$ and (b) $2 \mathrm{~nm}$.

4.18 Calculated carbon solubility in (a) Fe and (b) Fe-18Cr-12Ni considering various carbides.

4.19 TTT curves for $\mathrm{M}_{23} \mathrm{C}_{6}$ at varying carbon concentrations..................................... 38

4.20 Cyclic potentiodynamic polarization curves for: (a) non-treated and carburized 316 samples, and (b) carburized 316 samples with varying degrees of roughness.

4.21 Corrosion results for a variety of alloys.

4.22 (a) Residual stress determination by X-ray diffraction, and (b) the residual stresses

plotted as a function of depth.

4.23 Polarization curves from an non-treated 316 stainless steel sample and a carburized 316 stainless steel sample that has been plastically strained to relieve residual stresses. ..... 42 4.24 X-ray photo spectroscopy depth profiles of an as-carburized 316 sample. The enhanced carbon content in the passivating oxide layer is evident.............................................. 43

4.25 Weight loss as a function of time for non-treated materials................................... 44

4.26 Weight loss as a function of time for treated materials. ....................................... 44

4.27 Regression analysis of weight loss data for all treated materials.............................. 45

4.28 Surface appearance of 321 stainless steel after six hours of sonication. .................... 46

4.29 Surface appearance of 254 SMO material after six hours of sonication..................... 46

4.30 Initial stress-strain behavior of uncarburized and low-temperature colossal supersaturation, carburized 316,321 , and 254 SMO round tensile bars.

4.31 Stress-strain curves of carburized 316L, carburized 316L with the carburized case removed, and a uncarburized $316 \mathrm{~L}$ control sample.

4.32 Load-displacement/stress-strain curves of carburized and non-treated 0.002-in.-thick $316 \mathrm{~L}$ foil

4.33 Scanning electron microscopy image of fracture surface of one time carburized sample tested in tension.

4.34 (a) Stainless steel sample; (b,c) finite element analysis results for a stainless steel sample pulled in uniaxial tension at a load of $200 \mathrm{MPa}$ showing (b) the principal normal stresses and (c) plot of principal normal stresses along the section A-A'; and (d) optical micrograph with scanning electron microscopy insets showing the surface roughness of the fatigue specimens.

4.35 Fatigue results for carburized and non-treated 316 samples.................................. 52

4.36 Scanning electron microscopy (SEM) fractographs of $(a, b)$ one-time carburized; and $(\mathrm{c}, \mathrm{d})$ non-treated 316L stainless steel samples taken from batch $\mathrm{B}$, tested under $\mathrm{R}=-1$ at 570 $\mathrm{MPa}$ maximum stress and a load oscillation frequency of $10 \mathrm{~Hz}$. The fatigue life of the 
carburized sample was $167 \times 10^{4}$ cycles, while that of the non-treated sample was only $5 \times$ $10^{4}$ cycles. (e-g) Increasing magnification SEM fractographs of a $4 \mathrm{x}$-carburized sample which had a fatigue life of $523 \times 10^{4}$ cycles at a maximum stress of $334 \mathrm{MPa}$. (h) The X-ray energy dispersion spectroscopy spectrum for the inclusion labeled " 1 " in (g)................... 53

4.37 Stress and number of cycle curves for carburized and non-treated(a) 254 and (b) 304 stainless steels.

4.38 Internal friction results for carburized 316 stainless steel measured in three-point bending:

(a) the frequency was fixed at $1 \mathrm{~Hz}$. The carburized trace (red) shows a unique peak at $270^{\circ} \mathrm{C}$.

(b) The frequency was varied. 55

4.39 Etched ( $2 \%$ Nital) cross section of a carburized disk specimen. ............................. 56

4.40 Cross-sectional hardness profiles (Knoop's micro-induntation at $25 \mathrm{~g}$-f load)........... 57

4.41 Effects of temperature on hardness: (a) hot hardness and (b) hardness ratio between the treated and non-treated disks.

4.42 Results for replicate tests on carburized and non-carburized specimens.................... 59

4.43 Effects of temperature on friction behavior........................................................ 61

4.44 Effects of temperature on wear behavior. .......................................................... 62

4.45 Wear tracks on non-treated balls: (a) room temperature, (b) $200^{\circ} \mathrm{C}$, and (c) $400^{\circ} \mathrm{C} \ldots \ldots .63$

4.46 Wear scars on carburized balls: (a0 room temperature, (b) $200^{\circ} \mathrm{C}$, and (c) $400^{\circ} \mathrm{C} \ldots \ldots . .64$

4.47 Work hardening induced by tribo-testing: (a) Vickers hardness of unworn areas and wear scars and (b) hardness profiles below disk wear tracks.

4.48 Wear debris produced by NT/NT at: (a) room temperature and (b) $400^{\circ} \mathrm{C} \ldots \ldots \ldots \ldots \ldots . . . . . .66$

4.49 Wear debris produced by $\mathrm{T} / \mathrm{T}$ at: (a) room temperature and $(\mathrm{b}) 400^{\circ} \mathrm{C} \ldots \ldots \ldots \ldots \ldots \ldots . . . \ldots 66$

4.50 Disk wear tracks produced at room temperature: (a) non-treated disk tested in NT/NT and (b) treated disk tested in $\mathrm{T} / \mathrm{T}$.

4.51 (a) Non-treated and (b) treated 304 stainless steel pump plates after three months in corrosive pumping service in a pulp and paper facility. Non-treated plate shows significant scoring and wear, while the treated plate still retains its original grind marks. (b) Treated pump plate after nine months

4.52 (a) Sonoco 150-HP pump impeller recently treated at Swagelok, and (b) Sonoco strainer basket in line for low-temperature colossal supersaturation treatment at Swagelok in March 2006.

4.53 Hardness profiles after carburization for the four experimental alloys: (a) $6.0 \mathrm{wt} \% \mathrm{Mo}$, (b) $3.0 \mathrm{wt} \% \mathrm{Ti}$, (c) $3.2 \mathrm{wt} \% \mathrm{~V}$, and (d) $5.8 \mathrm{wt} \% \mathrm{Nb}$.

4.54 X-ray diffraction (XRD) results for experimental alloys: (a) XRD traces; the peaks are labeled. (b) The peak positions from (a) shown in a Nelson-Riley plot. 


\section{List of Tables}

1.1 Significant Performance Enhancements from LTCSS ............................................. 4

1.2 List of Components Treated with LTCSS Process and their Operating Experience ...... 5

2.1 Cost Benefit from the Introduction of Low-Temperature Colossal Supersaturation ...... 9

2.2 Results from the Energy Benefits Impact Analysis ....................................................... 9

2.3 Environmental Benefits from the Low-Temperature Colossal Supersation Technology 9

4.1 Carbon Content from Lattice Parameters Obtained from X-ray Diffraction Analyses ... 30

4.2 Using $\mathrm{Cu}-\mathrm{K} \alpha$ Radiation, Measured Integrated Intensities of X-ray Diffraction and Calculated Theoretical Intensities for $\alpha$-ferrite Peak (200) and $\gamma$-austenite Peak (200). 31 4.3 Atom Composition of the As-received 316 Alloy and the Composition Measured by Local Electrode Atom Probe Microscopy of the 1x-Carburized 316 at the Surface

4.4 Data for Sectioned Low-temperature Colossal Supersaturation-treated 316

Stainless Steel Samples. The Depth Indicates the Amount of Material Removed after Carburization.

4.5 Average weight loss versus time slope

4.6 The $0.2 \%$ Yield Strength (YS), Ultimate Tensile Strength (UTS), and \%

Elongation Upon Fracture for the Three Steel Alloys

4.7 Indentation Hardness and Elastic Modulus of Treated and Non-Treated Type 316

Stainless Steel Surfaces.

4.8 Friction and wear results of dry sliding at room temperature ...................................... 60

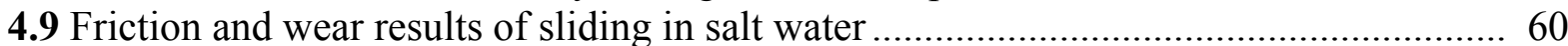

5.1 Significant Performance Enhancements from LTCSS ............................................. 75 


\section{Abbreviations and Acronyms}

$\begin{array}{ll}\text { AES } & \text { Auger electron spectroscopy } \\ \text { AFM } & \text { Atomic force microscopy } \\ \text { ASM } & \text { ASM International } \\ \text { ASTM } & \text { American Society for Testing Materials } \\ \text { at. } & \text { Atomic } \\ \text { BCC } & \text { Body-centered cubic } \\ \text { Btu } & \text { British thermal unit } \\ \text { CALPHAD } & \text { Calculation of phase diagrams } \\ \text { CBED } & \text { Convergent beam electron diffraction } \\ \text { CWRU } & \text { Case Western Reserve University } \\ \text { DOE } & \text { Department of Energy } \\ \text { EDS } & \text { Electron dispersion spectroscopy } \\ \text { EP } & \text { Electropolishing } \\ \text { FCC } & \text { Face-centered cubic } \\ \text { FEA } & \text { Finite element analysis } \\ \text { FIB } & \text { Focused ion beam } \\ \text { GDOES } & \text { Glow discharge optical emission spectroscopy } \\ \text { LEAP } & \text { Local electrode atom probe } \\ \text { LTCSS } & \text { Low-temperature colossal supersaturation } \\ \text { MFM } & \text { Magnetic force microscopy } \\ \text { NRL } & \text { Naval Research Laboratory } \\ \text { ODOD } & \text { Ohio Department of Development } \\ \text { OIM } & \text { Orientation imaging microscopy } \\ \text { ORNL } & \text { Oak Ridge National Laboratory } \\ \text { S-N } & \text { Stress and number of cycles } \\ \text { SEM } & \text { Scanning electron microscopy } \\ \text { SS } & \text { Stainless steel(s) } \\ \text { TEM } & \text { Transmission electron microscopy } \\ \text { TTT } & \text { Time, temperature, transformation } \\ \text { XEDS } & \text { X-ray energy dispersion spectroscopy } \\ \text { XPS } & \text { X-ray photo spectroscopy } \\ \text { XRD } & \text { X-ray diffraction } \\ & \end{array}$




\section{Executive Summary}

\subsection{Purpose}

Low-temperature colossal supersaturation (LTCSS) is a novel surface hardening method for carburization of austenitic stainless steels (SS) without the precipitation of carbides. The formation of carbides is kinetically suppressed, enabling extremely high or colossal carbon supersaturation. As a result, surface carbon concentrations in excess of 12 at. \% are routinely achieved. This treatment increases the surface hardness by a factor of four to five, improving resistance to wear, corrosion, and fatigue, with significant retained ductility.

LTCSS is a diffusional surface hardening process that provides a uniform and conformal hardened gradient surface with no risk of delamination or peeling. The treatment retains the austenitic phase and is completely non-magnetic. In addition, because parts are treated at low temperature, they do not distort or change dimensions.

During this treatment, carbon diffusion proceeds into the metal at temperatures that constrain substitutional diffusion or mobility between the metal alloy elements. Though immobilized and unable to assemble to form carbides, chromium and similar alloying elements nonetheless draw enormous amounts of carbon into their interstitial spaces. The carbon in the interstitial spaces of the alloy crystals makes the surface harder than ever achieved before by more conventional heat treating or diffusion process. The carbon solid solution manifests a Vickers hardness often exceeding $1000 \mathrm{HV}$ (equivalent to $70 \mathrm{HRC}$ ).

Swagelok Company, Case Western Reserve University (CWRU), and Oak Ridge National Laboratory (ORNL) have completed a $\$ 2.5$ million, three-year research project, funded in part by the Department of Energy (DOE) through the Energy Efficiency and Renewable Energy Industrial Technologies Program. The project objective was to extend the LTCSS treatment to other austenitic alloys, and to quantify improvements in fatigue, corrosion, and wear resistance.

\subsection{Scope}

Highlights from the research include the following:

- Extension of the applicability of the LTCSS process to a broad range of austenitic and duplex grades of steels

- Demonstration of LTCSS ability for a variety of different component shapes and sizes

- Detailed microstructural characterization of LTCSS-treated samples of 316L and other alloys

- Thermodynamic modeling to explain the high degree of carbon solubility possible in austenitic grades under the LTCSS process and experimental validation of model results

- Corrosion testing to determine the corrosion resistance improvement possible from the LTCSS process

- Erosion testing to determine the erosion resistance improvement possible from the LTCSS process

- Wear testing to quantify the wear resistance improvement possible from the LTCSS process

- Fatigue testing for quantifying the extent of improvement from the LTCSS process

- Component treating and testing under simulated and in-line commercial operations 


\subsection{Results}

The key results from this work are highlighted below.

\subsubsection{Microstructural Characterization}

The XRD evaluation of treated materials at CWRU verified expanded austenite lattice, with no evidence of carbide precipitation. Carbon concentration profiles via Auger and electron dispersion spectroscopy (EDS) showed carbon levels in excess of 12 at. \% in treated, type 316 SS. Scanning electron microscopy (SEM) of pulled-to-failure treated tensile specimens showed slip bands and no de-cohesion of the treated layer, verifying that the layer remains ductile. Compressive stresses in excess of $2 \mathrm{GPa}(300 \mathrm{ksi})$ have been calculated at the surface of the case, based on the XRD lattice expansion and the carbon concentration.

\subsubsection{Thermodynamic Modeling}

Calculation of phase diagram (CALPHAD) (ThermoCalc) and Wagner dilute solution thermodynamic models were developed at CWRU. These models calculate the solubility of carbon in austenite as a function of alloying content for the process time and temperature. Elements considered in the model include $\mathrm{Fe}, \mathrm{Cu}, \mathrm{Ni}, \mathrm{Co}, \mathrm{Cr}, \mathrm{Mn}, \mathrm{Si}, \mathrm{Mo}, \mathrm{W}, \mathrm{Al}, \mathrm{V}, \mathrm{Nb}, \mathrm{Ti}, \mathrm{Zr}$, and N. Special efforts were made to determine the necessary carbon-matrix element interaction parameters relevant to LTCSS. Several commercial alloys have been modeled, and the model has been used to design experimental alloys with enhanced affinity for carbon solubility at treatment temperatures.

At ORNL, four of the experimental alloys were melted, rolled, and manufactured into test specimens, and the LTCSS treatment indicated successfully enhanced results and validated the predictions based on thermodynamic modeling.

\subsubsection{Corrosion Resistance}

Electrochemical polarization curves determined at Swagelok, CWRU, and the Naval Research Laboratory (NRL) show a 600 to $800 \mathrm{mV}$ increase in pitting potential in treated $(900-1000 \mathrm{mV})$ versus non-treated (200-300 mV) type 316 in chloride solutions.

Two possible causes for the enhanced corrosion resistance were postulated: the concentration of carbon at the surface, or the enormous surface compressive stress. An electrochemical polarization curve was prepared for the plastically deformed gage length of a pulled-to-failure treated tensile pull specimen, to remove the effect of the residual compressive stress. This curve showed the same enhanced corrosion behavior, indicating that the enhancement is due to the high carbon concentration.

Polarized crevice corrosion tests at NRL showed five orders of magnitude improvement in crevice-corrosion resistance for treated versus non-treated Type 316L. Treated 316L showed crevice-corrosion behavior similar to that of Ti-6Al-4V and Hastelloy C22. 


\subsubsection{Erosion Resistance}

Cavitation tests were performed at ORNL for up to six hours in duration, with a vibratory horn and mercury as the dense liquid medium. Results of these tests showed significant increases in cavitation resistance for the treated materials as compared to the non-treated materials. The increase in resistance was most pronounced for Types 316 and $321 \mathrm{SS}$, which showed an approximately 8-fold reduction in weight loss rate, while 254 SMO showed an approximately three-fold reduction in weight loss rate. This finding is particularly important for slurry and corrosive pumping applications.

\subsubsection{Wear Resistance}

Wear tests at ORNL also indicate significant enhancement in wear properties, important for bearing applications. Standard ASTM pin-on-disk sliding friction and reciprocating friction tests show wear rates of treated couples (ball and disk) lowered by approximately 100 times compared to non-treated. An ASTM standard continuous loop abrasion test (rotating abrasive belt) showed a $30 \%$ reduction in wear volume for treated vs. non-treated 316 specimens.

\subsubsection{Fatigue Resistance}

Fatigue testing at CWRU showed an order of magnitude improvement for treated versus nontreated Type 316 at the same maximum stress level $(R=-1)$. The maximum stress at $10^{7}$ cycles and the endurance stress for infinite life, improved by approximately 50\%, from 30 to $45 \mathrm{ksi}$.

\subsection{Conclusions}

The LTCSS treatment on SS significantly enhances performance characteristics, and extends the use of these alloys into applications currently served by more expensive materials. Swagelok received the 2006 ASM International Engineering Materials Achievement Award for the development of this technology.

The energy savings from this project is estimated at 21.8 trillion Btu/year by 2020. This energy savings will be associated with a $\mathrm{CO}_{2}$ reduction of 1.3 million ton/year.

Just one small application of this technology in a sludge pump of a cardboard recycling plant during the course of this project has resulted in an energy savings of $84 \times 10^{6}$ Btu and cost savings of $\$ 900$.

The most significant performance enhancements from LTCSS are presented in Table 1.1. 
Table 1.1. Significant Performance Enhancements from LTCSS

\begin{tabular}{|c|c|c|}
\hline No. & Characteristic & Outcome from LTCSS Process \\
\hline 1 & Alloy system applicability & $\begin{array}{l}\text { - Broad base } \\
\text { - } 29 \text { different alloys }\end{array}$ \\
\hline 2 & Shape and size applicability & $\begin{array}{l}\text { - Sheet, bar, and complex shapes such as valves and impellers } \\
\text { - Size limited by current furnace size } \\
\text { - No distortion after treatment }\end{array}$ \\
\hline 3 & Microstructure & $\begin{array}{l}-\sim 10-\mu \mathrm{m} \text {-deep hard layer } \\
-\sim 12 \text { at. } \% \text { carbon on surface } \\
-4-5 \times \text { hardness increase } \\
\text { - Compressive surface stress of } 300 \mathrm{ksi}\end{array}$ \\
\hline 4 & Thermodynamic modeling & $\begin{array}{l}\text { - Modeling able to predict carbon solubilities } \\
\text { - New alloy design possibility demonstrated }\end{array}$ \\
\hline 5 & Corrosion resistance & $\begin{array}{l}-3 \times \text { Improvement in pitting corrosion } \\
-5 \times \text { Improvement in crevice corrosion }\end{array}$ \\
\hline 6 & Cavitation erosion & $-8 \times$ Improvement over non-treated \\
\hline 7 & Wear resistance & - $100 \times$ Reduction in wear rates \\
\hline 8 & Fatigue resistance & $\begin{array}{l}\text { - } 10 \times \text { in fatigue life } \\
-50 \% \text { increase in } 10^{7} \text { cycle endurance limit }\end{array}$ \\
\hline 9 & $\begin{array}{l}\text { Component operating } \\
\text { experience }\end{array}$ & - $5 \times$ Life extension demonstrated in commercial applications \\
\hline
\end{tabular}

\subsection{Recommendations}

This project was one of the most successful in that it was able to accomplish all aspects of the identified scope of work. The completion of this project led to very exciting benefits (see Table 1.1 above) which suggests a very broad market for use of LTCSS technology.

In order to take advantage of the LTCSS technology, it may be well worth for subsequent DOE funding to carry out cost-shared pilot to full-scale demonstration of the technology in the most energy intensive industry with significant benefits of energy savings, reduced greenhouse gases, cost savings and increased productivity, and improved product quality.

The highest priority trials could be a series of pump components trials for the most demanding applications in pulp and paper, chemical, and mining industries.

\subsection{Commercialization}

The unique properties imparted by LTCSS process to SS led to the following commercialization opportunities:

Bearings - Because of improved wear and fatigue resistance, bearings of LTCSS-treated materials would last several times longer than conventional bearings.

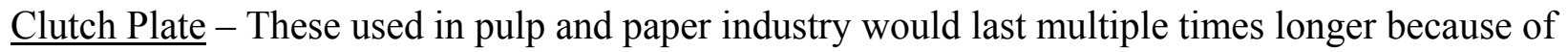
the improved wear resistance of LTCSS-treated material. 
Heat Exchangers - Because of improved pitting and crevice corrosion, the LTCSS-treated material will show reduced fouling and thus extended life.

$\underline{\text { Fasteners }}$ - The LTCSS-treated products can allow the substitution of lower cost alloys in highly corrosive environments and reduce galling.

Pumps - The improved wear and corrosion resistance and fatigue life of LTCSS-treated material can extend the pump life by several multiples.

Replacement for Certain Plating Treatments - The LTCSS process can be used in place of hard chromium plating and cadmium plating. Unlike these plating treatments, LTCSS is environmentally friendly and does not generate hazardous wastes.

Other Applications - The LTCSS-treated components can also be used for automotive, aircraft, desalinization equipment, and many consumer goods.

Leading companies for each of the applications listed above had discussions with Swagelok.

In addition to improved properties by the LTCSS process, a recent increase of seven fold in nickel prices from $\$ 3.30 / 1 b$ in 2003 have further increased the application potential for this process.

The increase is manifested in two ways: (1) use of lower nickel steels such as 301 with 6-8\% Ni to replace $8-12 \% \mathrm{Ni}$ in 304 or $10-14 \% \mathrm{Ni}$ in $316 \mathrm{~L}$ grades, and (2) use of LTCSS-treated SS steels for certain applications where nickel-based alloy (C22) with nickel content of $60 \%$ can be replaced with LTCSS-treated 316L with only $10-14 \% \mathrm{Ni}$.

The commercialization approach during this project consisted of: (1) making technical presentations (many presentations across many industries) to likely users of technology, (2) obtaining parts from most interested companies and treating those parts, and (3) getting the treated parts into service or simulated service tests.

Parts treated during this project, and their operating experience, are summarized in Table 1.2 below.

Table 1.2. List of Components Treated with LTCSS Process and their Operating Experience

\begin{tabular}{|c|c|c|c|c|}
\hline Part & Material & Application & $\begin{array}{c}\text { Service Test } \\
\text { Duration } \\
\end{array}$ & $\begin{array}{l}\text { Performance } \\
\text { Improvement }\end{array}$ \\
\hline Clutch Plate & 304 & $\begin{array}{l}\text { Pump used in cardboard pulping @ } \\
\text { RT }\end{array}$ & $>18$ months & $>6 \times$ \\
\hline Steam Valve Stem & 316 & $\begin{array}{l}\text { Valve for steam operation at } 350^{\circ} \mathrm{F} \\
\left(177^{\circ} \mathrm{C}\right)\end{array}$ & $>20$ months & $\mathrm{a}$ \\
\hline Orifice for Steam Trap & 304 & $\begin{array}{l}\text { Steam traps for condensate } \\
\text { drainage operating at } 30 \mathrm{psi} \text { and } \\
275^{\circ} \mathrm{F}\left(135^{\circ} \mathrm{C}\right)\end{array}$ & $>12$ months & $\mathrm{b}$ \\
\hline
\end{tabular}

${ }^{\mathrm{a}}$ No wear noted after $>10^{6}$ cycles of operation at $350^{\circ} \mathrm{F}$. More testing needed to determine multiples of improvement.

${ }^{\mathrm{b}}$ One year of testing showed performance as good as $420 \mathrm{SS}$, which is hardened to $50 \mathrm{HR}_{\mathrm{C}}$. 
Based on the operating experience listed above, a proposal entitled "Commercialization of LowTemperature Carburization" was submitted to the Ohio Department of Development (ODOD) for state funding of $\$ 5,500,611$ with a cost share of $\$ 5,500,613$ by Swagelok. The proposal was funded and the next step to commercialization is currently underway. 


\section{Introduction}

\subsection{Technology Description}

Swagelok has developed and patented a novel surface carburization treatment, also called lowtemperature colossal supersaturation (LTCSS) for Cr-containing alloys in general, and SS in particular [1-4]. The process is a gas phase heat treatment performed at atmospheric pressure at temperatures around $450^{\circ} \mathrm{C}$. It can be applied conformably to case harden finished components of any shape, without distortion or change to dimension. At present, the dimensions of components or subassemblies that can be treated are limited only by current furnace design. Surface hardness increases by a factor of four to five, along with improved corrosion, wear and fatigue resistance. The LTCSS treatment on SS significantly enhances performance characteristics, and extends the use of these alloys into applications currently served by more expensive materials. It also improves the wear and erosion resistance of notoriously soft corrosion resistant alloys such as Alloy C22, substantially eliminating galling.

\subsection{Focus}

The objective of this project was to greatly improve the wear, fatigue, and corrosion performance of SS components through the use of the LTCSS process with improved energy efficiencies for many of the industrial processes. The project objectives were met through a combination of basic understanding of the LTCSS process; validation of the LTCSS process to a broad range of alloys; generation of wear, fatigue, and corrosion data; and in-service or simulated testing of components.

\subsection{Potential Applications and Energy Savings}

This project quantified the great improvement in wear, fatigue and corrosion performance of austenitic SS, which will allow increased energy efficiencies to be achieved in a wide range of commercial components. A specific example is pump impellers, where improved durability will yield an estimated energy savings by the year 2020 of 21.8 trillion Btu/year and cost savings of approximately $\$ 108$ million/year for pumps used in the paper, chemicals, and petroleum and coal industries in the United States. The long term economic benefits of the project will be appreciable. LTCSS surface hardening can be employed for any austenitic SS and will enhance the wear and corrosion characteristics. Less expensive grades of austenitic alloys (with lower alloy content, or with less expensive alloying elements substituted for more expensive ones) can be used for comparable or even improved service life and performance. In particular, it is likely that highly alloyed, costly SS grades could be replaced in many applications by LTCSS casehardened "standard" SS, for example the standard 301 or 304 SS or a similarly inexpensive alloy.

Under the title "Better Stainless" the February 2002 issue of Science News (www.sciencenews.org) states on page 99: "There's a gigantic market for less expensive corrosion-resistant steel, says Roger C. Newman, a materials scientist at the University of Manchester in England. Possible customers include industries that use stainless pipes and vats in making products such as food, deodorants, and shampoos. Newman estimates that a new inexpensive stainless steel could result in a 10 percent reduction of the initial costs of such vats 
and pipes and an overall savings of 30 to 40 percent over the life of a manufacturing system that includes such equipment."

Austenitic SS of types $316,304,347$, and 321 are the primary materials of choice for a very broad range of applications when one needs corrosion resistance in aqueous solutions at ambient temperatures. While austenitic SS are excellent for their corrosion resistance, they possess low hardness values and cannot be heat treated to increase their hardness like the ferritic steels. Thus, when used for applications such as pumps for liquids and slurries in chemical, petrochemical, pulp and paper, steel, and other industries, they undergo wear of the pump impellers and the pump casings. The wear causes the pumps to operate with decreasing efficiency. In order to pump the same quantities of fluids with worn parts, the following solutions are used:

1. Operate pumps at higher speeds, although this requires more energy;

2. Add additional pumps in the loops, which also require more energy;

3. Provide frequent replacement of worn out pump impellers and pump housings, which also require more energy in the manufacture of pumps; and

4. Undergo frequent shut downs to replace worn out pumps, which also has energy consequence through the overall production rate reduction.

A recent DOE report (United States Industrial Electric Motor Systems Market Opportunities Assessment: December 2002) has compiled extensive data on motors and pumps used in all of the Industries of the Future sector. This report gives the following important data for energy calculations:

1. Total energy used by all pumps = $142690 \mathrm{GWh} /$ year

2. Paper and allied products $=31309 \mathrm{GWh} /$ year

3. Chemicals and allied products $=37591 \mathrm{GWh} /$ year

4. Petroleum and coal products $=30643 \mathrm{GWh} /$ year

5. Fabricated metal products $=903 \mathrm{GWh} /$ year

6. Industrial machinery and equipment $=968 \mathrm{GWh} /$ year

If we only consider the pumps used in industries that pump corrosive liquids (paper, chemicals, and petroleum), the energy used is $99,543 \mathrm{GWh} /$ year. We further assume that only $10 \%$ of the pumps will be affected by our technology. This will use $9954.3 \mathrm{GWh} / \mathrm{year}$. Based on the improvement in corrosion resistance (from preliminary testing of non-treated and surface treated samples) and expected large improvements in the wear resistance based on the increased surface hardness provided by the LTCSS treatment, it is anticipated that the pump life will be increased with improvement in energy efficiency in the range of 1 to $10 \%$. Considering the conservative number of $1 \%$, the energy savings using the new technology will be 99.5 billion $\mathrm{kWh} / \mathrm{year}$.

Use of DOE's Industrial Technology Program's Government Performance Reporting Act Spreadsheet 2000, resulted in the following calculations of energy, cost and environmental emissions savings from reduced energy use. 
Table 2.1. Cost Benefit from the Introduction of Low-Temperature Colossal Supersaturation

\begin{tabular}{|l|l|l|l|l|l|l|}
\hline \multicolumn{1}{|c|}{ Impact By Year } & \multicolumn{1}{c|}{$\mathbf{2 0 0 5}$} & $\mathbf{2 0 1 0}$ & $\mathbf{2 0 1 5}$ & $\mathbf{2 0 2 0}$ & $\mathbf{2 0 2 5}$ & \multicolumn{1}{c|}{$\mathbf{2 0 3 0}$} \\
\hline Units installed* & 0 & 8 & 36 & 58 & 64 & 68 \\
\hline $\begin{array}{l}\text { Energy cost savings } \\
\text { (\$million/year) }\end{array}$ & 0 & 16 & 68 & 108 & 117 & 119 \\
\hline
\end{tabular}

*Each unit corresponds to $10^{3}$ pumps.

Table 2.2. Results from the Energy Benefits Impact Analysis

\begin{tabular}{|l|l|l|l|l|l|l|}
\hline \multicolumn{1}{|c|}{ Impact By Year } & \multicolumn{1}{c|}{$\mathbf{2 0 0 5}$} & $\mathbf{2 0 1 0}$ & $\mathbf{2 0 1 5}$ & $\mathbf{2 0 2 0}$ & \multicolumn{1}{|c|}{$\mathbf{2 5}$} & \multicolumn{1}{c|}{$\mathbf{2 0 3 0}$} \\
\hline Units installed & 0 & 8 & 36 & 58 & 64 & 68 \\
\hline Target market penetration & 0 & $15 \%$ & $61 \%$ & $93 \%$ & $99 \%$ & $100 \%$ \\
\hline $\begin{array}{l}\text { Total primary energy saved } \\
\text { (trillion Btu) }\end{array}$ & 0 & 3.35 & 14.4 & 21.8 & 24.6 & 26.1 \\
\hline
\end{tabular}

Table 2.3. Environmental Benefits from the Low-Temperature Colossal Supersaturation Technology

\begin{tabular}{|l|l|l|l|l|l|l|}
\hline \multicolumn{1}{|c|}{ Impact By Year } & \multicolumn{1}{|c|}{$\mathbf{2 0 0 5}$} & $\mathbf{2 0 1 0}$ & $\mathbf{2 0 1 5}$ & $\mathbf{2 0 2 0}$ & $\mathbf{2 0 2 5}$ & \multicolumn{1}{c|}{$\mathbf{2 0 3 0}$} \\
\hline Units installed & 0 & 8 & 36 & 56 & 64 & 68 \\
\hline $\begin{array}{l}\text { Carbon dioxide emissions } \\
\text { saved (thousand TCE)* }\end{array}$ & 0 & 0.8 & 3.46 & 5.59 & 6.24 & 6.61 \\
\hline
\end{tabular}

$* \mathrm{TCE}=$ Tons carbon equivalent.

Note that even a $1 \%$ improvement in energy efficiency of the pumps through the implementation of this technology has the potential for very large energy savings of 21.8 trillion Btu/year and cost savings of $\$ 108$ million/year by 2020 .

Components other than pumps, such as steam traps, will also result in large energy savings, which will further increase the values reported above.

The projected energy savings and environmental benefits of LTCSS treatment of commercial austenitic SS are shown in Tables 2.2 and 2.3. However, further environmental benefits can be anticipated. LTCSS hardening of SS has the potential for reducing the need for mining strategically important alloying elements, such as nickel and chromium. In addition of saving these resources, the project will help reduce $\mathrm{CO}_{2}$ emission, air pollution, water pollution, noise pollution, destruction of biotopes, and other environmental costs related to mining. Moreover, prolonged lifetime of SS products will reduce the demand for metal recycling, since products will last longer. This will reduce corresponding $\mathrm{CO}_{2}$ emission, air pollution, water pollution, noise, destruction of biotopes, other environmental costs related to recycling of SS. More importantly, however, as detailed in the previous section, enormous energy savings are possible due to reduced wear of certain critical components in service, such as SS impellers in pumps for the paper, chemical and petroleum industries. 


\subsection{Commercialization Status and Plans}

The project milestones and stage gates followed during this project are shown in Figure 2.1 below. 


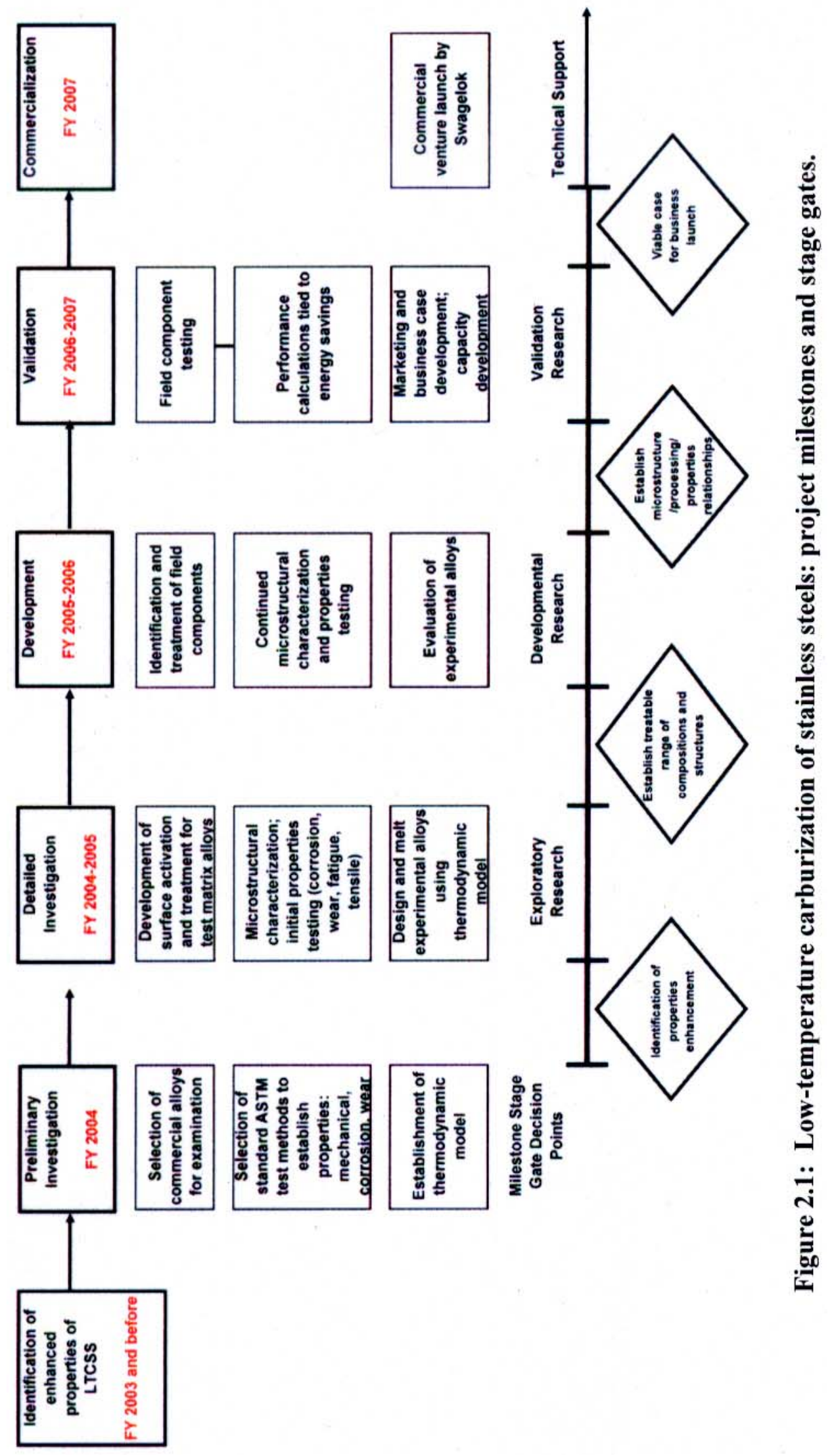


A stage gate approach shown in Figure 2.1 was used to guide the project's progress for its technical and commercial aspects. Specific activities towards technology commercialization included:

1. Introducing Technology and Its Advantages: Potential users were introduced to the technology and its advantages through several methods: (a) presentation of technical papers at national meetings; (b) exhibit booths at trade shows where technology was demonstrated on coupons, discussions held, and samples handed out to potential users; and (c) visits to companies to see plant equipment and discuss possible components that will gain the most in energy savings and increased productivity from this technology.

2. Treating Components for Simulated and In-plant Trials: In this activity, we worked closely with the most interested users by obtained their parts, treated them with the LTCSS process, and got them into simulated and in-plant trial testing. This aspect of commercialization was the most successful approach for evaluating and commercializing the LTCSS technology.

3. Creation of New Business Division of Swagelok: Swagelok has established a new subsidiary company to market and commercialize the LTCSS process. This new business unit is Swagelok Technology Services Company and the new process name for LTCSS is Swagelok ${ }^{\circledR}$ SAT12 (SM) patented surface hardening process.

4. Expanding Activities of New Business for Commercialization of the LTCSS Technology through Additional Funding from Ohio's Third Frontier Project: Swagelok Company and CWRU were awarded a three-year, \$5.5 million grant from Ohio's Third Frontier Project. The grant will enable Swagelok, in partnership with CWRU, to further research, evaluate, and commercialize the LTCSS technology. The Third Frontier Project is a ten-year, \$1.6 billion initiative designed to expand Ohio's high-tech research capabilities, promote innovation and company formation, and create high-paying jobs.

The Third Frontier Project grant will provide for the development of the research, manufacturing, and infrastructure elements necessary to convert the LTCSS technology into a commercially viable, Ohio-based metals surface enhancement business. Swagelok will undertake technology and business development efforts, and CWRU will continue research study on expanding the technology to other commercially important alloys for future business development. 


\section{Background}

\subsection{Conventional Case Hardening Technology}

The conventional practice used to harden the surface of austenitic SS operates at temperatures where carbide phases form during the carburization treatment. Such processes reduce the concentration of chromium in the austenitic matrix to a level that greatly reduces its corrosion resistance. The research team at Swagelok evaluated data in the literature concerning the combinations of times and temperatures that caused $\mathrm{M}_{23} \mathrm{C}_{6}$ to form in 316 austenitic SS with various carbon contents. The observation was made that at relatively low temperatures, the kinetics of carbide precipitation were rather sluggish. At temperatures below $500^{\circ} \mathrm{C}$, times in excess of 100 hours were required to form $\mathrm{M}_{23} \mathrm{C}_{6}$. Carburization at low temperatures thus offered the possibility of hardening the surface of austenitic SS without forming phases that would deplete the matrices of chromium and thereby degrade corrosion resistance. A major hurdle to such low temperature processing is the passive chromium oxide on the surface of SS that acts as a barrier to the inward diffusion of carbon. Through extensive research and development efforts, three patented procedures have been developed by Swagelok that eliminate the inhibiting effects of the chromium oxide and activate the surface for efficient transport of carbon from a conventional carburizing atmosphere into the SS.

To the best of our knowledge, Swagelok is the only domestic company to have developed and applied this low temperature carburization technology to harden the surface of austenitic SS. However, worldwide several institutions have developed low-temperature carburization processes that are currently available commercially.

\subsection{State of the Art - LTCSS Process}

Swagelok is clearly the only company that has developed the LTCSS process in the United States. They own four patents for various aspects of this technology and have both a laboratory and a production system for treating ferrules.

Commercially available low-temperature carburizing processes currently are being advertised by the University of Birmingham, (called LTPC which is plasma-based), Nitruvid, France (called Nivox 4 and Nivox LH which are also plasma-based), Airwater Ltd., Japan (called NV Poinite which is HF activation and conventional carburizing gas-based) and Bodycote Hardiff BV, Netherlands (called Kosterizing, which is a completely secretive process). [Trade journals and internet-based information]

Kosterizing is probably the next most well known process for low-temperature carburization in the U.S. other than the Swagelok process.

\subsection{Specific Area being Addressed}

The Swagelok process has been developed for one component, a rear ferrule of a two ferrule fitting for fluid systems (both gaseous and liquid) made of 316 austenitic SS. Whether the existing process can be used for other components and its applicability for other SS compositions needs to be ascertained, although the prospects are extraordinarily favorable. The composition 
of austenitic SS can be changed in so many ways that it is virtually impossible to optimize LTCSS hardening merely by an empirical approach. DOE funds were used to support further development of LTCSS by focused materials research. Only comprehensive, fundamental understanding of the basic processes occurring during LTCSS and their effect on hardness, wear, and corrosion has enabled identification for the broad scope of LTCSS technology for industrial applications.

\subsection{Statement of Project Objectives}

The objectives for this project included the following:

- Extension of the applicability of the LTCSS process to a broad range of austenitic and duplex grades of steels

- Demonstration of LTCSS ability for a variety of different component shapes and sizes

- Detailed microstructural characterization of LTCSS-treated samples of 316L and other alloys

- Thermodynamic modeling to explain the high degree of carbon solubility possible in austenitic grades under the LTCSS process and experimental validation of model results

- Corrosion testing to determine the corrosion resistance improvement possible from the LTCSS process

- Erosion testing to determine the erosion resistance improvement possible from the LTCSS process

- Wear testing to quantify the wear resistance improvement possible from the LTCSS process

- Fatigue testing for quantifying the extent of improvement from the LTCSS process

- Component treating and testing under simulated and commercial operations

\subsection{Technical Approach}

Technical approach for this project consisted of performing the following tasks to accomplish the project objectives:

1. Understanding the effects of alloying on the maximum solubility of carbon in austenite Preliminary literature studies and use of the software Thermo Calc ${ }^{\mathrm{TM}}$ have shown that additions of moderate carbide forming elements such as chromium and molybdenum can greatly increase the solubility of carbon in austenite when carbide formation is suppressed. These two elements do not stabilize an austenitic matrix. Other alloy additions such as nickel and manganese are required to establish an austenitic matrix that can be carburized. Nickel reduces the solubility of carbon while manganese increases carbon solubility in austenite. A stronger carbide element like vanadium may enable even high concentration of interstitial carbon in an austenite matrix to be achieved. A thermodynamic analysis will be conducted to define what alloying combinations will maintain a stable austenitic matrix while maximizing the potential for carbide phase formation.

2. Obtain alloy compositions with the maximum capacity for colossal supersaturation of carbon. Based upon the results of Task 1, alloy compositions will be chosen that have a stable austenitic matrix and maximum carbon solubility potential with a minimized tendency for carbide precipitation. Both standard 300 and 200 series austenitic SS will be studied, as well 
as experimentally prepared heats. Alloys will be prepared in sheet form to examine surface treatments of thick material, and as foils which can be processed to study hardness.

3. Establish methods for activating the surfaces of candidate alloys.

A key facet of low temperature carburization is modifying the surfaces of alloys so that they do not present a barrier to the inward diffusion of carbon from the gas phase. Swagelok has two distinctly different procedures that can be used to remove passive surface films. The appropriate surface activation processing conditions will need to be established for each candidate alloy.

4. Defining carburization heat treatment processing parameters.

The maximum carburization times and temperatures must be established that bound the condition where carbide formation occurs. The candidate alloys will be subjected to a range of carburization processing cycles to define the maximum carbon concentrations at their surfaces and the rate of carbon diffusion through their matrices. The best performing alloys are anticipated to present a compromise between higher carbon solubility and lower carbon diffusivity.

5. Maximum Surface Hardness and Depth of Hardening.

The primary effect of the low temperature carburization heat treatments is to increase the hardness and flow stress, of the surface layer of the austenite. The maximum hardness will indicate both how successful the surface activation was and the maximum concentration of carbon in solution in the austenite. The rate of decrease in hardness from the surface into the interior reflects the magnitude of the diffusivity of carbon in a particular alloy.

6. Microstructural Characterization

A major issue is whether the surface of an alloy remains 100 percent austenitic after a low temperature carburization heat treatment cycle. Establishing the presence or absence of fine scale carbide particles will require transmission electron microscopy (TEM) analysis of the hardened surface layer on candidate samples. The expansion of the lattice parameter of the austenite phase with increasing carbon content provides a method for measuring the carbon content of the near-surface region of samples using x-ray diffraction. Other x-ray diffraction procedures can be employed to determine the level of residual stress in carburized surface layers.

\section{Corrosion Resistance Testing}

The central driving force for the development of a low temperature carburization process that kinetically suppressed carbide formation in austenitic SS was to retain their outstanding corrosion resistance. The colossal supersaturations of carbon, the extreme harnesses, and the ultra high levels of compressive residual stress generated on the surfaces of LTCSS treated alloys offer the possibility of actually achieving increased resistance to pitting, crevice and stress corrosion compared to untreated austenitic SS. Both corrosion and stress corrosion testing of LTCSS treated alloys will be a facet of our research program.

8. Tribological Evaluation of Hardened Austenitic Stainless Steel Surfaces

The extreme hardness levels that can be achieved on austenitic SS surfaces strongly suggest a corresponding improvement in their wear characteristics. It is well known that superior wear 
resistance requires a combination of high hardness and significant toughness. Wear resistance is sensitive to the type of wear to which materials are exposed. To address this issue, three types of wear processes will be examined by subjecting hardened austenitic surfaces to unidirectional, unlubricated sliding, reciprocating lubricated sliding, and reciprocating sliding in the presence of abrasive slurry.

9. Fatigue testing

The ultra high compressive residual stresses associated with low temperature carburization of austenitic SS offer the potential for enhanced fatigue strength. Important considerations are the absence of cracks in the hardened surface of LTCSS-treated samples, along with the retention of toughness and the magnitudes of the tensile residual stress under the hardened layers. Changes in the fatigue strength due to LTCSS treatments will be assessed through a series of cyclic stress-controlled tests.

\section{Component testing}

One important aspect of this project will be to identify components that could be subjected to the LTCSS process and be tested in the field or under field-simulated conditions.

\subsection{Relevant Qualifications and Experience of Team Members}

The key personnel at Swagelok included Drs. Sunniva Collins, Peter Williams, Steve Marx and Mr. George Vraciu. Collins served as the Swagelok project investigator with responsibility for the overall project coordination; Marx was responsible for LTCSS processing of all alloys studied under this program, and Williams handled all metallurgical and hardness testing, as well as interfacing with potential industrial consumers of LTCSS hardened SS components. Vraciu worked with Collins on the surface activation portion of the program.

The CWRU team consisted of Arthur Heuer (CWRU team leader), Frank Ernst, and Gary Michal who are faculty in the Department of Materials Science and Engineering. Heuer had specific project responsibility for alloy design and surface analysis of LTCSS hardened alloys, whereas Ernst had project responsibility for transmission electron microscopy (TEM) analysis and fatigue testing of LTCSS hardened alloys. Michal performed all of the thermodynamic modeling relevant to understanding LTCSS in austenitic SS and performed residual stress measurements of carburized alloys.

The ORNL team consisted of Vinod K. Sikka (ORNL team leader), Dane Wilson, and Peter Blau. Sikka had project responsibility for melting of novel alloys required for the thermodynamic analysis or novel alloys suggested by such analyses for enhanced properties or performance. Wilson handled all aspects of characterization of the corrosion resistance of LTCSS hardened austenitic SS, while Blau was responsible for studying the wear resistance of these materials.

\subsubsection{Resumes of Key Personnel}

Sunniva R. Collins received her Ph.D. in Materials Science and Engineering from CWRU in 1994. She has been with the Swagelok Company since 1995 as a Research Metallurgist in the Materials Technology group. She is responsible for assessing technical issues concerning 
materials. She is a member of ASM International, TMS, IMS, and APMI. She has several materials patents awarded and pending, has authored over a dozen publications and made more than 30 presentations on a variety of metallurgical topics.

Peter C. Williams is Chief Scientist for Swagelok. For over 20 years he built and led new product and research capabilities for valve and fitting product line expansions, including development of stainless alloy LTCSS. He received a BSChE - MSME from Tufts University with post graduate research at MIT, is named on over 35 patents, and is a PE.

Steven V. Marx received his Ph.D. in Physics from the University of Illinois in 1982. He has been with the Swagelok for 14 years as a Physicist in the Materials Technology group. While at Swagelok, he has been involved in the investigation and development of heat treatment processes for SS and other corrosion resistant alloys. He holds three patents in connection with this work.

George R. Vraciu received his Bachelor of Science in Chemical Engineering from the University of Akron in 1986. He has been with the Swagelok since 1989 as a Research and Development Engineer in the Materials Technology group. His area of expertise is metal/alloy surface preparation, activation and chemical/electrochemical treatment (electropolishing, passivation and plating).

Arthur H. Heuer, University Professor and Kyocera Professor of Materials Science and Engineering at CWRU, has over 40 years experience in a wide variety of materials R\&D projects. He has over 450 publications and nearly a dozen patents to his credit and has supervised scores of MS and PhD students. He was elected to the National Academy of Engineering in 1990.

Gary Michal, Professor Material Sciences and Engineering at CWRU, is a physical metallurgist with extensive experiences in steel metallurgy. His $\mathrm{PhD}$ is from Stanford University; he worked for seven years at LTV Steel Company before joining the CWRU faculty in 1983.

Frank Ernst, Professor Materials Sciences and Engineering at CWRU, is a materials physicist with particular experience in TEM. His Ph.D. is from the University of Gottingen; he was on the staff of the Max Planch Institute for Materials Science in Stuttgart, Germany from 1988 to 2000, when he joined the CWRU faculty.

Dr. Vinod K. Sikka has over 33 years of experience at ORNL in materials development, processing, and commercialization. His expertise includes development of ferritic and austenitic $\mathrm{SS}$, intermetallics, and coatings. His experience is directly related to the objectives of this project. He has over 200 publications, 41 U.S. patents, and10 R\&D 100 Awards. He is a corporate fellow of UT-Battelle and a fellow of ASM International.

Dr. Jun Qu is a R\&D Staff Member in the Materials Science and Technology Division at ORNL. He earned his Ph.D. (2002) and M.S. (1999) in Mechanical Engineering from North Carolina State University and Iowa State University, respectively. Dr. Qu's present research interests focus on tribology (friction, wear, and lubrication), surface engineering, and advanced manufacturing. He has published more than 30 papers in peer-reviewed journals. 
Dr. Peter J. Blau has 24 years of experience in friction and wear research, 15 of them as task leader for Tribology at ORNL. His expertise includes the development of standard Tribology and hardness test methods, studies of the fundamental mechanisms of wear and friction, and the microstructural analysis of materials, surface treatments, and coatings for use in friction- and wear-critical applications. The author of two Tribology books and over 100 publications, he is a fellow of both ASM and ASTM, currently serving as Chairman of ASTM Committee G-2 on Wear and Erosion.

Dr. Dane F. Wilson has 20 years of experience at ORNL in corrosion science and technology. His research experience covers high temperature gas/material interactions, molten salt corrosion, aqueous corrosion, and associated microstructural and microchemical analyses of materials surfaces. He serves as the materials lead for compatibility issues associated with Generation IV nuclear reactors. He is active in NACE International and presently is the Vice-chair of the Annual Conference Program Committee. He has one U.S. patent. 


\section{Results and Discussion}

\subsection{Project Approach}

This section provides the details of alloys selected for treating by the LTCSS process and extensive microstructural characterization of the treated specimens. This section also provides the results from mechanical, wear and erosion, and corrosion tests performed on the LTCSStreated specimens.

\subsubsection{Manufacture/Procure Alloys and Specimens, Process Alloys, and Perform Initial Evaluations (Swagelok)}

Based on the tests performed, test specimen geometries were determined and matched to product form. For the majority of the mechanical/tribological tests, most of the specimens were machined from 5/8 in. round bar stock. Quantities of the majority of the alloys listed in the statement of objectives were obtained. Most alloys (316, 304L, 309, 310, 317, 321, 347, 22-13-5, Nitronic 60, 254 SMO, A 286, MP35N, L605, Inconel 625, Incoloy 825) were found in bar stock form. Others were obtained as flat coupons, including: 201, 203,301,316Ti, 13-8 Mo. All of the alloys were treated at Swagelok's carburization facility [5]. As each set of specimens was treated, one was used for metallographic assessment (microstructure and microhardness). Specimens were considered successfully treated when metallographic evaluation shows an increase in surface hardness and a uniform case depth [6,7]. At this point, specimens were provided to CWRU for microstructural assessment.

\subsubsection{Microstructural Characterization (CWRU)}

\subsubsection{Optical and Scanning Electron Microscopy}

Carburized specimens of several alloys were polished, etched, and metallographically characterized. Optical microscopy images of the treated 316 and 254 SMO samples surfaces are shown in Fig. 4.1. The treated surfaces of both alloys show considerable plastic deformation. The deformation follows the slip planes of the material and results in a morphology that exposes differently oriented grains. Figure 4.2 compares the typical surface morphology taken at a higher magnification in the scanning electron microscope (SEM) of the treated and non-treated 316 and 254 SMO samples. The non-treated sample does not show any surface features, while in the treated sample the deformation due to the stresses developed during the carburization are observed as step-like features. The steps heights were analyzed by atomic force microscopy (AFM) and found to range between a few tens to a few hundreds of nanometers.

Figure 4.3 shows SEM and optical images of carburized 304 samples that had been electropolished prior to carburization. The electropolishing treatment removed the $\mathrm{MnS}$ stringers in the material. As shown, particularly in Fig. 4.3(c), the carburizing treatment penetrated hundreds of microns into the pits left behind by the stringers, proving the conformal nature of the carburization. 


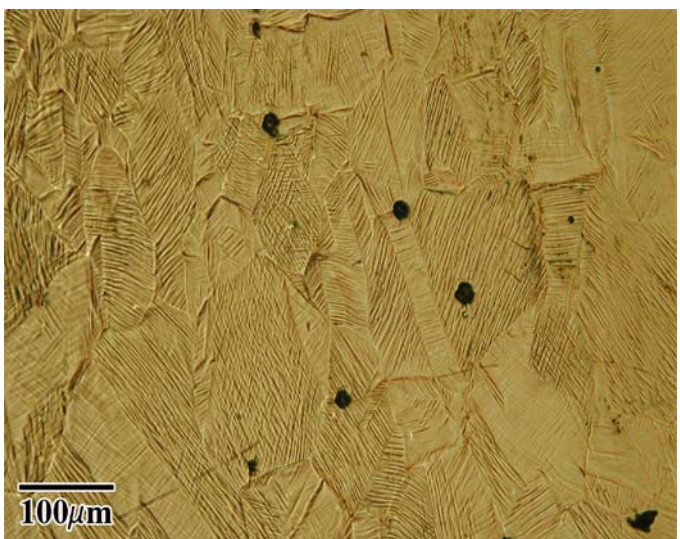

(a)

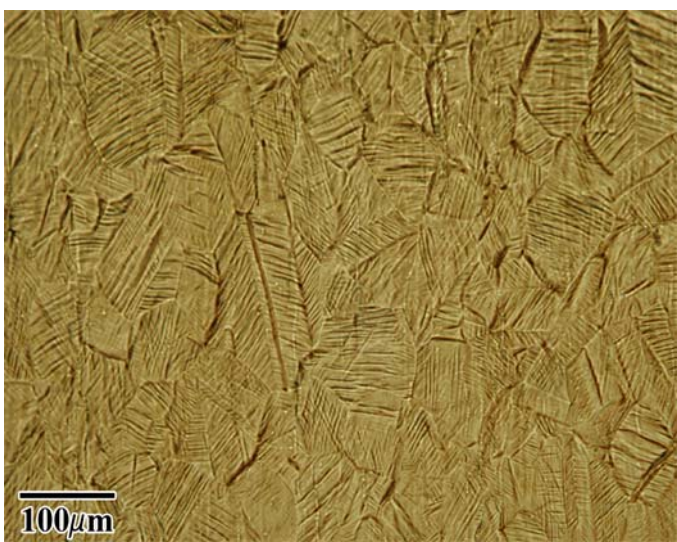

(b)

Figure 4.1. Optical microscope images of the treated surfaces: (a) the 254 SMO, and (b) 316 alloys. The deformation of the deformation following the carburization treatment may be seen in the images.

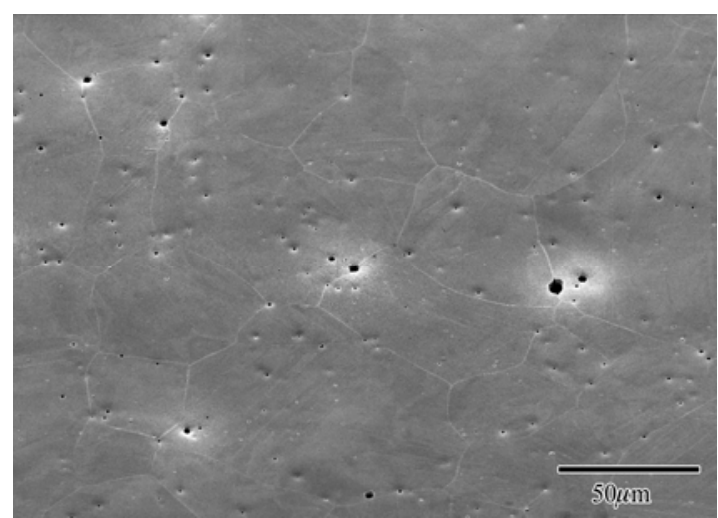

(a)

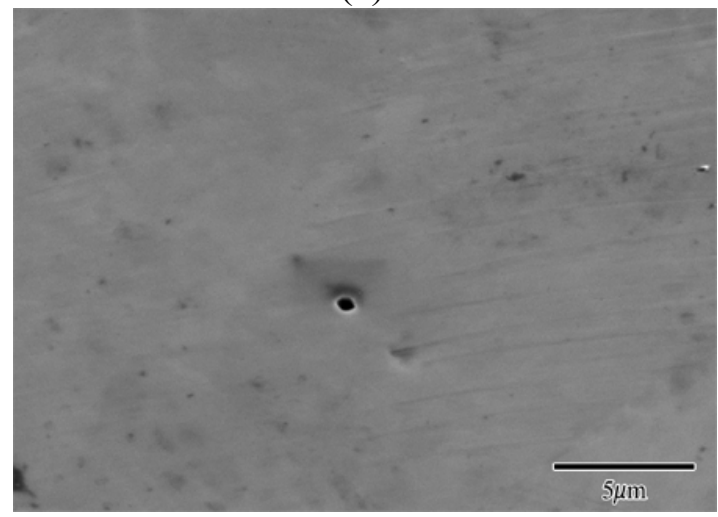

(c)

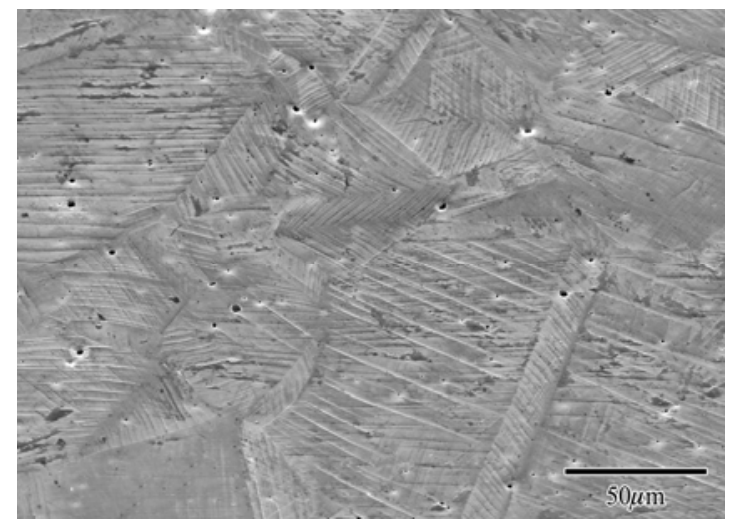

(b)

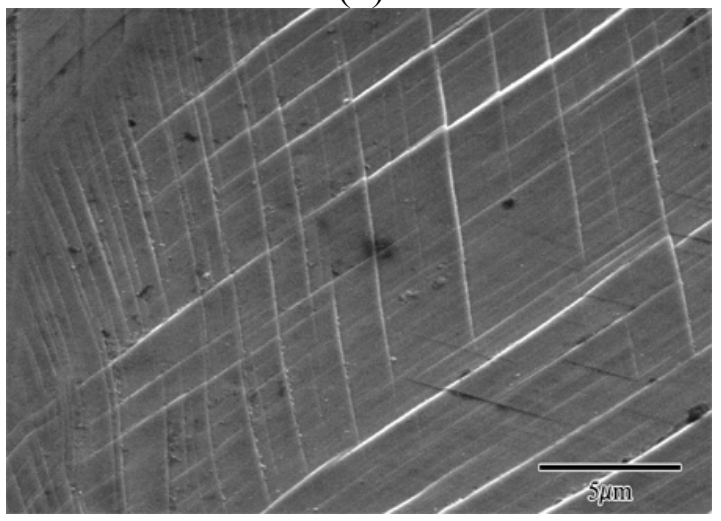

(d)

Figure 4.2. Scanning electron microscopy micrographs of: (a) non-treated and (b) treated 316 alloy showing the surface deformation at a higher magnification, and (c) non-treated and (d) treated 254 SMO alloy showing the surface deformation at a higher magnification. 


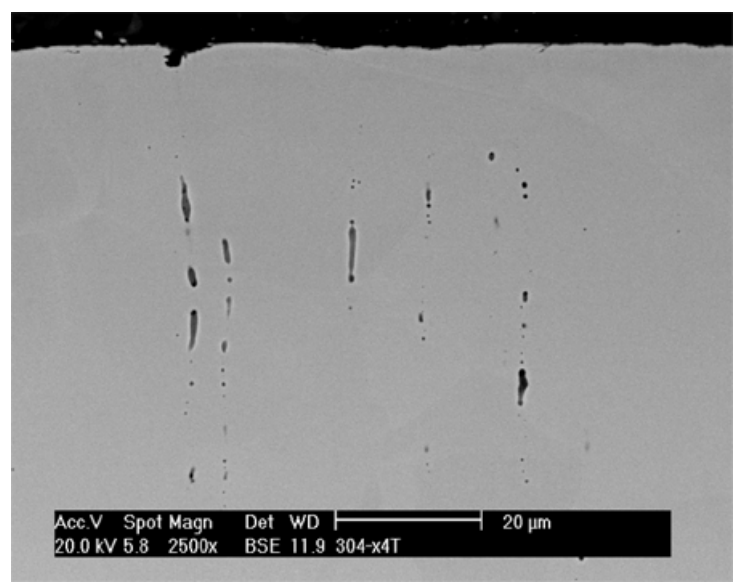

(a)

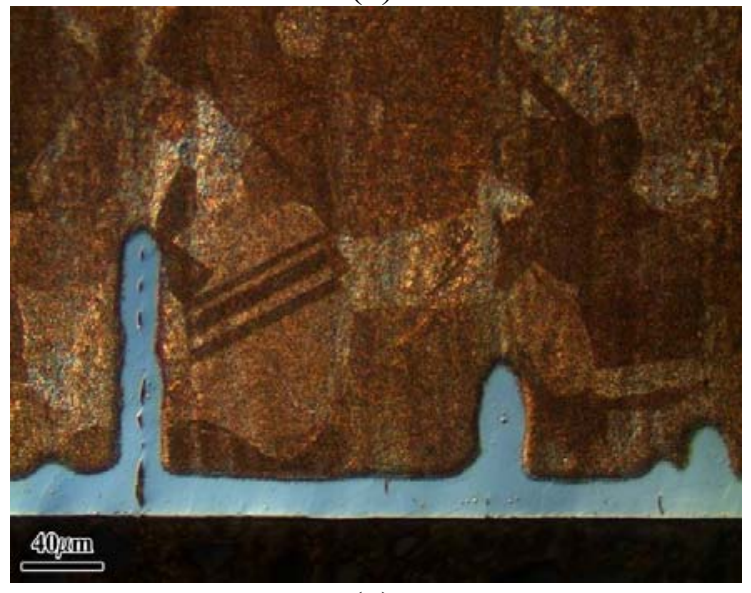

(c)

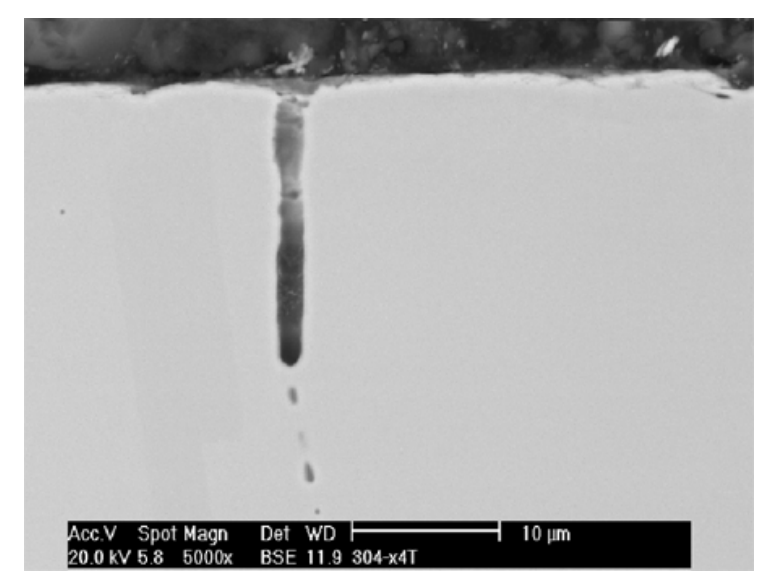

(b)

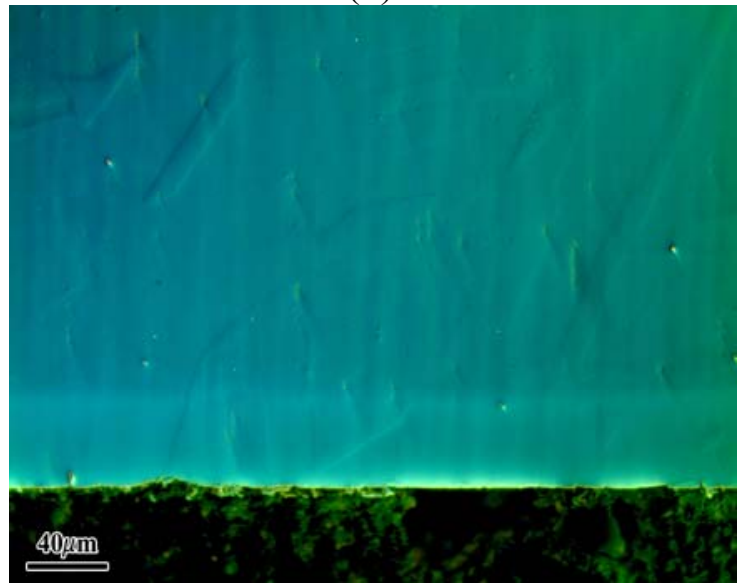

(d)

Figure 4.3. (a) and (b) Scanning electron microscopy images showing secondary phase found in 4x-carburized 304 stainless steel (SS) samples. (c,d) Optical microscopy images of 304 SS samples; (c) 1x carburized and etched with Marble's reagent; and (d) $4 x$ carburized and chemo-mechanically polished with a $\mathrm{SiO}_{2}$ suspension.

Figure 4.4 shows optical microscopy images of a 301 carburized sample: (a) is a 4x-treated specimen at the final stage of polishing with an $\mathrm{Al}_{2} \mathrm{O}_{3}$ suspension, which reveals the carburized layer via surface relief; (b) is an image taken after etching. The thickness of the carburized layers is approximately 25-30 $\mu \mathrm{m}$. In Figure 4.4(b), grain boundaries and twins were delineated by etching, and the continuation of the substrate grains was observed in the hardened case, some of which even continue from the substrate through the entire carburized layer. Figure 4.4(c) shows an optical micrograph of the 1x-treated, 301 specimen after etching $30 \mathrm{~s}$ with one part $\mathrm{HNO}_{3}$, one part $\mathrm{HCl}$, and one part $\mathrm{H}_{2} \mathrm{O}$. The etching not only revealed the carburized surface layer but also clearly outlined the twins and the different phases in the substrate: lighter areas are the $\gamma$-(austenite) phase and darker areas are $\alpha$-(ferrite) phase. 


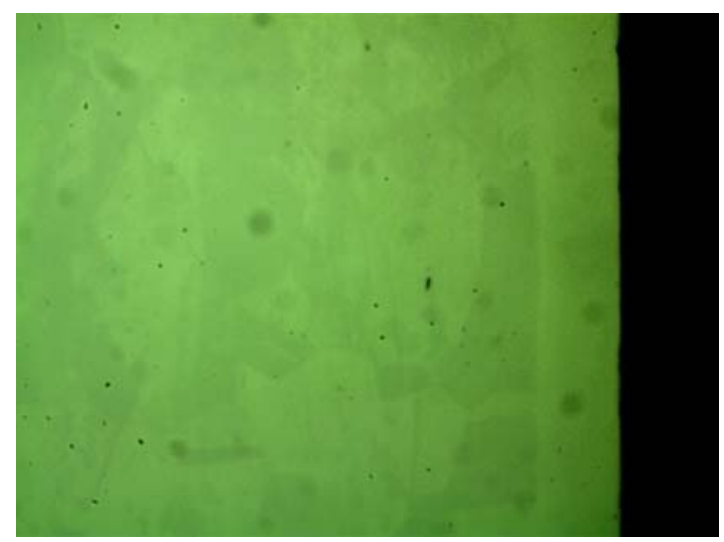

(a)

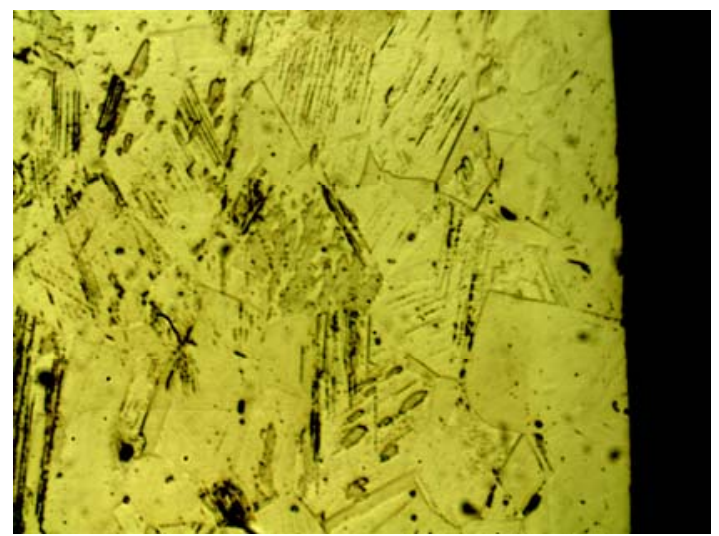

(b)

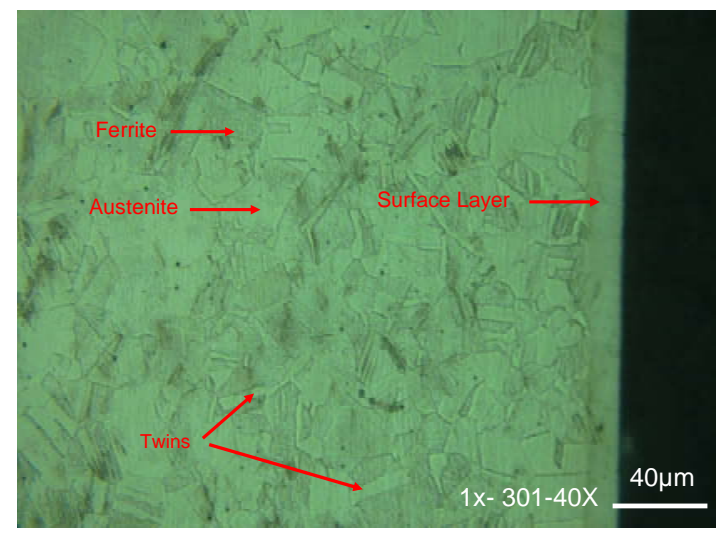

(c)

Figure 4.4. (a) Carburized 301 polished with $0.05-\mu \mathrm{m} \mathrm{Al}_{2} \mathrm{O}_{3}$ powder, (b) 301 etched by Glyceregia, and (c) 301 after etching 30 seconds with $\mathrm{HNO}_{3}$ : $\mathrm{HCl}: \mathrm{H}_{2} \mathrm{O}=1$ : 1 : 1 .

Orientation image microscopy (OIM) images of the non-treated samples are presented in Fig. 4.5; the relative grain orientations and microstructure can be observed. From these images and optical micrographs there is indication of a higher occurrence of twining and stacking faults in the $316 \mathrm{~L}$ alloy relative to the 254 . OIM of the as-treated surface was not possible due to the high degree of surface deformation.

\subsubsection{Transmission Electron Microscopy}

We determined sample preparation procedures preparatory to microstructural characterization to ensure that that no artifacts are introduced during these procedures. Two alloys were investigated: 316L and 254 SMO. TEM samples of 254 SMO measuring $0.5-\mathrm{mm}$ thick by 3-mm diam were prepared by electrodischarge machining. Another set was prepared by conventional mechanical polishing to thicknesses of $0.3-0.5 \mathrm{~mm}$, so as to compare the effect of mechanical grinding and whether this introduces unwanted defects to the specimens. Both samples were electropolished in a perchloric acid (5 vol. \%), methanol (60 vol. \%), and butanol (35 vol. \%) solution. No significant difference was observed between the two preparation methods. For the 316L samples, the effect of different sample thickness was also investigated. For samples thinner than $0.200-0.3 \mathrm{~mm}$, an increase in twins and stacking faults was found. Since the starting 


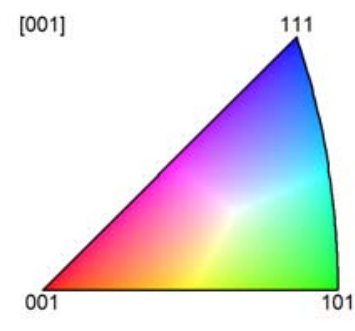

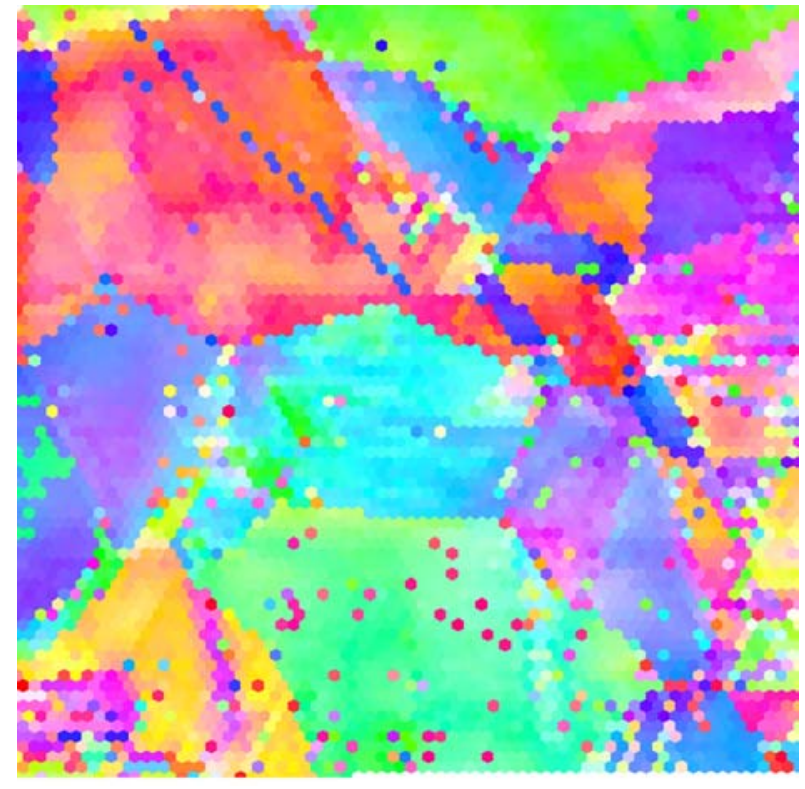

(a)

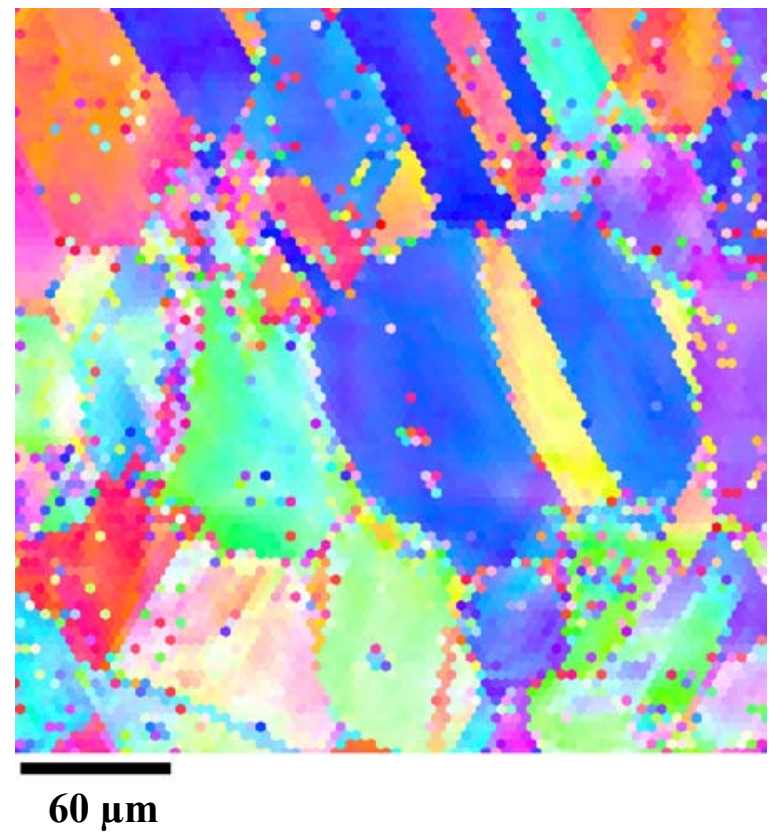

(b)

Figure 4.5. Orientation image microscopy micrographs of the non-treated alloy surfaces of: (a) 254 and (b) 316L.

material was already cold worked, it was not possible to separate this effect from possible preparation damage for the thicker samples. Samples prepared by dimpling and ion milling resulted in extensive damage.

Important insight was gained into the micro-mechanisms of carbide formation under the conditions of low-temperature carburization. Understanding the microscopic mechanism by which these form is extremely important because carbide formation is the ultimate limit of colossal supersaturation. Figure 4.6 shows an atomic-resolution high resolution TEM image of an interface between Hägg carbide and austenite in a Type 316 austenitic SS after ten cycles of carburization. The interface is recognized as the horizontal border between the two contrast patterns in the lower half of the image. The material above the interface is Hägg carbide. The inset shows a projection of the atomistic structure, which belongs to the monoclinic crystal systems. The material below the interface is carburized austenite with a carbon concentration of $\approx 12$ at. $\%$. The black and bright dots above and below the interface represent atom columns precisely aligned along the viewing direction in the thin TEM specimen. 


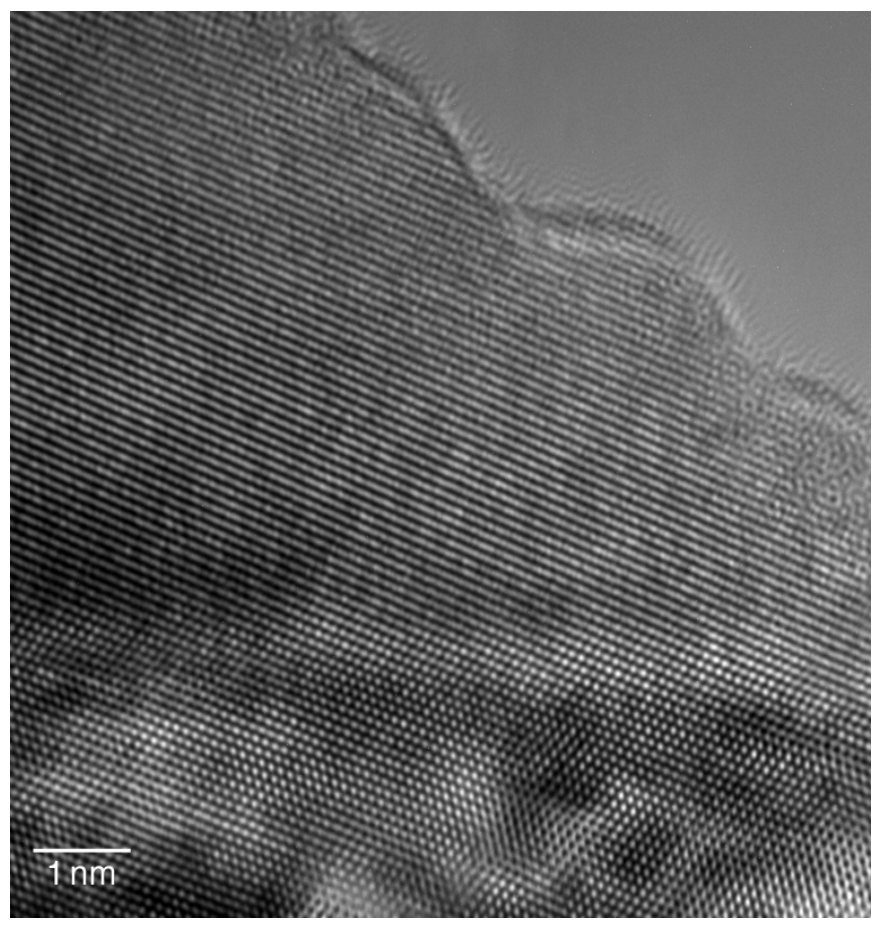

Figure 4.6. High resolution transmission electron microscopy image of the interface between Hägg carbide and austenite in carburized 316L austenitic stainless steel.

Remarkably, the transition from the atomic planes in the Hägg carbide to the atomic planes in the austenite does not show any discontinuity. There is a one-to-one match of lattice planes across the interface, which is therefore denoted as "coherent." Considering the entirely different symmetry of the two crystal structures, it is rather unexpected that such an interface can form. Moreover, the orientation of the carbide lattice with respect to the austenite lattice is such that the dominant planes continue straight across the interface. These observations suggest that Hägg carbide actually forms as the first carbide phase in highly supersaturated austenite because it can develop a structurally perfect interface with the austenite. The high structural perfection (coherence) of the interface in Fig. 4.7 implies low interface energy and, correspondingly, a low nucleation barrier. The continuation of planes across the interface, on the other hand, suggests that the two structures have a common sublattice and that it may in fact require only short-range atom displacements to transform the supersaturated austenite into Hägg carbide. This hypothesis is further supported by considering the volume per Fe atom in (1) Hägg carbide and (2) austenite with an expanded lattice parameter corresponding to a carbon concentration of $\approx 12$ at. $\%$. A rough estimation shows that the corresponding atom volumes are practically identical. Apparently, therefore, Hägg carbide forms at the point where the lattice expansion of the austenite by interstitially dissolved carbon has become so large that the austenite can transform into Hägg carbide without a significant expansion of the volume per atom, which would require long-range material transport. 


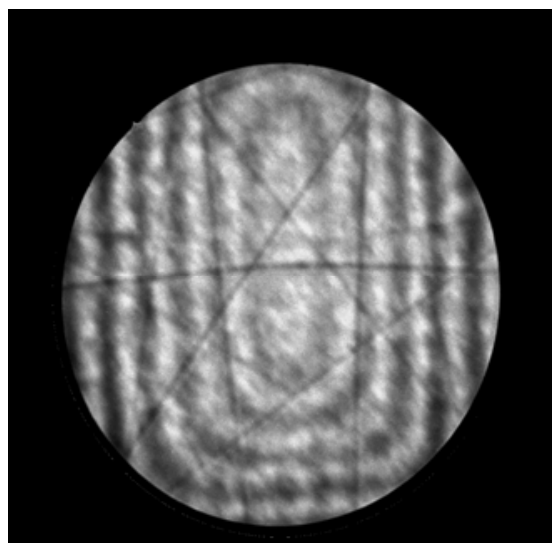

(a)

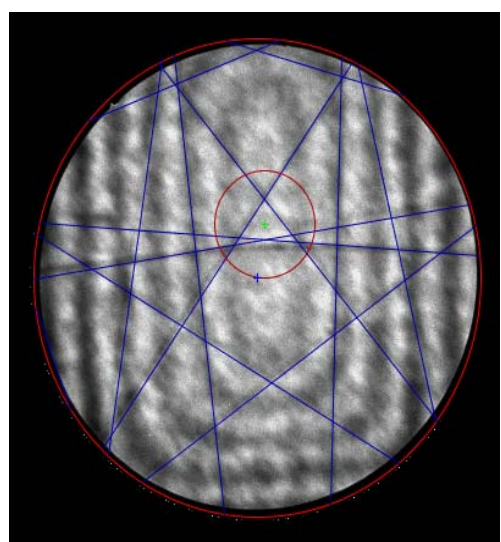

(b)

Figure 4.7. Energy filtered convergent beam electron diffraction (CBED) images taken from [323] zone axis of the austenite phase in the 254 SMO sample: (a) a raw CBED image, and (b) the same image with an overlay of the best fit higher order low zone lines simulation indicating a lattice parameter of $3.618 \pm 0.0005 \mathrm{~nm}$.

Another issue addressed was the lattice expansion of the austenite due to the carbon supersaturation. As has been apparent from previous work, the XRD measurements indicate an expansion of up to $2.8 \%$, but the fitting procedure was unsatisfactory. Furthermore, XRD averages over a depth of about $5 \mu \mathrm{m}$ and an area of a few square mm. In order to improve the spatial resolution of lattice parameter determination, CWRU has employed convergent-beam electron diffraction, in particular, the high spatial resolution and sensitivity of convergent beam electron diffraction (CBED) patterns. The local lattice parameter on non-treated $254 \mathrm{SMO}$ samples (see Fig. 4.7) has been measured with accuracy better than $0.2 \%$. These measurements are in good agreement with the lattice parameter extracted from XRD measurements.

\subsubsection{Hardness Testing}

As stated in Section 4.1.1, microhardness testing was a standard screening test performed on all carburized alloys to determine the surface hardness after treatment and the hardness versus depth behavior. Nano-indentation was also performed on many carburized cross-sectional samples in order to obtain hardness values close to the carburized surface. Figure 4.8 shows the hardness results for a carburized $316 \mathrm{~L}$ sample. The microhardness and nano-hardness values are in good agreement. 


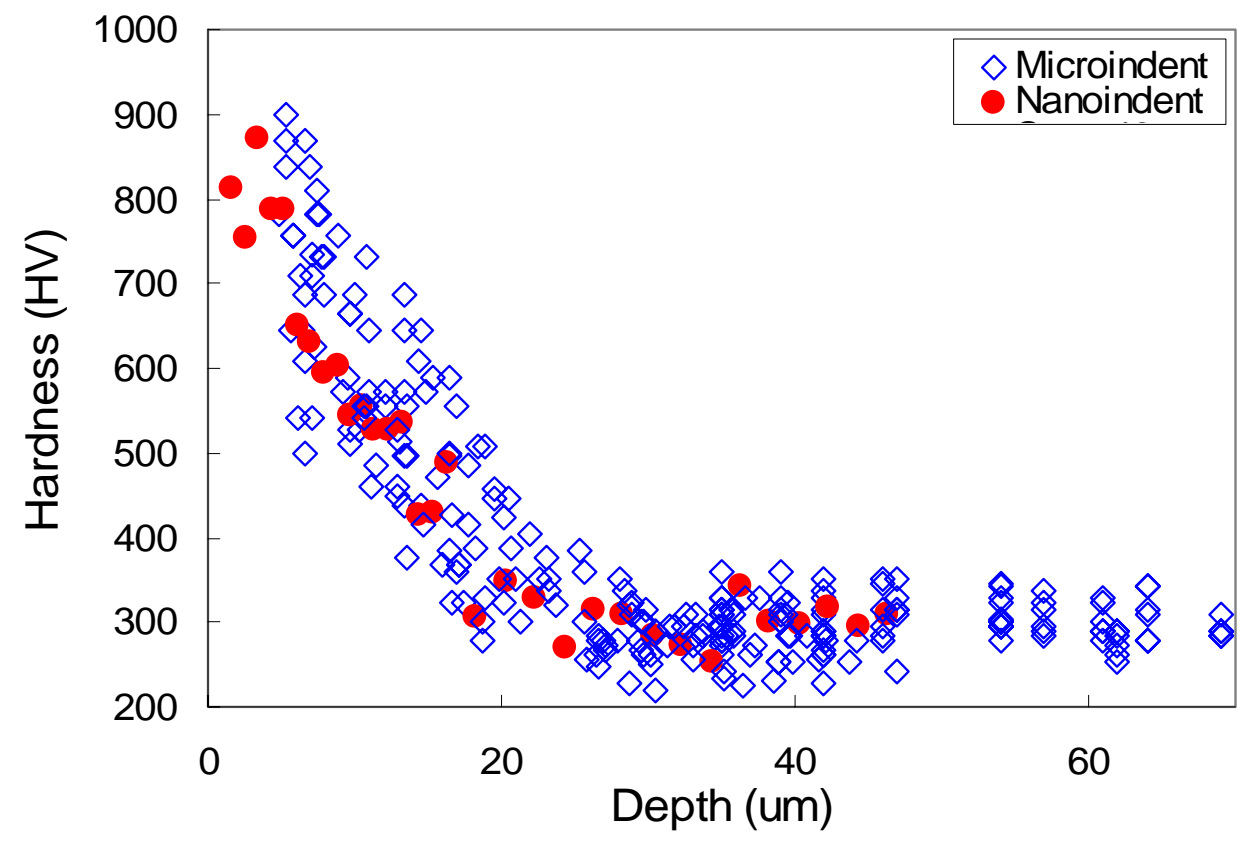

Figure 4.8. Hardness versus depth for a carburized 316L sample using both microindentation and nano-indentation.

\subsubsection{Microchemical Analysis}

The issue of carbon composition and the profile resulting from the carburization treatment was addressed using calibrated Auger electron spectroscopy (AES). Obtaining a reliable profile using AES under regular measurement conditions yielded unrealistic results of the carbon composition and profile. This was due to accumulation of carbon contamination on the surface of the sample during the measurement. To overcome this problem, a continuous light sputtering was used to prevent the carbon from accumulating at the surface over time. This method enabled us to obtain more reliable and reproducible results. However, these results although reproducible did not represent the actual carbon content in the material due to preferential sputtering effects. Since the results seem to converge to a steady state values, a calibration of the measurement was performed by using five different standards with known carbon compositions. Every measurement was repeated at least six times. Figure 4.9 shows the fitting and linear regression performed on the measured and actual carbon compositions. The red and blue lines represent the upper and lower boundary of the fit with $95 \%$ confidence level. Using this calibration, the carbon concentration profiles of 316 and 254 alloys was corrected and is presented in Fig. 4.10. 


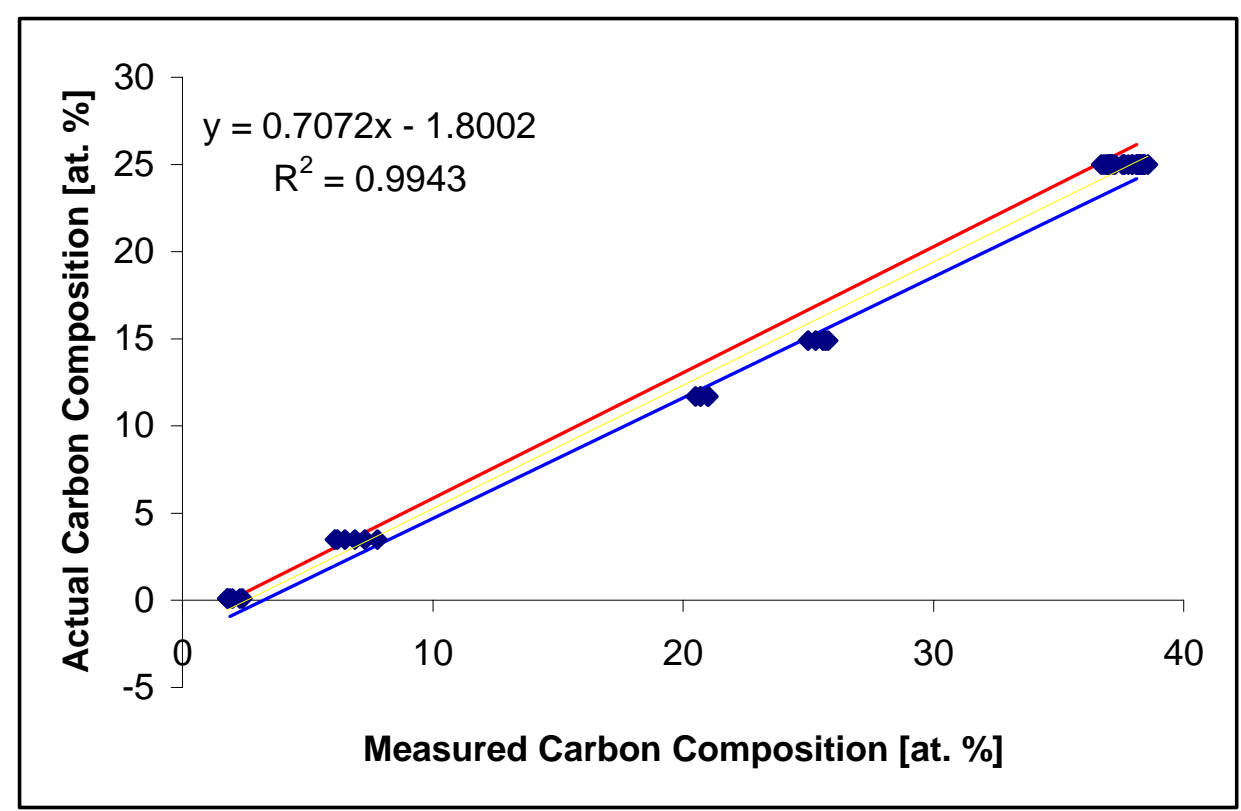

Figure 4.9. Calibration of the Auger measurement performed by using five different standards with known carbon compositions. Every measurement consists of at least six times. The red and blue lines represent the upper and lower boundary of the fit with $\mathbf{9 5 \%}$ confidence level.

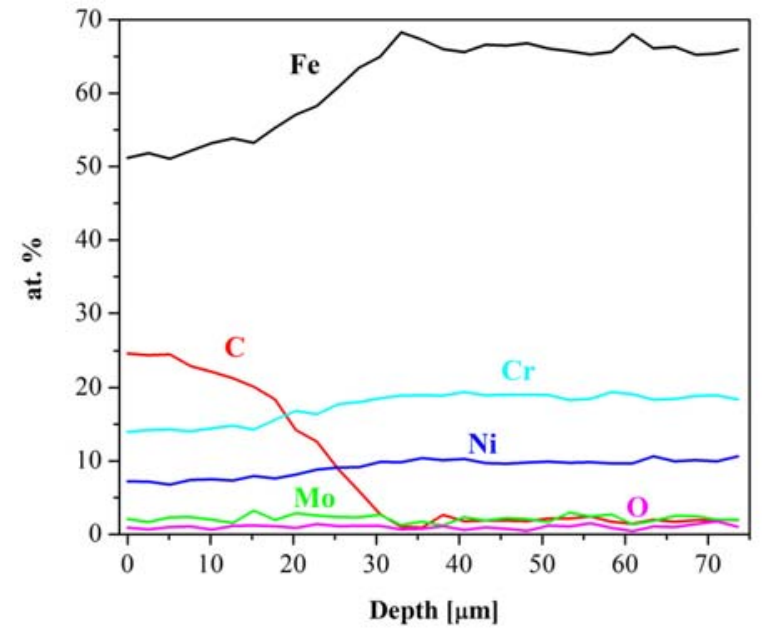

(a)

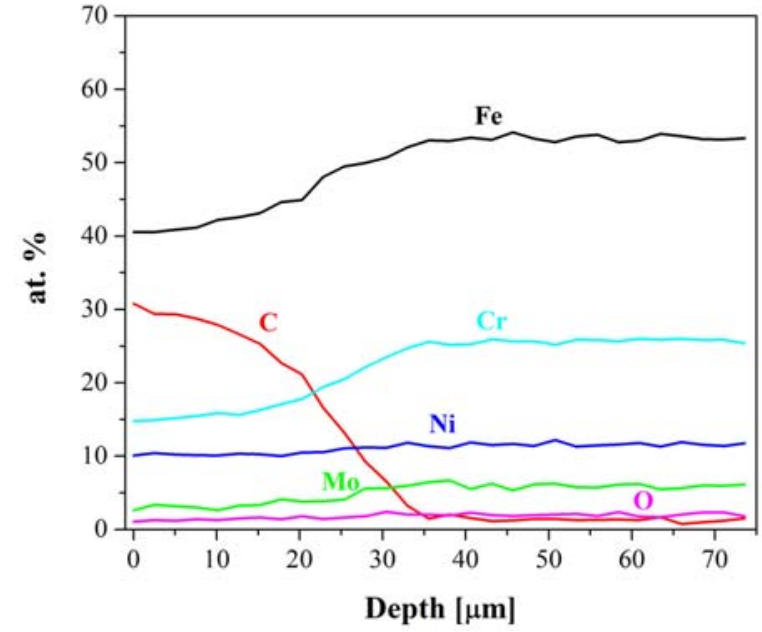

(b)

Figure 4.10. Compositional profile obtained by line-scan using Auger electron spectroscope, taken from (a) 316 and (b) 254 SMO alloys. The measurements were performed under a continuous sputtering at a minimal dose to prevent carbon contamination during the measuring. 
Knowing both the hardness and carbon concentration profiles for the 316L sample [Fig. 4.11(a)], it is interesting to determine the relationship between the two variables. They are plotted in Fig. 4.11(b) as hardness versus carbon concentration to the two-thirds power. According to standard theory, the hardness data should be linear in this type of plot, but clearly the hardness increases more rapidly for higher carbon concentrations.

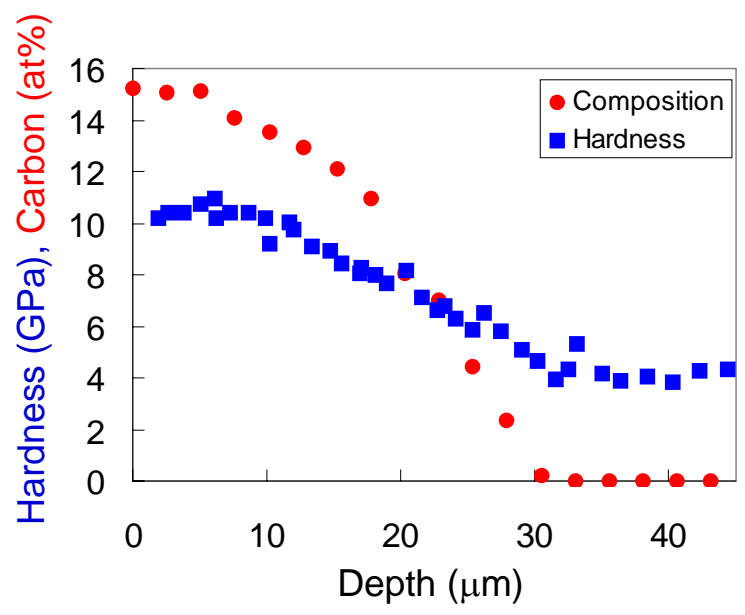

(a)

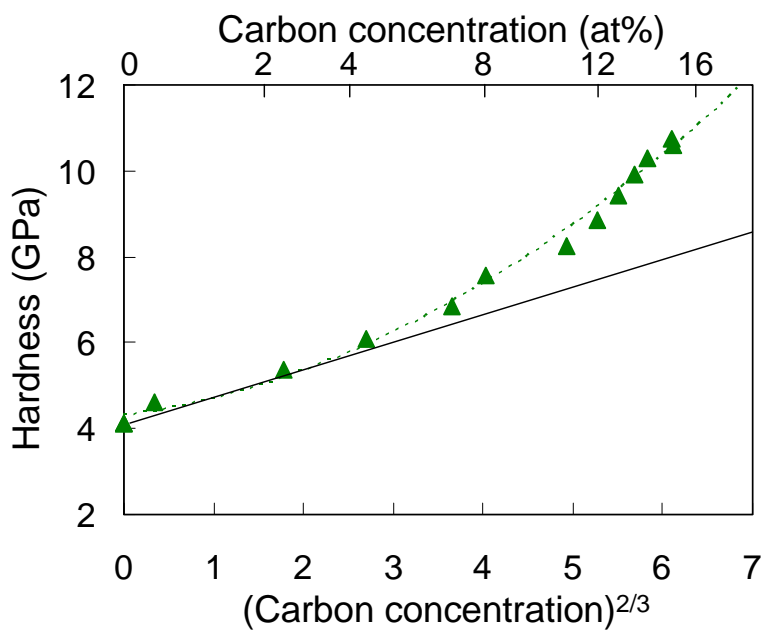

(b)

Figure 4.11. (a) Hardness and carbon concentration data for carburized 316 $\mathrm{L}$ and (b) the same data as hardness versus carbon concentration. The solid line is a linear extrapolation.

\subsubsection{X-ray Diffraction}

$\mathrm{X}$-ray diffraction (XRD) was performed routinely on the carburized samples to ensure that no second phases, such as carbides, formed during the treatment. Also, the shift of the XRD peaks revealed the extent of lattice expansion due to carbon interstitials. Figure 4.12 shows the XRD scans for a carburized 316L sample that was serially sectioned by electropolishing. The shift in the peaks to lower 2-theta values for lesser amounts removed (higher concentrations of carbon) indicates the increasing lattice expansion. The lattice parameters determined from the peak positions are plotted in Fig. 4.12(b), as lattice parameter vs $\cos \theta \cot \theta$, which is the Nelson-Riley plot designed to reveal the precise lattice parameter without any effects of sample misalignment. The systematic deviations from linear behavior in this plot for the carburized samples were originally thought to be due to stacking faults in the material. However, this explanation does not account for all the peak variations, and so the origin of this behavior remains unknown. 


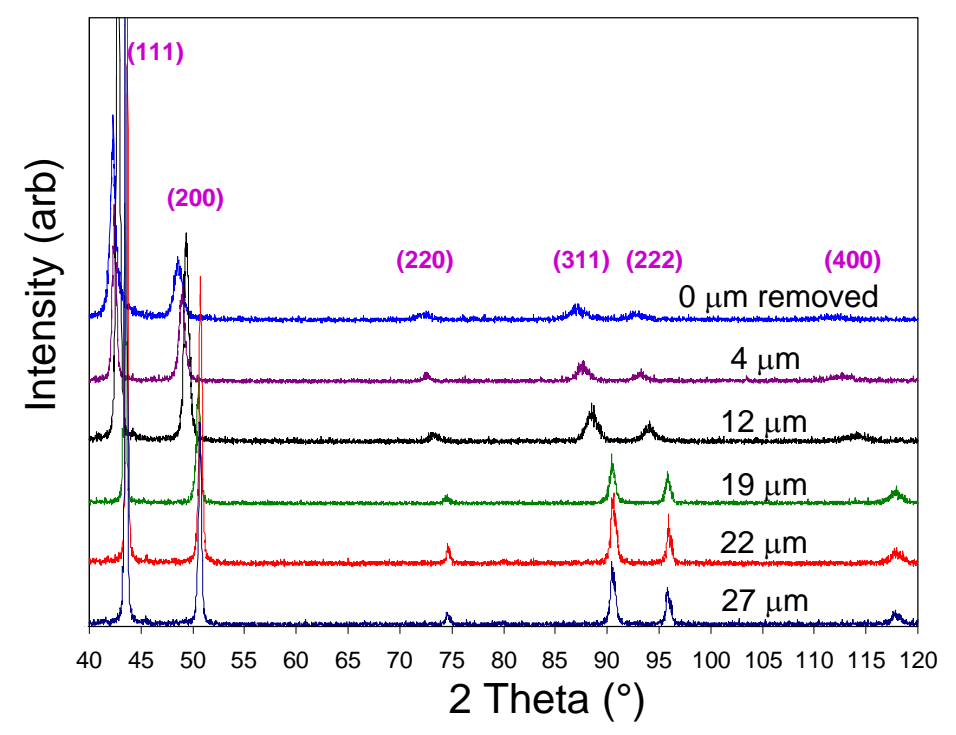

(a)

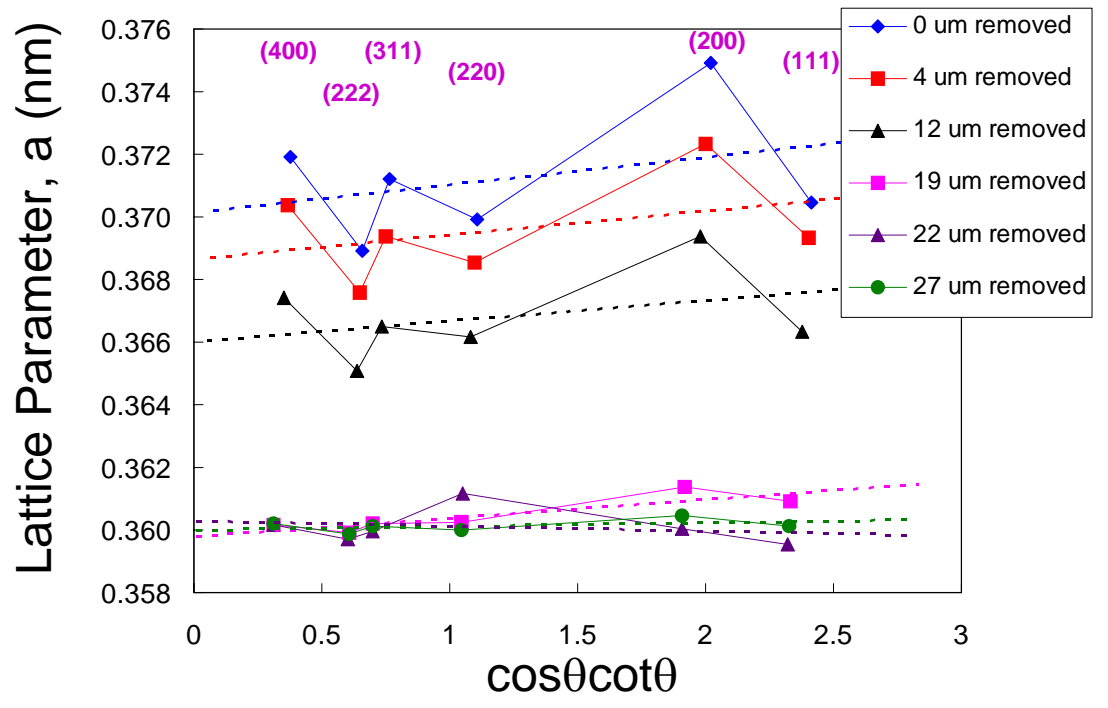

(b)

Figure 4.12. (a) X-ray diffraction results for a carburized 316L sample, which was serially sectioned by electropolishing, and (b) the lattice parameters determined by the peak positions in (a).

XRD analyses were performed on several carburized alloys, and the precision lattice parameters were determined using the Nelson-Riley fitting procedure. The lattice parameters are listed in Table 4.1. The carbon concentrations, assuming a linear relation between carbon concentration and lattice expansion, are also listed in this table. 
Table 4.1. Carbon Content from Lattice Parameters Obtained from X-ray Diffraction Analyses

\begin{tabular}{|c|c|c|c|c|c|}
\hline Alloy & $\begin{array}{c}\text { Times } \\
\text { Treated }\end{array}$ & $\mathbf{a}^{\boldsymbol{a}}$ & $\mathbf{a}^{* \boldsymbol{b}}$ & $\begin{array}{c}\mathbf{C ~ 3 1 1} \\
\text { (at. } \%)\end{array}$ & $\begin{array}{c}\text { C N-R } \\
\text { (at. \%) }\end{array}$ \\
\hline $\mathbf{3 0 3}$ & 0 & 0.3593 & 0.3593 & 0 & 0 \\
\hline $\mathbf{3 0 3}$ & 1 & 0.3593 & 0.3694 & 10 & 8 \\
\hline $\mathbf{3 0 4}$ & 0 & 0.3597 & 0.3597 & 0 & 0 \\
\hline $\mathbf{3 0 4}$ & 1 & 0.3597 & 0.3695 & 9 & 8 \\
\hline $\mathbf{3 0 4}$ & 4 & 0.3597 & 0.3703 & 10 & 9 \\
\hline $\mathbf{3 1 6}$ & 1 & 0.3595 & 0.3714 & 11 & 6 \\
\hline $\mathbf{3 1 7}$ & 1 & 0.3595 & 0.3712 & 11 & 9 \\
\hline $\mathbf{3 2 1}$ & 0 & 0.3616 & 0.3616 & 0 & 0 \\
\hline $\mathbf{3 2 1}$ & 1 & 0.3616 & 0.3726 & 11 & 11 \\
\hline CF8M & 0 & 0.3595 & 0.3595 & 0 & 0 \\
\hline CF8M & 1 & 0.3595 & 0.3717 & 12 & 12 \\
\hline $\mathbf{2 2 - 1 3 - 5}$ & 0 & 0.3616 & 0.3616 & 0 & 0 \\
\hline $\mathbf{2 2 - 1 3 - 5}$ & 4 & 0.3616 & 0.3735 & 11 & 7 \\
\hline
\end{tabular}

$\mathrm{a}_{0}=$ the lattice parameter for the alloy with zero carbon content determined from a N-R fit of the zero times treated sample.

$\boldsymbol{b}^{*}$ = the lattice parameter from the 311 peak.

${ }^{c}$ The values from the 311 peak are more consistent and higher than the values obtained from the N-R fit.

The XRD analysis can also be used to determine the fraction of ferrite and austenite in a steel sample. Figure 4.13 shows XRD patterns from surfaces of the non-treated and 1x-treated 301 specimens. The indexed XRD patterns indicate that there were two major phases in the nontreated 301 specimen. The phases are $\gamma$-(austenite) and $\alpha$-(ferrite). Volume fractions of $\alpha$-(ferrite) and $\gamma$-(austenite) phases in the non-treated 301 specimen were calculated by comparing the relative sizes of the XRD peaks, as shown in Table 4.2, and are 41 and 59\%, respectively. After exposure to a single low temperature carburization cycle, the $\alpha$-(ferrite) phase completely transformed to austenite in the hardened layer. From the XRD peak positions in Fig. 4.13, the lattice parameter of the austenite phase in the $1 \mathrm{x}$-treated specimen increased by $2.1 \%$ from 0.3601 to $0.3676 \mathrm{~nm}$. 


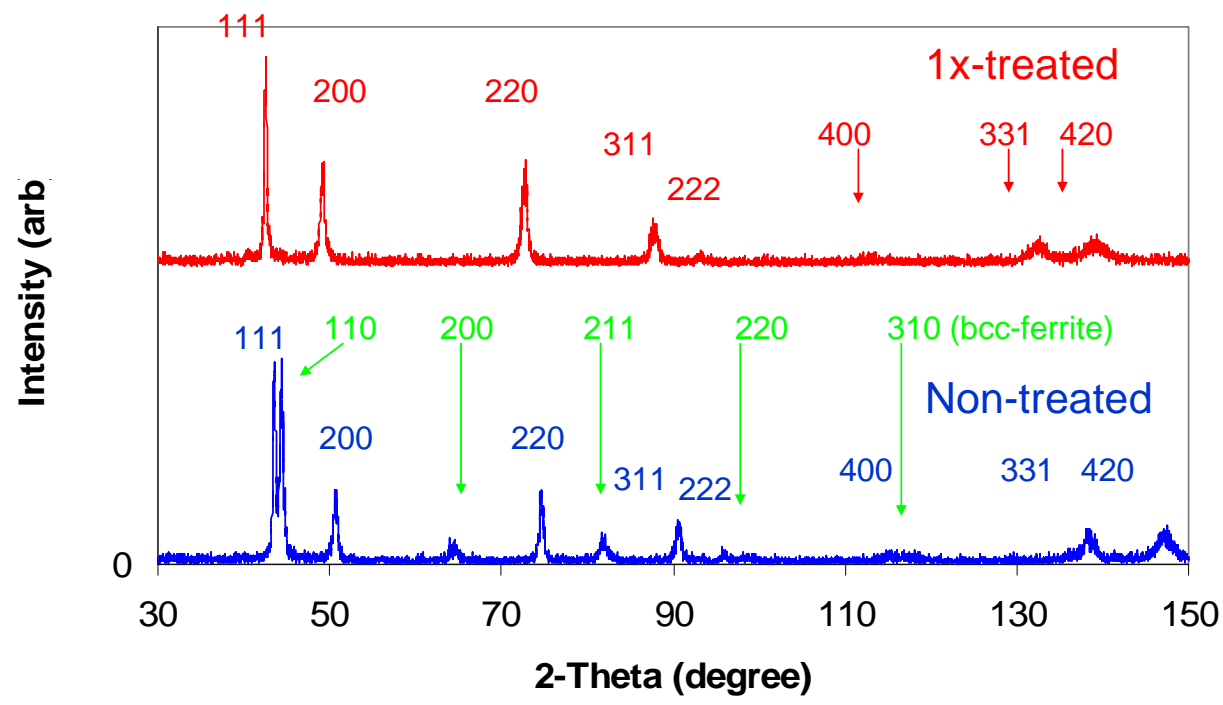

Figure 4.13. X-ray diffraction patterns of 1x-treated and non-treated 301 specimens.

Table 4.2. Using $\mathrm{Cu}-\mathrm{K} \alpha$ Radiation, Measured Integrated Intensities of X-ray Diffraction and Calculated Theoretical Intensities for $\alpha$-Ferrite Peak (200) and $\gamma$-Austenite Peak (200)

\begin{tabular}{|c|c|c|c|c|c|}
\hline \multirow{2}{*}{ hkl } & \multirow{2}{*}{$\begin{array}{l}2 \theta \text { Position } \\
( \pm 0.02 \mathrm{deg})\end{array}$} & \multicolumn{2}{|c|}{$\begin{array}{c}\text { Peak Bound } \\
( \pm 0.02 \mathrm{deg})\end{array}$} & \multirow{2}{*}{$\begin{array}{c}\text { Channels } \\
\text { of Peak }\end{array}$} & \multirow{2}{*}{$\begin{array}{c}\text { Integrated Intensity } \\
\text { (Counts) } \\
\text { (Background } \\
\text { Subtracted) }\end{array}$} \\
\hline & & Lower B & Upper B & & \\
\hline 200 ( $\alpha$-ferrite) & 65.02 & 64.32 & 65.40 & 54 & 481.49 \\
\hline 200 ( $\gamma$-austenite) & 50.68 & 50.12 & 51.20 & 55 & 1702.49 \\
\hline
\end{tabular}

(a) Integrated intensities for ferrite (200) peak and for austenite (200) peak

\begin{tabular}{|c|c|c|c|c|c|c|c|c|}
\hline $\mathbf{h k l}$ & $\operatorname{Sin} \boldsymbol{\theta} / \boldsymbol{\lambda}\left(\AA^{-1}\right)$ & $\mathbf{f}$ & $|F|^{2}$ & $\mathbf{L P}$ & $\mathbf{P}$ & $e^{-2 M}$ & $\mathbf{V}=a^{3}\left(\AA^{3}\right)$ & $\mathbf{R}$ \\
\hline $200(\alpha$-ferrite $)$ & 0.34887 & 15.218 & 926.4 & 4.72 & 6 & 0.9172 & 23.54 & 43.42 \\
\hline $\begin{array}{c}200 \\
(\gamma \text {-austenite })\end{array}$ & 0.27778 & 17.442 & 4867.60 & 8.46 & 6 & 0.9467 & 46.69 & 107.30 \\
\hline
\end{tabular}

(b) Theoretical intensities for ferrite (200)peak and for austenite (200)peak

\section{Vo-ferrite}

$41 \%$

\section{V $\gamma$-austenite}

$59 \%$

(c) Volume fraction determined by the direct comparison method (ASTM 1994) 


\subsubsection{Magnetic Force Microscopy of Carburized 301 SS}

$301 \mathrm{SS}$ have such a low Ni content that they typically contain $\sim 25 \%$ ferrite. After carburization, the amount of ferrite within a few microns of the surface has significantly decreased, as shown by XRD results, suggesting that carbon is a strong austenite stabilizer. To study this further, and to explore more deeply into the material, magnetic force microscopy (MFM) was done on a cross-sectioned sample of a carburized 301 steel specimen. In MFM, a resonating Ni-coated cantilever is brought into close $(\sim 100 \mathrm{~nm})$ proximity with the surface of a sample. If the sample is ferromagnetic, its magnetic field will affect the vibration of the cantilever, which can be detected as a phase shift in the resonance. Figure 4.14 shows a 50 - by $50-\mu \mathrm{m}$ scan of the carburized 301 steel specimen, near the surface. The dark features denote phase shifts and the presence of ferrite. For $\sim 20 \mu \mathrm{m}$ beneath the surface (i.e., corresponding to the carburized case), the 301 steel specimen is almost entirely austenite. Below this, depth there is a significant ferrite volume fraction. Clearly, the enhanced carbon content due to carburization led to a ferrite-toaustenite transformation in the near-surface case, a testament to the effectiveness of carbon as an austenite stabilizer in SS.

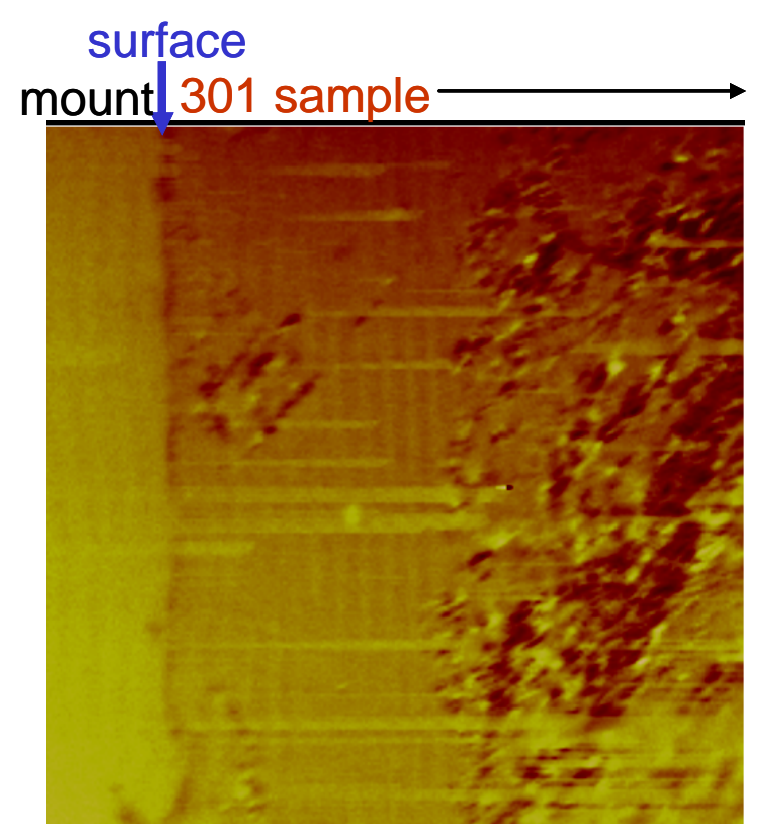

Figure 4.14. Magnetic force microscopy cross-sectional image of carburized 301 stainless steel near the surface. The area shown is $50 \times 50 \mu \mathrm{m}$. The sample mount is on the left side of the image.

\subsubsection{Local Electrode Atom Probe Microscopy}

CWRU investigated the composition and atomic structure of a 1x-carburized 316 sample using local electrode atom probe (LEAP) microscopy [8]. LEAP microscopy involves the use of a fine needle-like specimen with a tip diameter of less than $100 \mathrm{~nm}$. This tip is subjected to a periodic high voltage cycle, which creates a sufficient field to pull atoms off, one at a time. These atoms 
are then analyzed using a position-sensitive time-of-flight detector to determine both their massto-charge ratio and their spatial origin, allowing the construction of a three-dimensional atomic resolution image of the specimen.

The specimens used for the LEAP microscopy were prepared using focused ion beam system (Fig. 4.15). The samples for the analysis were prepared from the outermost surface of a carburized 316 SS. Four different data sets were acquired from three different tips; in all cases, the results indicated that carbide precipitates, if present, must have diameters less than $1 \mathrm{~nm}$ (i.e., the LEAP analysis confirmed the single phase character of the carburized case).

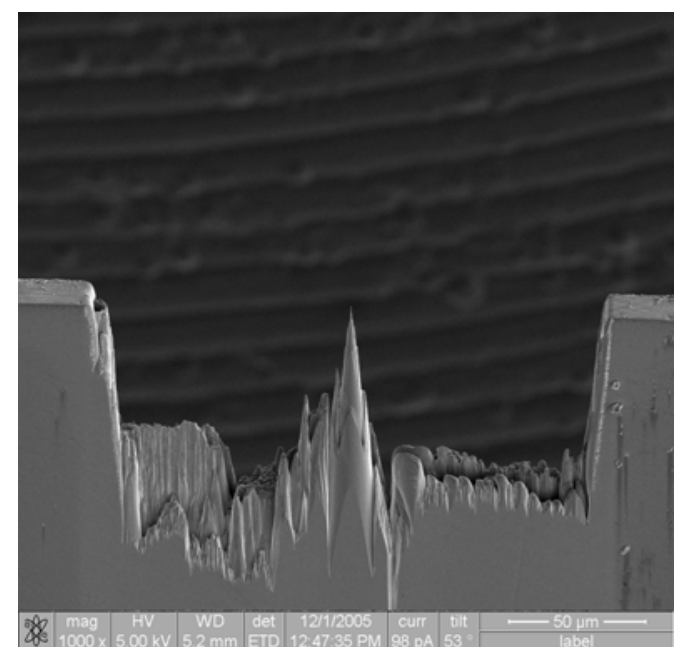

(a)

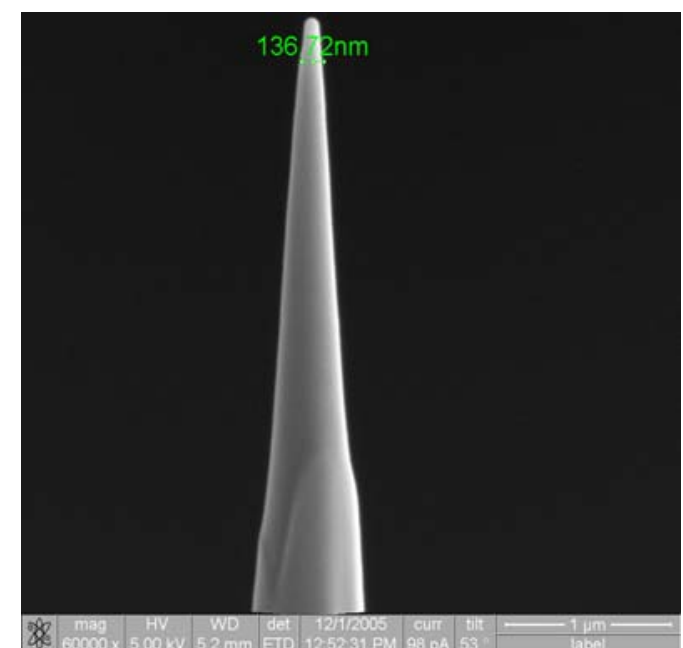

(b)

Figure 4.15. Scanning electron microscopy micrographs of a 1x-carburized 316 sample prepared for local electrode atom probe analysis by focused ion beam: (a) is a lowmagnification image showing the tip and the opening on both sides (allowing the approach of the electrode) and (b) is a higher magnification image of the tip.

Figure 4.16 shows a set of reconstructed images obtained using the LEAP technique. The images consist of 2-nm slices, each showing a single element, a combination of elements, or a cluster. No significant local concentrations of $\mathrm{Cr}$ or Mo are observed. Previous TEM analysis showed that when carbides formed, some Ni was rejected from the carbides, and was enriched at the carbide/austenite interface. However, in the present single phase specimens, the Ni distribution is uniform.

The carbon analyzed in the LEAP experiments appears in a few forms, having different charges and cluster sizes: $1 \mathrm{C}^{+}, 1 \mathrm{C}^{2+}, 2 \mathrm{C}^{+}, 3 \mathrm{C}^{2+}$, and $3 \mathrm{C}^{+}$. An interesting finding is the detection of $\mathrm{Mo} / \mathrm{C}$ clusters. It is not clear if Mo was preferentially bonded in the material or clustering occurred during the measurement. Figure 4.17 is a reconstructed image showing the main matrix elements - Fe, Cr, and Ni. (Some texturing may be present in the image, although "plane bending" is a known artifact due to the reconstruction method). This is further evidence of the homogeneous single-phase nature of the carburized case. 

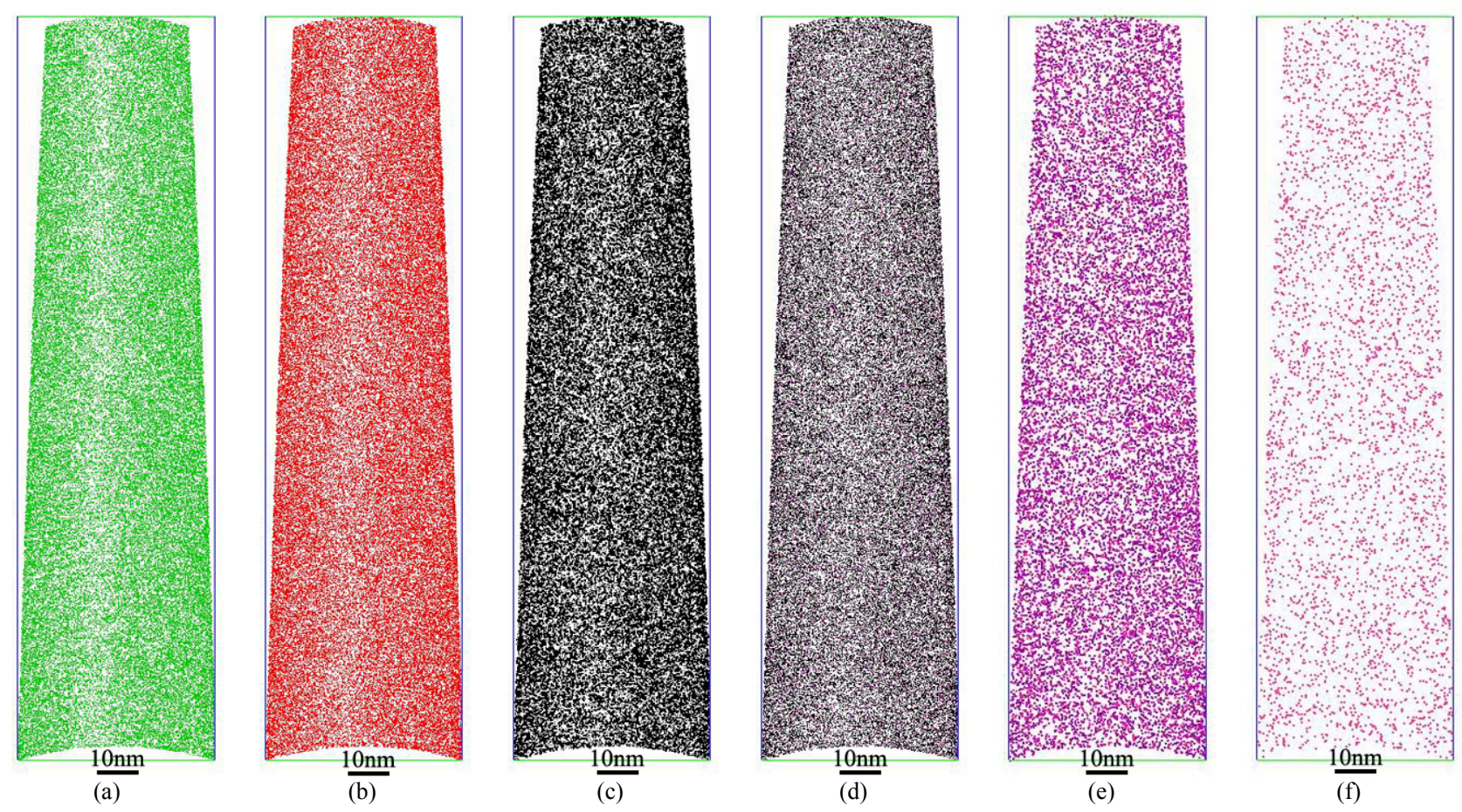

Figure 4.16. Reconstructed atom images obtained by the local electrode atom probe analysis. The images are a projection of a $2-\mathrm{nm}$ slice taken through the central area of the tip. In some of the images, a light-shaded line can be seen going from the top to the bottom; this is due to an artifact of the multi-channel detector and is not a bona fide structural feature. The values presented as a percent are the ratio of the atoms present in the figure to the total number of atoms recorded in the same area $x$ 100: (a) $\mathrm{Ni}^{+2} \mathbf{1 0 0 \%}$; (b) $\mathrm{Cr}^{+2} 77 \%$; (c) $\mathrm{C}^{+}, \mathrm{C}^{+2}, 2 \mathrm{C}^{+}, 3 \mathrm{C}^{+2}, 3 \mathrm{C}^{+}, 100 \%$; (d) all $\mathrm{Mo} \& \mathrm{C}, 100 \%$; (e) $\mathrm{Mo}^{+2}, \mathrm{Mo}^{+3}, \mathrm{MoC}^{+2}$, $100 \%$; and (f) $\mathrm{MoC}^{+2}, 100 \%$.

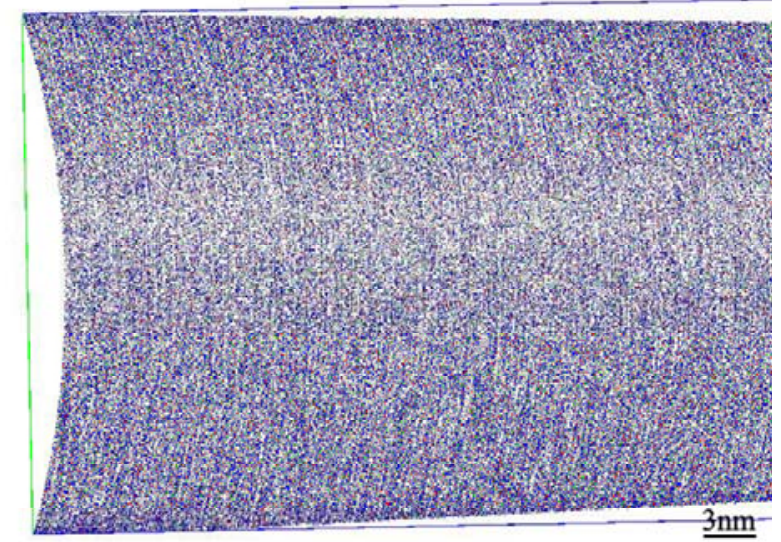

(a)

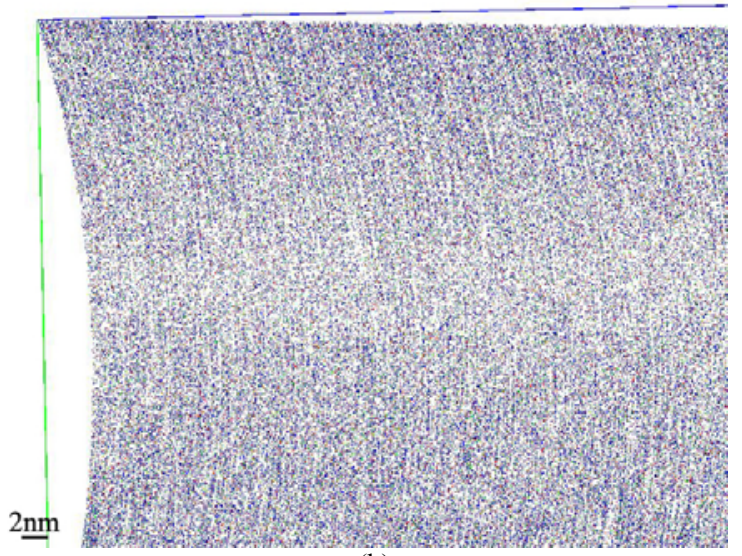

(b)

Figure 4.17. Reconstructed atom images obtain by the local electrode atom probe analysis based on the main matrix elements; Fe-Ni-Cr. The results are presented at two different magnifications: (a) $3 \mathrm{~nm}$ and (b) $2 \mathrm{~nm}$. 
The composition of the as-received 316 alloy and the values measured by LEAP microcopy on the $1 \mathrm{x}$-carburized 316 samples are given in Table 4.3. The ratios of the primary elements versus Fe are calculated to enable a better evaluation of the measurement accuracy. The agreement between the known and measured values is good. (The calculation is performed by integrating the areas under the elemental peaks).

Table 4.3. Atom Composition of the As-received 316 Alloy and the Composition Measured by Local Electrode Atom Probe Microscopy of the 1x-Carburized 316 at the Surface

\begin{tabular}{|c|c|c|c|c|}
\hline \multirow[b]{2}{*}{ Element } & \multicolumn{4}{|c|}{316} \\
\hline & $\begin{array}{c}\text { From } \\
\text { Swagelok } \\
\text { Non-treated }\end{array}$ & $\begin{array}{l}\text { Ratio } \\
\text { X/Fe }\end{array}$ & $\begin{array}{c}\text { From } \\
\text { LEAP } \\
\text { 2-nm slice }\end{array}$ & $\begin{array}{l}\text { Ratio } \\
\mathrm{X} / \mathrm{Fe}\end{array}$ \\
\hline $\mathrm{Fe}$ & 64.9 & & 56.7 & \\
\hline $\mathrm{Cr}$ & 18.8 & 0.29 & 17.9 & 0.32 \\
\hline $\mathrm{Ni}$ & 11.5 & 0.18 & 11.2 & 0.20 \\
\hline $\mathrm{Mn}$ & 1.7 & 0.03 & 1.3 & 0.02 \\
\hline Mo & 1.4 & 0.02 & 0.9 & 0.02 \\
\hline $\mathrm{Si}$ & 1.2 & 0.02 & 1.6 & 0.03 \\
\hline $\mathrm{C}$ & 0.2 & & 10.3 & \\
\hline
\end{tabular}

\subsubsection{Thermodynamic Modeling}

\subsubsection{Carbon Solubility in FCC Steels}

A thermodynamic model $[9,10]$ for a Fe-based face-centered cubic (FCC) solid solution has been formulated using the CALPHAD two-sublattice framework. The most up-to-date parameters representing the effects of alloying elements on the chemical potentials of elements in the FCC solid solution have been obtained directly from the CALPHAD literature. The influence of $\mathrm{Al}, \mathrm{Co}, \mathrm{Cr}, \mathrm{Cu}, \mathrm{Mn}, \mathrm{Mo}, \mathrm{N}, \mathrm{Nb}, \mathrm{Ni}, \mathrm{Si}, \mathrm{Ti}, \mathrm{V}, \mathrm{W}$, and $\mathrm{Zr}$ on the solubility of $\mathrm{C}$ in FCC solid solutions encompassing the range of compositions of 20 candidate SS has been assessed. A significant discrepancy between two research groups was found in a review of the literature regarding the effect of $\mathrm{Cr}$ on the solubility of $\mathrm{C}$ in FCC Fe-based solid solutions. The thermodynamic interaction coefficients from the two research groups differ by a factor of three in their predictions of $\mathrm{C}$ solubility.

The essence of the problem is shown in Fig. 4.18, which was done for pure Fe and a model 316 alloy containing $18 \% \mathrm{Cr}$ and $12 \% \mathrm{Ni}$. The two sets of calculations are labeled "Wagner" and "CALPHAD". Figure 4.18(a) shows that the calculated carbon solubility in pure Fe is in good agreement for the two sets of parameters, and in agreement with the equilibrium Fe-carbon phase diagram (the austenite form of $\mathrm{Fe}$ is stable in $\mathrm{Fe}$-carbon alloys above $1013 \mathrm{~K}$ ). The equilibrium solubility of the model alloy in equilibrium with either $\mathrm{M}_{23} \mathrm{C}_{6}$ of $\mathrm{M}_{7} \mathrm{C}_{3}$ carbides is shown in Fig. 4.18(b) (the carbide stoichiometry depends on carbon content of the alloy so we have performed calculations for two stoichiometries). This calculation reveals modest differences between results using the two sets of interaction coefficients, but more importantly reveal that the carbon solubility is drastically lowered in the model 316 alloy compared with pure Fe. 


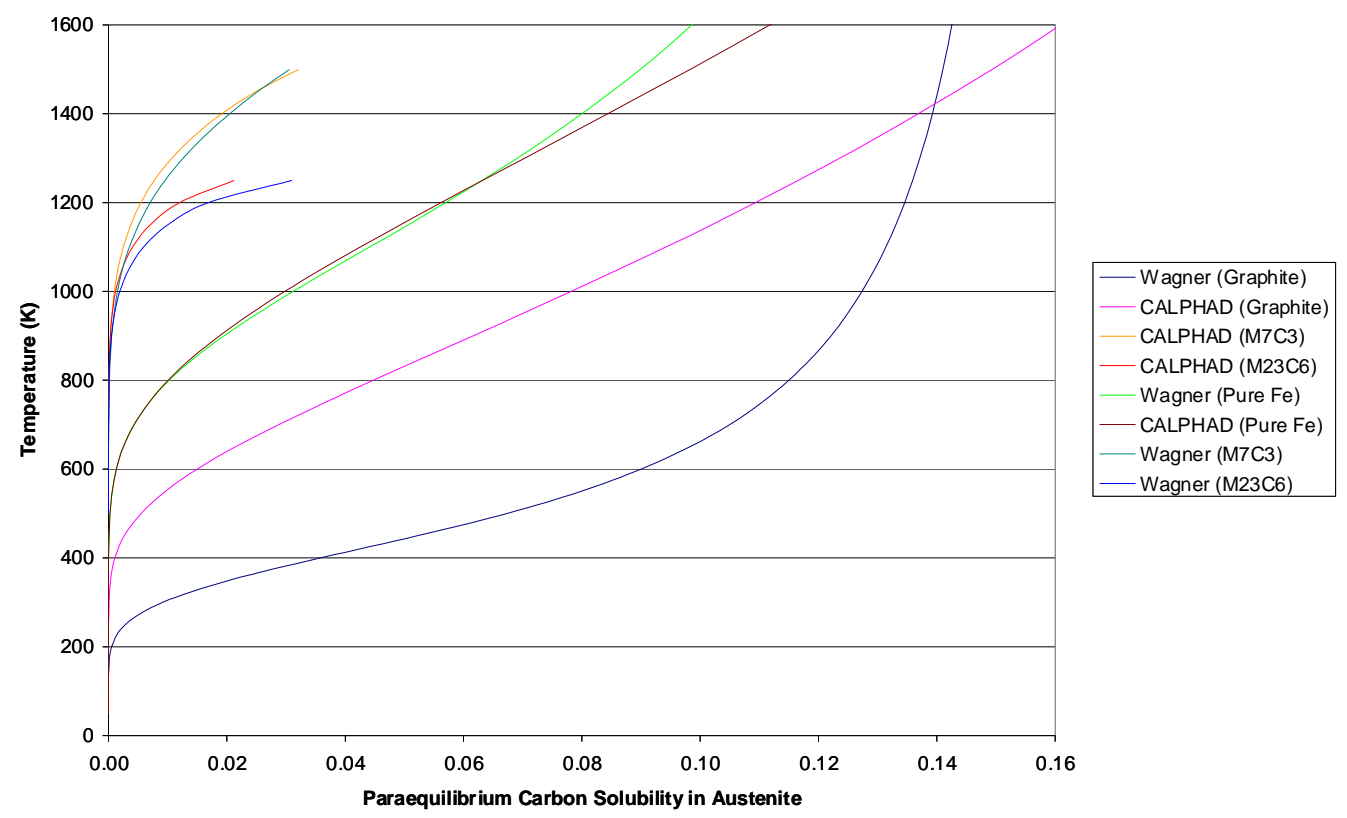

(a)

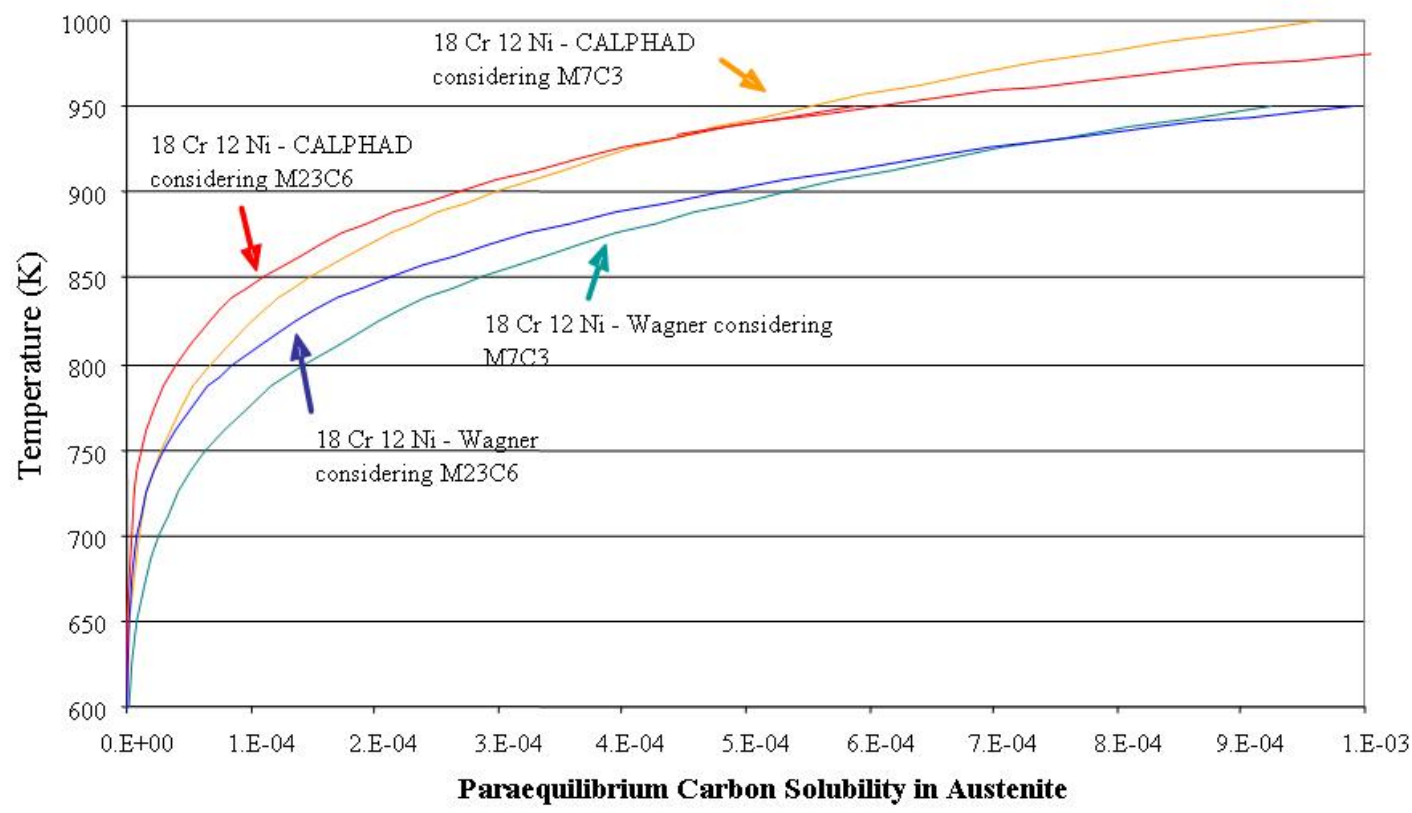

(b)

Figure 4.18. Calculated carbon solubility in (a) Fe and (b) Fe-18Cr-12Ni considering various carbides.

The paraequilibrium solubilities, on the other hand, are drastically increased in the model alloy. Paraequilibrium here connotes that the formation of the equilibrium $\mathrm{Cr}$-containing carbides are suppressed because of kinetic considerations - the limited diffusivities of substitutional solutes at the carburization temperature used for LTCSS $(775-800 \mathrm{~K})$. The predicted carbon solubilities at $775 \mathrm{~K}$ are $4.2 \%$ (CALPHAD) and $11.35 \%$ (Wagner). The CALPHAD parameters are obviously incorrect, as we find surface carbon concentration of $\sim 11$ at. \% in an actual 316 alloy after 
LTCSS. As the Wagner and CALPHAD curves intersect at $1435 \mathrm{~K}$, a temperature within the range where the carbon solubilities were determined experimentally, the problem lies in the temperature coefficients of the interaction parameters. The most recent assessment of the CALPHAD parameters for the Cr-Fe-Ni-carbon system completed by B. J. Lee, Department of Materials Science and Engineering, Pohang University of Science and Technology, Pohang 790784, Republic of Korea, was used to update our solution thermodynamic database. The new parameters were used to calculate the solubility of carbon in model $18 \mathrm{Cr}-12 \mathrm{Ni}$ austenitic steel under paraequilibrium conditions (i.e., when no carbides of any type form, and equilibrium conditions when $\mathrm{M}_{23} \mathrm{C}_{6}$ forms). The agreement between the predicted solubility under paraequilibrium conditions and the experimentally observed value at $750 \mathrm{~K}$ is now within a factor of two. The new CALPHAD parameters also were used to establish the solubility of carbon in equilibrium with a $\mathrm{M}_{23} \mathrm{C}_{6}$ carbide phase which has an $\mathrm{M}$ composition equal to that of its austenite matrix. The presence of a partitionless carbide generates a state where the carbon solubility is just less than that for the paraequilibrium condition.

As a basis for alloy development, the CALPHAD database was used to determine the change in carbon solubility under paraequilibrium conditions for additions of $\mathrm{Cr}, \mathrm{Ni}, \mathrm{Si}, \mathrm{Al}, \mathrm{Mo}, \mathrm{Ti}, \mathrm{V}, \mathrm{Nb}$, and $\mathrm{Zr}$. The strong carbide-forming elements are capable of a considerable increase in the carbon solubility.

\subsubsection{TTT Diagrams}

To examine the effects of increased carbon content, and therefore the thermodynamic driving force for carbide formation, on carbide precipitation kinetics, a mathematical model was developed and used to generate time, temperature, transformation (TTT) diagrams. The model, based on experimental research on $\mathrm{M}_{23} \mathrm{C}_{6}$ precipitation from 316, was built on nucleation and growth kinetics equations and a CALPHAD-type thermodynamic model. The data of interest was the extrapolation of the TTT model to high-carbon concentrations: 10 at. \%. Around the processing temperature, the thermodynamic driving force was found to have a negligible impact on transformation kinetics. The energy driving carbide nucleation and growth did have a profound effect on carbide solubility temperature.

Figure 4.19 shows the extrapolated $\mathrm{M}_{23} \mathrm{C}_{6}$ TTT curves at 1,3 , and 10 at. $\% \mathrm{C}$. The more broken line represents 0.1 vol. \% transformed, the less broken line represents 1 vol. \% transformed, and the solid line represents 10 vol. \% transformed.

\subsubsection{Carbon Solubility in Other Alloys}

Calculations have been completed for the effect of chromium in cobalt alloys on the paraequiliburium solubility of carbon. This work shows that for a composition similar to MP-35-N, with 22.3 at. $\% \mathrm{Cr}, 34.5$ at. $\% \mathrm{Ni}$, maximum $1 \%$ at. $\% \mathrm{Fe}$, and 43.2 at. $\% \mathrm{Co}$, the carbon solubility at $700 \mathrm{~K}$ is 0.36 at. \%; however, by increasing the composition of Cr by $20 \%$ (from $20-25 \mathrm{wt} \%$ ), the solubility is doubled to 0.63 at. $\% \mathrm{C}$. 


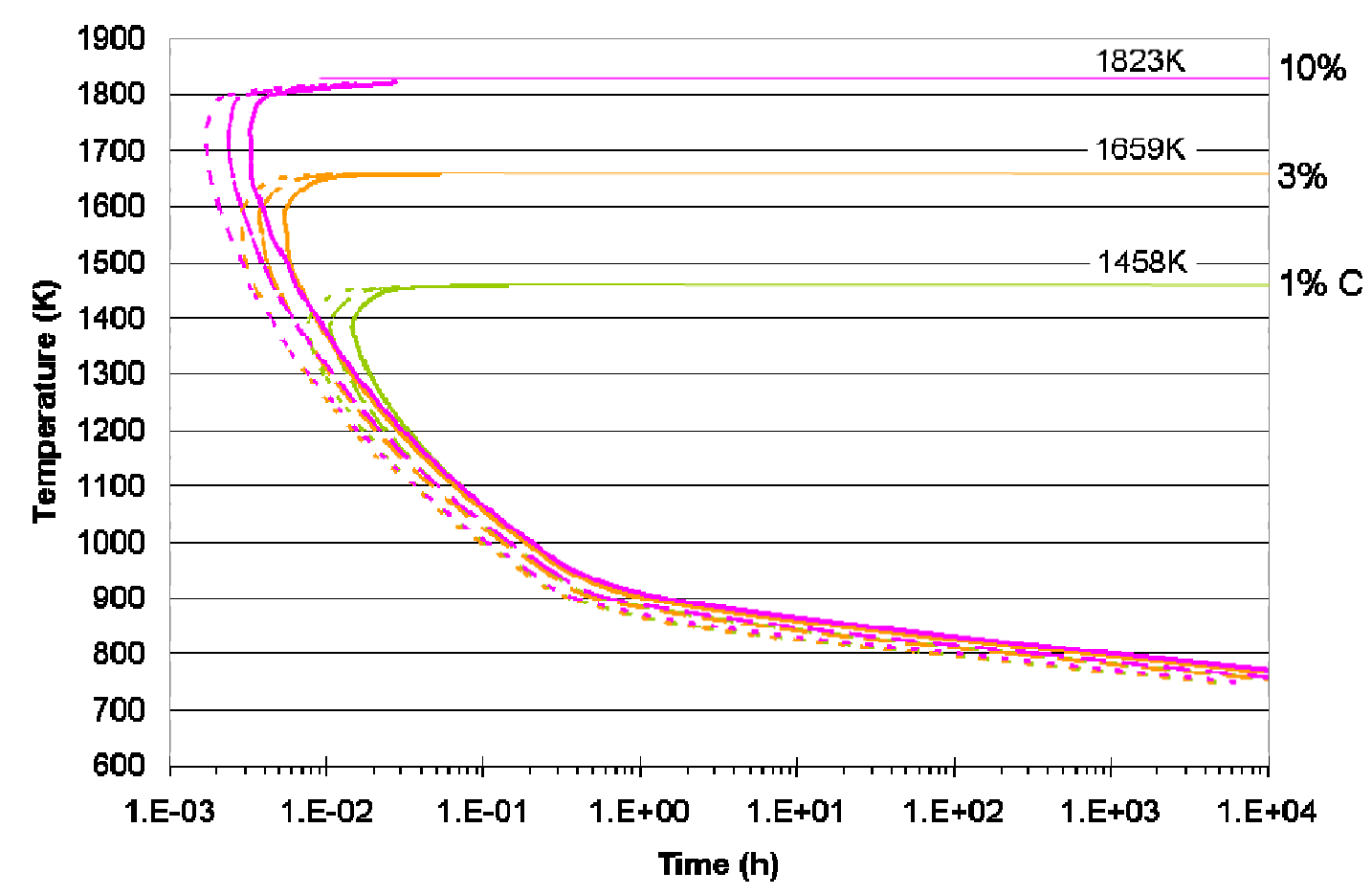

Figure 4.19. Time, temperature, transformation curves for $M_{23} C_{6}$ at varying carbon concentrations.

The solubility of carbon in a body-centered cubic (BCC) matrix was evaluated using CALPHAD-based thermodynamic modeling. For a binary Fe-carbon alloy at $750 \mathrm{~K}$, the solubility was 0.001 at. \%, a factor of 680 less than that found in an equivalent FCC matrix. With the addition of $30 \mathrm{wt} \% \mathrm{Cr}$ to a $\mathrm{BCC}$ Fe matrix, the carbon solubility increased by a factor of 4000 , bringing the solubility to within a factor of 2.5 of that found in an equivalent FCC matrix. Low-temperature carburization of PH 13-8 Mo was observed using XRD; the carbon concentration in its case was comparable to that predicted by the thermodynamic modeling.

\subsubsection{Ferrite/Austenite Stability}

XRD analyses conducted on carburized $301 \mathrm{SS}$ revealed that the $\sim 50 \%$ austenite $/ 50 \%$ ferrite material completely transformed to austenite in the case-hardened layer. The CALPHAD-based solution thermodynamic modeling has been expanded to allow evaluation of the relative stability of ferritic and austenitic phases as a function of their carbon contents. Carbon is an austenite stabilizer, and diffusion of carbon into the ferrite constituent of duplex SS provides the diving force for the transformation of the ferrite to austenite at the carburization temperature. Calculations have been performed with a model $301 \mathrm{SS}$ alloy $(17 \mathrm{Cr}-7 \mathrm{Ni}$ wt \%) that have established the carbon concentration range over which the alloy is in its two-phase (ferrite plus austenite) field at $750 \mathrm{~K}$, our standard carburization temperature. For the model 301 alloy, the carbon concentration in the case must exceed 6 at. $\%$ to achieve complete transformation to austenite. The measured carbon concentration in $301 \mathrm{SS}$ specimens exposed to a single carburization cycle was 8.6 at. $\%$. 
Additional calculations regarding ferrite/austenite phase stability at temperatures below those used for carburization were conducted to determine if a significant driving force for partial transformation of austenite to ferrite will occur during cooling after treatment. (The cooling rate after a standard treatment is quite sluggish which may provide time for a bainitic transformation to occur.)

\subsubsection{Corrosion Testing}

\subsubsection{Polarization Measurements}

Cyclic potentiodynamic polarization measurements (ASTM G61) [11] were performed on both non-treated and carburized 316 (Fig. 4.20). The results showed that the corrosion potential of the treated sample was about $600 \mathrm{mV}$ higher than the non-treated sample, which amply demonstrated higher corrosion resistance. Also, the surface finish of the samples had no effect on the improvement [Fig. 4.20(b)].
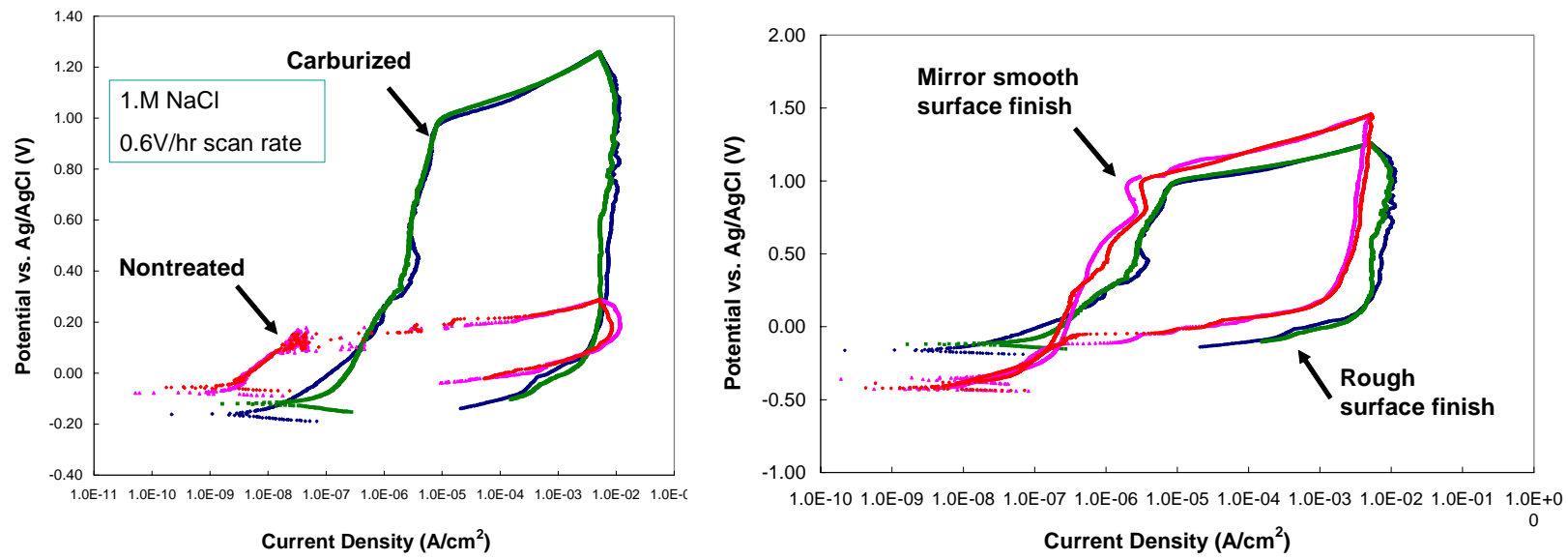

Figure 4.20. Cyclic potentiodynamic polarization curves for: (a) non-treated and carburized 316 samples and (b) carburized 316 samples with varying degrees of roughness.

Baseline electrochemical corrosion testing of other treated and non-treated alloys were also completed at Swagelok. A summary of the findings is shown in Fig. 4.21 and is described as follows:

- Pitting Corrosion: Carburization treatment improved the breakdown potentials $\left(\mathrm{E}_{\mathrm{b}}\right)$ of austenitic alloys CF3M, CF8M, 316, 316Ti, and 317 by an average $696 \mathrm{mV}$. Austenitic alloys 22-13-5 and Biodur 108, superaustenitic alloys 254 SMO, AL-6XN, alloy 20, and alloy $904 \mathrm{~L}$, all of which have intrinsically high $\mathrm{E}_{\mathrm{b}}$, exhibited minor changes in their $\mathrm{E}_{\mathrm{b}}$ and remained above $900 \mathrm{mV}$ after treatment. The alloys that exhibited the biggest increase in breakdown potentials also exhibited the greatest increase in pitting resistance range, an average of $665 \mathrm{mV}$. The remaining high alloys exhibited minor increases, less than $150 \mathrm{mV}$. 
The highly alloyed superaustenitic alloys AL-6XN, alloy 904L, and alloy 20 exhibited the smallest pit propagation range. All three were less than $40 \mathrm{mV}$.

- General Corrosion: Short term (i.e., $48 \mathrm{~h}$ ) immersion tests showed that the corrosion resistance of LTCSS (316) can be significantly better or worse than that of regular $316 \mathrm{SS}$, depending on the nature of the corrosive liquid, its composition and temperature, and the length of exposure of the material to the liquid.

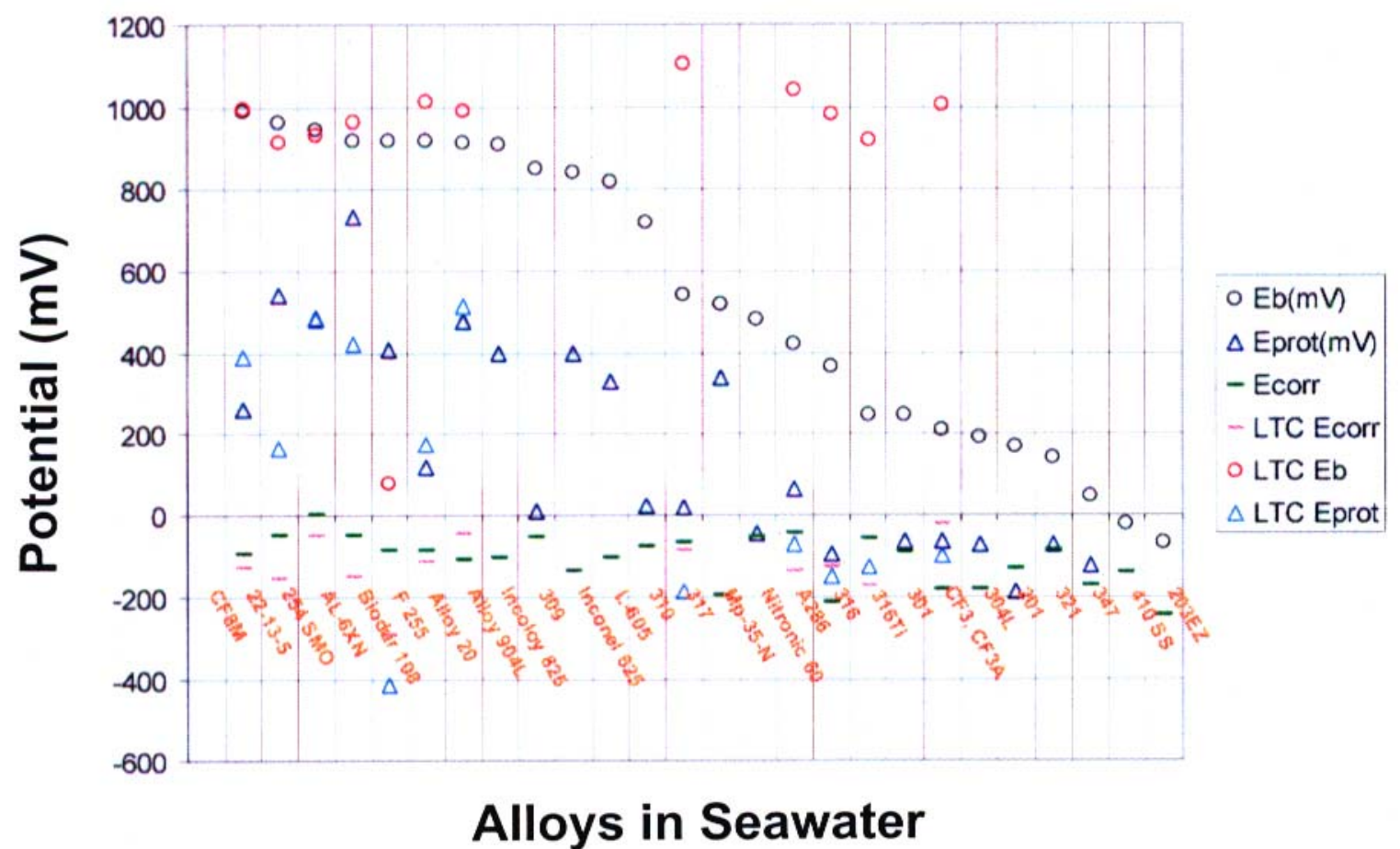

Figure 4.21. Corrosion results for a variety of alloys.

\subsubsection{Critical Pitting Temperature and Electrical Pitting Potential of Sectioned} 316L

A set of 316L coupons was treated. Sample disks were electropolished for 0, 40, 80, 160, 200, and $240 \mathrm{~s}$ to progressively remove the case. These specimens were then evaluated by glow discharge optical emission spectroscopy (GDOES) XRD, and X-ray photo spectroscopy (XPS). Sets of the samples were also corrosion tested using ASTM G150 and ASTM G61. This experiment was performed to evaluate the effect of carbon content and compressive residual stress associated with carbon diffusion, on corrosion resistance. The carbon concentrations, determined by the three methods, and the critical pitting temperature and electrical pitting potential are listed in Table 4.4 . 
Table 4.4. Data for Sectioned Low-Temperature Colossal Supersaturation-Treated 316 Stainless Steel Samples: the Depth Indicates the Amount of Material Removed after Carburization

\begin{tabular}{|c|c|c|c|c|c|}
\hline $\begin{array}{c}\text { Depth } \\
(\boldsymbol{\mu m})\end{array}$ & $\begin{array}{c}\text { C at. \% } \\
(\mathbf{X R D})\end{array}$ & $\begin{array}{c}\text { C at. \% } \\
(\mathbf{X P S})\end{array}$ & $\begin{array}{c}\text { C at\% } \\
(\mathbf{G D O E S})\end{array}$ & $\begin{array}{c}\text { Average Ep* } \\
(\mathbf{m V ~ S H E})\end{array}$ & $\begin{array}{c}\text { Average CPT** } \\
\left({ }^{\circ} \mathbf{C}\right)\end{array}$ \\
\hline 0 & 10.2 & 12.5 & 11.4 & 717.4 & 74.1 \\
\hline 4 & 8.8 & 10.7 & 9.6 & 752.7 & 86.6 \\
\hline 12 & 6.2 & 6.3 & 7.8 & 750.7 & 31.7 \\
\hline 19 & 0.3 & 1.7 & 6.0 & 256.7 & 21.3 \\
\hline 22 & 0.7 & & 4.7 & 492.4 & 21.8 \\
\hline 27 & 0.5 & & 2.5 & 429.8 & 22.9 \\
\hline
\end{tabular}

${ }^{*} \mathrm{Ep}=$ electrical pitting. ${ }^{* *} \mathrm{CPT}=$ critical pitting temperature.

To investigate the origin of this significant improvement in corrosion resistance, the surface (passive) oxide layer of the four samples with the least material removed were analyzed using XPS - the four samples included the complete range of corrosion resistance. Fig. 4.22 shows the $\mathrm{Cr}$ :Fe ratio in the passive oxides on the four samples as a function of depth. On all four samples, the passive oxide is about 2-nm thick. It is generally understood that the enhanced corrosion resistance of SS, compared to regular carbon steels, comes about by an increase in the $\mathrm{Cr}$ content of the passive oxide. The Cr oxides are much less resistant to dissolution than the Fe oxides.

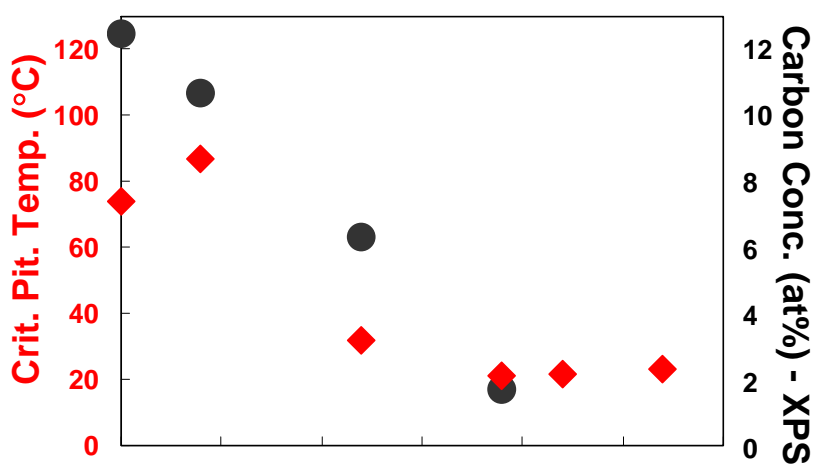

(a)

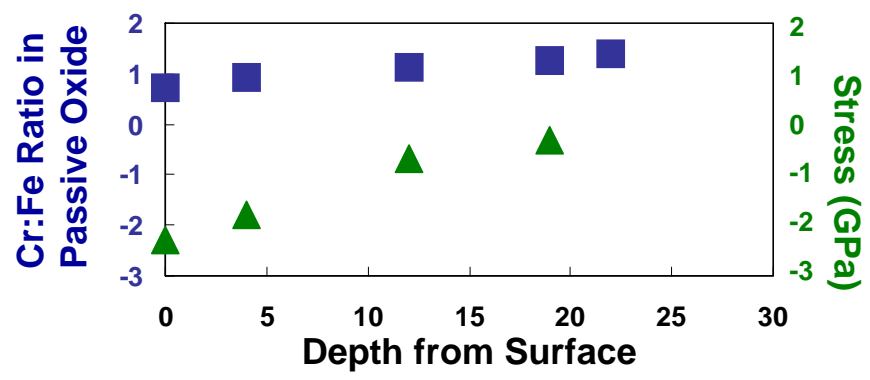

(b)

Figure 4.22. (a) Critical pitting temperature and carbon concentration determined by $X$ ray photoelectron spectroscopy and (b) the $\mathrm{Cr}$ : Fe ratio in the passive film and the residual stresses plotted as a function of depth. 
As seen in Fig. 4.22, the sectioning brought about by electropolishing led to an artificial increase in the $\mathrm{Cr}$ content in the passive oxides of the samples which had more material removed. Presumably, electropolishing removes Fe at a higher rate than $\mathrm{Cr}$. However, even though the sample, which had the entire carburized layer removed (or almost the entire layer), labeled $19 \mu \mathrm{m}$, had the highest $\mathrm{Cr}$ content in its passive layer; this sample displayed the worst corrosion resistance. This result indicates that the enhanced corrosion resistance is not due to an increased $\mathrm{Cr}$ content in the passive layer. Rather, the origin is something inherent in the LTCSS process, such as the increased $\mathrm{C}$ content or the residual surface stresses.

To distinguish between these, cyclic polarization behavior of two flat failed "dogbone" tensile specimens (one carburized and one as-received) was measured (Fig. 4.23). These two samples had similar strains to failure $[\sim 40 \%$ (carburized) and $\sim 60 \%$ (uncarburized)]. The residual stress due to the LTCSS process will be relieved just past yielding, and any residual stress present after failure (due to accumulated dislocation debris, for example) will be modest and essentially identical in two samples. [We attempted to measure the residual stress after testing using the Xray $\sin ^{2} \Psi$ technique, but residual stresses were too small ( $\left.<50 \mathrm{MPa}\right)$ to detect.] The improved corrosion potential shown in Fig. $4.23(\sim 1 \mathrm{~V}$ for the carburized material compared to $\sim 200 \mathrm{mV}$ for the as-received material) showed clearly that it is the carbon alone in the carburized samples that are responsible for the improved corrosion resistance.

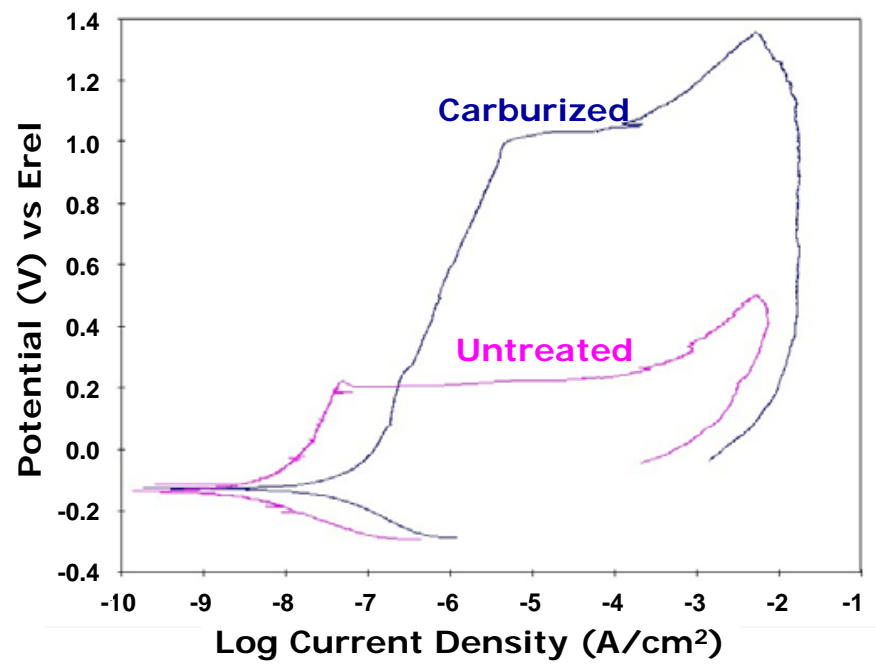

Figure 4.23. Polarization curves from an non-treated 316 stainless steel (SS) sample and a carburized 316 SS sample that had been plastically strained to relieve residual stresses.

Figure 4.24 shows an XPS-derived composition-depth profile through the passive oxide on a carburized sample. Carbon is clearly present within the passivating $\mathrm{Cr}-\mathrm{Fe}$ oxide and must be responsible for the improved corrosion resistance. We speculate that the presence of carbon within this passivating oxide changes the transport properties of the electronic defects (electrons, holes, oxygen vacancies, etc.) that control the corrosion behavior and thereby enhances the corrosion resistance. 


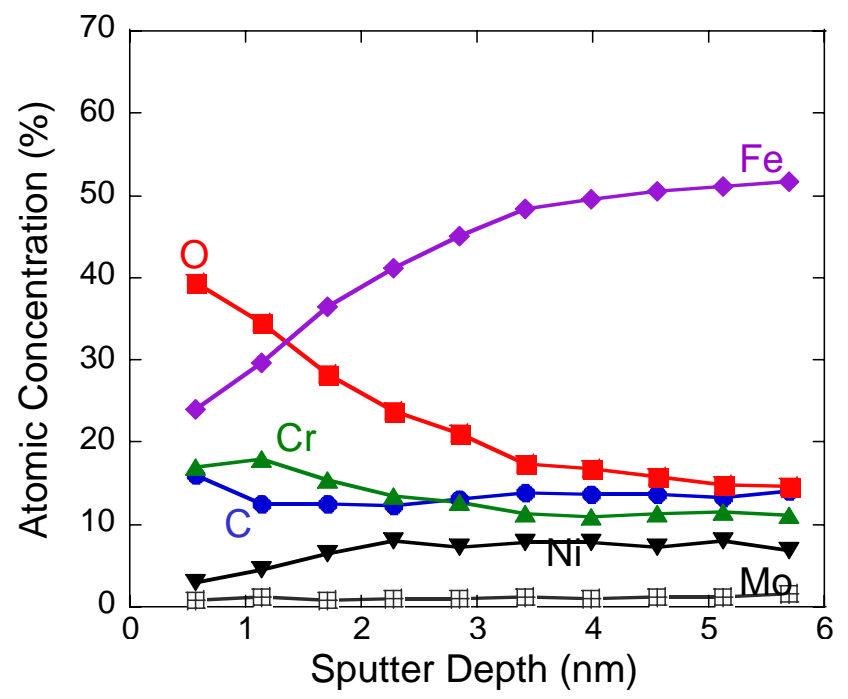

Figure 4.24. X-ray photo spectroscopy depth profiles of an as-carburized 316 sample. The enhanced carbon content in the passivating oxide layer is evident.

\subsubsection{Cavitation Erosion}

At ORNL, two ultrasonic-based cavitation-erosion systems were modified to allow for an accurate recording of time of testing. The required circuits involving sensors, timers, and hold and reset circuits were designed and built in-house. Without these modifications, if the system performed an unplanned shutdown, the time of testing would not be recorded by test apparatus and hence, be unknown unless the equipment was being monitored continuously. ASTM G-32 specifications served as the basis for the testing. The tests were conducted at $25^{\circ} \mathrm{C}$ and $20 \mathrm{kHz}$ with a $25-\mu \mathrm{m}$ peak-to-peak displacement. Testing was performed in 1- to 2 -h increments for total exposure of $6 \mathrm{~h}$. The total mass change and maximum pit depth were monitored as a function of exposure time. Two specimens $\left(1.80 \mathrm{~cm}^{2}\right.$ surface area $)$ per condition were examined.

Sonication data for treated and non-treated materials are presented in Figs. 4.25 and 4.26. As seen, the weight loss for the non-treated material is very much greater than for the non-treated material. In the non-treated state, $254 \mathrm{SMO}$ exhibits much greater resistance to cavitation than either $316 \mathrm{SS}$ or $321 \mathrm{SS}$. In the treated state, all three materials behave similarly. This performance differential is also demonstrated in Table 4.5 where the slopes of the weight versus time data are presented. The rate of weight loss per hour is significantly less for the treated material as compared to the treated material and the rate for the non-treated 254 SMO is approximately one-half that for $321 \mathrm{SS}$ and $316 \mathrm{SS}$. Also, as presented in Table 4.5, the rates of weigh loss show some correlation to surface hardness in the treated material but much more work will need to be performed to establish the correlation. The cavitation data presented in Fig. 4.27 show an average weight loss rate of $-1.08 \mathrm{mg} / \mathrm{h}$ for all the treated materials. This regression value for all treated materials versus those for the individual treated materials, presented in Table 4.5, strongly suggests that higher alloy content in treated materials does not contribute to the cavitation resistance. 


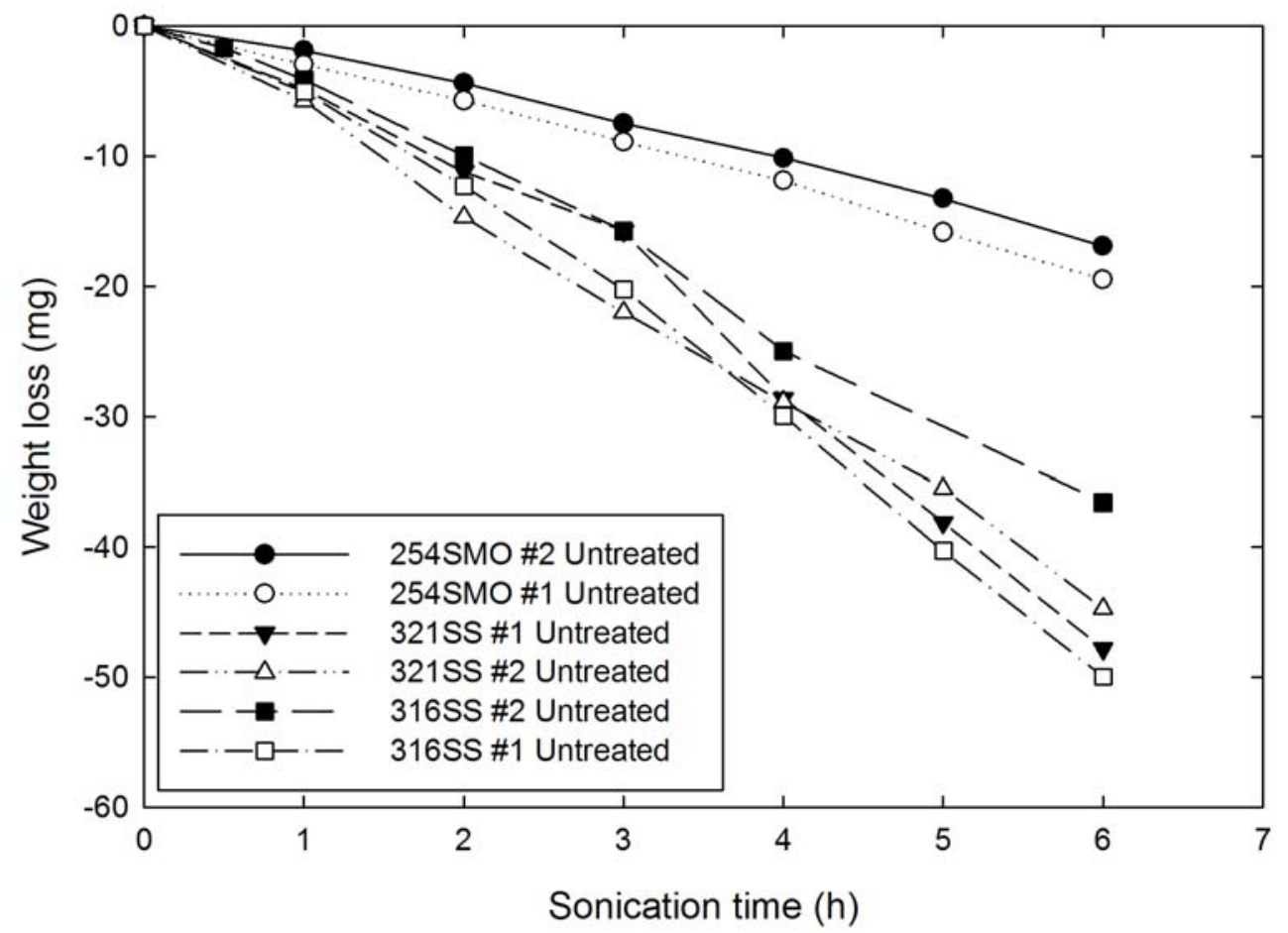

Figure 4.25. Weight loss as a function of time for non-treated materials. $254 \mathrm{SMO}$ exhibited much better cavitation resistance as compared to 321 and 316 stainless steels.

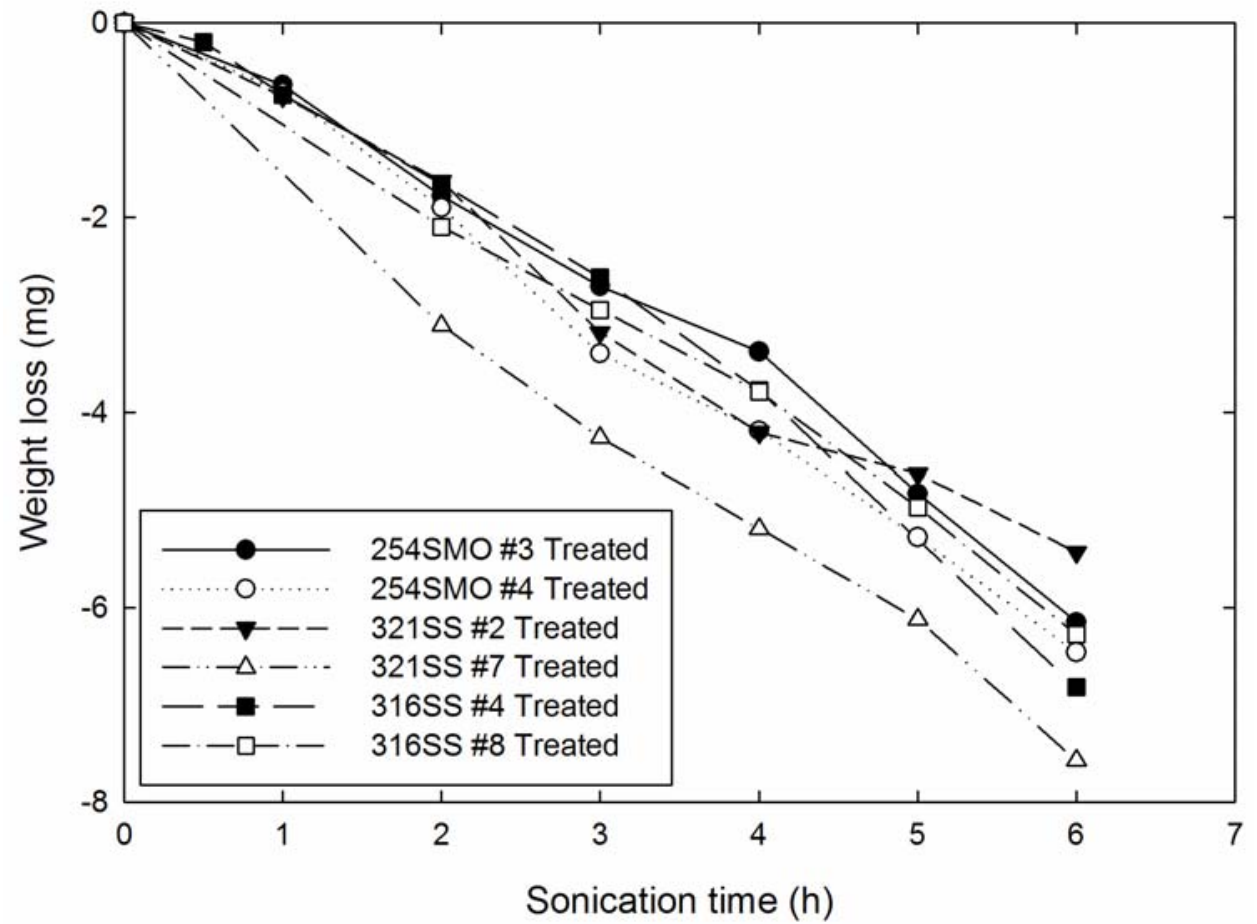

Figure 4.26. Weight loss as a function of time for treated materials. All materials behave similarly. 
Table 4.5. Average Weight Loss Versus Time Slope

\begin{tabular}{|l|l|l|l|l|l|}
\hline \multirow{2}{*}{ Materials } & $\begin{array}{c}\text { Treated Material } \\
\text { Slope }\end{array}$ & \multicolumn{2}{c|}{$\begin{array}{c}\text { Non-treated } \\
\text { Material Slope }\end{array}$} & \multicolumn{2}{|c|}{$\begin{array}{c}\text { HV from Swagelok QA Fitted } \\
\text { Equation for Treated Material }\end{array}$} \\
\cline { 2 - 6 } & \multicolumn{1}{|c|}{$\mathbf{m g} / \mathbf{h}$} & $\mathbf{m g} / \mathbf{h}$ & $\mathbf{5} \boldsymbol{\mu}$ & $\mathbf{1 0} \boldsymbol{\mu}$ & $\mathbf{4 0} \boldsymbol{\mu}$ \\
\hline $254 \mathrm{SMO}$ & -1.0930 & -3.2630 & 1079 & 850 & 391 \\
\hline $321 \mathrm{SS}$ & -0.9915 & -8.4535 & 915 & 729 & 355 \\
\hline $316 \mathrm{SS}$ & -1.1629 & -8.4408 & 1007 & 783 & 337 \\
\hline
\end{tabular}

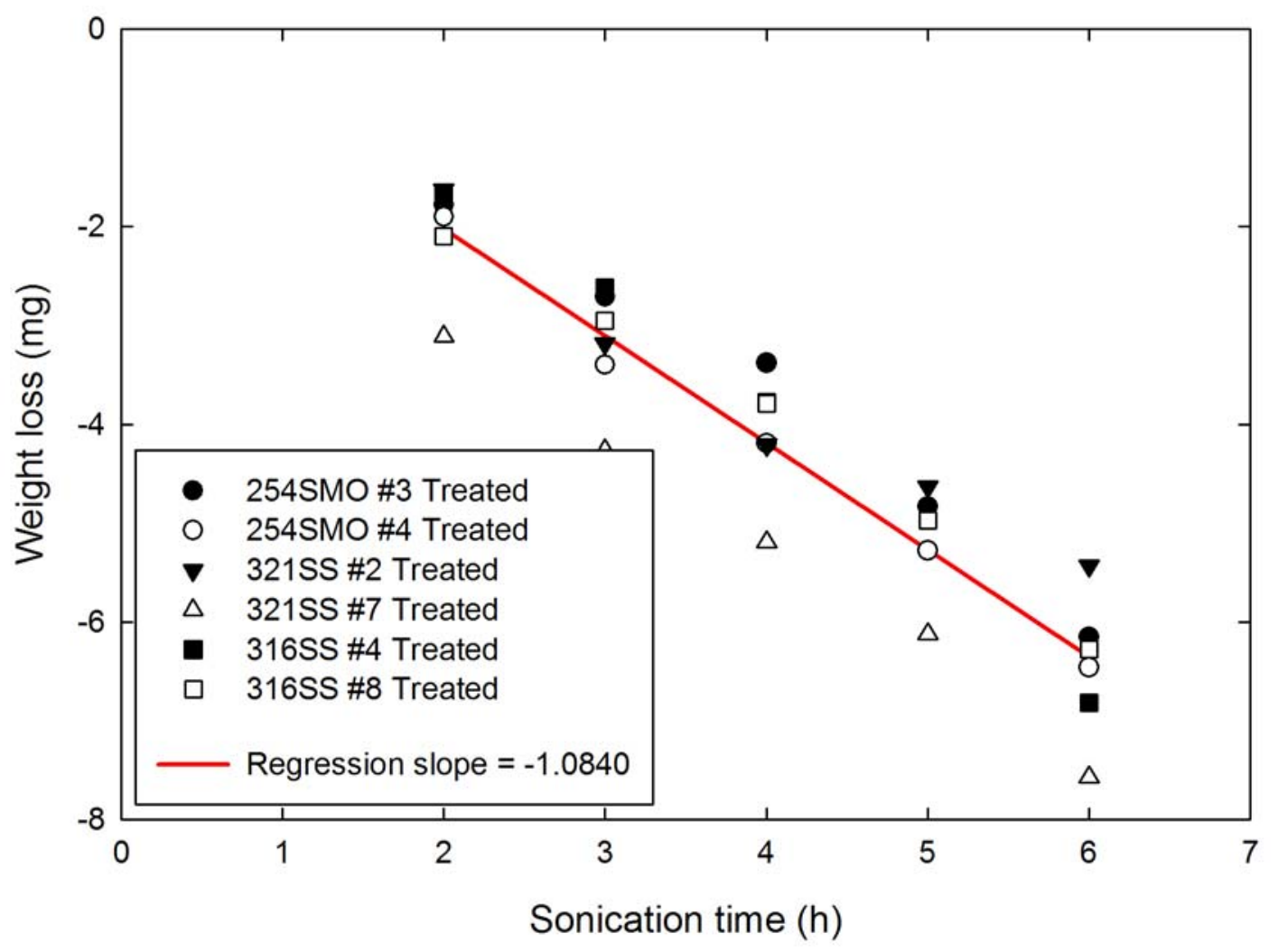

Figure 4.27. Regression analysis of weight loss data for all treated materials. Rates of weight loss are in good agreement with each other.

The surface appearance of the $321 \mathrm{SS}$ and $254 \mathrm{SMO}$ after $6 \mathrm{~h}$ of testing are presented in Figs. 4.28 and 4.29, respectively. A shown in Fig. 4.28, there is a highly developed surface relief on the non-treated $321 \mathrm{SS}$ (left) corresponding to its much larger weight loss, while the treated $321 \mathrm{SS}$ (right) surface is smoother with isolated cavitated areas. In contrast, as shown in Fig. 4.29, the 254 SMO shows less surface relief especially for, the treated material (right). 


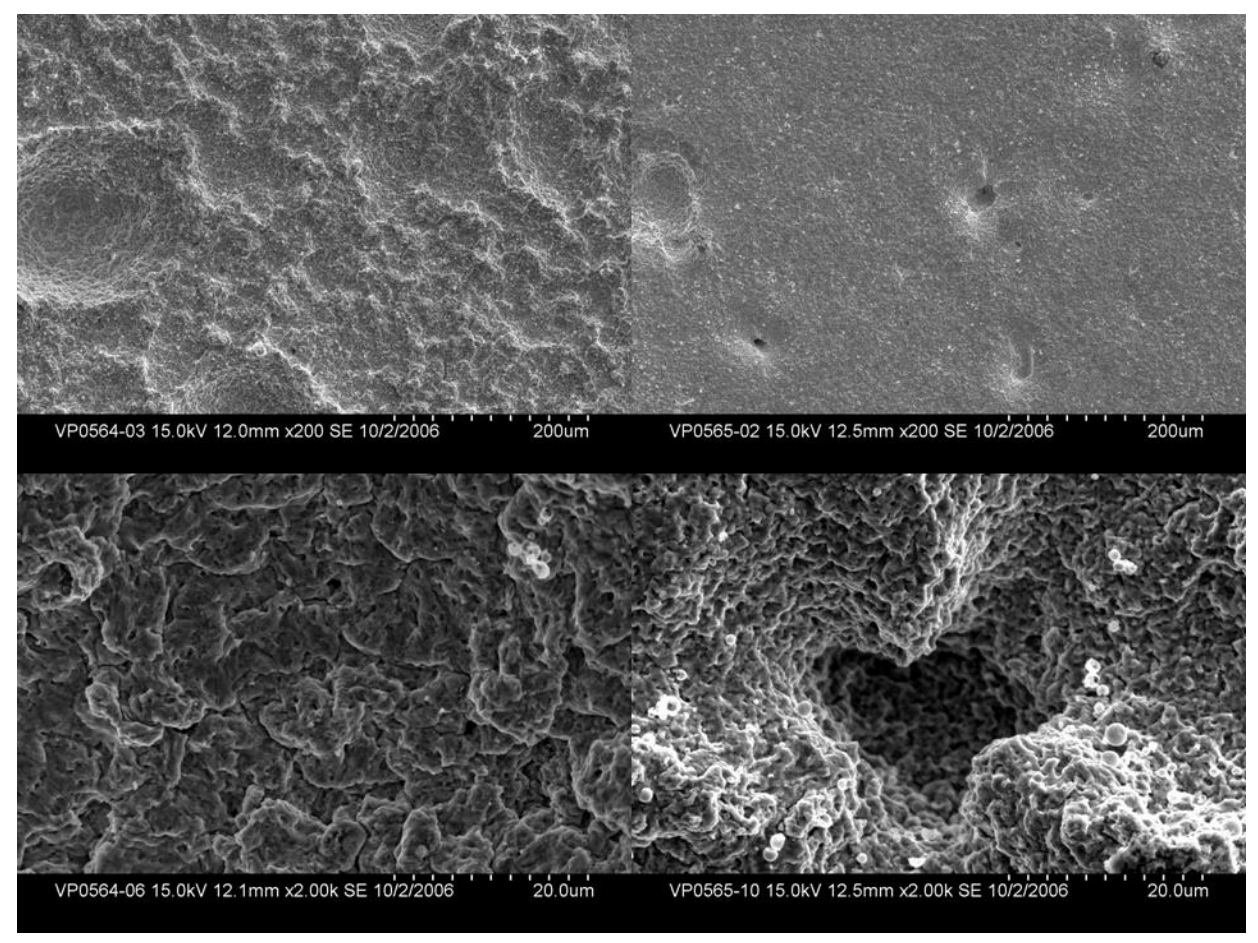

Figure 4.28. Surface appearance of 321 stainless steel after six hours of sonication. Note significant more surface relief for the non-treated material (left) as compared to the treated material (right).

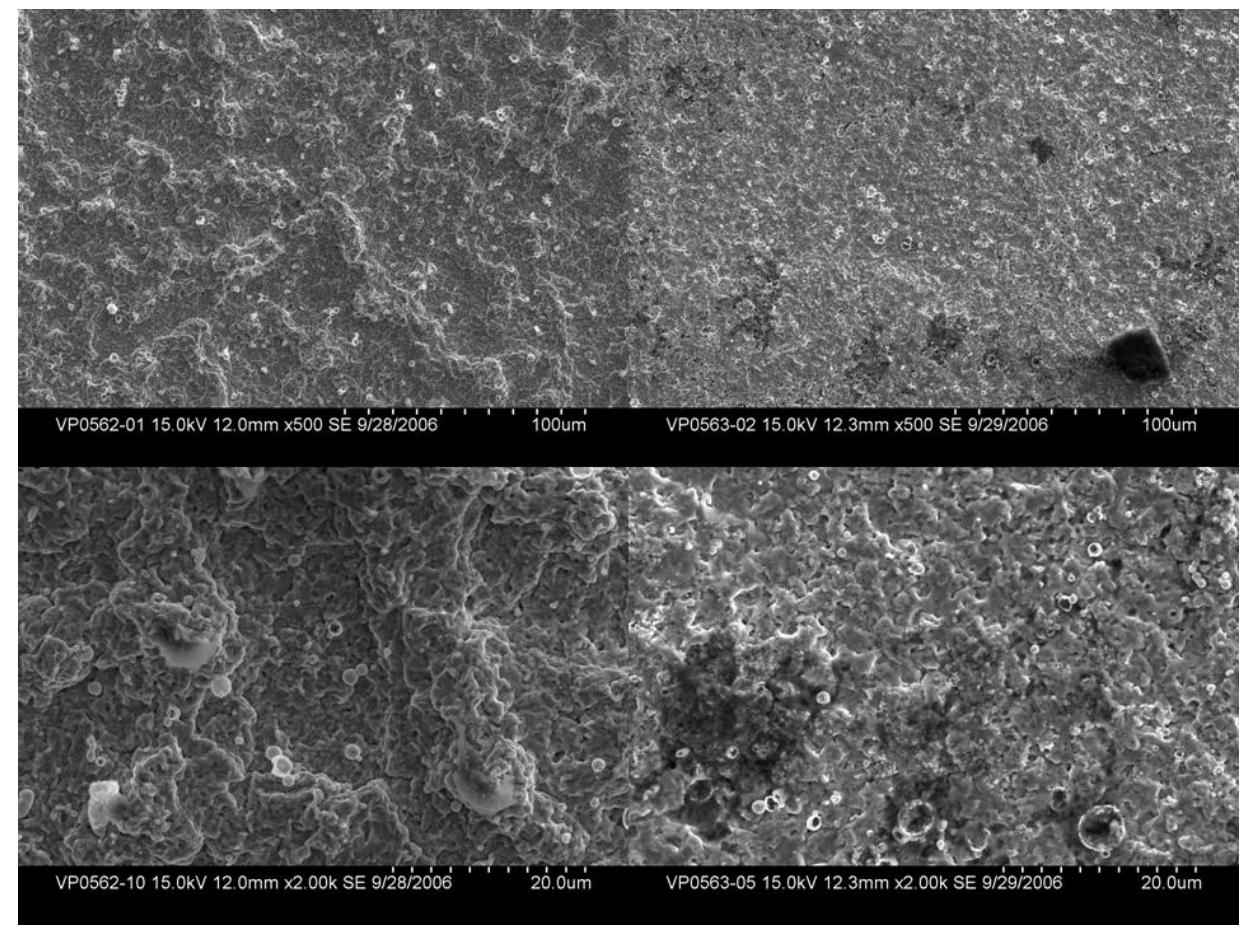

Figure 4.29. Surface appearance of 254 SMO material after six hours of sonication. Note much less surface relief for the treated material (right) as compared to non-treated material (left) and in comparison to 321 stainless steel material (Fig. 4.28). 


\subsubsection{Mechanical Testing}

\subsubsection{Tensile Tests}

Tensile specimens ( 0.25 -in.-round tensile bars) were fabricated from 316, 321, and 254 SMO SS. Some were carburized using the standard LTCSS method, and others were not. Three specimens from each steel sample in the as-received state and after carburization were pulled in tension. The behaviors are summarized in Table 4.6, and an example showing the stress-strain behavior of each sample is shown in Fig. 4.30. It is clear that the carburization process leads to a decrease in the initial yielding of each steel. As a result, the initial linear behavior extends through higher stresses/strains, and the resulting $0.2 \%$ offset yield stress is increased. The enhanced mechanical properties (increased hardness, increased residual compressive stresses) of the carburized case lead to a profound change in the low strain-stress/strain behavior. Several carburized specimens were ground such that the entire carburized case was removed and finished in the same manner as the specimens whose behavior is shown in Fig. 4.30. They were then pulled in tension, and the stress-strain behavior compared with identical specimens that had their carburized cases intact. As shown in Fig. 4.31, there is no difference in the stress-strain curves between the two types of specimens. The delayed yielding of the carburized specimens must be due to the heat treatment associated with carburization, and not the presence of the carburized case. All of the specimens were carburized in the cold-worked state. Apparently, mobile dislocations present in cold-worked samples were "pinned" during carburization (perhaps due to the low-carbon content in as-received samples, leading to the higher $0.2 \%$ yield strength.

Table 4.6. The 0.2\% Yield Strength (YS), Ultimate Tensile Strength (UTS), and \% Elongation upon Fracture for the Three Steel Alloys

\begin{tabular}{|l|c|c|c|}
\hline \multicolumn{1}{|c|}{ Alloy } & $\begin{array}{c}\mathbf{0 . 2 \%} \text { YS } \\
\text { (ksi) }\end{array}$ & $\begin{array}{c}\text { UTS } \\
\text { (ksi) }\end{array}$ & $\begin{array}{c}\text { \% } \\
\text { Elongation }\end{array}$ \\
\hline 316- Uncarburized & $81.4 \pm 6.6$ & $104.7 \pm 0.51$ & $37.5 \pm 0$ \\
\hline 316 - LTCSS & $93.5 \pm 2.1$ & $113.2 \pm 1.0$ & $30.7 \pm 0.9$ \\
\hline 321 - Uncarburized & $58.8 \pm 2.6$ & $96.6 \pm 0.34$ & 50.0 \\
\hline 321 - LTCSS & $66.3 \pm 1.4$ & $99.91 \pm 0.5$ & $47.5 \pm 1.8$ \\
\hline 254SMO - Uncarburized & $118.4 \pm 0.4$ & $140.8 \pm 1.0$ & $25.5 \pm 0.9$ \\
\hline 254SMO - LTCSS & $128.8 \pm 3.0$ & $144.5 \pm 1.8$ & $27.1 \pm 0.9$ \\
\hline
\end{tabular}

Tensile tests were also performed on thin foil samples [0.002-in. $(50-\mu \mathrm{m})$ thick], made from annealed 316 SS (Fig. 4.32). The yield stress is greatly improved. The ductility is decreased, but this is a result of the tensile stresses that are generated in the outer portion of the foil, in contrast to the compressive stresses that occur for thicker samples. Figure 4.33 shows the fracture surface of a carburized thin foil sample tested in tension, showing ductile failure. 

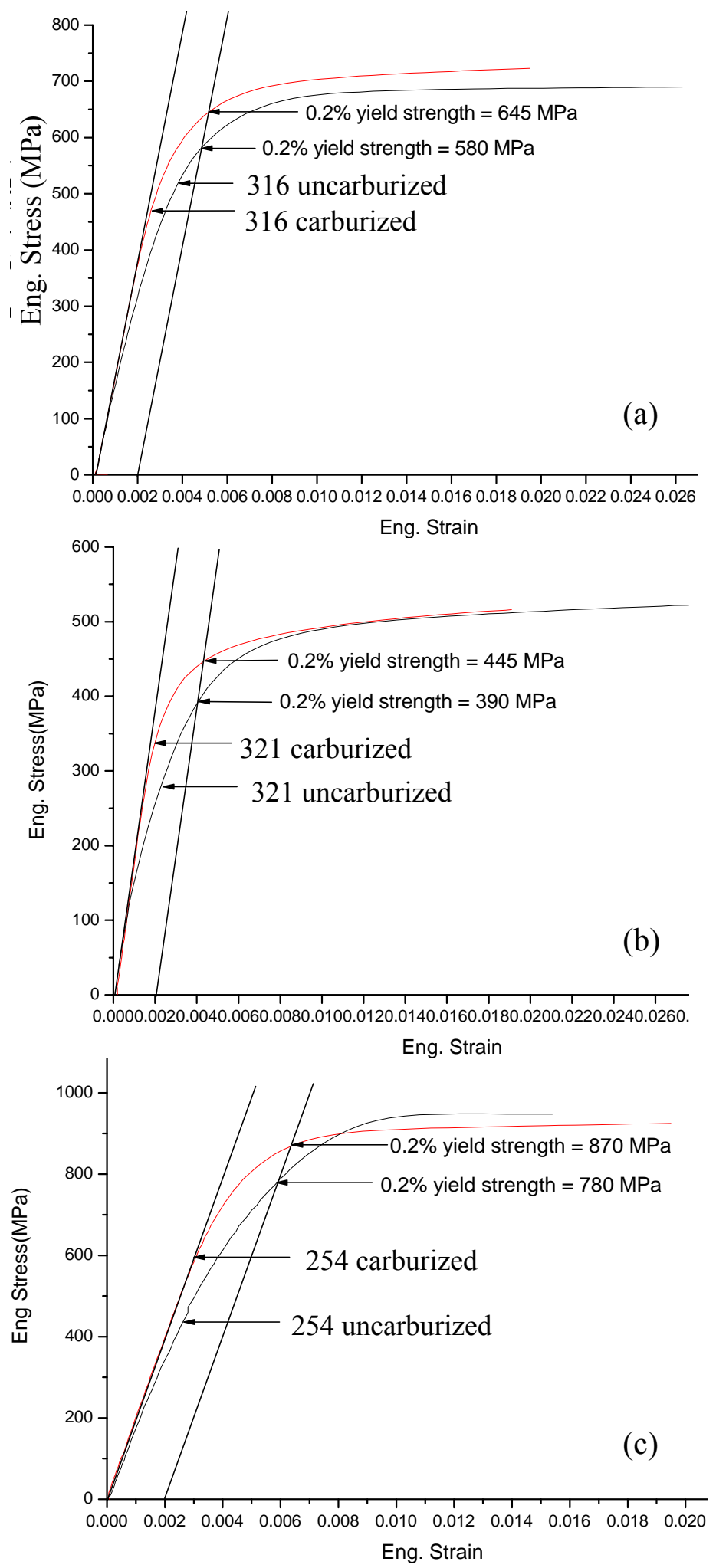

Figure 4.30. Initial stress-strain behavior of uncarburized and low-temperature colossal supersaturation, carburized 316, 321, and 254 SMO round tensile bars. 


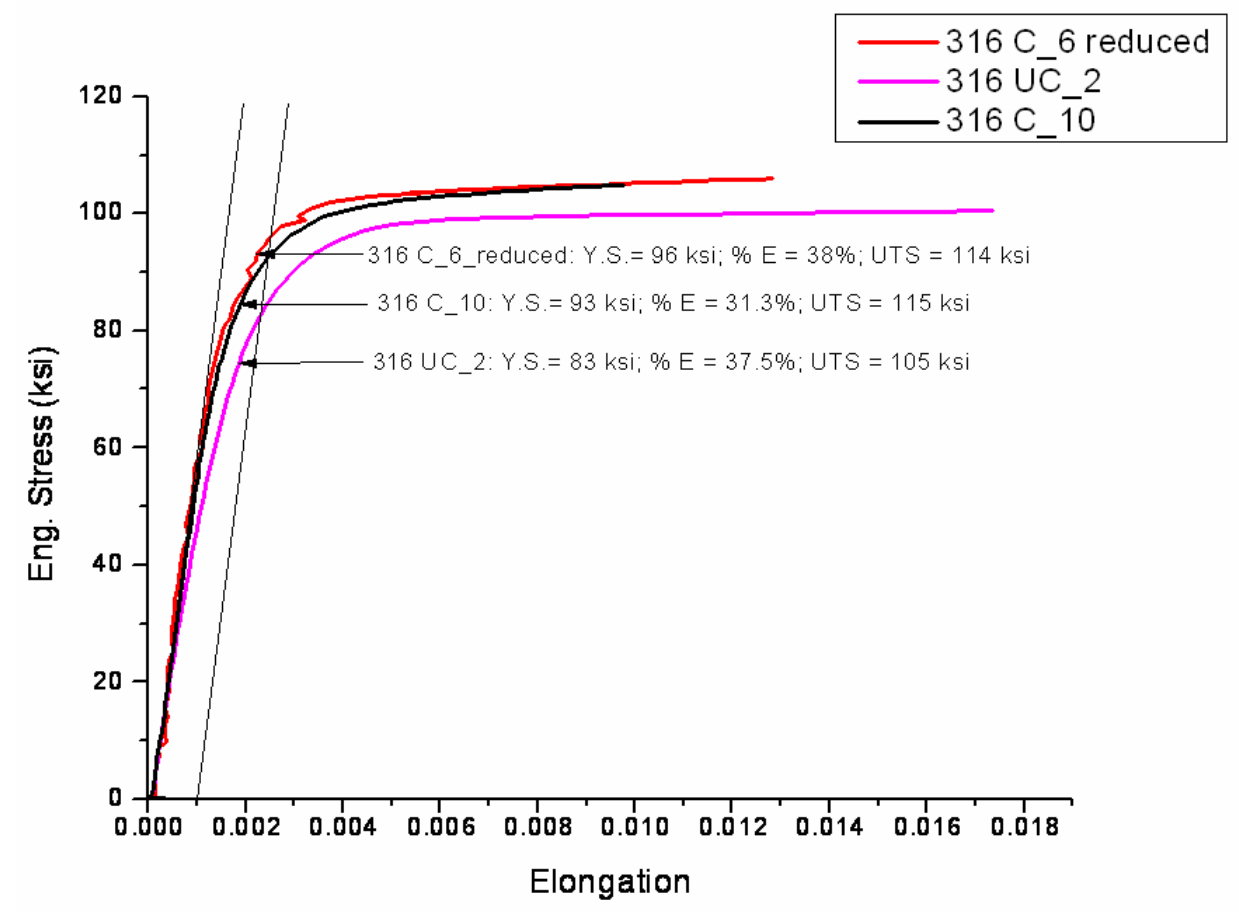

Figure 4.31. Stress-strain curves of carburized 316L, carburized 316L with the carburized case removed, and an uncarburized $316 \mathrm{~L}$ control sample.

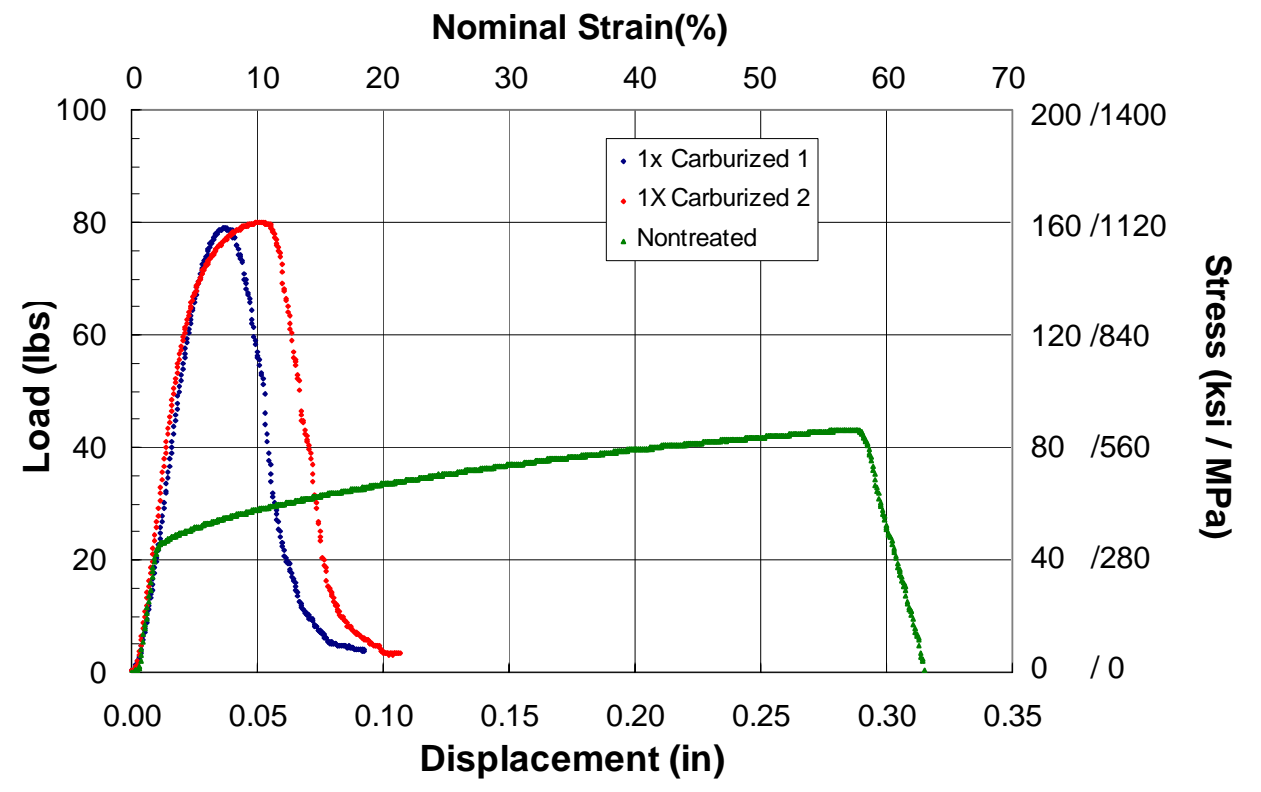

Figure 4.32. Load-displacement/stress-strain curves of carburized and non-treated 0.002-in.-thick 316L foil. 


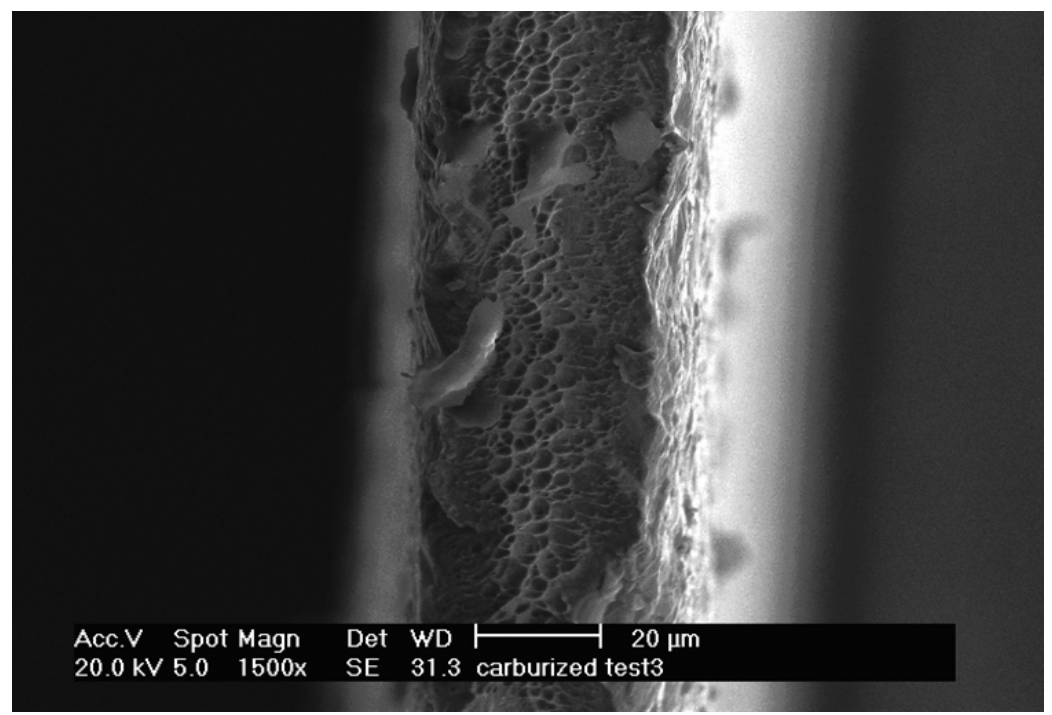

Figure 4.33. Scanning electron microscopy image of fracture surface of one-time carburized sample tested in tension.

\subsubsection{Fatigue Testing}

Reversed, $R=-1$, fatigue testing was conducted [12,13] extensively on 316L carburized, nontreated, and heat-treated with the same temperature cycle but with no carburizing gases (heattreated) samples, using cylindrical, 0.25-in.-diam specimens, as shown in Fig. 4.34. Figure 4.35 shows that the carburized 316 specimens failed at much higher number of cycles as compared to the non-treated and heat-treated ones. The number of carburization cycles does not affect the results nor does electropolishing or diamond polishing the non-treated samples. This change in fatigue behavior can be attributed to the presence of compressive residual stresses on the surface of the carburized material, which lead to delayed crack initiation and thus to a higher fatigue life. This was supported by the fractographs in Fig. 4.36, which show clearly that the crack initiation for carburized specimens took place at a subsurface location, possibly at a MnS inclusion. Also, the carburization treatment offered resistance to stress concentrations - most of the non-treated samples failed at the shoulder (where there are high stress concentrations), whereas all the carburized samples failed in the gauge lengths.

$R=-1$ fatigue testing of 304 and 254 SMO SS was also performed. The carburization process has proven to be beneficial for these alloys as well. The reason for this is thought to be the presence of compressive residual stresses. Figure 4.37 shows the data obtained for 304 and 254 SMO SS. 


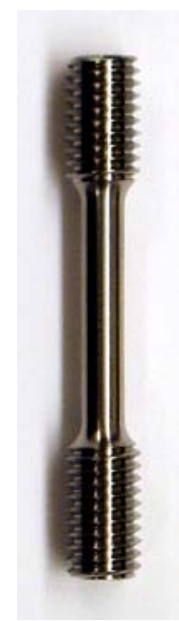

(a)

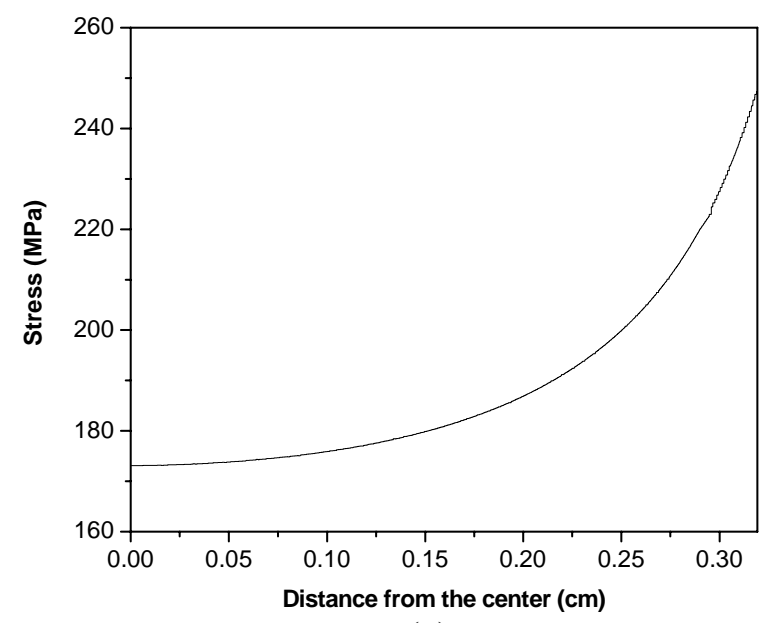

(c)

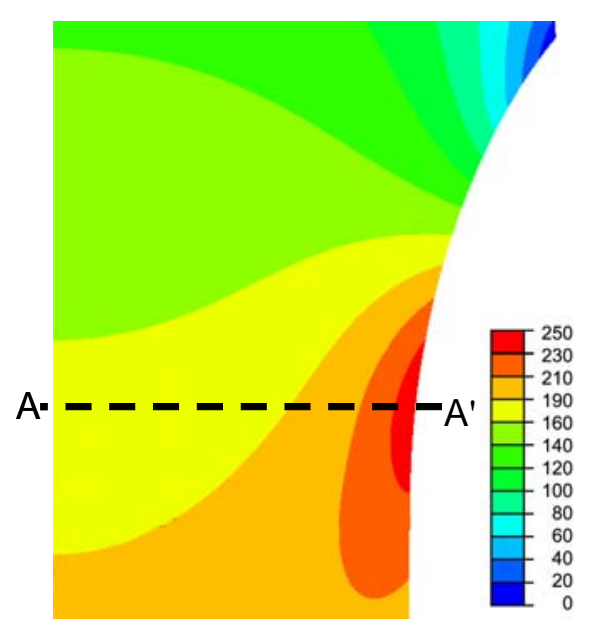

(b)

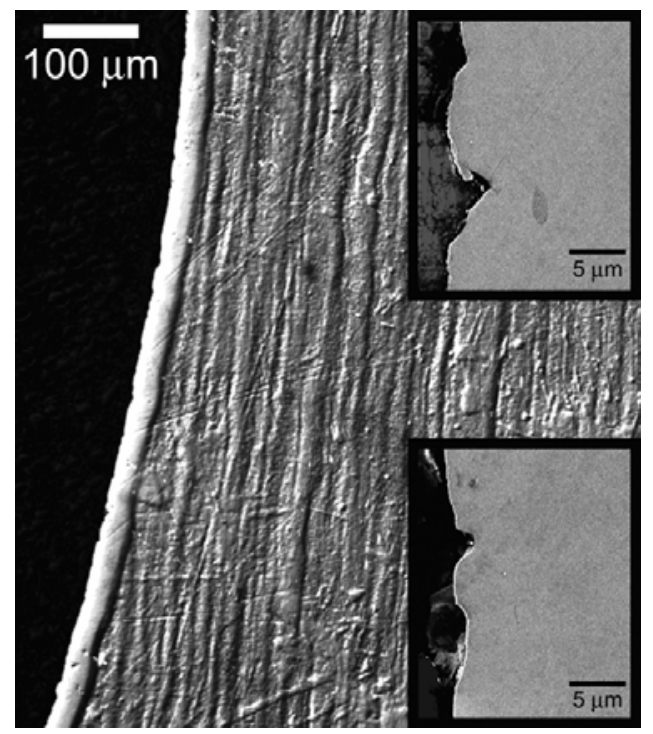

(d)

Figure 4.34. (a) Stainless steel (SS) sample; (b,c) finite element analysis results for a SS sample pulled in uniaxial tension at a load of 200 MPa showing (b) the principal normal stresses and (c) plot of principal normal stresses along the section A-A'; and (d) optical micrograph with scanning electron microscopy insets showing the surface roughness of the fatigue specimens. 


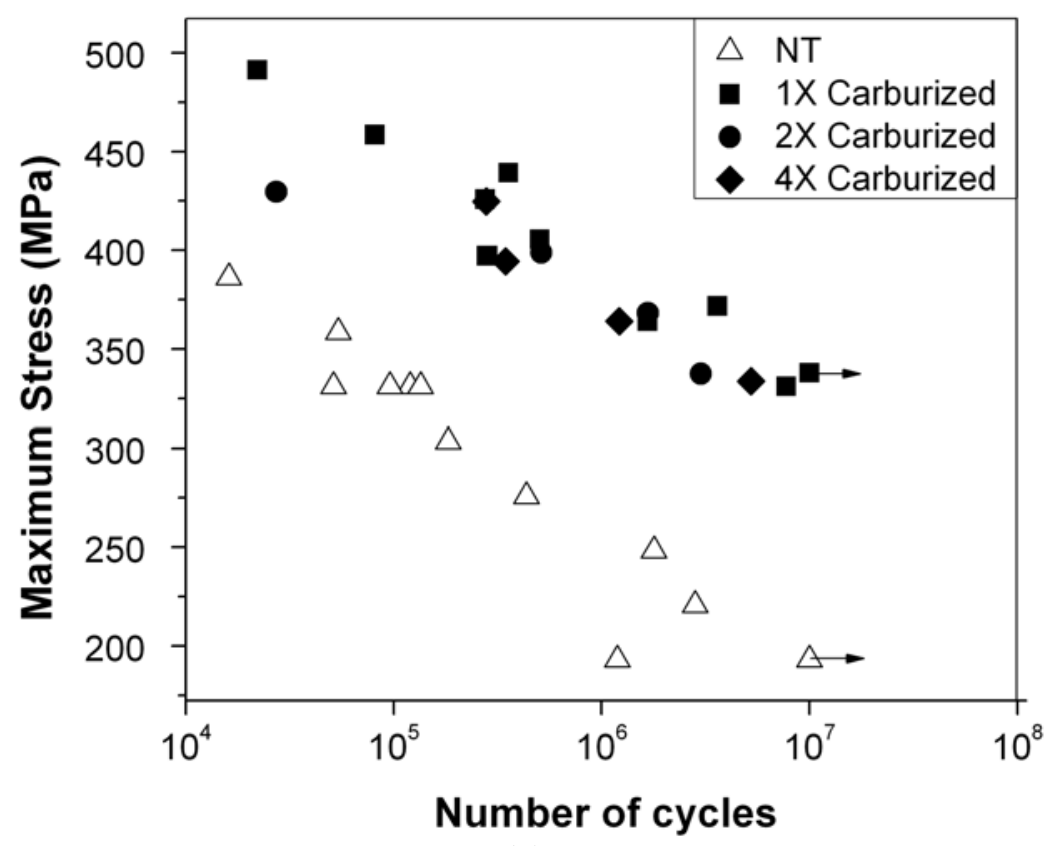

(a)

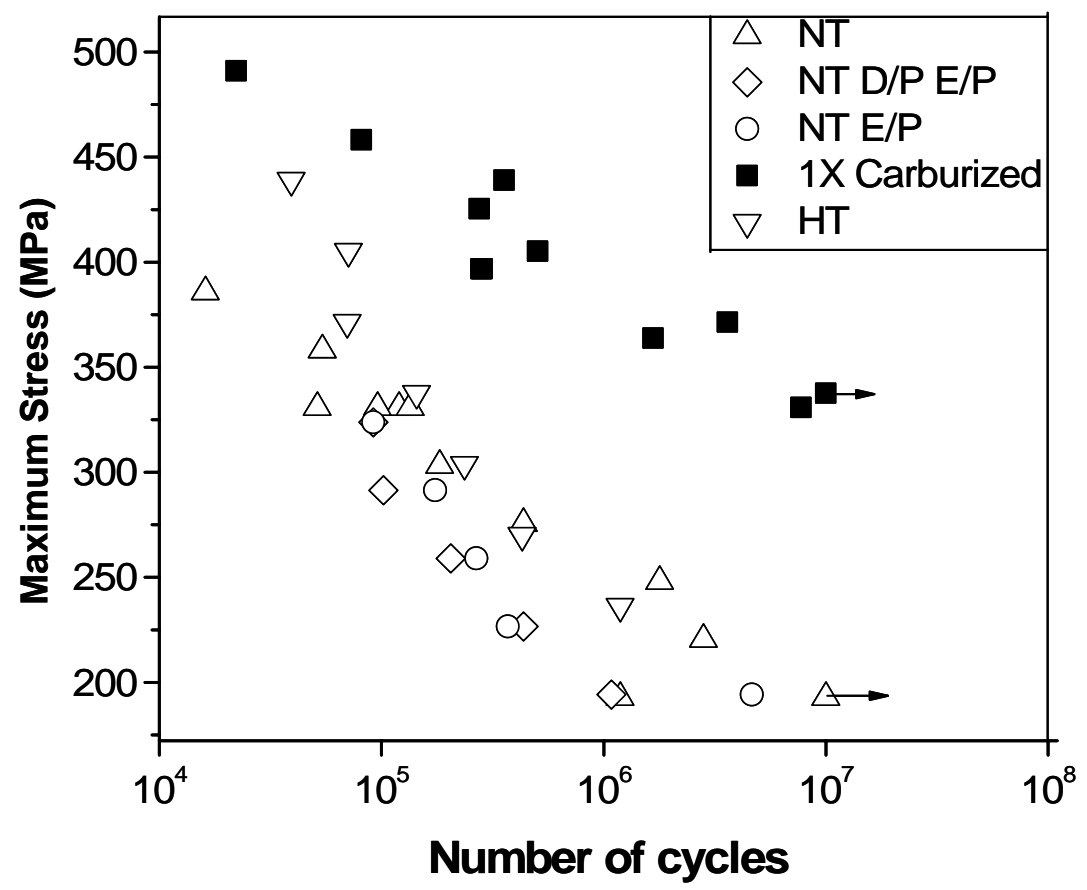

(b)

Figure 4.35. Fatigue testing results for (a) carburized and (b) non-treated 316 samples. 


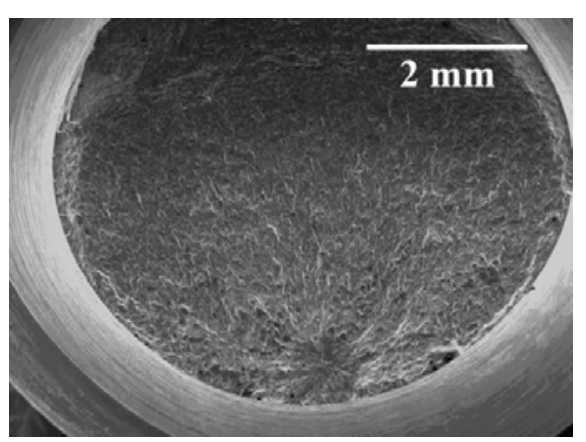

(a)

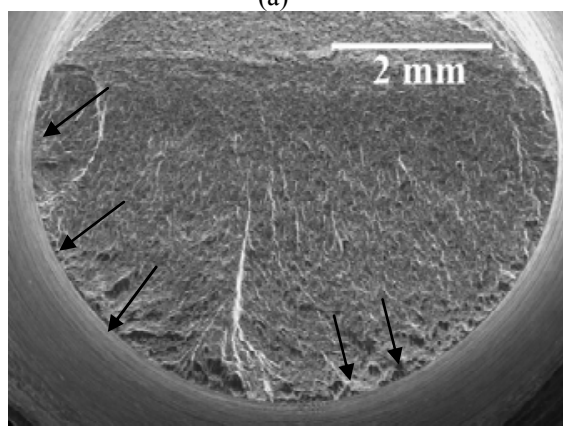

(c)

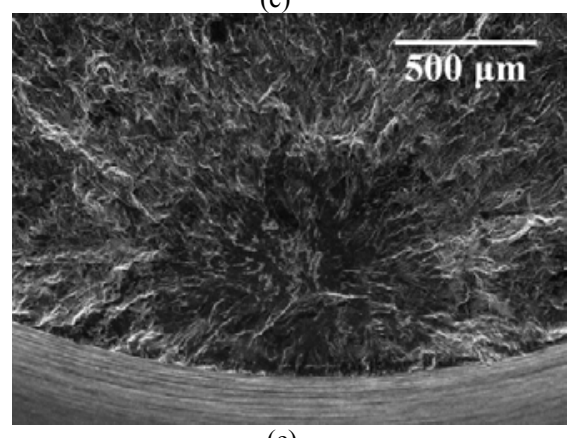

(e)

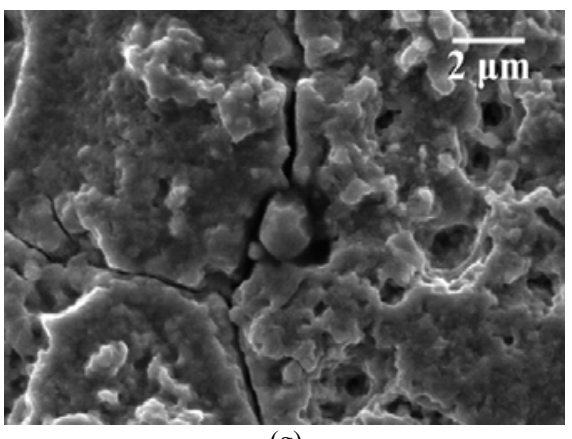

(g)

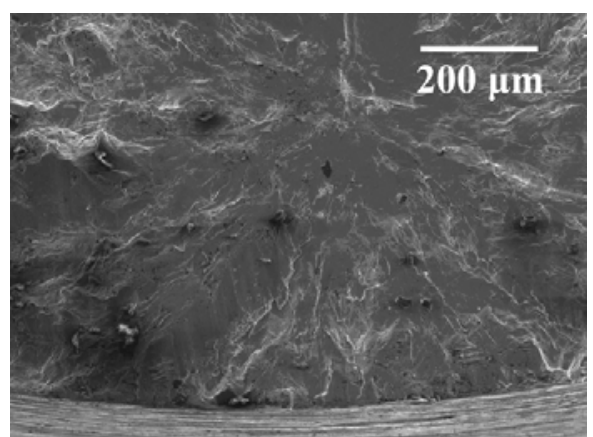

(b)

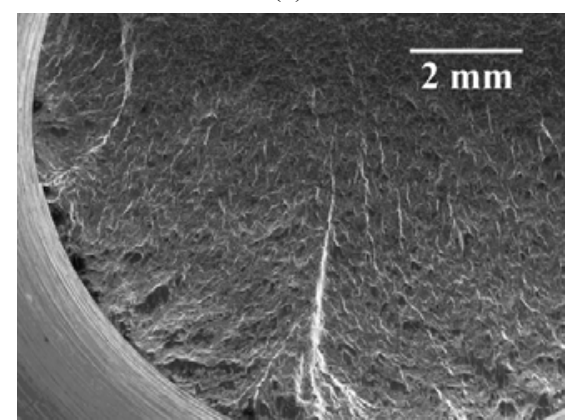

(d)

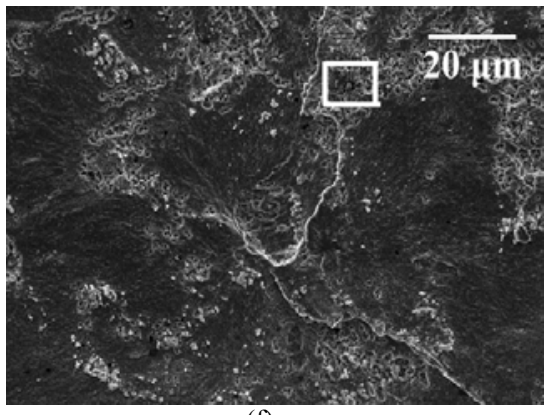

(f)

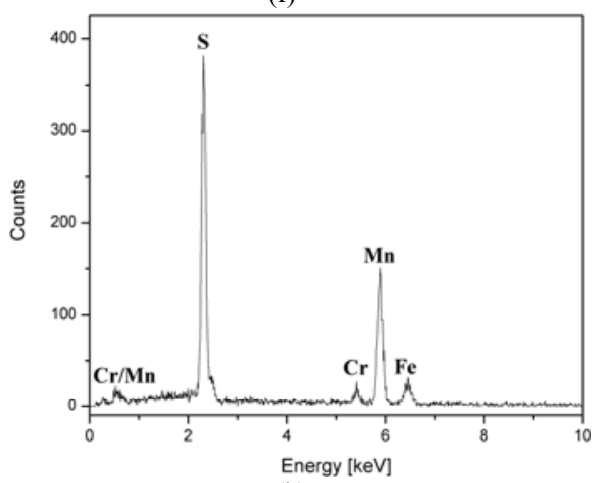

(h)

Figure 4.36. Scanning electron microscopy (SEM) fractographs of (a,b) one-time carburized; and (c,d) non-treated 316L stainless steel samples taken from batch $B$, tested under $R=-1$ at 570 MPa maximum stress and a load oscillation frequency of $10 \mathrm{~Hz}$. The fatigue life of the carburized sample was $167 \times 10^{4}$ cycles, while that of the non-treated sample was only $5 \times 10^{4}$ cycles. (e,f,g) Increasing magnification SEM fractographs of a $4 \times$-carburized sample which had a fatigue life of $523 \times 10^{4}$ cycles at a maximum stress of $334 \mathrm{MPa}$. (h) The X-ray energy dispersion spectroscopy spectrum for the inclusion labeled " 1 " in (g). 


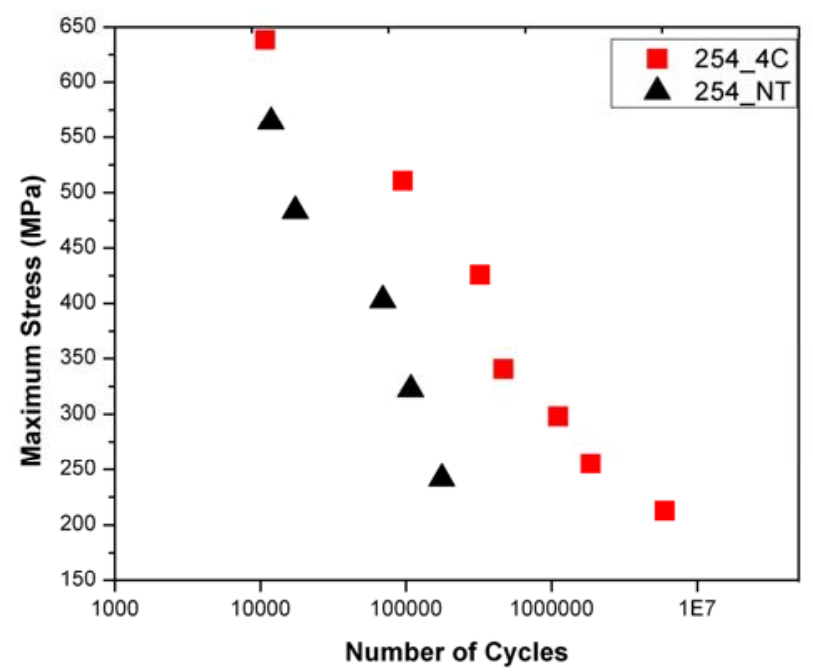

(a)

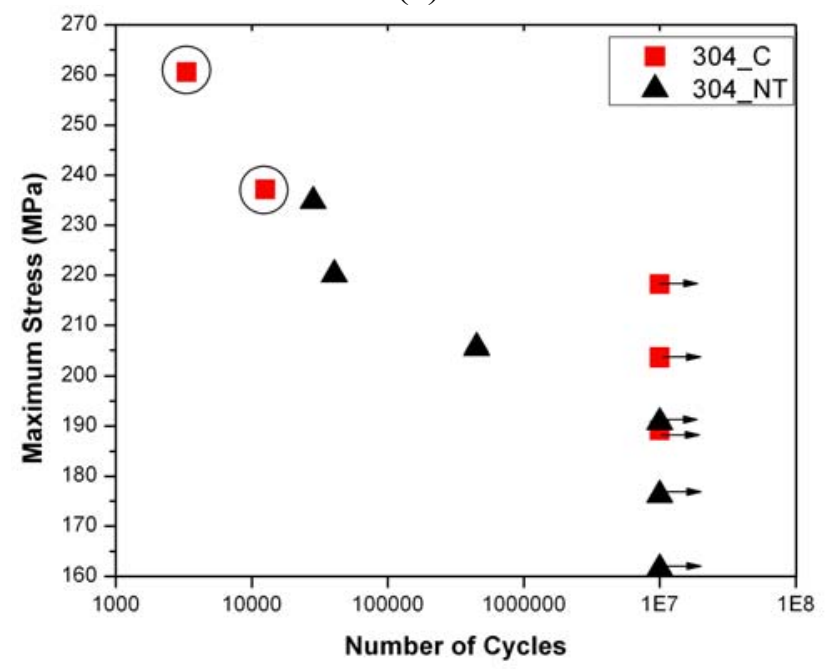

(b)

Figure 4.37. Stress and number of cycle curves for carburized and non-treated (a) 254 and (b) 304 stainless steels.

\subsubsection{Internal Friction}

Internal friction measurements [14] were made on carburized and non-treated 316 SS samples. The results are shown in Fig. 4.38(a) for three-point bending at $1 \mathrm{~Hz}$. The carburized sample shows a unique peak around $270^{\circ} \mathrm{C}$, almost certainly due to stress-induced reorientation of a defect showing "tetragonal" (or lower) symmetry. (A simple jump of an interstitial carbon atom from one interstitial site to another cannot be the source of the internal friction peak.) One possible source of the peak would be the reorientation of a carbon-vacancy or carbonsubstitutional atom complex. If these complexes exist in the carburized sample, they could produce the enormous surface hardening and residual compressive stresses that are observed. Figure 4.38(b) shows further internal friction measurements around this temperature for several different frequencies. By analyzing the peak shifts with varying frequency assuming Arrenhius 
behavior, the activation energy for the transition responsible for the internal friction peak is determined to be $1.6 \mathrm{eV}$. This is good evidence that the reorientation involves carbon jumping from an interstitial site belonging to one complex to another crystallographically equivalent interstitial site.

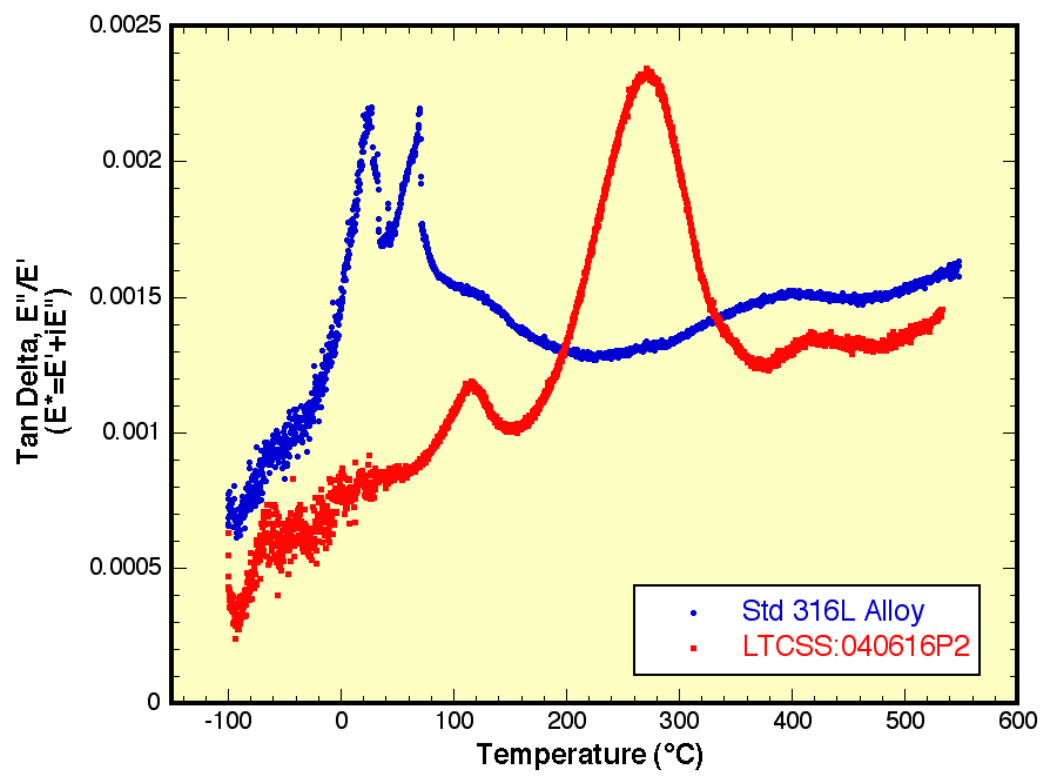

(a)

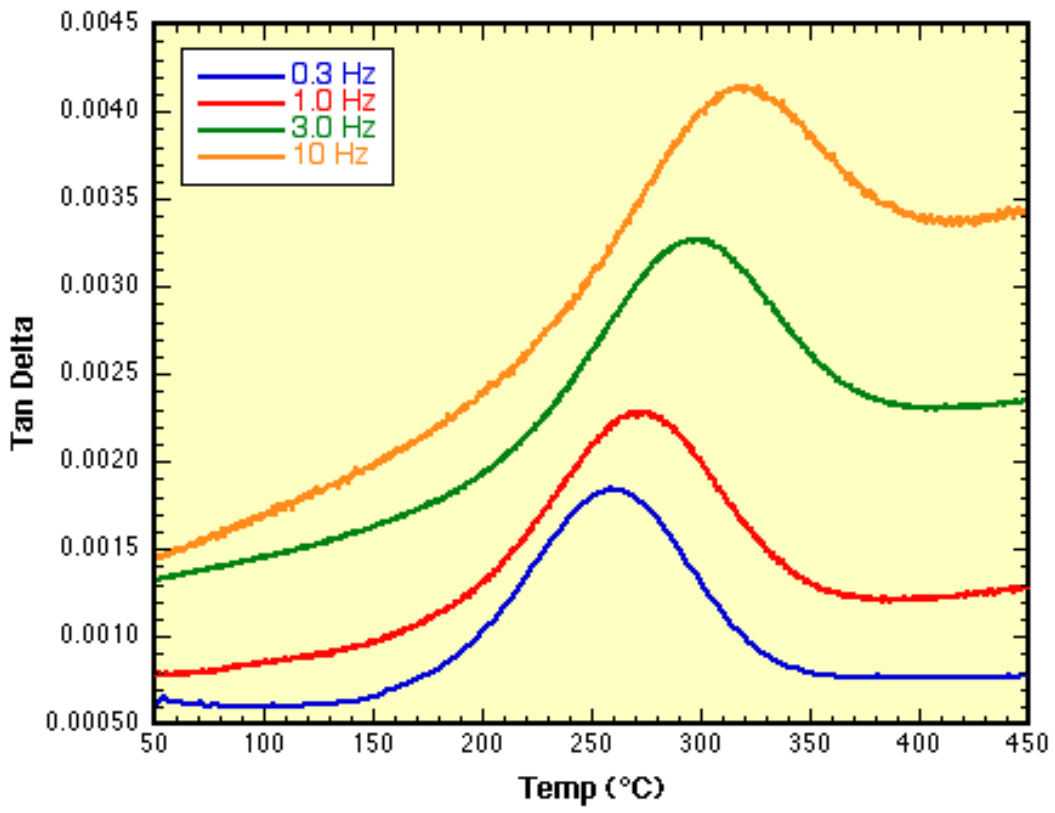

(b)

Figure 4.38. Internal friction results for carburized, 316 stainless steel measured in threepoint bending: (a) the frequency was fixed at $1 \mathrm{~Hz}$. The carburized trace (red) shows a unique peak at $270^{\circ} \mathrm{C}$. (b) The frequency was varied. 


\subsubsection{Tribological Evaluations}

\subsubsection{Material Characterization}

Type 316 SS was obtained in two forms: (1) 25-mm-diam round rod stock, and (2) 9.525-mm-diam bearing balls (AFBMA Grade 100). The rod stock was used to prepare flat disk specimens. Disks and balls (pin specimens) were sent to Swagelok Company, Ohio to receive their supersaturation carburization treatment to a nominal depth of $\sim 25 \mu \mathrm{m}$.

Scanning acoustic microscopy (KSI SAM-2000), coupled with light microscopy, enabled us to study the structure of the carburized layers on treated SS specimens. As noted in Fig. 4.39(a) (optical image), the Nital etchant showed the grain structure of the base material but not that of the $\sim 30-\mu \mathrm{m}$-thick supersaturated layer at the surface. The layer's resistance to acid etching is a further indication of its corrosion resistance. The acoustic image obtained at $1.0 \mathrm{GHz}$ [Fig. 4.39(b)] revealed that the treated layer retains a grain structure similar to that of the base metal.

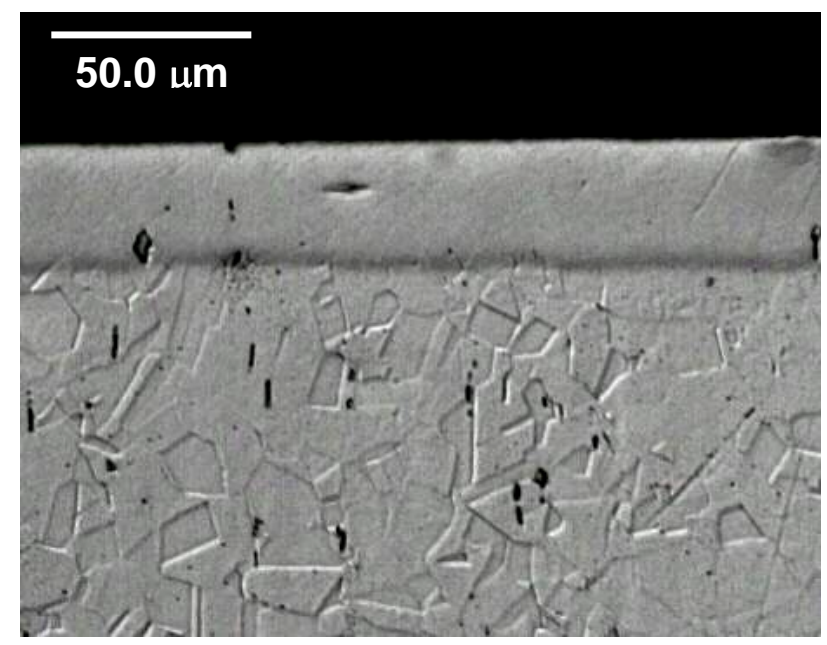

(a)

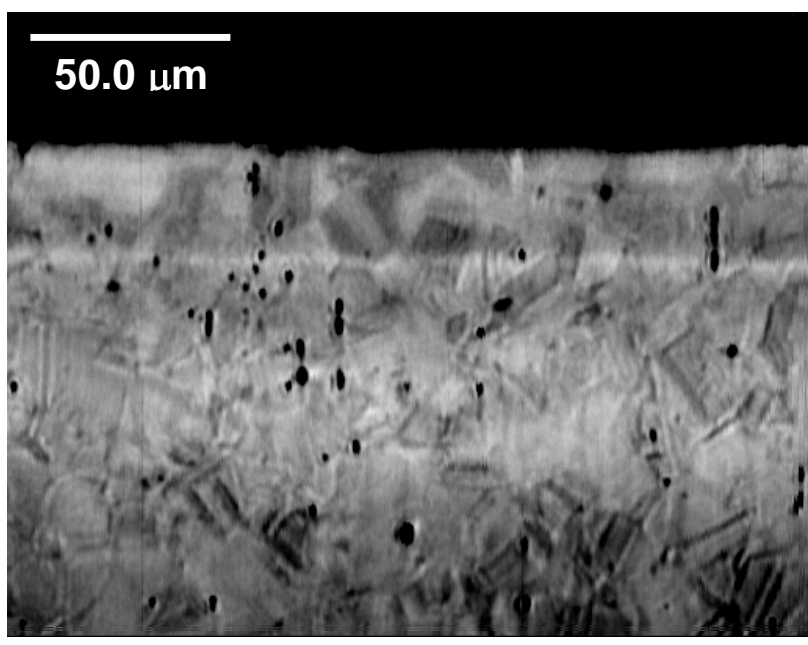

(b)

Figure 4.39. Etched ( $2 \%$ Nital) cross section of a carburized disk specimen: (a) optical image and (b) acoustic image (1.0 GHz).

Microindentation (Buehler Micromet ${ }^{\circledR} 2100^{\mathrm{TM}}$ ) and nanoindentation (Hysitron Triboindenter ${ }^{\mathrm{TM}}$ ) tests were conducted on treated and non-treated balls and disks using $1.96 \mathrm{~N}$ and $10 \mathrm{mN}$ loads, respectively. Hardness and elastic modulus values are given in Table 4.7. Non-treated bearing balls and disks had unequal hardness numbers because the disks were cut from rod stock then ground and polished, but the balls were produced by a ball bearing manufacturing process. The hardness of disks was improved by nearly four times by the treatment (7.56 versus $1.98 \mathrm{GPa}$ ), and the hardness of balls used for sliders was enhanced by at least a factor of two (9.08 versus $3.84 \mathrm{GPa}$ ). The treatment also seemed to moderately increase the elastic modulus (200 versus $179 \mathrm{GPa})$. 
Table 4.7. Indentation Hardness and Elastic Modulus of Treated and Non-treated Type 316 Stainless Steel Surfaces

\begin{tabular}{|l|c|c|c|c|}
\hline \multicolumn{1}{|c|}{ Test Method } & Non-treated ball & Treated ball & Non-treated disk & Treated disk \\
\hline $\begin{array}{l}\text { Microindentation } \\
\text { HV (GPa, 1.96 N) }\end{array}$ & $3.84 \pm 0.12$ & $9.08 \pm 0.42$ & $1.98 \pm 0.23$ & $7.56 \pm 0.58$ \\
\hline $\begin{array}{l}\text { Nanoindentation } \\
\text { HN (GPa, 10 mN) }\end{array}$ & - & - & $3.65 \pm 0.09$ & $11.63 \pm 1.12$ \\
\hline $\begin{array}{l}\text { Modulus of elasticity } \\
\text { by indentation }(\mathrm{GPa})\end{array}$ & - & - & $179.3 \pm 0.6$ & $199.9 \pm 4.8$ \\
\hline
\end{tabular}

Subsurface hardness profiles were obtained by Knoop microindentation using a load of $0.245 \mathrm{~N}$ on polished cross sections of treated and non-treated disk specimens, as plotted in Fig. 4.40. It can be seen that the hardness of the treated disk remains $\sim 7$ GPa until $10 \mu \mathrm{m}$ below the surface, then gradually decreases to $\sim 3 \mathrm{GPa}$ at $30 \mu \mathrm{m}$, similar to the hardness of the non-treated metal, $\sim 2.7 \mathrm{GPa}$. This confirmed the treatment depth of $\sim 30 \mu \mathrm{m}$.

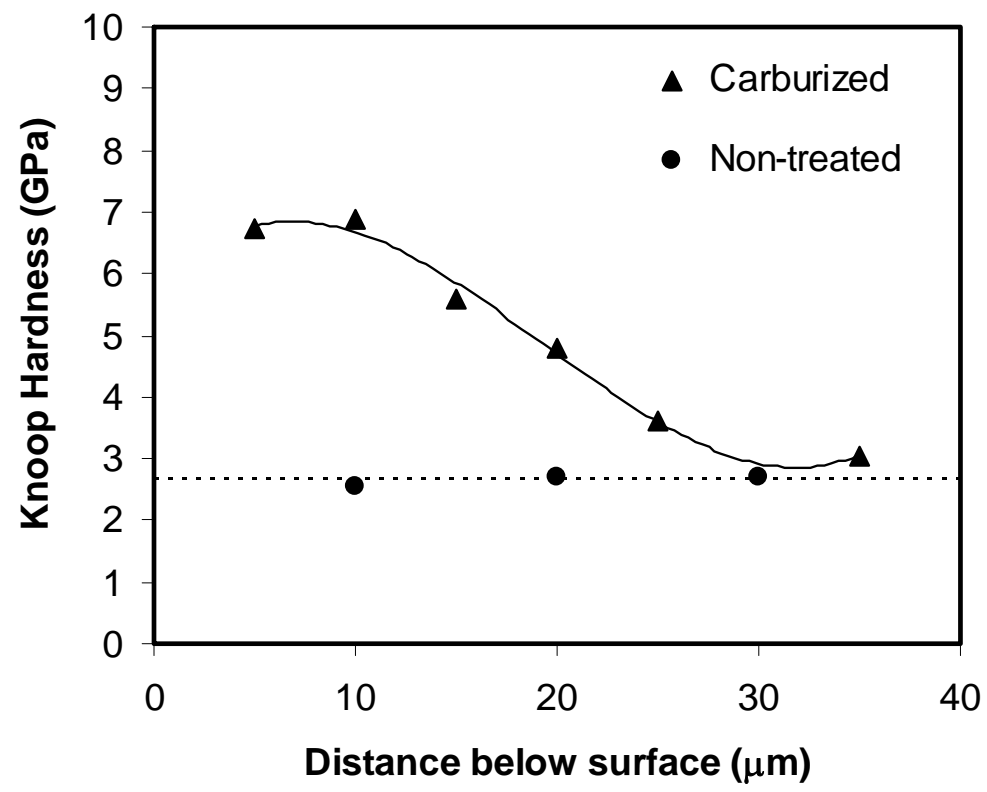

Figure 4.40. Cross-sectional hardness profiles (Knoop's microindentation at 25 g-f load).

Hot hardness measurements were conducted using Vickers microindentation at 200 and $400^{\circ} \mathrm{C}$. Each temperature was held for $\sim 30 \mathrm{~min}$ for conducting indentations. Hardness decreased linearly with increasing temperature for both treated and non-treated disk specimens [Fig. 4.41(a)]. The hardness ratio between the treated and non-treated surfaces remained roughly constant at about 4:1 [Fig. 4.41(b)]. 


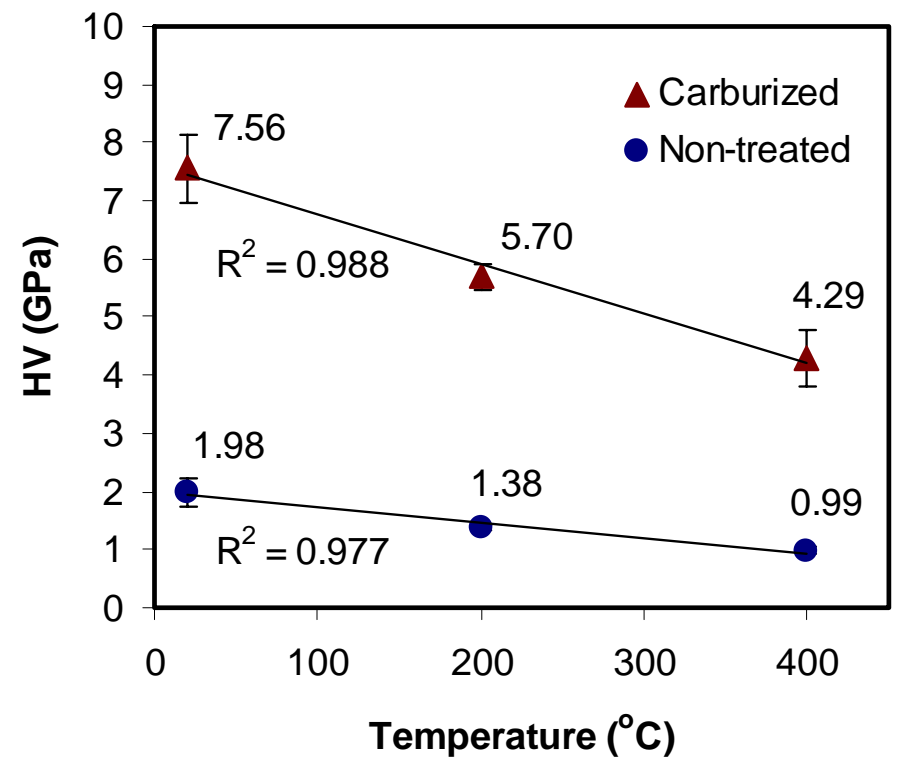

(a)

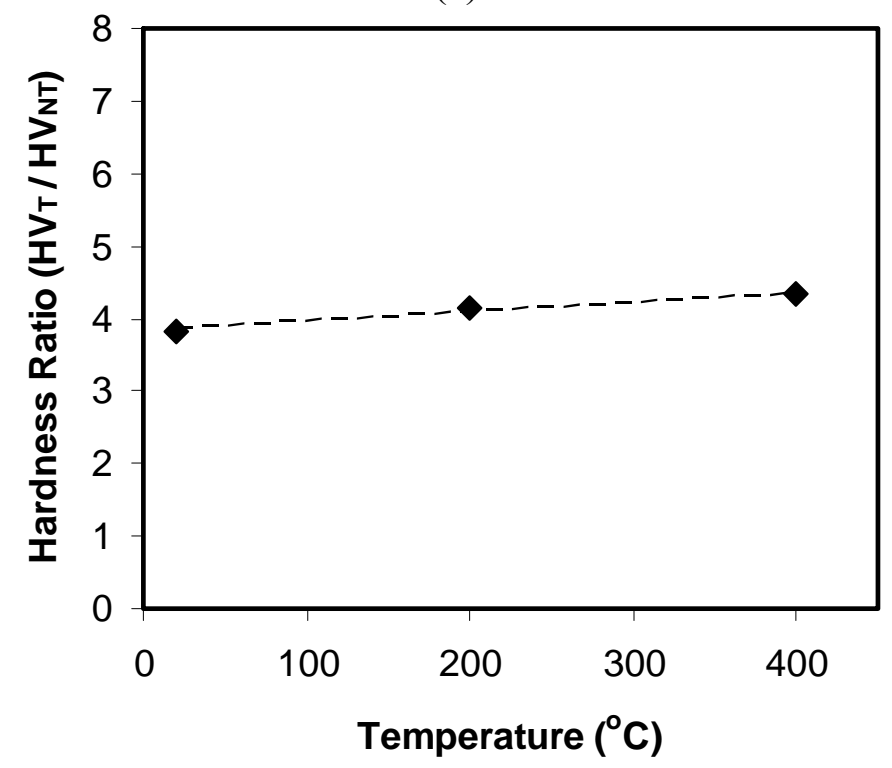

(b)

Figure 4.41. Effects of temperature on hardness: (a) hot hardness and (b) hardness ratio between the treated and non-treated disks.

\subsubsection{Loop Abrasion Tests}

A series of abrasion-resistance tests was performed using a modification of the standard ASTM continuous loop abrasion test (ASTM G-174). An alumina (3- $\mu \mathrm{m}$ grit) belt was used with a load of 100 gf. The width of the wear track was measured periodically and the wear volume of the specimen was computed. Results for replicate tests on carburized and non-carburized specimens are shown in Fig. 4.42. The abrasive wear volume of the treated specimens was reduced by about $30 \%$ compared to the non-treated type 316 SS specimen. 


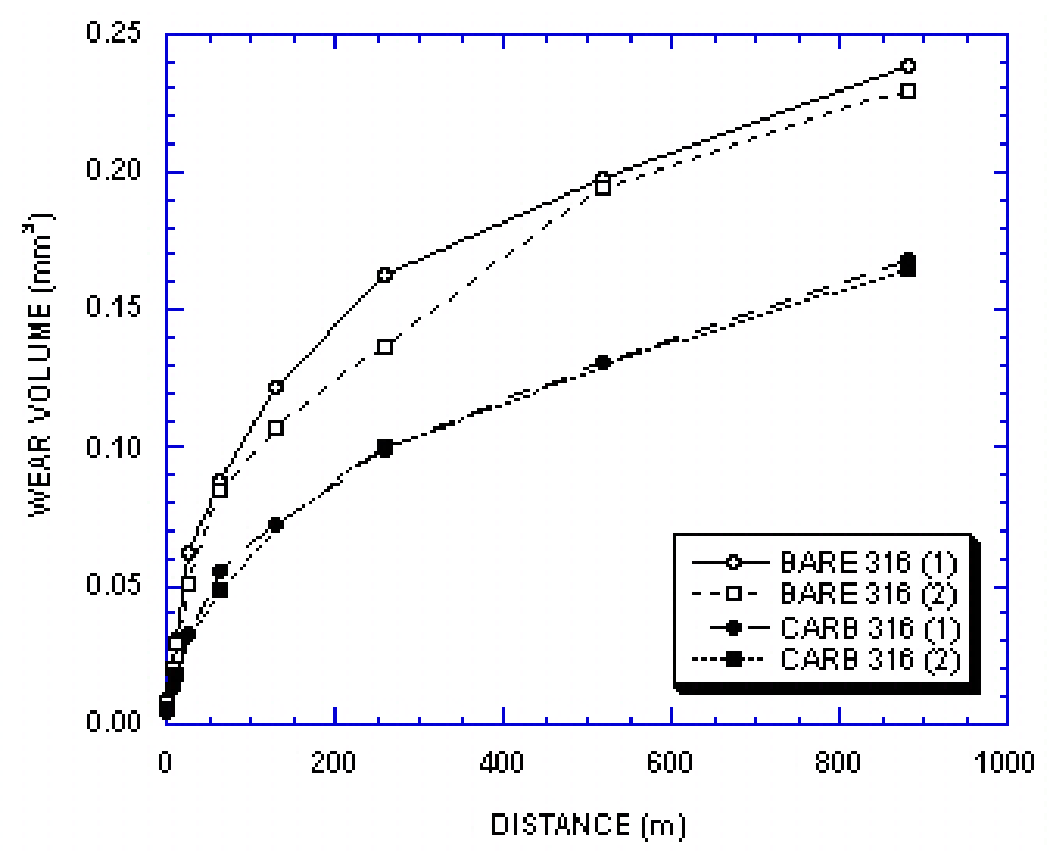

Figure 4.42. Results for replicate tests on carburized and non-carburized specimens.

\subsubsection{Sliding Friction and Wear Tests}

Friction and wear characteristics of the carburized and non-treated 316 SS were evaluated $[15,16]$ using a unidirectional sliding ball-on-disk apparatus. Non-treated balls were tested asreceived and non-treated disk specimens were metallographically polished $\left(R_{a}: 0.016 \mu \mathrm{m}\right)$ before testing. The disks were metallographically polished before the treatment and the treated surfaces had an arithmetic average roughness of $R_{a} 0.072 \mu \mathrm{m}$. The carburized balls and disks were tested as received. A surface cleaning procedure using acetone followed by ethanol was applied to the contact surfaces before each test.

Non-lubricated tests were conducted in ambient air at both room and elevated temperatures (20, 200 , and $400^{\circ} \mathrm{C}$ ). Four material combinations, a non-treated ball against a non-treated disk $(\mathrm{NT} / \mathrm{NT})$, a non-treated ball against a treated disk (NT/T), a treated ball against a non-treated disk $(\mathrm{T} / \mathrm{NT})$, and a treated ball against a treated disk $(\mathrm{T} / \mathrm{T})$, were tested at room temperature. The elevated temperature tests were applied to NT/NT and T/T sets only. A limited number of tests were also carried out in salt water at room temperature. The $2.4 \mathrm{wt} \%$ salt solution was prepared using United States Pharmaceutical grade $\mathrm{NaCl}$ and distilled water.

The same testing parameters were used in all tests: a load of $5 \mathrm{~N}$, a sliding speed of $0.1 \mathrm{~m} / \mathrm{s}$ (wear track diameter 13-16 mm), and a total sliding distance of $500 \mathrm{~m}(5000 \mathrm{~s})$. At least two replicates were conducted at each testing condition. For each elevated-temperature test, the furnace was heated to the test temperature and held for $\sim 15 \mathrm{~min}$ to reach equilibrium before sliding. The sliding time was $83 \mathrm{~min}$ and $20 \mathrm{~s}(0.1 \mathrm{~m} / \mathrm{s}$ for $500 \mathrm{~m})$. So, the total heating time for each test was about $100 \mathrm{~min}$. 
The friction force was measured by a load cell and used to calculate the friction coefficient. Two methods were used to determine the wear volume: (1) weight loss when $>1 \mathrm{mg}$ (the uncertainty of the balance is $0.2 \mathrm{mg}$ ) and (2) worn surface profiling.

\subsection{Dry Sliding at Room Temperature}

A summary of the friction coefficient and wear rate data [16] for various material combinations is given in Table 4.8. The treated specimens produced somewhat higher steady-state friction coefficients than the non-treated specimens indicating a need to supply lubrication for these materials if used in bearings. The calculated volumetric wear rates [volume loss/(normal force $\times$ distance slid)] indicate much higher wear-resistance of the treated specimens than that of the non-treated ones. Clearly, the least wear occurred for self-mated carburized surfaces $(\mathrm{T} / \mathrm{T})$. The wear rates of the ball and disk tested in $\mathrm{T} / \mathrm{T}$ were nearly two orders of magnitude lower than those of the ball and disk tested in NT/NT. Note that in self-mated conditions (NT/NT and T/T) at room temperature, the balls wore faster than the disks.

Table 4.8. Friction and Wear Results of Dry Sliding at Room Temperature

\begin{tabular}{|c|c|c|c|}
\hline \multirow{2}{*}{ Material } & \multirow{2}{*}{$\begin{array}{c}\text { Steady-state } \\
\text { friction coefficient }\end{array}$} & \multicolumn{2}{|c|}{ Wear rate $\left(\mathbf{m m}^{\mathbf{3}} \mathbf{/ N}-\mathbf{m}\right)$} \\
\cline { 3 - 4 } & 0.51 & $6.1 \mathrm{E}-04$ & Disk \\
\hline NT/NT & 0.60 & $1.3 \mathrm{E}-04$ & $2.4 \mathrm{E}-04$ \\
\hline $\mathrm{NT} / \mathrm{T}$ & 0.68 & $1.1 \mathrm{E}-05$ & $4.3 \mathrm{E}-05$ \\
\hline $\mathrm{T} / \mathrm{NT}$ & 0.70 & $8.9 \mathrm{E}-06$ & $6.4 \mathrm{E}-04$ \\
\hline $\mathrm{T} / \mathrm{T}$ & &
\end{tabular}

\subsection{Sliding in Salt Water}

$\mathrm{NT} / \mathrm{NT}$ and $\mathrm{T} / \mathrm{T}$ were tested in salt water at room temperature and the results are summarized in Table 4.9. The average steady state friction coefficients were 0.43 and 0.50 for NT/NT and T/T, respectively. Compared to the dry sliding results, the friction coefficient in salt water sliding was lower for both material combinations, because the salt water reduces the adhesion between contact asperities. Wear was significantly reduced in salt water, as shown in Table 4.9, especially for the disk specimens that had non-measurable wear. The treated ball still had lower wear than the non-treated ball, though the difference is much smaller. No pitting (a typical feature of corrosive wear) was observed for either case.

Table 4.9. Friction and Wear Results of Sliding in Salt Water

\begin{tabular}{|c|c|c|c|}
\hline \multirow{2}{*}{ Material } & \multirow{2}{*}{$\begin{array}{c}\text { Steady-state } \\
\text { friction coefficient }\end{array}$} & \multicolumn{2}{|c|}{ Wear rate $\left(\mathrm{mm}^{3} / \mathbf{N}-\mathbf{m}\right)$} \\
\cline { 3 - 4 } & 0.43 & Ball & Disk \\
\hline \hline $\mathrm{NT} / \mathrm{NT}$ & 0.50 & $5.1 \mathrm{E}-06$ & $\mathrm{~N} / \mathrm{M}^{*}$ \\
\hline $\mathrm{T} / \mathrm{T}$ & $2.3 \mathrm{E}-06$ & $\mathrm{~N} / \mathrm{M}^{*}$ \\
\hline
\end{tabular}

$* \mathrm{~N} / \mathrm{M}=$ Not measurable. 


\subsection{Sliding at Elevated Temperatures}

4.1.6.3.3.1 Effects of temperature on friction. Figure 4.43 summarizes the friction behavior for both T/T and NT/NT at room and elevated temperatures. The initial and steadystate friction coefficients are represented by dashed and solid curves, respectively. Some observations are:

- The initial friction coefficients of T/T were lower than those of NT/NT at both room and elevated temperatures (see dashed curves in Fig. 4.43).

- At room temperature, the steady-state friction coefficient of T/T was higher than that of NT/NT. When the temperature increased, opposite trends were observed for the steady-state friction coefficients of T/T and NT/NT: the former gradually decreased while the latter slowly increased (see solid curves in Fig. 4.43). The two friction coefficient curves eventually crossed over between 200 and $400^{\circ} \mathrm{C}$, and ended up with a lower friction coefficient for $\mathrm{T} / \mathrm{T}$ than that for $\mathrm{NT} / \mathrm{NT}$ at $400^{\circ} \mathrm{C}$.

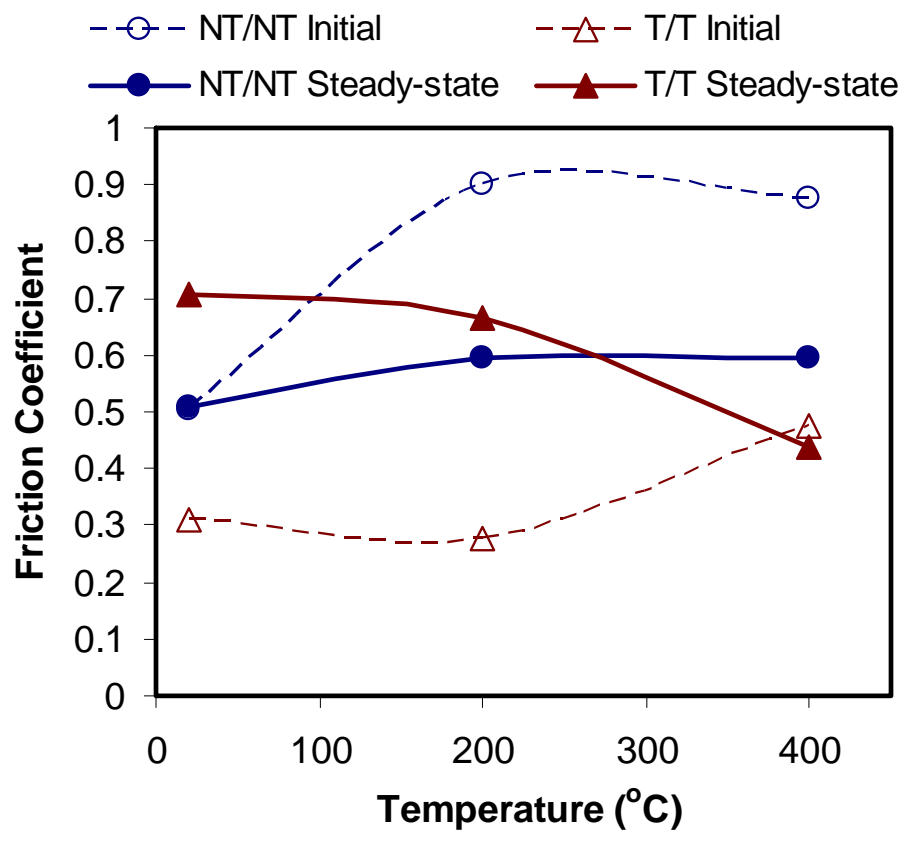

Figure 4.43. Effects of temperature on friction behavior.

4.1.6.3.3.2 Effects of temperature on wear. The wear rates of the balls and disks in $\mathrm{T} / \mathrm{T}$ and NT/NT at various testing temperatures are plotted in Fig. 4.44. The dotted curves with open markers represent the ball wear and the dashed curves with solid markers represent the disk wear. The thick solid curves are the summations of the ball and disk wear rates. The wear scars on the non-treated and carburized balls are shown in Figs. 4.45 and 4.46, respectively. Major observations include: 
- The total wear rate of $\mathrm{T} / \mathrm{T}$ was still lower than that of NT/NT at elevated temperatures, but the difference was not as much as that at room temperature.

- For both NT/NT and T/T, the balls wore faster than the disks at room temperature. However, the results were reversed at elevated temperatures where the ball wear rates were much lower than the disk wear rates.

- The wear rate of the non-treated ball decreased sharply with increasing temperature. Correspondingly, Fig. 4.45 shows shrinking wear scars at higher temperatures. The wear rate of the non-treated disk, however, was not significantly affected by the temperature.

- For the carburized specimens, both the ball and disk wore more at $200^{\circ} \mathrm{C}$ than at room temperature, but diverged at $400^{\circ} \mathrm{C}$ where the disk wear rose up while the ball wear dramatically dropped down.

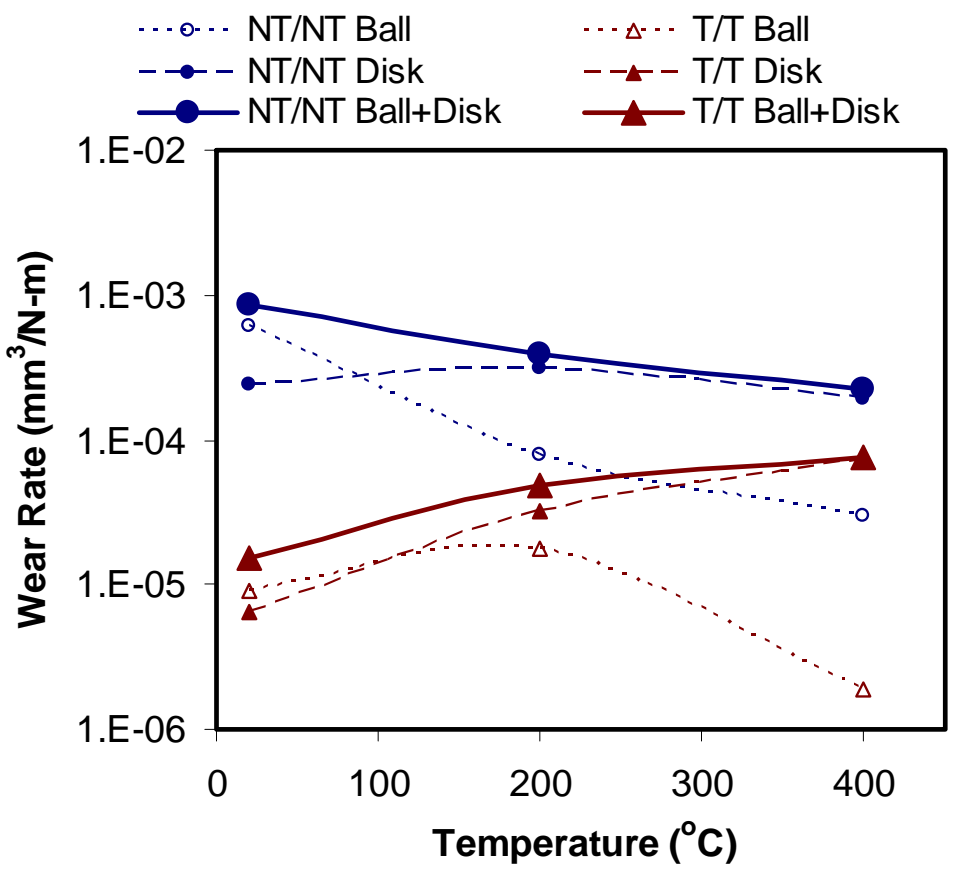

Figure 4.44. Effects of temperature on wear behavior.

\subsubsection{Discussion}

\subsection{Work Hardening}

Vickers micro-indentation hardness was measured on the wear scars/tracks on the ball and disk specimens to determine the hardness change due to tribo-testing. Figure 4.47(a) shows that the sliding contact introduced work-hardening in most of the NT and T specimens. The only exception was the $\mathrm{T}$ ball whose carburized layer thickness was worn through after testing [Fig. 4.46(a)]. Apparently, the NT disk had the most significant hardness increase $(>150 \%)$. The hardness profiles below the disk wear tracks shown in Fig. 4.47(b) indicate that the workhardening zones were $\sim 40-\mu \mathrm{m}$ deep for both treated and non-treated surfaces. 


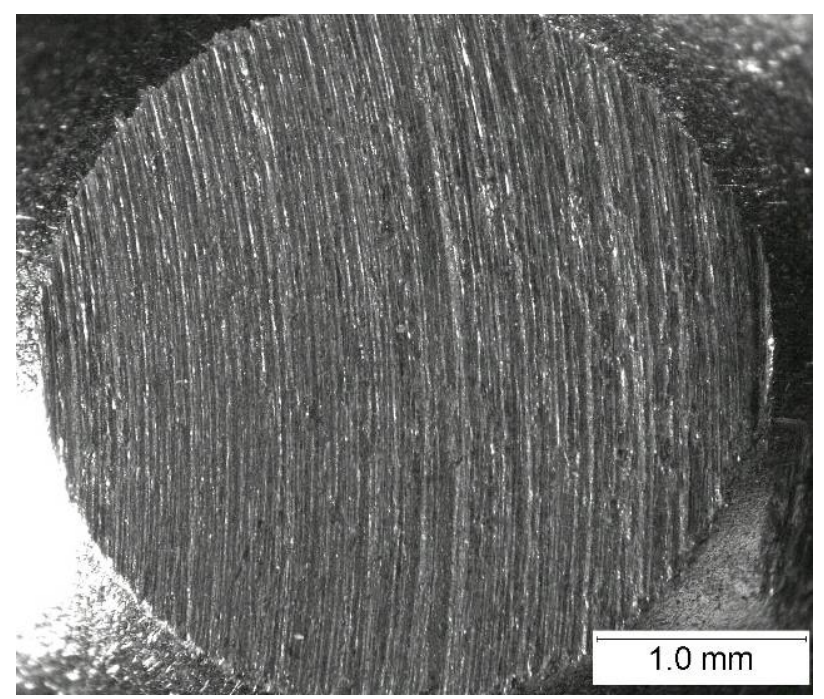

(a)

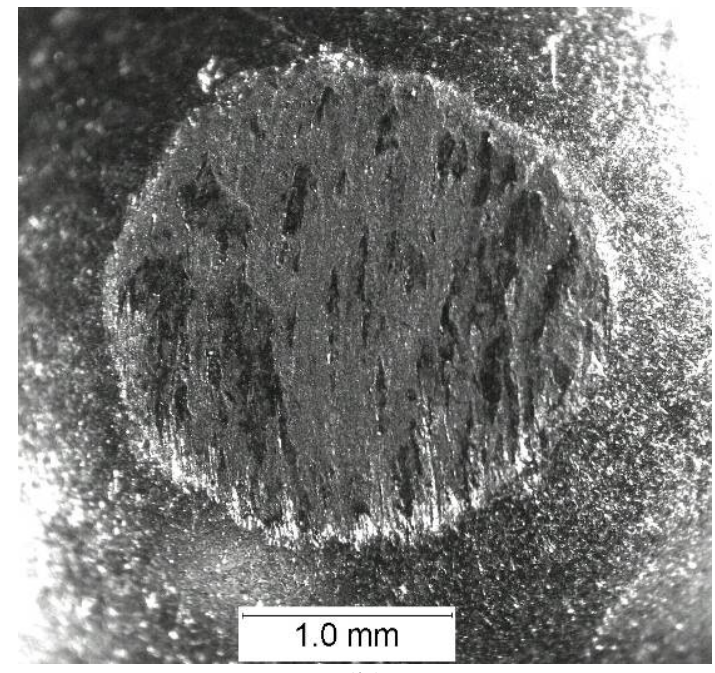

(b)

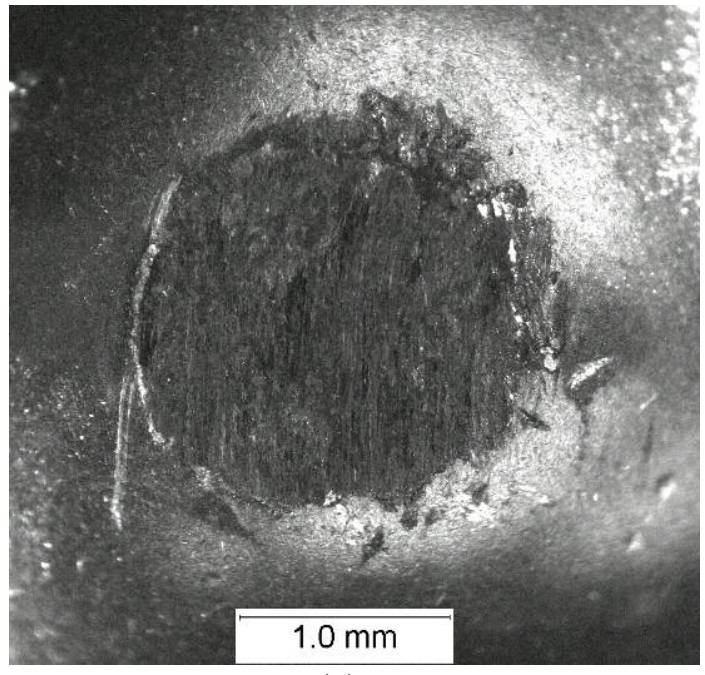

(c)

Figure 4.45. Wear tracks on non-treated balls: (a) room temperature, (b) $200^{\circ} \mathrm{C}$, and (c) $400^{\circ} \mathrm{C}$. 


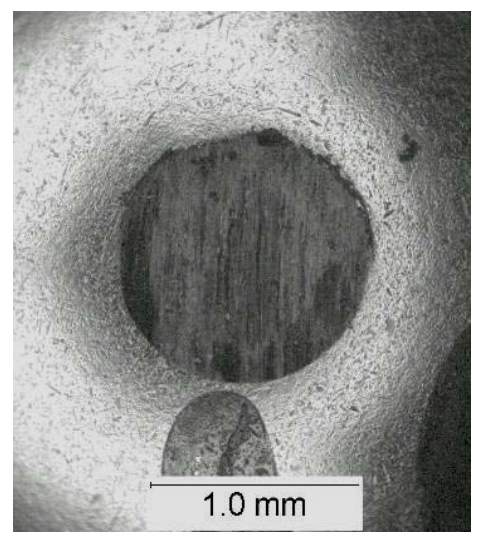

(a)

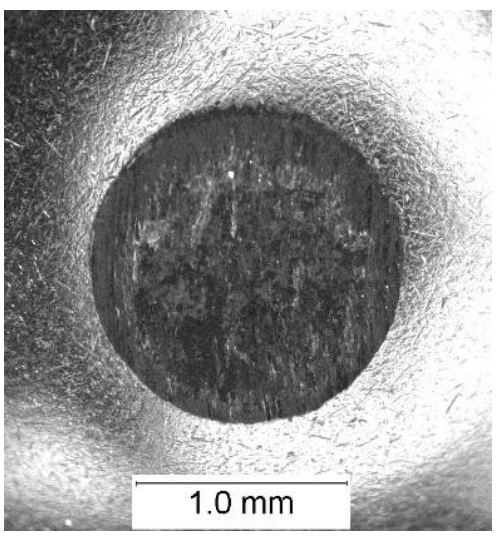

(b)

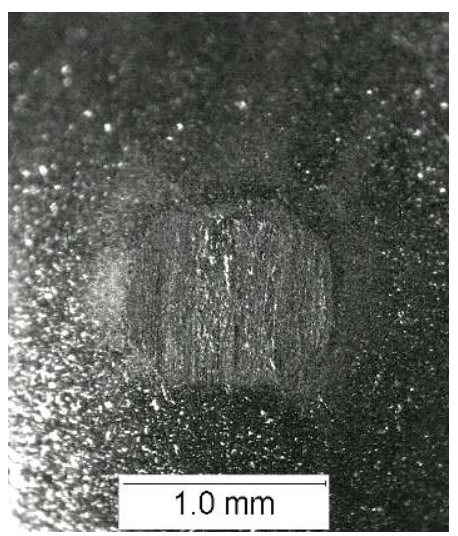

(c)

Figure 4.46. Wear scars on carburized balls: (a) room temperature, (b) 200C, and (c) 400C.

After room-temperature sliding, the hardness of the worn disk surface is higher than that of the worn ball surface for both NT/NT and T/T. This is partially responsible for the higher ball wear than the disk wear observed in self-mated room-temperature sliding (see Table 4.8).

\subsection{Stability of the Carburized Surface at Elevated Temperatures}

At elevated temperatures, especially at $400^{\circ} \mathrm{C}$ that approaches the $470^{\circ} \mathrm{C}$ carburization temperature, some amount of decarburization may occur, but it probably takes place at a slow rate because of the presence of a chromia film that acts as a diffusion barrier to carbon. Microindentation tests showed that the hardness of the carburized disk before and after being tested at $400^{\circ} \mathrm{C}$ (unworn surface area) was $7.56 \pm 0.58$ and $7.68 \pm 0.49$, respectively (i.e., no statistically significant change). This implies a good stability of carburized surface after heating $\sim 130 \mathrm{~min}$ ( $\sim 100$ min wear testing plus $\sim 30$ min hot-hardness measurement). Depending on the intended application, a longer term stability study at elevated temperatures would prove useful.

In the wear tests at elevated temperatures, however, the chromia film is expected to be removed by wear. If the chromia reformation is not quick enough to cover the worn surface, decarburization will occur in a higher rate. This may contribute to the lower wear-resistance at elevated temperatures.

\subsection{Frictional Behavior}

The NT/NT pair consistently had higher initial friction coefficient than T/T in dry sliding [Fig. 4.44(a)]. This was probably due to the more severe adhesion between the non-treated surfaces, which were softer and initially smoother compared to the carburized surfaces. 


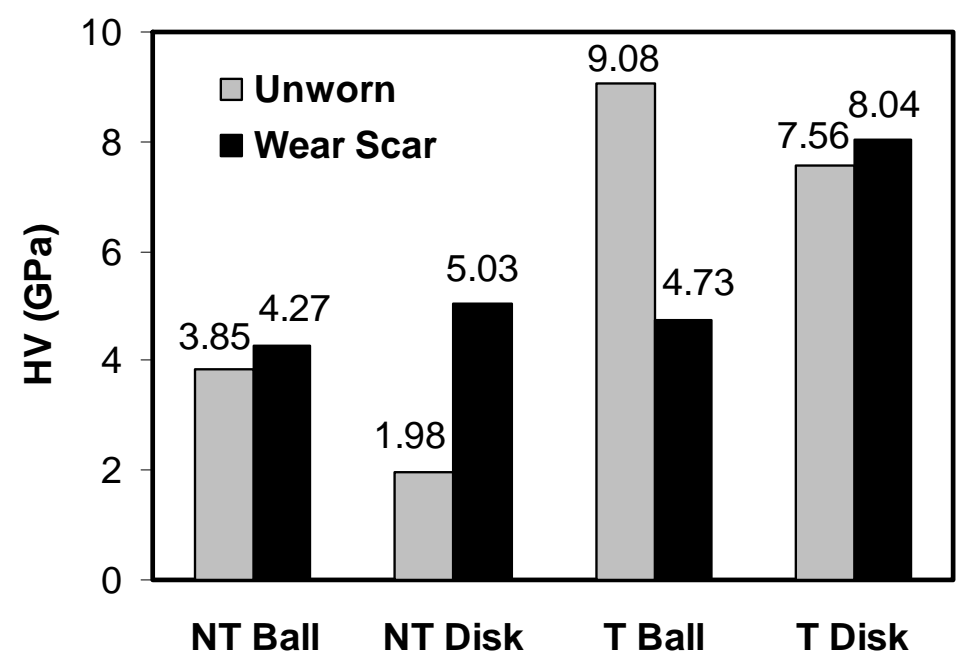

(a)

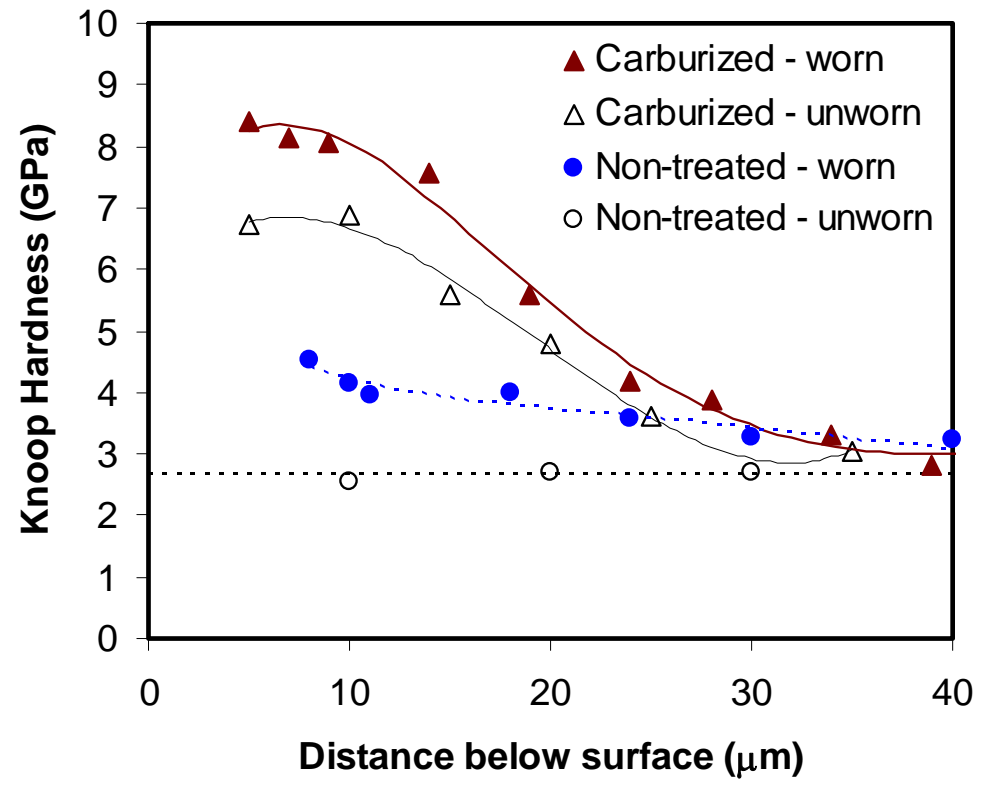

(b)

Figure 4.47. Work-hardening induced by tribo-testing: (a) Vickers hardness of unworn areas and wear scars and (b) hardness profiles below disk wear tracks.

When the sliding reached the steady-state, large amount of wear debris had been produced and the debris composition may significantly influence the friction behavior (e.g., softer debris usually produces lower friction). The wear debris was mainly composed of metallic phase and/or iron oxides. The hardness of iron oxides formed in wear testing is not readily available. Iron oxides in the forms of hematite $\left(\mathrm{Fe}_{2} \mathrm{O}_{3}\right)$ and magnetite $\left(\mathrm{Fe}_{3} \mathrm{O}_{4}\right)$ have the hardness of 6 and 5.5 Mohs, roughly equivalent to 7.5 and $6.5 \mathrm{GPa} \mathrm{HV}$, respectively. If using these values as estimation, the iron oxides are much harder than the non-treated $316 \mathrm{SS}(2-4 \mathrm{GPa})$, but similar to or slightly softer than the carburized surfaces $(7.5-9 \mathrm{GPa})$. 
The wear debris of NT/NT changed from metallic (large shinny flakes), that dominated at room temperature [Fig. 4.48(a)], to a mixture of soft metallic flakes and hard iron oxide particles that occurred at elevated temperatures [Fig. 4.48(b)]. The harder, less deformable wear debris at a higher temperature led to a higher friction coefficient [Fig. 4.44(a)]. In contrast, the wear debris of T/T became darker when the temperature increased: i.e., reddish $\left(\mathrm{Fe}_{2} \mathrm{O}_{3}\right)$ at room temperature [Fig. 4.49(a)] and black $\left(\mathrm{Fe}_{3} \mathrm{O}_{4}\right)$ at $400{ }^{\circ} \mathrm{C}$ [Fig. 4.49(b)]. Therefore, the wear debris became softer (because $\mathrm{Fe}_{3} \mathrm{O}_{4}$ is softer than $\mathrm{Fe}_{2} \mathrm{O}_{3}$ ) and that led to a decreasing friction coefficient as the temperature rose [Fig. 4.44(a)].

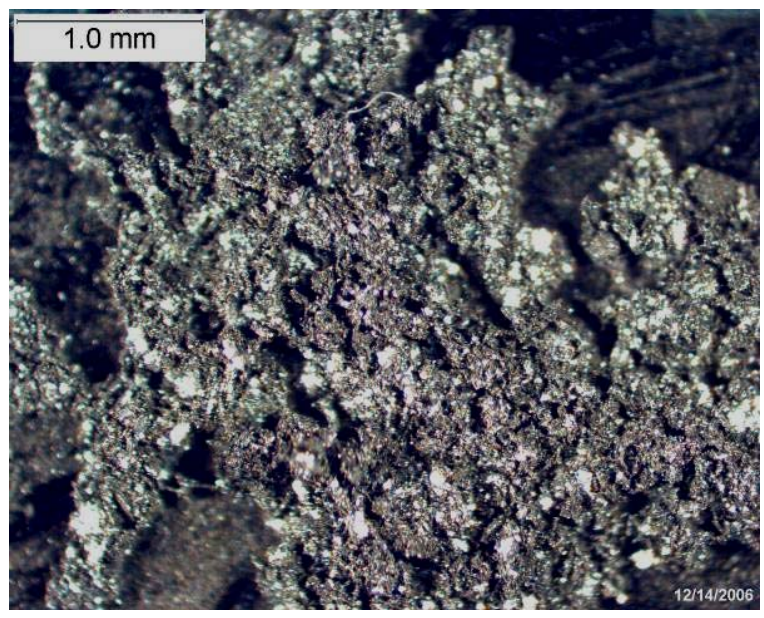

(a)

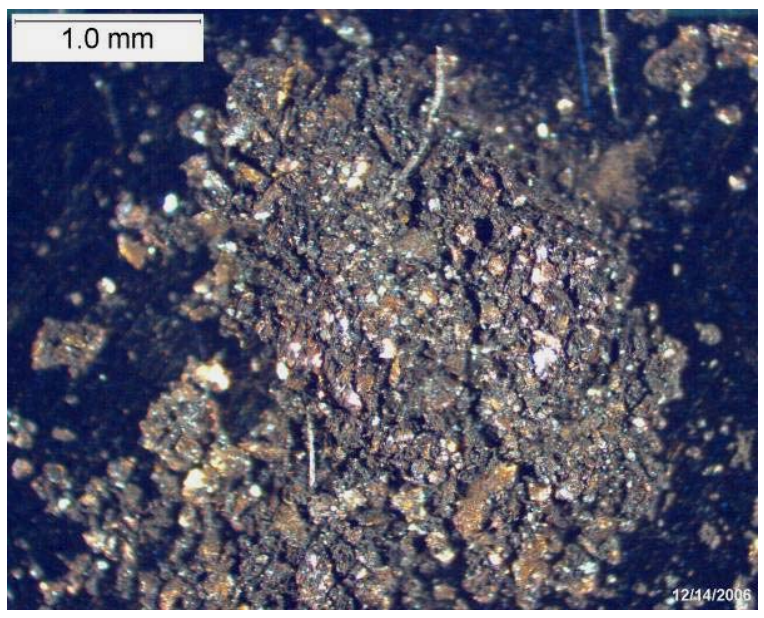

(b)

Figure 4.48. Wear debris produced by NT/NT at: (a) room temperature and (b) $400^{\circ} \mathrm{C}$.

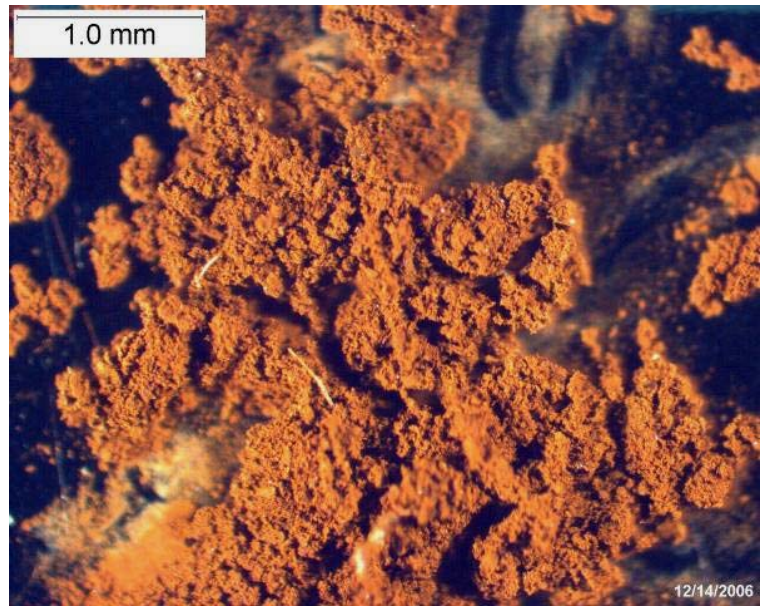

(a) Room temperature

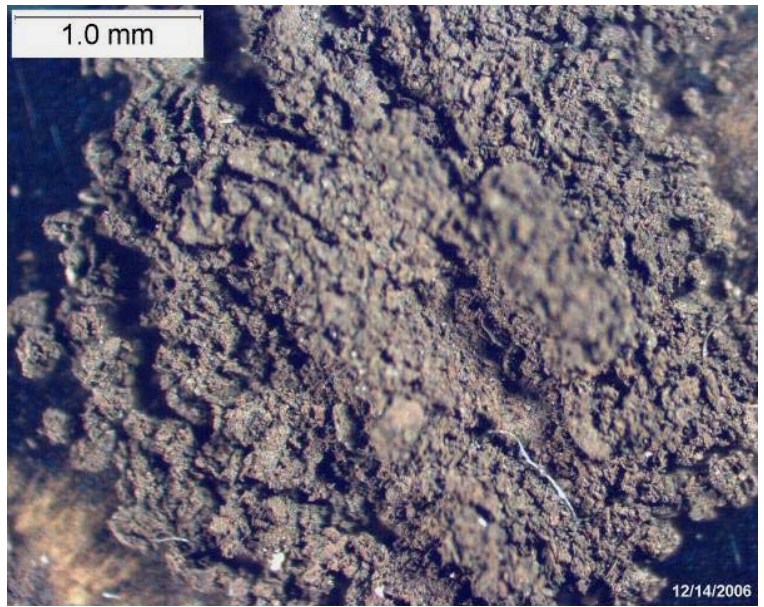

(b) $400{ }^{\circ} \mathrm{C}$

Figure 4.49. Wear debris produced by $T / T$ at: (a) room temperature and (b) $400^{\circ} \mathrm{C}$. 


\section{$\underline{\text { 4.1.6.4.4 Wear Mechanisms }}$}

There were clear differences [15] in the morphology of the wear surfaces of treated and nontreated specimens. At room temperature, the non-treated ball and disk displayed evidence for the kind of plastic deformation and tearing characteristic of severe metallic wear [Figs. 4.45(a) and 4.50(a)], with wear debris mainly composed of large, metallic flakes [Fig. 4.48(a)]. In contrast, the worn surfaces of the carburized ball and disk exhibited deposits of a discontinuous reddish film [Figs. 4.46(a) and 4.50(b)] and fine reddish wear debris [Fig. 4.49(a)]. The wear debris of $\mathrm{T} / \mathrm{T}$ contained higher percentage of oxidized phase, because of the presence of much finer wear particles whose large surface to volume ratios made them easier to oxidize under the tribo-testing induced thermal-mechanical stresses.

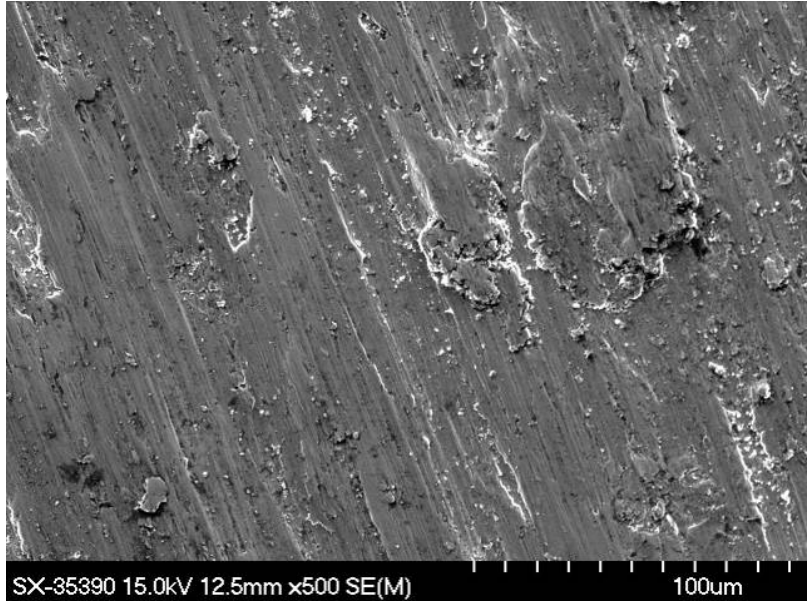

(a)

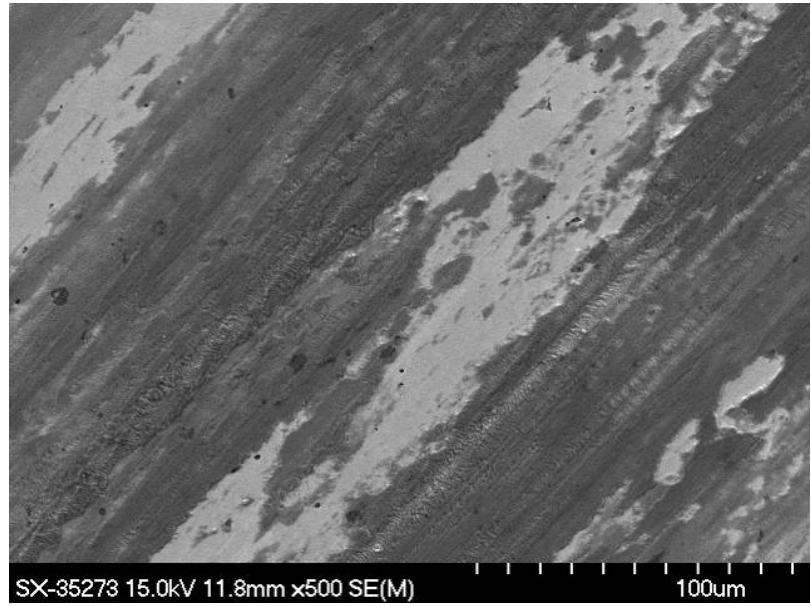

(b)

Figure 4.50. Disk wear tracks produced at room temperature: (a) non-treated disk tested in NT/NT and (b) treated disk tested in T/T.

For both NT/NT and T/T, the ball wore faster than the disk at room temperature but slower at elevated temperatures, as shown in Fig. 4.44. Two possible reasons are:

- A geometry effect, as the ball wear scar is relatively small and in a continuous contact but the disk has a larger wear track in intermittent contact during sliding. At room temperature, the ball is in a more severe wear condition due to continuous rubbing. However, at elevated temperatures, the ball wear scars are largely covered by oxide deposits that separate mating surfaces. Generally, the higher temperature, the more areas on the ball wear scars were covered by the deposits (Figs. 4.45 and 4.46), leading to lower wear. In contrast, the intermittent contact introduced a fatigue stress on the disk wear tracks and caused spallation of the deposits, thus providing less protection to the disk surface. [Note: An exception was the carburized ball tested at $200^{\circ} \mathrm{C}$, which did not have enough oxide deposits built-up (much less debris compared with the non-treated test) to overcome the heat-softening effect, thus had slightly higher wear rate than the ball tested at room temperature.]

- Material property effects could be influential. Although the mating ball and disk are made of the same alloy, they are likely to have experienced different machining processes and heat 
treatments (e.g., annealing and quenching) prior to carburization. Thus, they may have different microstructures, hardness, and residual stresses, and consequently had different responses to temperature changes. It is possible that the balls had less wear-resistance degradation after heating.

\subsubsection{Conclusion of Tribological Evaluation}

Friction and wear behavior of $316 \mathrm{SS}$, treated by a new low-temperature carburization process, were investigated at 20,200 , and $400^{\circ} \mathrm{C}$. Various combinations of treated and non-treated specimen pairs were investigated. The following conclusions have been drawn:

1. The micro-indentation hardness of carburized surfaces was 2-4 times greater than that for non-treated surfaces at both room and elevated temperatures. Nano-indentation-determined elastic modulus of the treated surfaces was increased by about $12 \%$.

2. For dry sliding at room temperature, the most effective wear reduction was obtained using self-mated carburized surfaces, with a wear reduction of two orders of magnitude compared with the non-treated pair.

3. The wear resistance of the carburized surfaces was degraded at elevated temperatures, but was still higher than the non-treated surfaces by one order of magnitude.

\subsubsection{Component Testing}

\subsubsection{Sonoco Pulp and Paper Facility in Tennessee}

A pump plate, manufactured from $304 \mathrm{SS}$, was treated and put into service at Sonoco. It was removed after three months during a routine maintenance cycle. Figure 4.43 shows the treated plate on the right and the non-treated plate on the left. There is no visible wear on the treated plate, and the original grind marks are still visible. The treated plate was reinstalled for additional service life.

After nine months, Swagelok received the following message from Steve Glenn at Sonoco: "I have attached a picture - Fig. 4.51(b) below of the wear plate. No surprise - zero wear is evident after nine months or $3 \times$ ! You can still see the original grind marks on the plate as well as the original surface "orange peel" of the 304. What this does for us energy wise is based on the fact that many of our pumps do not have adjustable wear plates but adjustable impellers. Therefore, as you pull in the worn impeller to a worn wear plate, the variable frequency drive controlling the motor would indicate the increase in hertz to maintain the same flow. In the case of the sludge pump wear plate that we have been trialing, we are only talking about a 10-HP motor that runs normally at $75 \%$ load with a new wear plate. 


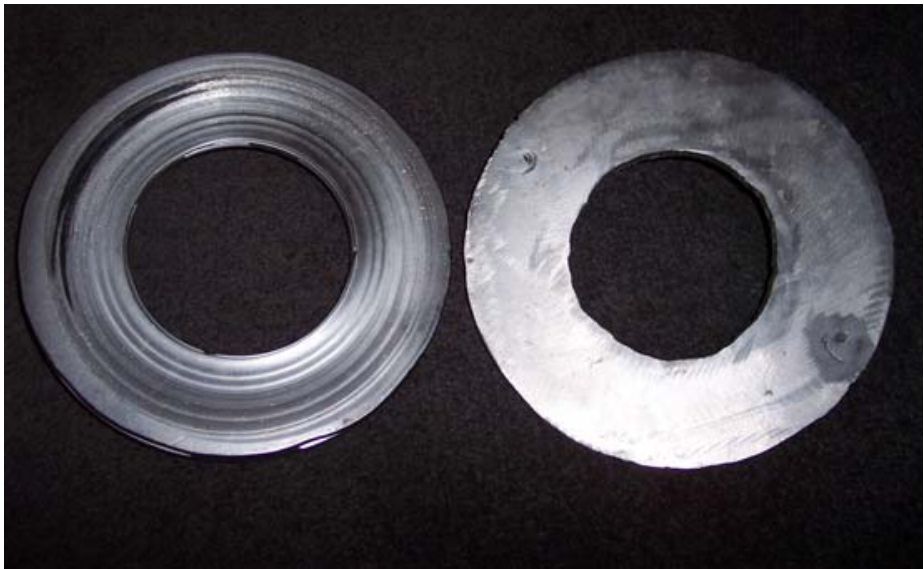

(a)

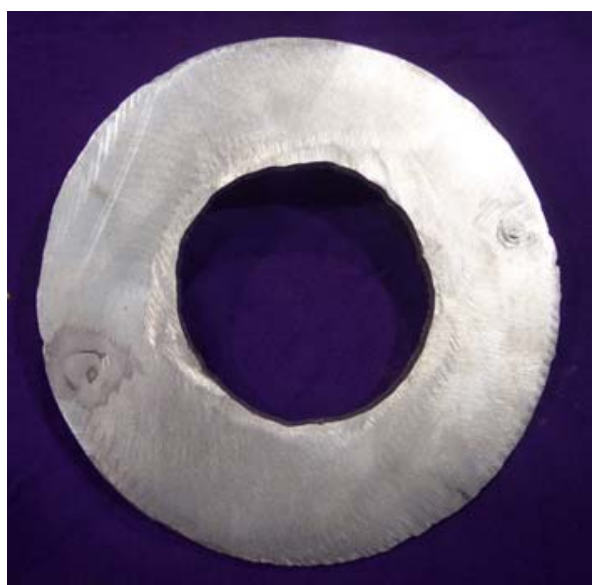

(b)

Figure 4.51. (a) Non-treated and (b) treated 304 stainless steel pump plates after three months in corrosive pumping service in a pulp and paper facility. Non-treated plate shows significant scoring and wear, while the treated plate still retains its original grind marks. (b) Treated pump plate after nine months.

Over a three-month time frame, the load shoots up to $100 \%$ with an non-treated plate. Therefore, what we have seen and can surmise is that in this small application we would probably save in the neighborhood of $2.5 \mathrm{HP} \times \$ 235$ per horsepower per year or roughly $\$ 500-\$ 600$ in energy cost per year. The real coup would be in our larger process pumps such as our stock slurry pumps that range from 50 to $200 \mathrm{HP}$. We have many applications where 10-50 HP in savings could be possible during one year which would mean roughly $\$ 2,000-\$ 12,000$ in savings per application.

The impeller and wear plate recently treated at Swagelok are for a 150-HP pump [Fig. 4.52(a)]. The impeller plate has been placed back in service for a fourth cycle.

A strainer basket manufactured from $316 \mathrm{SS}$ was also treated for Sonoco. The strainer basket is considered to be a consumable item, experiencing approximately three months of service before it is removed and hard-chrome-plated for another three months of service. After the second service cycle, it is worn and not reused. The strainer basket is approximately 28 -in. diameter by 36-in. high. It is a complex structure with welds and machined surfaces, and is shown queued up for treatment in Swagelok's furnace assembly in Fig. 4.52(b). Several strainer baskets with different perforation sizes are used in the straining of pulp in the manufacture of paper. Abrasive corrosive wear leading to material wastage is the mode of failure. The Sonoco strainer basket underwent successful treatment in March 2006 and was returned to Sonoco in April 2006. 


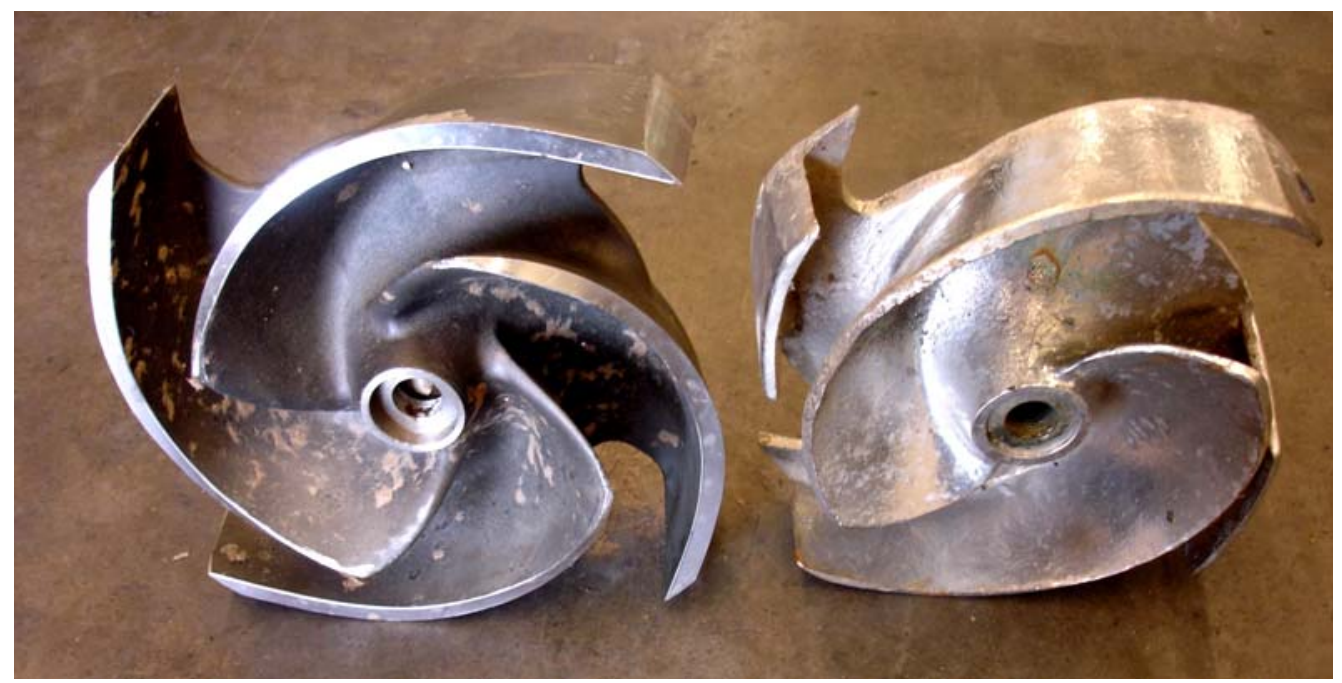

(a)

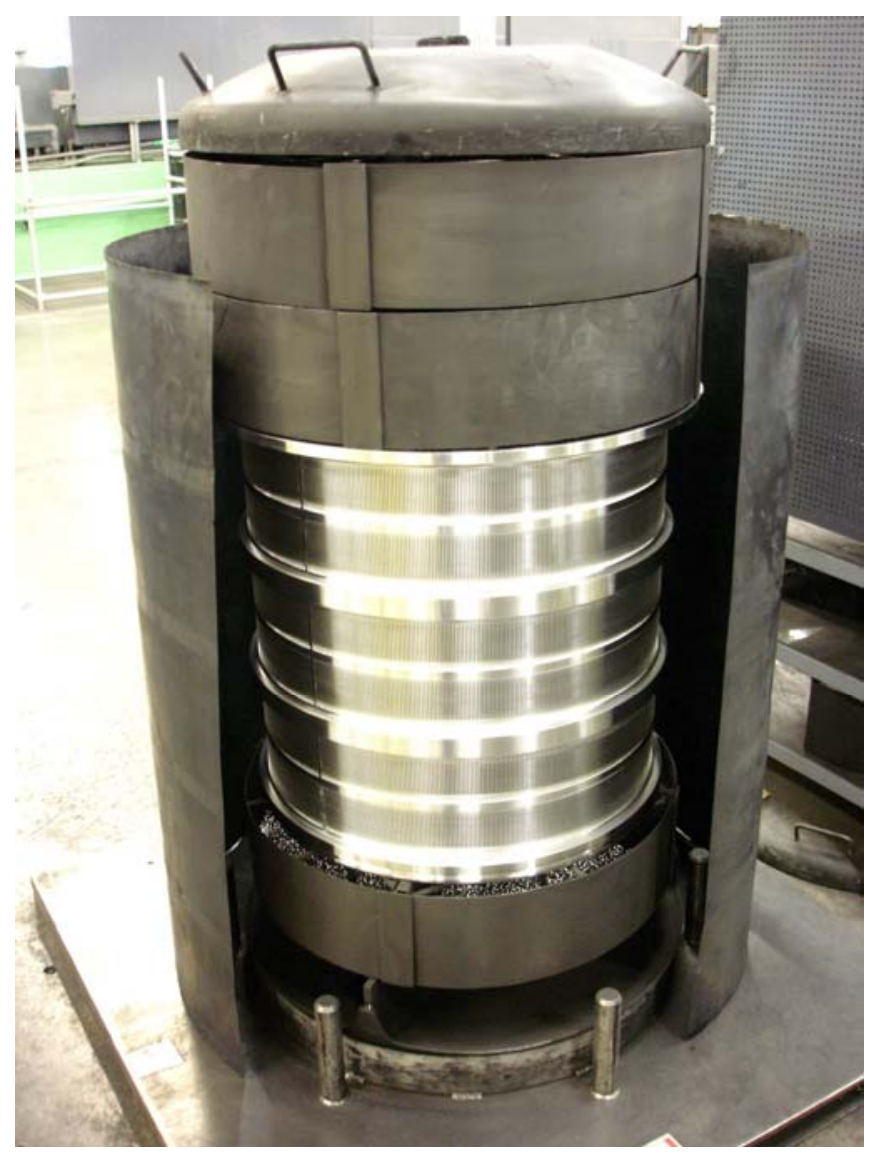

(b)

Figure 4.52. (a) Sonoco 150-HP pump impeller recently treated at Swagelok and (b) Sonoco strainer basket in line for low-temperature colossal supersaturation treatment at Swagelok in March 2006. 


\subsubsection{Other Components}

Jeffrey Chain (now known as Renold Jeffrey) was identified as a potential industrial partner for testing parts treated by the low-temperature carburization technology. Stainless steel (316 and 410) components from Jeffrey Chain were supplied to Swagelok for the carburization process. Interestingly, the $410 \mathrm{SS}$ components did not treat, most likely a result of the alloy content (no Ni) and the crystal structure (ferritic). Data from these treated specimens were transmitted to Jeffrey Chain.

MP35N was treated this quarter at the request of The Timken Company for evaluation. A site visit with Timken was planned and attended in July 2007. Swagelok hosted a site visit for Timken technical representatives to give an overview of the technology and discuss its potential use in bearing applications.

Swagelok also received several components manufactured from CF8M and 303 SS from Spirax Sarco for low-temperature carburization treatment. These components were treated and returned to Spirax Sarco for testing, and showed significant performance improvement. The next step was cost estimating the components processed by the low-temperature carburization process.

ORNL representatives introduced results on treated Type 316 SS to Caterpillar on January 12, 2005.

\subsubsection{Manufacture of Experimental Alloy}

As a basis for alloy development, the CALPHAD database was used to determine the change in carbon solubility under paraequilibrium conditions for additions of $\mathrm{Cr}, \mathrm{Ni}, \mathrm{Si}, \mathrm{Al}, \mathrm{Mo}, \mathrm{Ti}, \mathrm{V}, \mathrm{Nb}$, and $\mathrm{Zr}$. The strong carbide-forming elements are capable of a considerable increase in the carbon solubility. As a result of this analysis, four experimental alloy compositions were determined that would be expected to have substantial carbon solubilities. The alloy compositions were based on the commercial 254 SMO, "superaustenitic" grade steel, with the Mo being replaced with an equivalent atomic fraction of $\mathrm{Ti}, \mathrm{V}$, or $\mathrm{Nb}$. Thus, the four alloys contained $6.0 \mathrm{wt} \% \mathrm{Mo}, 3.0 \mathrm{wt} \% \mathrm{Ti}, 3.2 \mathrm{wt} \% \mathrm{~V}$, or $5.8 \mathrm{wt} \% \mathrm{Nb}$. These alloys were melted at ORNL in approximately $1-1 \mathrm{~b}$ heats by nonconsumable-arc-melting process and cast into $1-\times 1-\times$ 4-in. ingots. These ingots were hot-rolled to 0.5 -in. thickness and cold-rolled to approximately 0.25-in. thickness.

The four alloys were carburized by Swagelok using the standard process, and the hardness profiles are shown in Fig. 4.53. With the exception of the Ti-containing alloy, surface hardening is apparent. In particular, the V-containing alloy achieved a Vickers hardness of 1100 at the surface. 


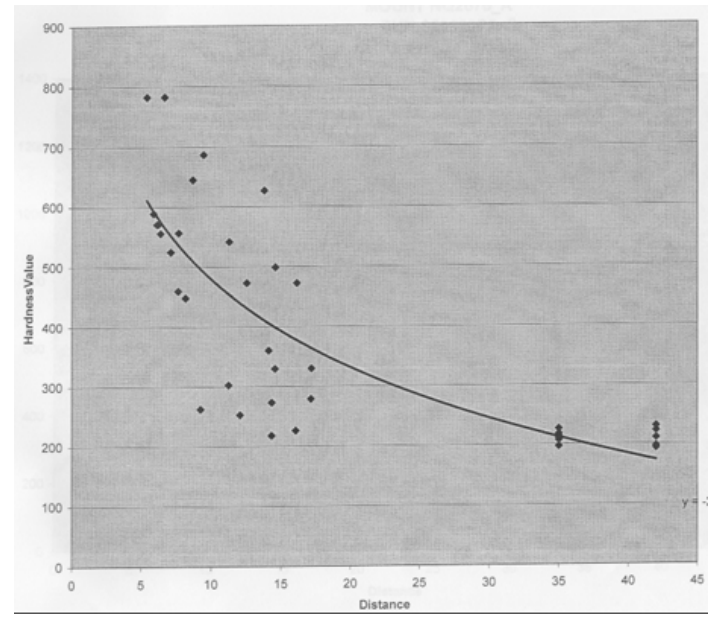

(a)

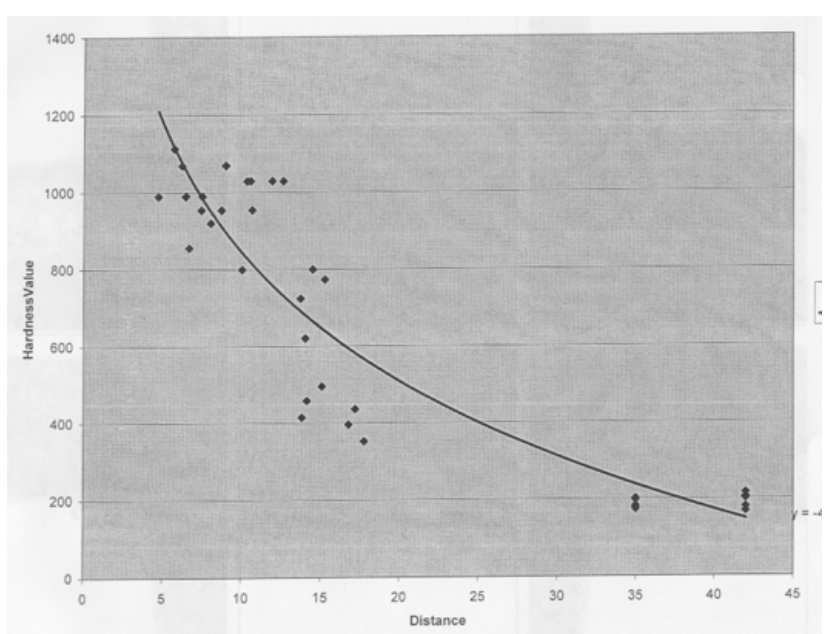

(c)

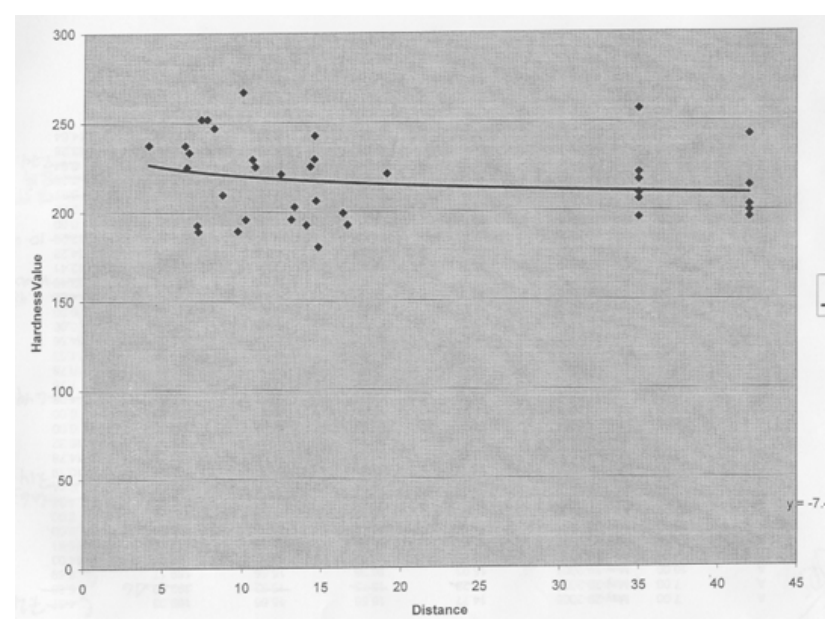

(b)

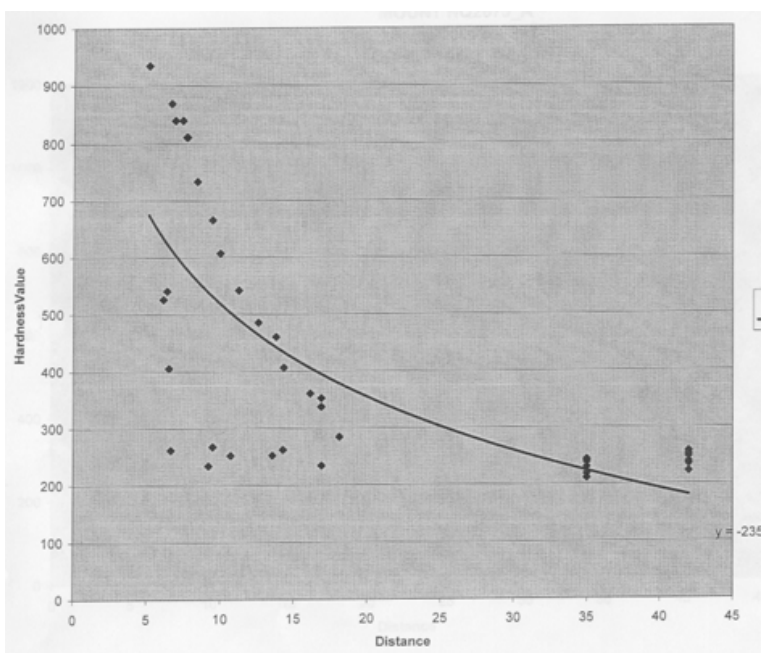

(d)

Figure 4.53. Hardness profiles after carburization for the four experimental alloys: (a) $6.0 \mathrm{wt} \% \mathrm{Mo}$, (b) $3.0 \mathrm{wt} \% \mathrm{Ti}$, (c) $3.2 \mathrm{wt} \% \mathrm{~V}$, and (d) $5.8 \mathrm{wt} \% \mathrm{Nb}$.

X-ray diffraction scans of the as-hot-rolled materials are shown in Fig. 4.54(a), with the peak positions plotted in the Nelson-Riley plot in Fig. 4.54(b). It is clear that all four alloys are austenitic, and that no carbides were formed. Their lattice parameters are all very similar, ranging from $0.3594 \mathrm{~nm}$ for the Nb-containing alloy to $0.3605 \mathrm{~nm}$ for the Mo-containing alloy. There are several small peaks visible in the XRD traces in Fig. 4.54(a), particularly for the Nband Mo-containing alloys. Since the XRD scans were taken of the as-hot-rolled materials, these peaks are probably due to thin oxide scales that formed during hot-rolling. 


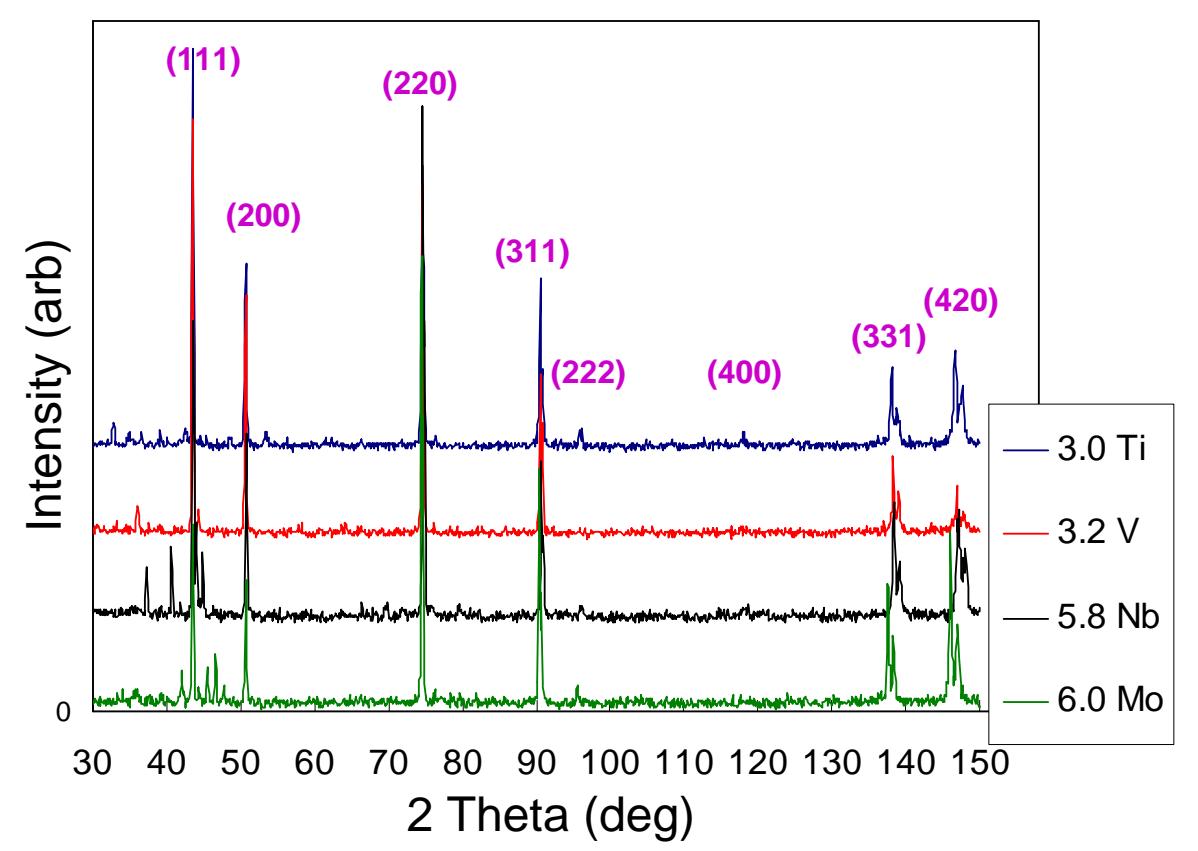

(a)

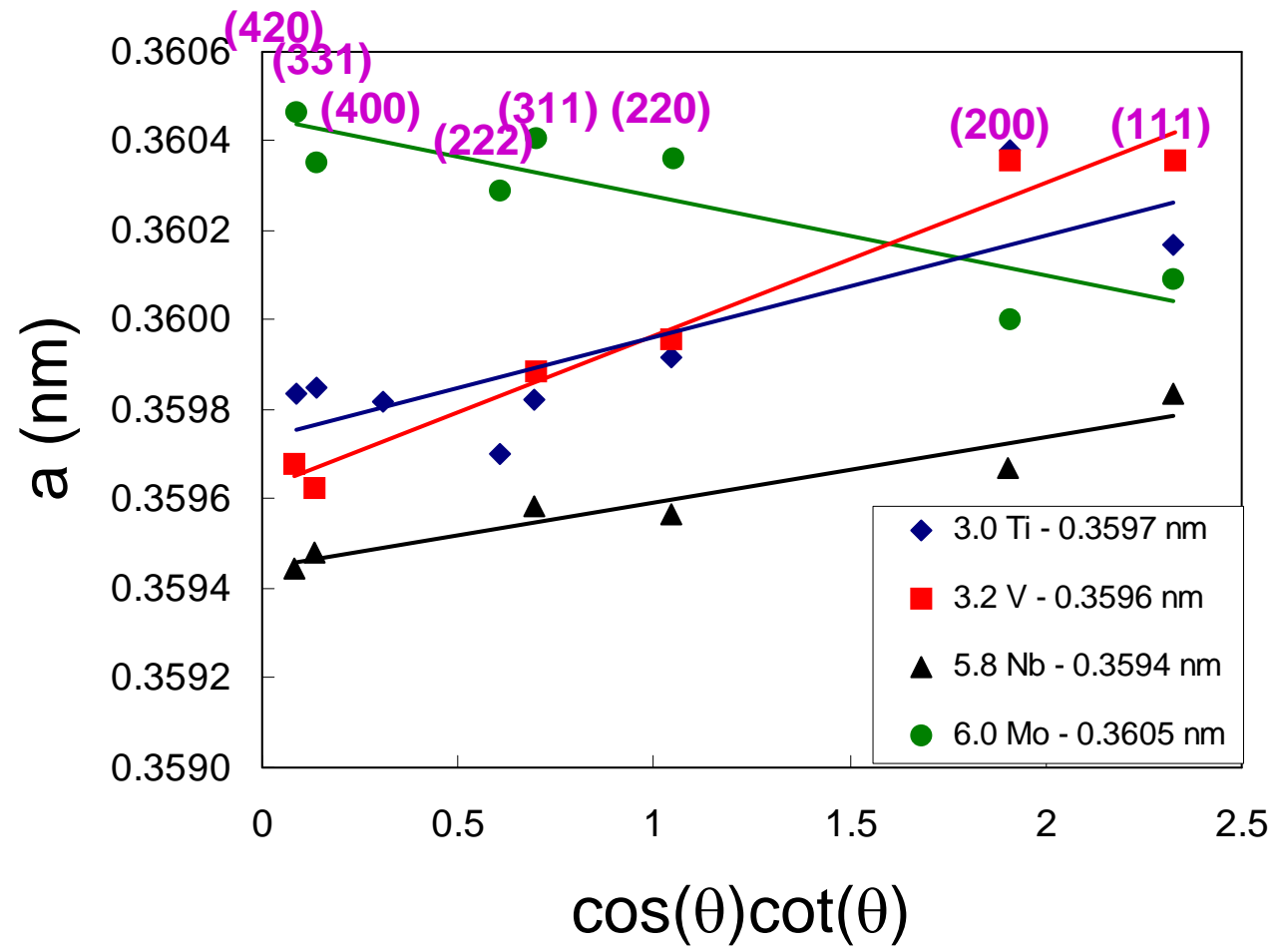

(b)

Figure 4.54. X-ray diffraction (XRD) results for experimental alloys: (a) XRD traces; the peaks are labeled. (b) The peak positions from (a) shown in a Nelson-Riley plot. 


\subsection{Meetings and Reports}

CWRU held weekly meetings throughout the project duration; Swagelok and CWRU held monthly meetings; and teleconference calls between ORNL, CWRU, and Swagelok project investigators occurred on a monthly basis. Quarterly project technical reviews were also held at varying locations with representatives from CWRY, Swagelok, ORNL, DOE, Energy Industries of Ohio, and other interested parties. The final project review was held on March 1, 2007 at Swagelok in Solon, Ohio.

A website for the project was set up and can be accessed at http://pulex.cwru.edu/ ernst/private/Carburization/Pages/index.html as user "Carbon" with password "Case" (URL, user, and password are case sensitive). The site contains e-mail links to the participants, meeting information, the proposal, reports, publications related to the project, presentations, literature, and micrographs. Note that the security level of this site is not particularly high — no higher than the security level of e-mail.

Swagelok was the recipient of the 2006 ASM Engineering Materials Achievement Award for the development of this technology. The award was presented in October 2006 at the MS\&T '06 meetings in Cincinnati, OH. A website for the award can be accessed at http://www.asminternational.org/Content/NavigationMenu/Membership/AwardsProgram/Award _Recipients/2006_Recipients2/2006_Recipients.htm

Swagelok developed a business plan for commercialization of this technology. Inputs from the research from this Industrial Materials of the Future project were pivotal and enabled the development of this commercialization plan. In June 2006, a proposal was submitted to the Ohio Department of Development in response to The Third Frontier Fiscal Years 2007 Request for Proposal, Research Commercialization Program in Engineering and Physical Sciences. The proposal went through a National Academy of Sciences review in Columbus in early September 2006, and Swagelok and CWRU received a three-year, \$5.5 million grant. The grant will enable Swagelok, in partnership with CWRU, to further research, evaluate, and commercialize the LTCSS technology. The announcement of the 2007 grant was made on December 15, 2006 by the Ohio Department of Development. The Third Frontier Project is a ten-year, \$1.6 billion initiative designed to expand Ohio's high-tech research capabilities, promote innovation and company formation, and create high-paying jobs. The Third Frontier grant will provide for development of the research, manufacture, and infrastructure elements necessary to convert the LTCSS technology into a commercially viable, Ohio-based, metals surface-enhancement business. Swagelok will undertake technology and business development efforts, and CWRU will continue research study on expanding the technology to other commercially important alloys for future business development. 


\section{Accomplishments}

\subsection{Process/Product Development}

The current project led to the following key enhancements from the LTCSS process:

Table 5.1. Significant Performance Enhancements from LTCSS

\begin{tabular}{|c|c|c|}
\hline No. & Characteristic & Outcome from LTCSS Process \\
\hline 1 & Alloy system applicability & $\begin{array}{l}\text { - Broad base } \\
\text { - } 29 \text { different alloys }\end{array}$ \\
\hline 2 & Shape and size applicability & $\begin{array}{l}\text { - Sheet, bar, and complex shapes such as valves and impellers } \\
\text { - Size limited by current furnace size } \\
\text { - No distortion after treatment }\end{array}$ \\
\hline 3 & Microstructure & $\begin{array}{l}-\sim 10-\mu \mathrm{m} \text {-deep hard layer } \\
-\sim 12 \text { at. } \% \text { carbon on surface } \\
-4-5 \times \text { hardness increase } \\
\text { - Compressive surface stress of } 300 \mathrm{ksi}\end{array}$ \\
\hline 4 & Thermodynamic modeling & $\begin{array}{l}\text { - Modeling able to predict carbon solubilities } \\
\text { - New alloy design possibility demonstrated }\end{array}$ \\
\hline 5 & Corrosion resistance & $\begin{array}{l}-3 \times \text { Improvement in pitting corrosion } \\
-5 \times \text { Improvement in crevice corrosion }\end{array}$ \\
\hline 6 & Cavitation erosion & $-8 \times$ Improvement over non-treated \\
\hline 7 & Wear resistance & - $100 \times$ Reduction in wear rates \\
\hline 8 & Fatigue resistance & $\begin{array}{l}\text { - } 10 \times \text { in fatigue life } \\
-50 \% \text { increase in } 10^{7} \text { cycle endurance limit }\end{array}$ \\
\hline 9 & $\begin{array}{l}\text { Component operating } \\
\text { experience }\end{array}$ & - $5 \times$ Life extension demonstrated in commercial applications \\
\hline
\end{tabular}

In summary, the LTCSS treatment is a paradigm-shifting technology: applied to stainless and corrosion-resistant alloys, it significantly enhanced performance characteristics, and extended the use of these alloys into applications currently served by more expensive materials. The DOE IMF research demonstrated a substantial reduction of the service-induced wear of austenitic SS parts in a variety of applications, including, for example, bearing surfaces and wear surfaces.

\subsection{Technology Transfer}

Several mechanisms for technology transfer were used.

- Potential user such as Spirax Sarco and Energy Industries of Ohio (EIO) were part of the program. This got the project an early start with the identification of certain components such as steam traps. Good experience with steam traps at Spirax Sarco led to the identification of valve application that needs to operate in steam at $350^{\circ} \mathrm{F}$.

- Vinod Sikka from ORNL made visits to companies such as Sonoco, a paper recycling company in Newport, TN, to talk about LTCSS technology and to identify components that could be 
tested in service. Early success at Sonoco led to their active participation in the project and identification of several additional components for field trial.

- A technology transfer meeting was held at ORNL that included participation from Sonoco and Renold-Jeffrey. Swagelok's sales staff in the Tennessee region also participated in the meeting.

- A technology booth was set up by Swagelok at the ASM Annual Meeting in Cincinnati, $\mathrm{OH}$ in 2006 and again in 2007 in Detroit, MI. Hundreds of meeting participants had a chance to get samples of treated SS and talk about potential uses of the technology in their industry.

- Several presentations about the LTCSS technology have been made by research staff that participated in this project.

- Several news releases related to LTCSS technology were made public (see Appendix A).

\subsection{Commercialization}

The major developments under this scope of work led to path forward for commercialization. The following are highlights from the commercialization:

1. Swagelok and CWRU were awarded \$5.5 million Third Frontier Project grant from the ODOD. This funding is committed to the following important goals:

- Stimulate the creation of new technology-based companies: commercialization of the LTCSS technology has the potential to create more than one technology-based company. LTCSS is a platform technology, applicable to a wide range of alloys, and could form the basis of several business units, each specializing in a particular alloy family and treatment procedure.

- Stimulate the expansion of existing technology based companies: Swagelok Company is a technology-based manufacturing company with a long history in Ohio and a strong commitment to the state. Third Frontier funds will enable Swagelok to expand into a new role as a provider of surface enhancement services to several industrially important sectors in the economy, including defense and energy.

- Create high-quality jobs for Ohio residents: By the end of year 3 of this project, Swagelok anticipates the creation of at least 37 new positions as a direct result of the commercialization effort. Additional jobs are anticipated in the years following, as the venture becomes profitable and self-sustaining. A large number of the opportunities created will be highly skilled positions for researchers, engineers, technicians, marketers and salespeople. Also, at least five graduate students and post-docs will be employed at Case for the duration of this project. In addition to providing an educational venue for these highly trained engineers, it is likely that initiation of the carburization business by Swagelok will provide many employment opportunities for Case and other Ohio university graduates. 
- Promote the development and commercialization of new technology-based products: for many applications, LTCSS is an enabling technology that will allow the development of new products. LTCSS surface hardening will enhance the wear, corrosion, and fatigue characteristics of a wide variety of commercially important alloys. Due to their close proximity to the center of LTCSS development and manufacture, Ohio-based companies are expected to be leading users of the technology and will gain significant advantages in their own markets by adopting the technology ahead of their competitors.

- Encourage the manufacture of these new products in Ohio: Case and Swagelok are Ohio-based institutions of long standing, with a strong commitment to the economic health of the state. LTCSS technology was developed in Ohio. Through the use of the Third Frontier funding, Swagelok will locate and grow the LTCSS business in Ohio.

- Create wealth for Ohio residents and companies: The project is organized to create a research - development - commercialization pipeline of process treatments applicable to different families of alloys (and therefore different components and markets). The economic benefits of the proposed project will be appreciable. Revenues in Year 5 (2011) are conservatively estimated at over $\$ 50$ million, as shown later in this proposal.

2. Swagelok established a new subsidiary company to market and commercialize the LTCSS process. The new business unit is called "Swagelok Technology Services Company (STSC).

3. Swagelok trademarked the LTCSS process under the name Swagelok ${ }^{\circledR}$ SAT12 (SM). The SAT12 is derived from a combination of "SAT" and "12". SAT is short for supersaturation and the number 12 represents the atomic mass of carbon.

4. Sonoco, with early success in the use of SAT12 process for clutch plate, is currently evaluating many other components and is negotiating a business relationship for extending the technology more broadly.

5. Spirax Sarco, a company dealing with steam systems, had great success in the performance of LTCSS-treated steam traps and steam valves. They are currently looking into process economics to move forward for certain critical applications.

6. Aqua-Chem Inc., a company in building desalination and water purification systems, is very interested in using the LTCSS technology for their systems. Some of the early trial samples have already been processed and are currently being tested by Aqua-Chem Inc.

7. Miscellaneous Applications - Several other companies are examining the use of the LTCSS process. These vary from specialty to consumer products.

8. Market Potential - A market study reported in Swagelok's ODOD proposal states that there is a total available market of $\$ 2$ billion per year for the LTCSS process. More details of the market breakdown include:

- Pulp and paper

- Pump and rotary equipment

- Defense 
- Commercial fasteners

- Bearings

- Fine chemicals

- Biopharmaceutical

- Cutting edges

- Process and analytical instruments

- Other business opportunities

The ODOD funding is expected to speed up the commercialization and market penetration.

\subsection{Publications, Presentations, Conference Proceedings, Patents, and Theses}

1. Nikhil Agarwal, "Improvement of Fatigue Properties of Stainless Steel by Low Temperature Carburization," Master's Thesis, Case Western Reserve University, January 2002.

2. Y. Cao, "Surface Hardening of Austenitic Stainless Steels via Low Temperature Carburization," Ph.D. Thesis, Case Western Reserve University, May 2003.

3. Y. Cao, F. Ernst, G.M. Michal, "Colossal Carbon Supersaturation in Austenitic Stainless Steels Carburized at Low Temperature," Acta Materialia 51 (2003) 4171-4181.

4. F. Ernst, Y. Cao, and G.M. Michal, "Carbides in Low-Temperature-Carburized Stainless Steels," Acta Materialia 52 (2004) 1469-1477.

5. G.M. Michal, F. Ernst, and Y. Cao, "Surface Hardening of Austenitic Steels by Low Temperature Colossal Supersaturation," in Proceedings of Materials Science \& Technology, Vol. II: AIST-TMS (Warrendale, PA), pp. 347-353 (2004).

6. G.M. Michal, F. Ernst, and A.H. Heuer, "Carbon Paraequilibrium in Austenitic Stainless Steel," Metallurgical and Materials Transactions A 37A (June 2006) 1819-1824.

7. G.M. Michal, F. Ernst, H. Kahn, Y. Cao, F. Oba, N. Agarwal, and A.H. Heuer, "Colossal Carbon Supersaturation Due to Paraequilibrium Carburization: Stainless Steels with Greatly Improved Mechanical Properties," Acta Materialia 54 (2006) 1597-1606.

8. J. Qu et al., "Tribological Properties of Stainless Steels Treated by Colossal Carbon Supersaturation," Wear 2007, doi: 10.1016/j.wear.2006.12.049 (in press).

9. Sunniva Collins and Peter Williams, "Low-Temperature Colossal Supersaturation," Advanced Materials \& Processes, September 2006, p. 32.

10. F. Ernst, G.M. Michal, H. Kah, and A.H. Heuer, "Paraequilibrium Surface Alloying with Interstitial Solutes: A New Concept for Improving the Performance of Medical Devices," in Medical Device Materials III, eds. K. Venugopalan and M. Wu, ASM International: Materials Park, Ohio, pp. 27-33 (2006).

11. J. Gentil, F. Ernst, G. Michal, and A. Heuer, "The Effect of Colossal Carbon Supersaturation on Stainless Steels of the Type PH13-8Mo and AL6XN," in Recent Developments in Steel Processing, eds. M. Merwin and B. Nelson, Materials Science \& Technology: AIST-TMS (Warrendale, PA), in press, 2006.

12. F. Ernst, Y. Cao, G.M. Michal, and A.H. Heuer, "Carbide Precipitation in Austenitic Stainless Steel Carburized at Low Temperature," Acta Materialia 55 (2007) 1895-1906.

13. J. Qu, P.J. Blau, and B.C. Jolly, "Tribological Properties of Stainless Steels Treated by Colossal Carbon Supersaturation," presentation at $16^{\text {th }}$ International Conference on Wear of Materials, Montreal, Quebec, Canada, Apr. 15-19, 2007. 
14. N. Agarwal, H. Kahn, A. Avishai, G. Michal, F. Ernst, and A.H. Heuer, "Enhanced Fatigue Resistance in 316L Austenitic Stainless Steel Due to Low-Temperature Paraequilibrium Carburization," to be published in Acta Materialia, 2007.

15. A.H. Heuer, F. Ernst, H. Kahn, A. Avishai, G.M. Michal, D.J. Pitchure, and R.E. Ricker, "Interstitial Defects in 316L Austenitic Stainless Steel Containing "Colossal" Carbon Concentrations: An Internal Friction Study," Scripta Materialia 56(12) pp. 1067-1070 (2007).

16. F.J. Martin, E.J. Lemieux, T.M. Newbauer, R.A. Bayles, P.M. Natishan, H. Kahn, G.M. Michal, F. Ernst, and A.H. Heuer, "Carburization-Induced Passivity of 316L Austenitic Stainelss Steel," Electrochemical and Solid State Letters, submitted, 2007.

17. A. Avishai, D. Isheim, D.N. Seidman, F. Ernst, G.M. Michal, and A.H. Heuer, "LocalElectrode Atom Probe (LEAPTM) Tomographic Microanalysis of Low-Temperature GasCarburized Austenitic Stainless Steel," in Proceedings of Microscopy \& Microanalysis, August 5-9, 2007, Ft. Lauderdale, FL, 2007. 


\section{Summary and Conclusions}

\subsection{Summary}

Low-temperature colossal supersaturation (LTCSS) is a novel surface hardening method for carburization of austenitic SS without the precipitation of carbides. The formation of carbides is kinetically suppressed, enabling extremely high or colossal carbon supersaturation. As a result, surface carbon concentrations in excess of 12 at. $\%$ are routinely achieved.

The project objective was to extend the LTCSS treatment to other austenitic alloys, and to quantify improvements in fatigue, corrosion, and wear resistance.

Results from this study showed the following benefits of LTCSS:

1. Microstructural Characterization: X-ray diffraction (XRD) evaluation of treated materials performed at CWRU verified expanded austenite, with no evidence of carbide precipitation. Carbon concentration profiles using Auger electron spectroscopy (AES) and energy dispersive spectrometry (EDS) showed C levels in treated 316 to be in excess of 12 at. \%. Scanning electron microscopy of failed treated tensile specimens showed slip bands and no decohesion of the treated layer, verifying that the layer remained ductile. Compressive stresses in excess of $2 \mathrm{GPa}$ were calculated at the surface of the case, based on the XRD lattice expansion and the carbon concentration.

2. Corrosion Resistance: Electrochemical polarization curves performed at Swagelok, CWRU, and the Naval Research Lab showed a 600 - to $800-\mathrm{mV}$ increase in pitting potential for treated $(1000 \mathrm{mV})$ vs. non-treated $(200 \mathrm{mV}) 316$. Crevice corrosion tests performed at the Naval Research Lab showed five orders of magnitude improvement in crevice corrosion resistance for treated vs. non-treated 316L. Treated 316L showed excellent crevice corrosion behavior similar to Ti-6Al-4V and Hastelloy C22.

3. Erosion Resistance: Cavitation tests up to six-hours duration, performed at ORNL using a vibratory horn and mercury as the dense liquid medium, showed that treatment on 316 specimens reduced weight loss by a factor of $\sim 5.5$ times. This finding is particularly important for slurry and corrosive pumping applications.

4. Wear Resistance: Wear tests performed at ORNL also indicated significant enhancement in wear properties, important for bearing applications. Standard ASTM pin-on-disk sliding friction and reciprocating friction tests showed wear rates of treated couples (ball and disk) lowered by approximately 100 times compared to non-treated. An ASTM standard continuous loop abrasion test (rotating abrasive belt) showed a 30\% reduction in wear volume for treated vs. non-treated 316 specimens.

5. Fatigue Resistance: Fatigue testing performed at CWRU $(\mathrm{R}=-1)$ showed an order of magnitude improvement for treated vs. non-treated 316 at the same maximum stress level. The maximum stress at $10^{7}$ cycles used as the design stress for infinite life, improved by approximately $50 \%$, from 30 to 45 ksi. 
Although initial commercialization of the LTCSS technology had begun under this project, the \$5.5 million grant to Swagelok and CWRU from ODOD strengthened this effort.

\subsection{Conclusions}

This was an extremely successful project in that it accomplished all of the proposed tasks and had led to additional funding for an expanded commercialization effort towards the estimated market potential of $\$ 2$ billion per year for this technology.

\subsection{Commercialization Aspects (Plans, Status, Barriers)}

\section{$\underline{\text { Plans }}$}

Details of commercialization plan are described under Section 5.3.

\section{$\underline{\text { Status }}$}

Significant progress in commercialization effort was made through field testing in the pulp and paper industry. Excellent results in simulated testing of components have also been achieved in steam applications (see Appendix B).

\section{$\underline{\text { Barriers }}$}

The following was identified as barriers and how they were addressed:

1. Availability of a large system(s) that can accommodate a broad range of component sizes. Although there is a commercial operating system available at Swagelok, it is dedicated to meeting their demands for treating of ferrules. Furthermore, the system is somewhat limited for some of the identified component sizes.

The ODOD grant is being used to design and construct the new system. The design of the new system will incorporate the largest number of possible size variables that were encountered during various technology transfer efforts.

2. Marketing is somewhat of a barrier in that the LTCSS technology is not something that a salesperson can go to a customer and take orders. It requires technical marketing where a skilled metallurgist or materials scientist needs to educate the customer on the process and its benefits. Under the ODOD grant, Swagelok is addressing this barrier by using specialized marketing staff for this technology.

3. Process economics might be seen as a barrier in that for some applications the process cost per part may be considered high. However, the design of a large system and market forces will take care of it by itself.

\subsection{Lessons Learned}

Industry, university, and national laboratory collaborations can address all aspects of science, property measurements, technology transfer, and commercialization for projects such as LTCSS in an effective manner. 
Another benefit is the training of scientists and engineers in the process of carrying out the project. This provides the work force needed to move the technology to the next level. 


\section{Recommendations}

As noted in the report, the LTCSS process offers a ubiquitous opportunity to change the way SS are used. The process improves the performance of the SS components where they are used now (as is the case with clutch plate); it can help upgrade the performance of cheaper (low nickel) SS to a higher performing SS or replace high-cost nickel-based alloy such as C22 with SS or even use of titanium for certain applications.

Clearly, with improvement in wear, fatigue, and cavitation resistance, there are significant opportunities for energy savings and resultant environmental benefits.

The major recommendations from this project include:

1. DOE-ITP to get the fact sheet on this project available as broadly as possible.

2. Swagelok to get the new furnace designed and constructed as quickly as possible, which will help speed up the commercialization process broadly across the industry.

3. Technical marketing of the technology needs to continue. Only a small percentage of the total potential market has heard about the benefits of this process.

It will be worth identifying all industrial applications with possible energy savings. Once identified, DOE may want to fund a project to pursue the highest energy savings application project. 


\section{References}

1. Peter C. Williams and Steven V. Marx, US Patent 6,547,888 B1, "Modified Low Temperature Case Hardening Processes," April 15, 2003.

2. Peter C. Williams and Steven V. Marx, US Patent 6,461,448 B1, "Low Temperature Case Hardening Processes," October 8, 2002.

3. Peter C. Williams and Steven V. Marx, US Patent 6,093,303, "Low Temperature Case Hardening Processes," July 25, 2000.

4. Peter C. Williams and Steven V. Marx, US Patent 6,165,597, "Selective Case Hardening Processes at Low Temperature," December 26, 2000.

5. Sunniva Collins and Peter Williams, "Low-Temperature Colossal Supersaturation," Advanced Materials \& Processes, September 2006, p. 32.

6. Y. Cao, "Surface Hardening of Austenitic Stainless Steels via Low Temperature Carburization," Ph.D. Thesis, Case Western Reserve University, May 2003.

7. Y. Cao, F. Ernst, G.M. Michal, "Colossal Carbon Supersaturation in Austenitic Stainless Steels Carburized at Low Temperature," Acta Materialia 51 (2003) 4171-4181.

8. A. Avishai, D. Isheim, D.N. Seidman, F. Ernst, G.M. Michal, and A.H. Heuer, "LocalElectrode Atom Probe (LEAPTM) Tomographic Microanalysis of Low-Temperature GasCarburized Austenitic Stainless Steel," in Proceedings of Microscopy \& Microanalysis, August 5-9, 2007, Ft. Lauderdale, FL, 2007.

9. G.M. Michal, F. Ernst, and A.H. Heuer, "Carbon Paraequilibrium in Austenitic Stainless Steel," Metallurgical and Materials Transactions A 37A (June 2006) 1819-1824.

10. G.M. Michal, F. Ernst, H. Kahn, Y. Cao, F. Oba, N. Agarwal, and A.H. Heuer, "Colossal Carbon Supersaturation Due to Paraequilibrium Carburization: Stainless Steels with Greatly Improved Mechanical Properties," Acta Materialia 54 (2006) 1597-1606.

11. F.J. Martin, E.J. Lemieux, T.M. Newbauer, R.A. Bayles, P.M. Natishan, H. Kahn, G.M. Michal, F. Ernst, and A.H. Heuer, "Carburization-Induced Passivity of 316L Austenitic Stainelss Steel," Electrochemical and Solid State Letters, submitted, 2007.

12. Nikhil Agarwal, "Improvement of Fatigue Properties of Stainless Steel by Low Temperature Carburization," Master's Thesis, Case Western Reserve University, January 2002.

13. N. Agarwal, H. Kahn, A. Avishai, G. Michal, F. Ernst, and A.H. Heuer, "Enhanced Fatigue Resistance in 316L Austenitic Stainless Steel Due to Low-Temperature Paraequilibrium Carburization," to be published in Acta Materialia, 2007.

14. A.H. Heuer, F. Ernst, H. Kahn, A. Avishai, G.M. Michal, D.J. Pitchure, and R.E. Ricker, "Interstitial Defects in 316L Austenitic Stainless Steel Containing "Colossal" Carbon Concentrations: An Internal Friction Study," Scripta Materialia 56(12) pp. 1067-1070 (2007).

15. J. Qu et al., "Tribological Properties of Stainless Steels Treated by Colossal Carbon Supersaturation," Wear 2007, doi: 10.1016/j.wear.2006.12.049 (in press).

16. J. Qu, P.J. Blau, and B.C. Jolly, "Tribological Properties of Stainless Steels Treated by Colossal Carbon Supersaturation," presentation at $16^{\text {th }}$ International Conference on Wear of Materials, Montreal, Quebec, Canada, Apr. 15-19, 2007. 
Appendix A

\section{SWAGELOK NEWS RELEASES}




\title{
Swagelok
}

\section{Noteworthy}

December 18, 2006

\begin{abstract}
SWAGELOK COMPANY AND CASE WESTERN RESERVE UNIVERSITY AWARDED $\$ 5.5$ MILLION THIRD FRONTIER GRANT FOR THE COMMERCIALIZATION OF BREAKTHROUGH MATERIALS TECHNOLOGY
\end{abstract}

Swagelok to Build Ohio Business Around Patented Technology, with Research Support from Case Western Reserve University

Swagelok Company, a major developer and provider of fluid system solutions headquartered in Solon, Ohio, along with its longtime research collaborator Case Western Reserve University, are the recipients of a three-year $\$ 5.5$ million grant from Ohio's Third Frontier Project. The grant will enable Swagelok, in partnership with Case, to further research, evaluate and commercialize a paradigm-shifting technology that the company developed and patented: Low-Temperature Colossal Supersaturation (LTCSS ${ }^{\mathrm{TM}}$ ). LTCSS is a method for heat-treating austenitic stainless steels that enables large-scale carbon absorption, dramatically improving hardness and other performance characteristics.

The announcement of the 2007 grant was made on December 15 by the Ohio Department of Development. The Third Frontier Project is a 10-year, $\$ 1.6$ billion initiative designed to expand Ohio's high-tech research capabilities, promote innovation and company formation, and create high-paying jobs.

"We recognize this opportunity as very significant, not only because of the breakthrough nature of the technology but also because of the resources available to us in the state of Ohio. We have top-notch laboratories and scientists, as well as manufacturing expertise and a world-class workforce right here in Northeast Ohio," said Art Anton, president and chief executive officer of Swagelok.

The Third Frontier grant will provide for development of the research, manufacturing, and infrastructure elements necessary to convert the LTCSS technology into a commercially viable, Ohio-based metals surface enhancement business.

Possible applications could include uses in the automotive, medical, aerospace and defense, oil and gas, and pulp and paper industries. Revenue from these initial efforts could provide funding 
for the research, development, and commercialization resources necessary to expand into other markets.

\section{LTCSS Technology}

LTCSS is a breakthrough technology that challenges the most basic knowledge about stainless steel. In materials science, it has been generally understood that carbon atoms cannot be introduced into austenitic stainless steel through heat treatment without the formation of chromium carbides, which compromise the corrosion resistant properties of the alloy. Hardness and corrosion resistance are typically regarded as tradeoffs.

And yet, LTCSS introduces carbon atoms into the austenitic, or face-centered-cubic (FCC), crystal structure without the formation of chromium carbides. In fact, the carbon absorption is about 80,000 greater than thermodynamics and kinetics would suggest would be possible. At the same time, corrosion resistance increases by 10,000 times; wear resistance by 100 times; erosion resistance by 5.5 times; and fatigue strength by approximately 50 percent.

These improvements occur at the surface of the stainless steel component being treated, not all the way through to the core. As a result, the LTCSS process is referred to as "case hardening." The surface hardness of austenitic stainless steels increases by about three to four times. LTCSS enables ordinary stainless steel to adopt performance characteristics of expensive alloys, like Hastelloy or titanium.

Finally, these improvements are achieved with no compromise to ductility. LTCSS may be performed on finished components without distortion or change of dimension, including components with complex shapes and structures.

These outcomes have been verified by research at Case, Oak Ridge National Laboratory, the U.S. Naval Research Laboratory, and Northwestern University.

"Arguably, this is one of the most significant breakthroughs in materials science in many decades, as well as one with many extraordinary technological implications," said Arthur Heuer, Ph.D., University Professor and Kyocera Professor of Materials Science and Engineering at Case, whose work has been instrumental in verifying the characteristics of LTCSS.

LTCSS has been successfully applied to other alloys besides austenitic stainless steels, including superaustenitic grade, duplex grade, ferritic grade, martensitic grade, Ni-base alloys, 
and Ni-Co-Cr alloys. With Third Frontier dollars, Case will research the application of LTCSS to these and other alloys.

\section{Engineering Materials Achievement Award}

In October 2006, Swagelok received the ASM International Engineering Materials Achievement Award for the development and commercialization of the LTCSS technology. This prestigious award is given to a company for a breakthrough technology that has been commercialized and proven.

Since 2000 , Swagelok has used LTCSS to case harden the rear ferrule of its signature tube fitting, which is designed with patented back ferrule geometry.

The LTCSS research team is led by Swagelok's Sunniva Collins, Ph.D., an accomplished research metallurgist who has been involved with LTCSS since its inception; Peter Williams, the company's chief scientist, who is the inventor of the technology; and Heuer of Case.

\section{About Swagelok Company}

Headquartered in Solon, Ohio, U.S.A., Swagelok Company is a major developer and provider of fluid system solutions, including products, assemblies, and services for the research, instrumentation, pharmaceutical, oil and gas, power, petrochemical, alternative fuels, and semiconductor industries. Its manufacturing, research, technical support, and distribution facilities support a global network of more than 200 authorized sales and service centers in 54 countries. For more information about Swagelok, visit the company's Web site at www.swagelok.com.

\section{About Case Western Reserve University}

Case is among the nation's leading research institutions. Founded in 1826 and shaped by the unique merger of the Case Institute of Technology and Western Reserve University, Case is distinguished by its strengths in education, research, service, and experiential learning. Located in Cleveland, Case offers nationally recognized programs in the Arts and Sciences, Dental Medicine, Engineering, Law, Management, Medicine, Nursing, and Social Work. http://www.case.edu. 


\section{Noteworthy}

\section{Swagelok}

January 5, 2007

\section{John Buda Named to Lead New LTCSS Business Sunniva Collins is Technology Director}

In December 2006, Swagelok received a \$5.5 million Third Frontier Grant from the Ohio Department of Development to commercialize our breakthrough technology, Low-Temperature Colossal Supersaturation (LTCSS). The grant was made in partnership with Case Western Reserve University. LTCSS is a method for heat-treating austenitic stainless steels that enables large-scale carbon absorption, dramatically improving hardness and other performance characteristics.

In order to focus our efforts to market and commercialize this process to a potentially different group of customers, many who we do not serve today, Swagelok has formed a new subsidiary to act as a separate business unit. This separate unit will be named shortly.

I am pleased to announce that John Buda has been named president of the new business unit. John will report to Mike Butkovic, vice president, marketing.

Formerly manager, strategic alliance accounts, John will be responsible for developing the LTCSS business, marketing, and operating plans. Until we identify a permanent replacement for John, Mike Chadwick, Andrew Dougherty, Paul Riley and Bill Moore will fill in to help manage some of John's accounts and current alliance negotiations.

Reporting to John Buda will be Sunniva Collins, who has accepted the position of technology director for the new business. Sunniva, a Ph.D. and accomplished research metallurgist, has been involved with LTCSS since its inception. She will work with John to market this new process to targeted applications and industries.

We have started the process to fill Sunniva's vacated position.

Please join me in extending your full support to John and Sunniva as they undertake this exciting new business venture.

Art Anton

President and Chief Executive Officer 


\section{Noteworthy}

\section{Swagelok}

April 16, 2007

\section{Names Established for New Subsidiary Company and Process}

A name has been established for the new subsidiary company to market and commercialize the Low Temperature Colossal Supersaturation (LTCSS) process. This new business unit is Swagelok Technology Services Company (STSC) and the new process name for LTCSS is Swagelok® SAT12 (SM) patented surface hardening process.

SAT12 is derived from a combination of "SAT" and "12". SAT is short for super-saturation and the number 12 represents the atomic mass of carbon.

As stated in an earlier distributor notice, John Buda is the company president, and Sunniva Collins is the technology director.

We will continue to communicate information about Swagelok Technology Services Company as it becomes available. In the meantime, please direct any questions to John or Sunniva via email: John.Buda@swagelok.com ; Sunniva.Collins@swagelok.com. 


\section{Swagelok}

\section{Noteworthy}

July 25,2007

\section{Swagelok Technology Services Company Receives First Order}

We are pleased to announce that our newest business unit, Swagelok Technology Services Company (STSC), received its first customer order for treatment of alloy specimens with the Swagelok ${ }^{\circledR}$ SAT $12^{\text {SM }}$ patented surface-hardening process. This order was placed by the U.S. Naval Research Laboratory.

STSC was formed earlier this year after a $\$ 5.5$ million Third Frontier Grant from the Ohio Department of Development was awarded to Swagelok to market and commercialize its SAT12 ${ }^{\mathrm{SM}}$ process into a commercially viable, Ohio-based metals surface enhancement business.

This breakthrough technology is a method for heat treating austenitic stainless steels that enables large-scale carbon absorption, dramatically improving hardness and other performance characteristics.

John Buda

President

Swagelok Technology Services Company 
Appendix B

\section{RESULTS OF FIELD TESTING}




\section{Pressure Regulator Valve}

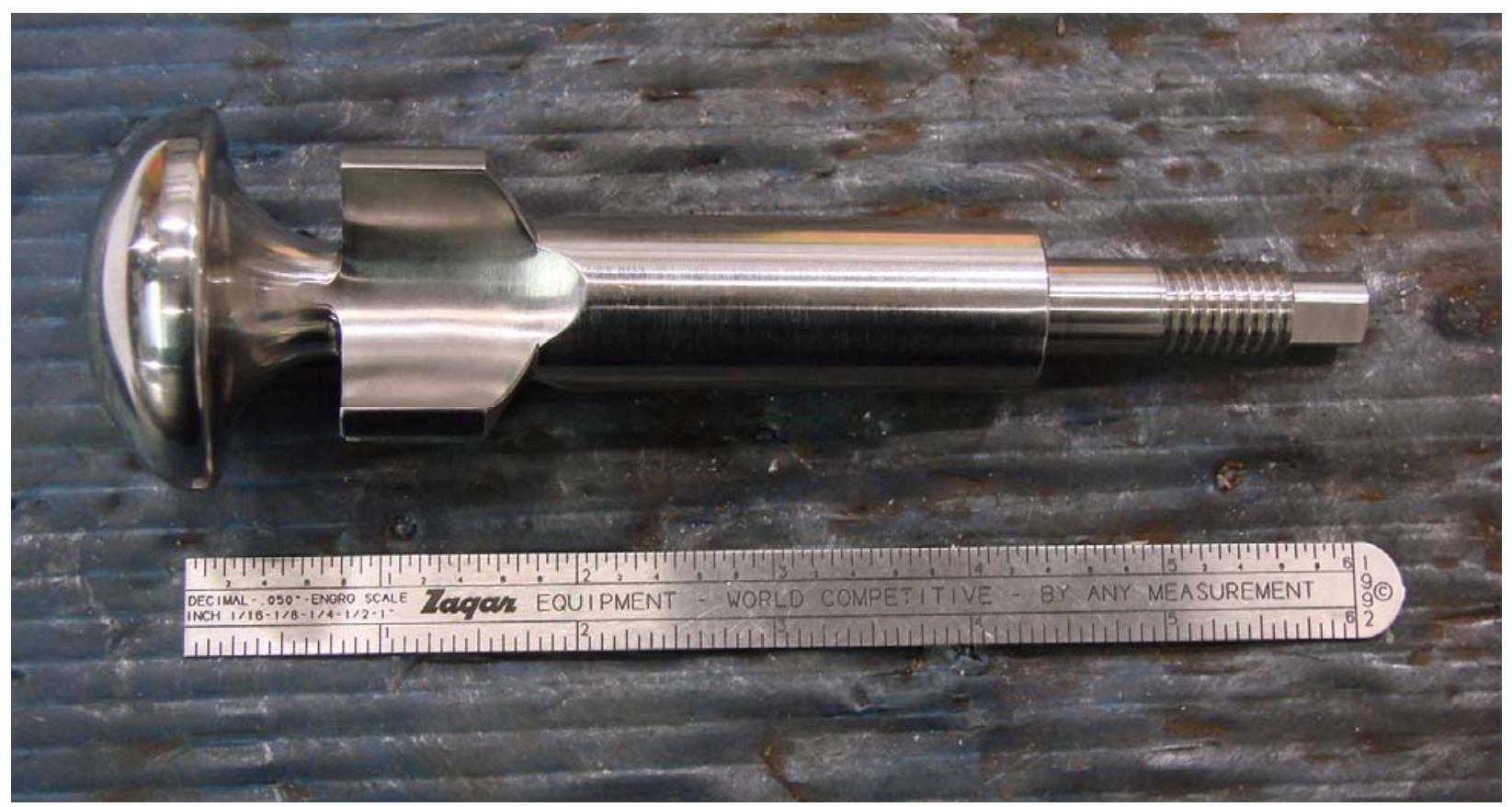

Figure B1: Pressure regulator valve of 316 stainless steel for operation in a 316L body in steam at $350^{\circ} \mathbf{F}$. New valve that was subjected to SAT-12 treatment (valve supplied by Spirax Sarco).

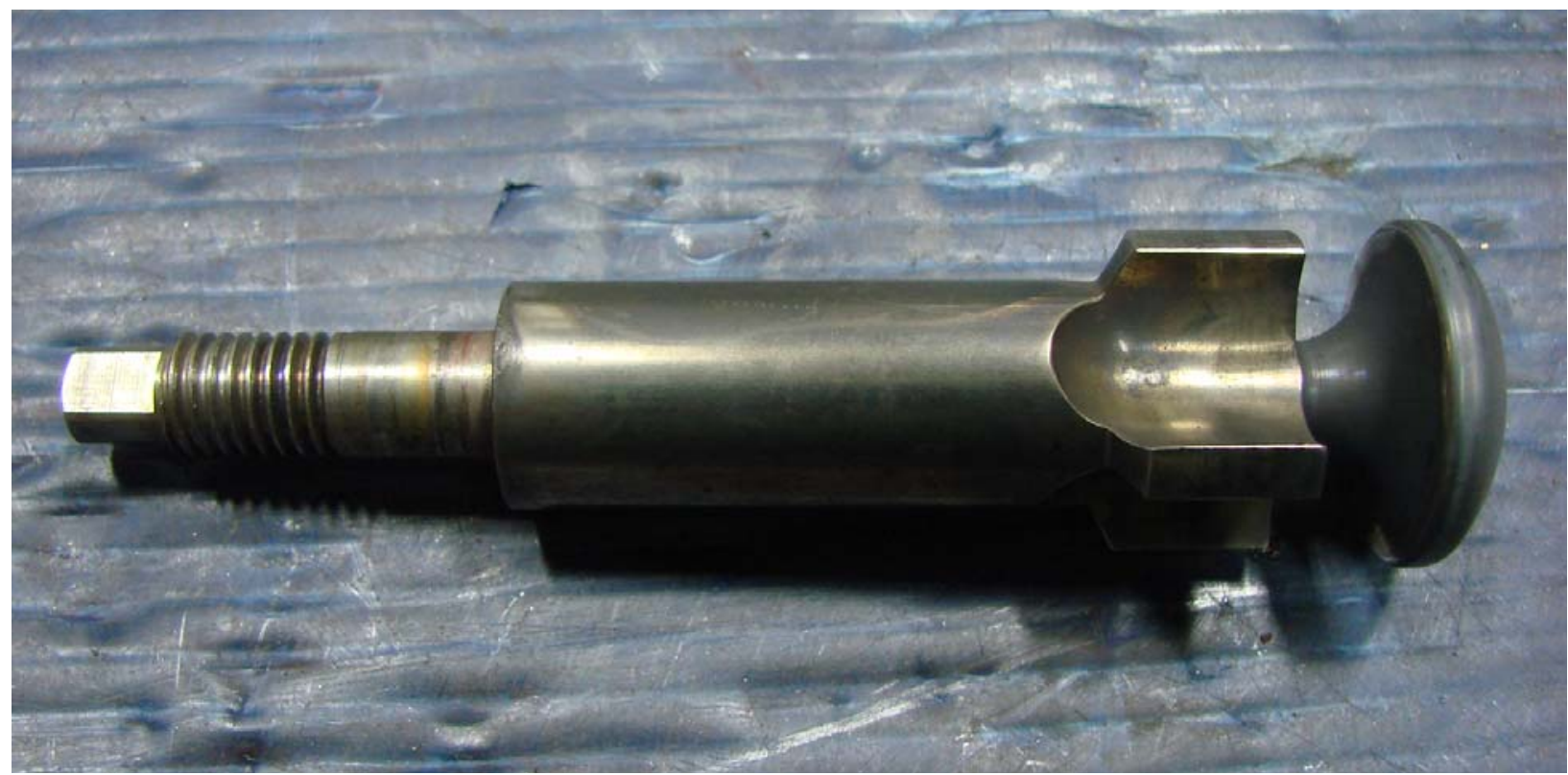

Figure B2: Pressure regulator valve of 316 stainless steel after $+1,000,000$ cycles of operation in a 316 L body in steam at $350^{\circ} \mathrm{F}$. Only slight polishing on the wear surfaces on the guide flues was noted. This was called "very impressive" by Spirax Sarco. 


\section{Pressure Regulator Valve}

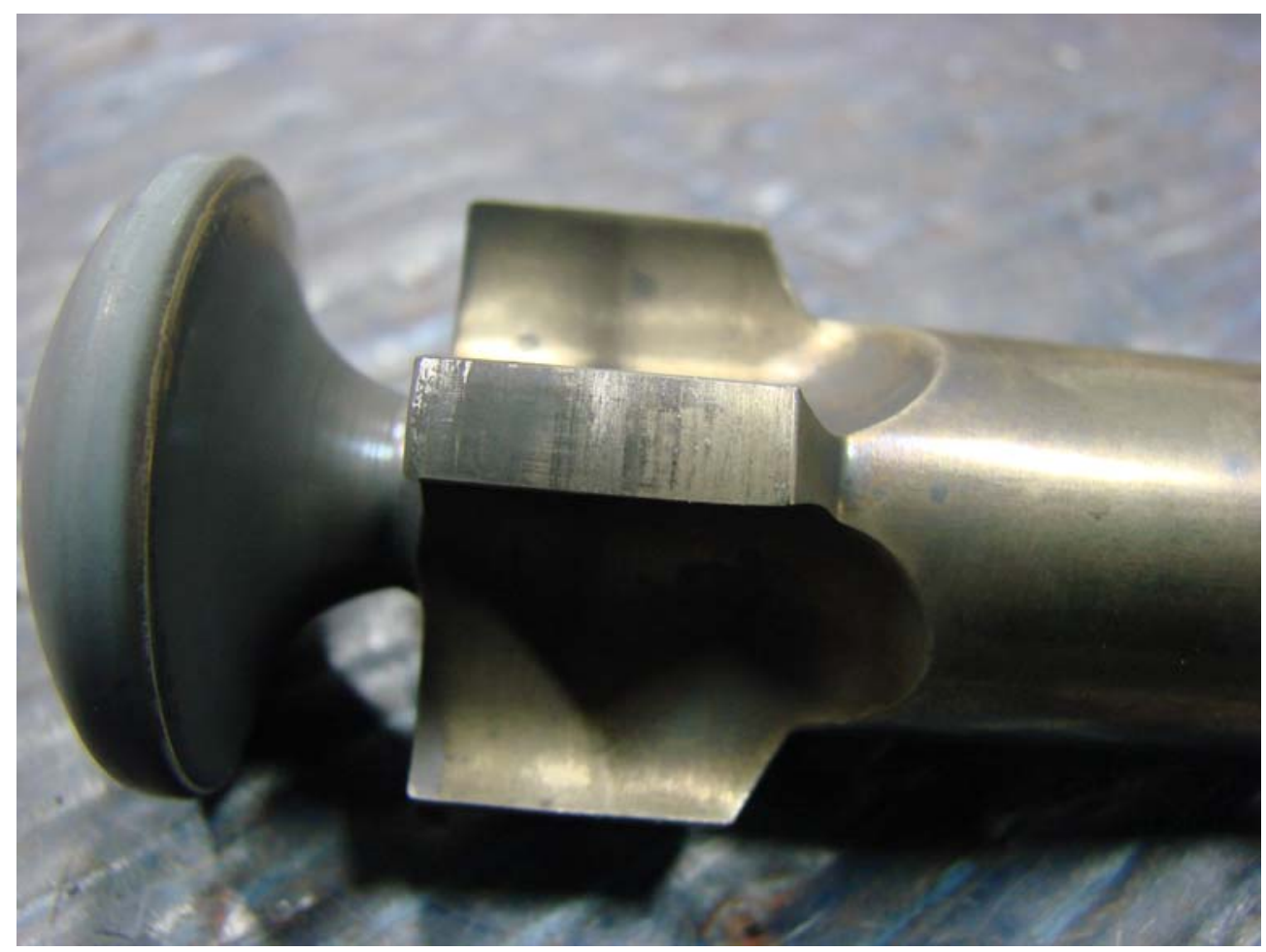

Figure B3: Pressure regulator valve of 316 stainless steel after $+1,000,000$ cycles of operation in a 316 $\mathrm{L}$ body in steam at $350^{\circ} \mathrm{F}$. Enlarged view of the polishing on the wear surface shows essentially no wear.

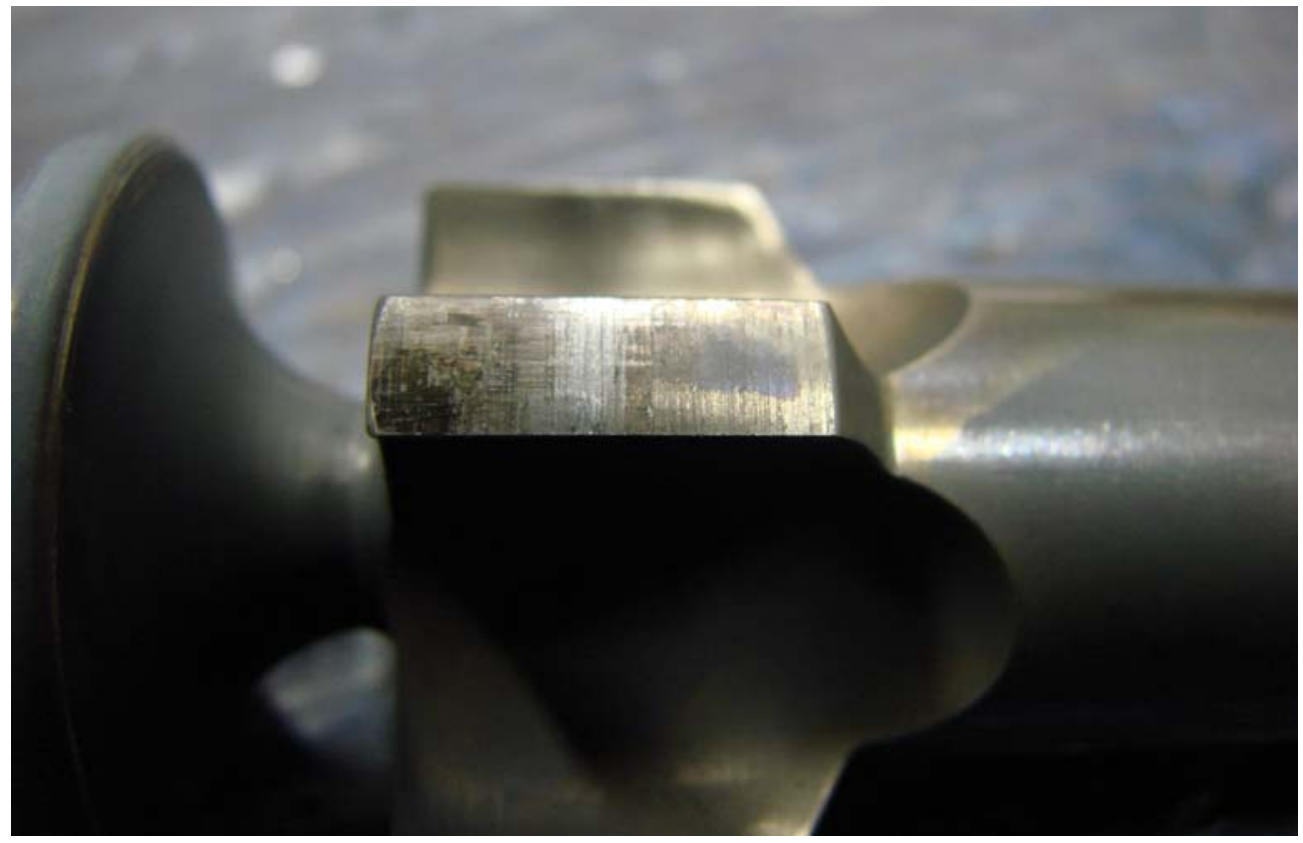

Figure B4: Pressure regulator valve of 316 stainless steel after $+1,000,000$ cycles of operation in a $316 \mathrm{~L}$ body in steam at $350^{\circ} \mathrm{F}$. Enlarged view of the polishing on the second wear surface shows essentially no wear. 


\section{Sludge Pump Plate}

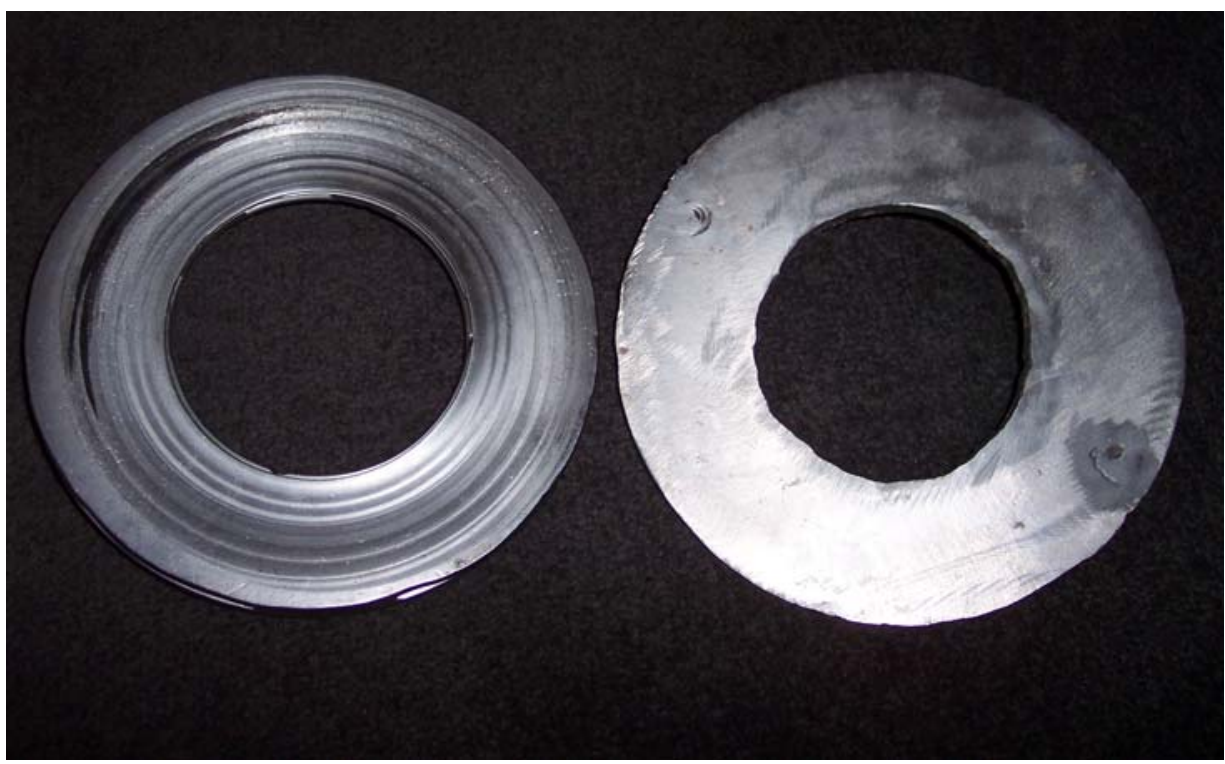

(a)

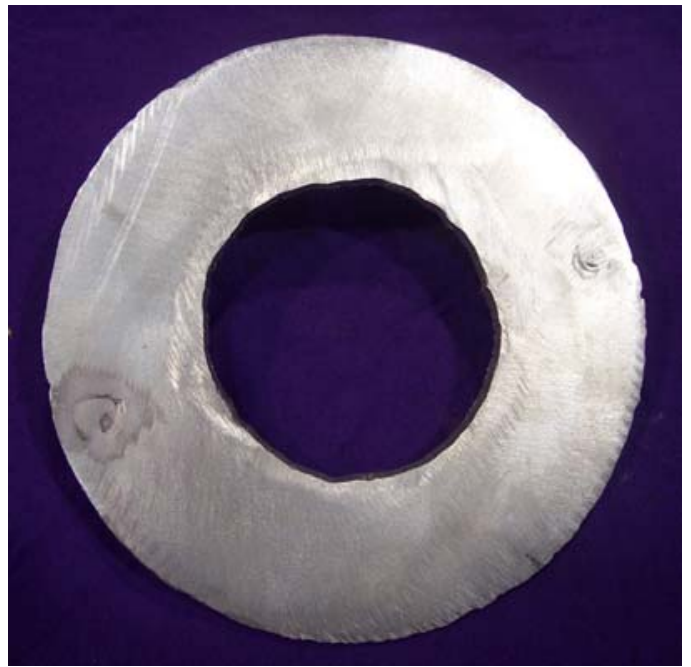

(b)

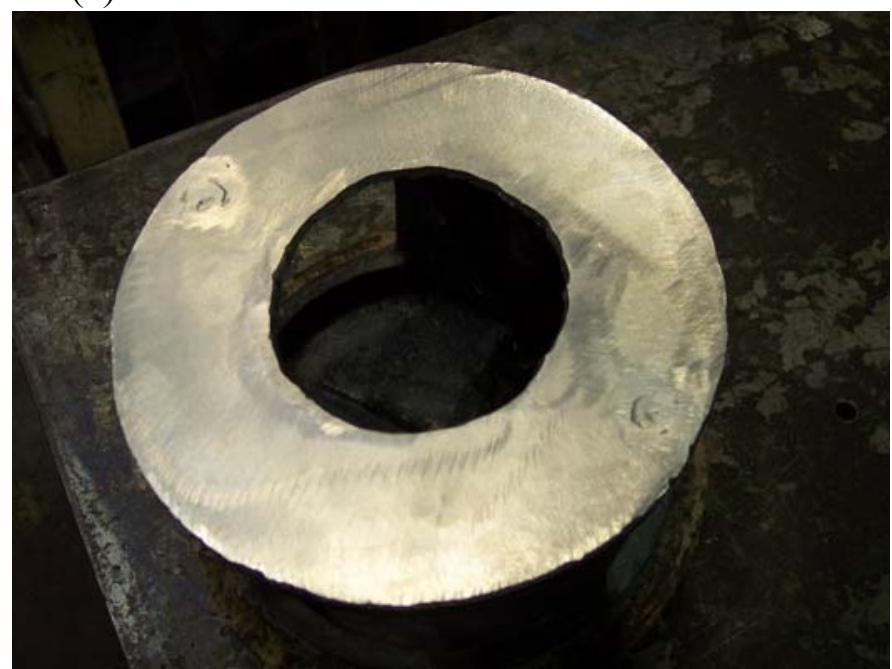

(c)

Figure B5: Photographs of the sludge plump plate of 304 stainless steel in SAT-12 treated condition (corrosive pumping service in Sonoco's cardboard recycling facility in Newport, TN) after: (a) three months, (b) nine months, and (c) eighteen months. The plate in (c) shows six times improvement with no noticeable wear. Sonoco called this "simply amazing." 


\section{Steam Trap Seats}

The following photographs are of steam trap seats of 300 series stainless steel after SAT-12 treatment and testing in saturated steam at $\sim 275^{\circ} \mathrm{F}$ for twenty months by Spirax Sarco. The seat parts retained acceptable corrosion with no signs of wear. Based on these data, Spirax Sarco considers successful proving of wear enhancement obtained by the SAT-12 process.

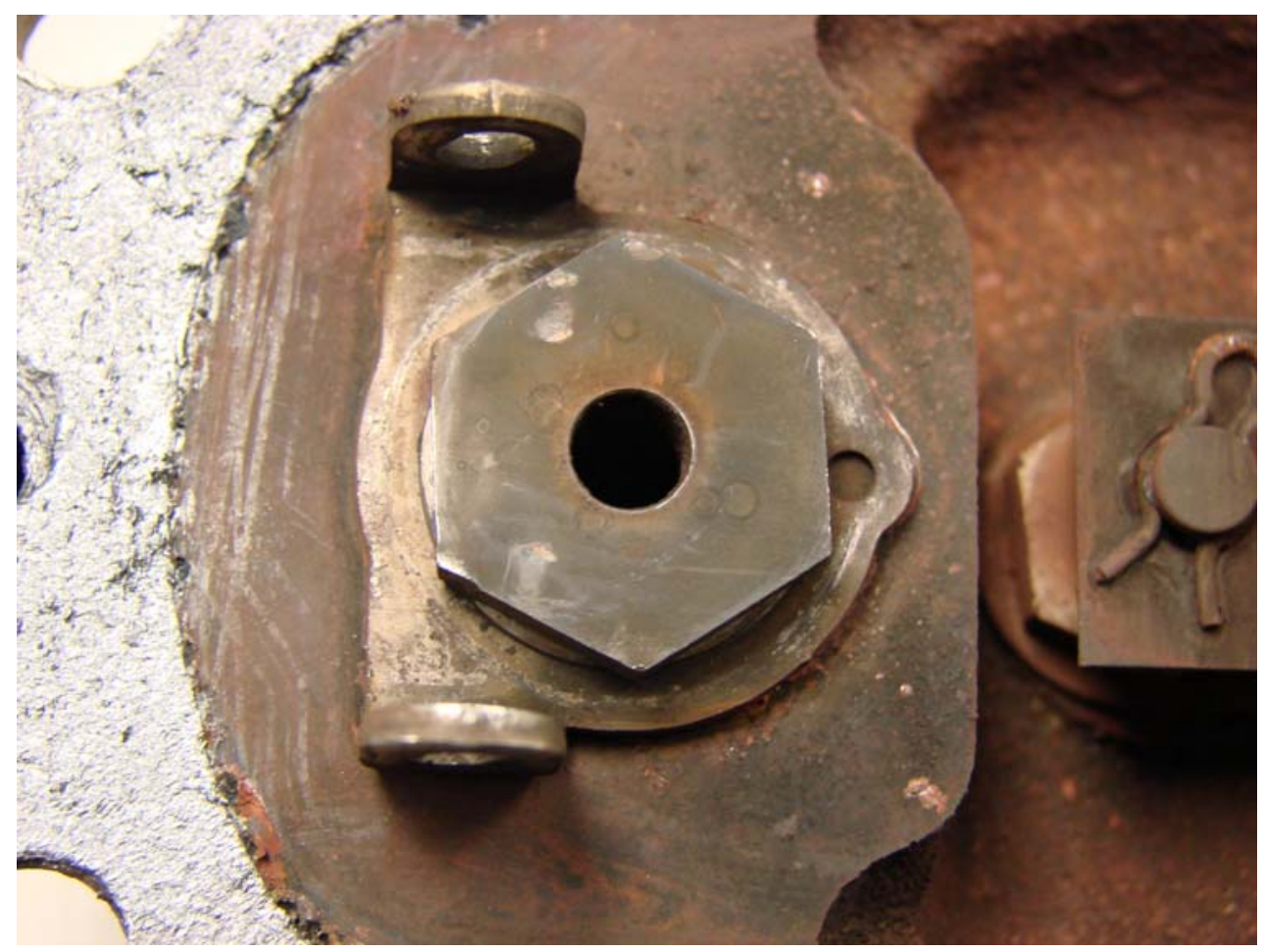

(a)

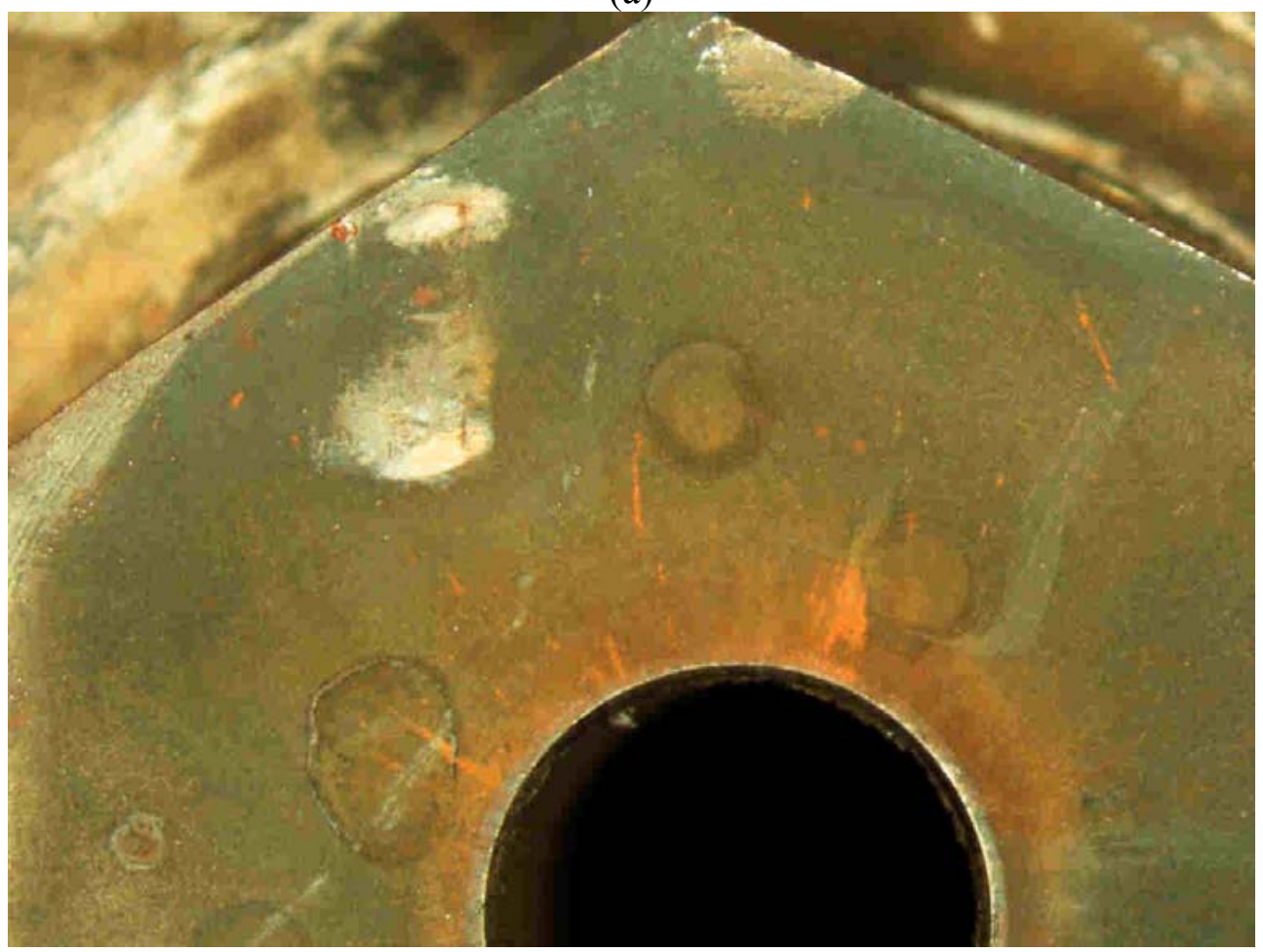

(b) 


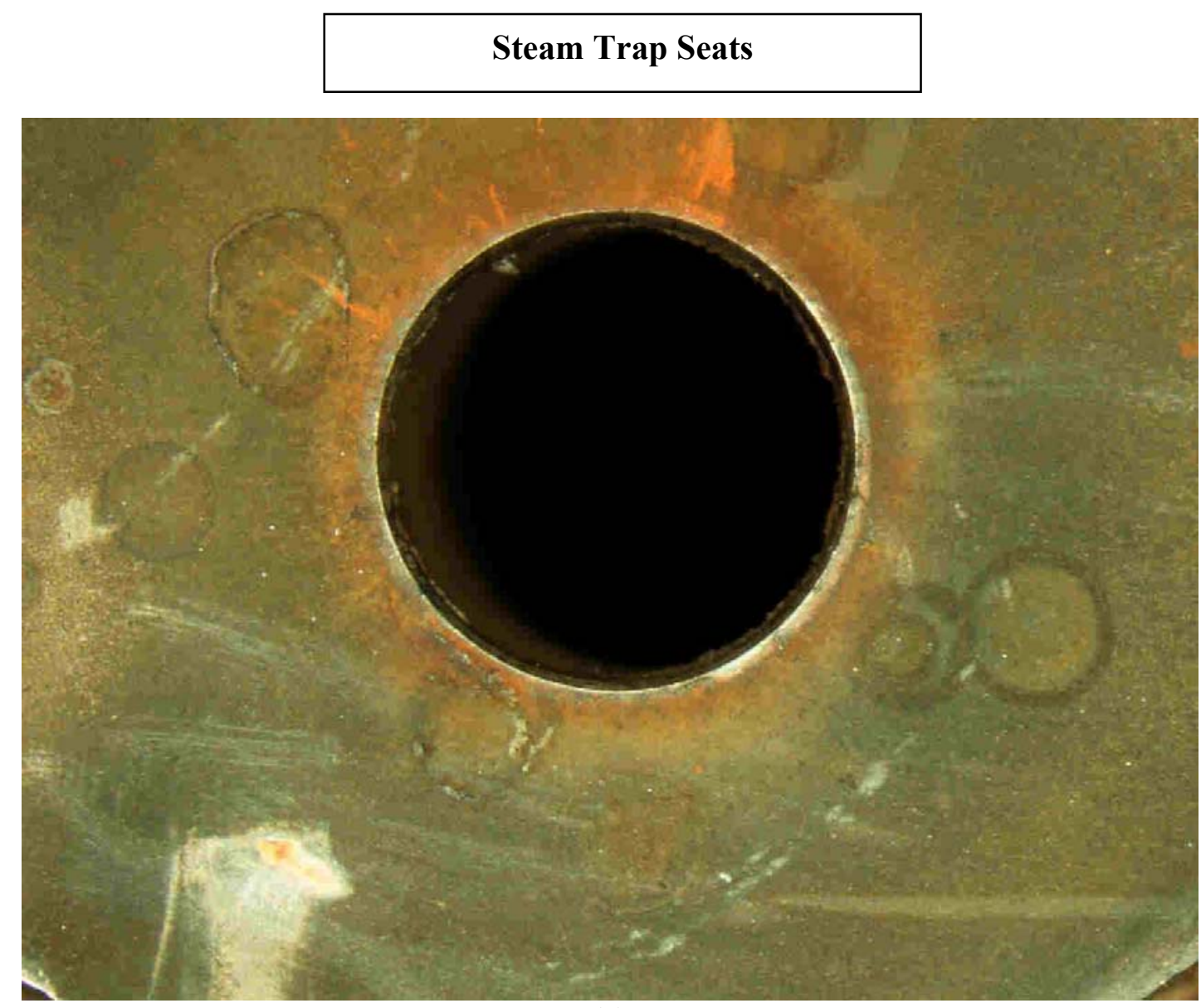

(c)

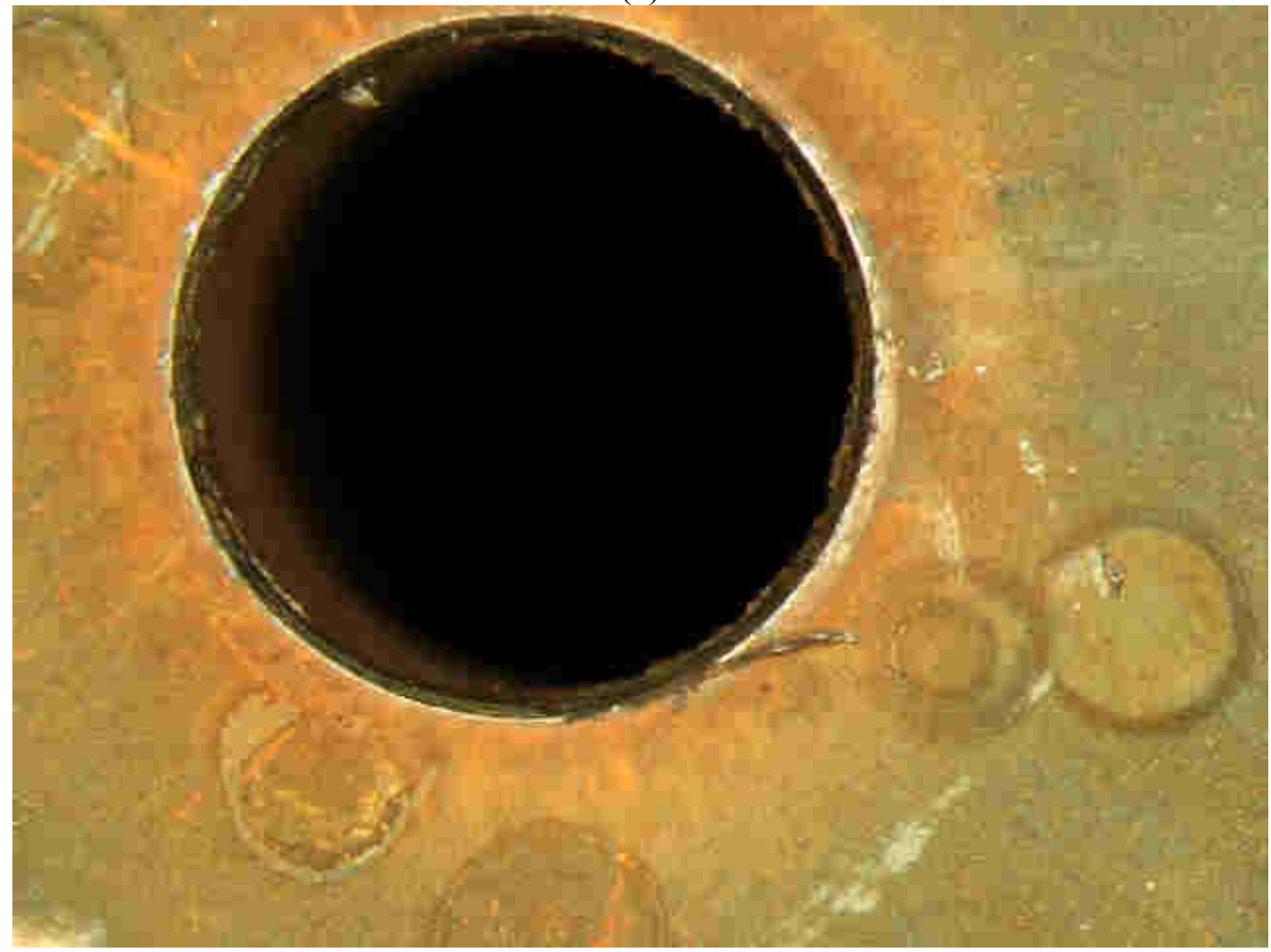

(d) 


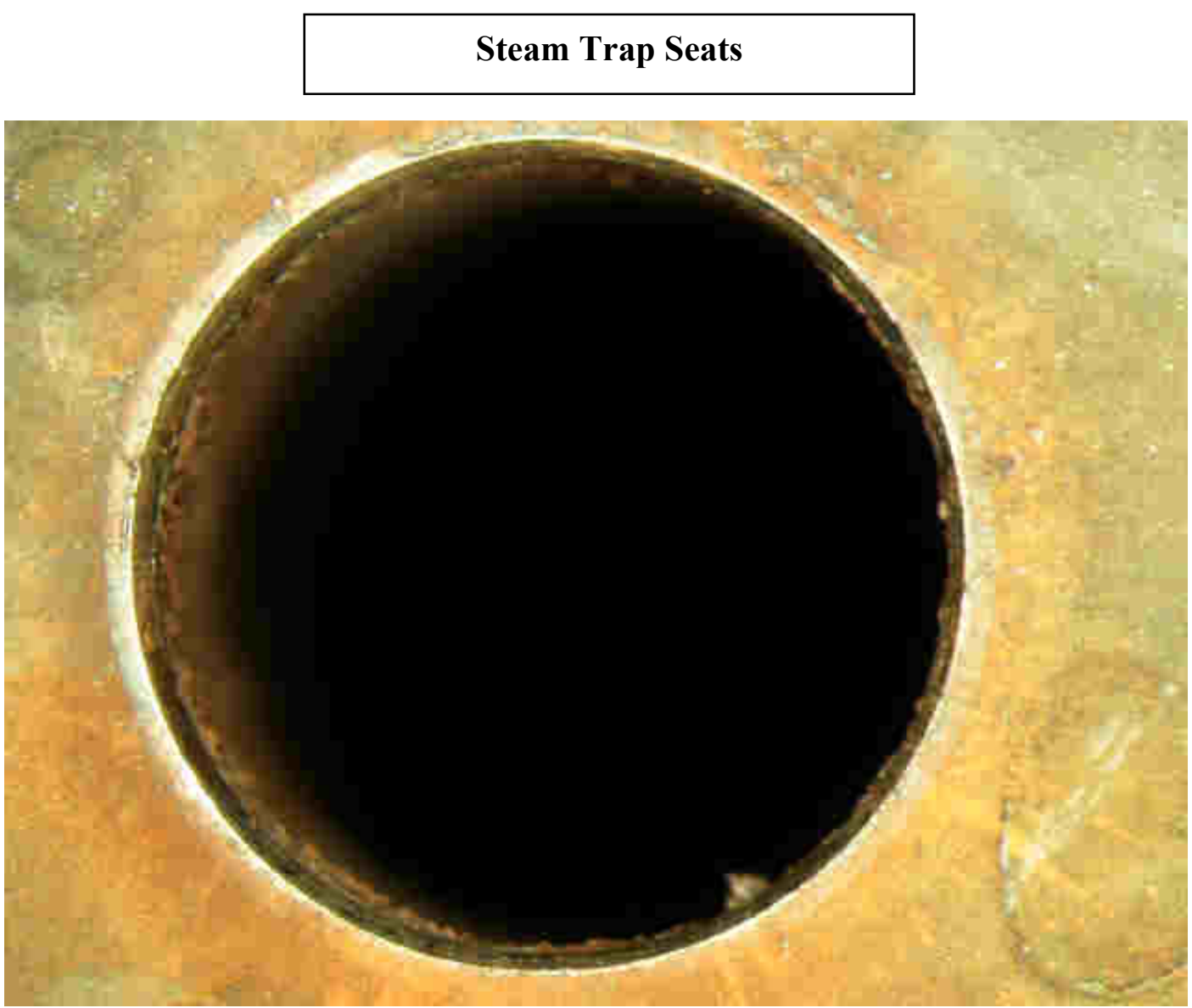

(e)

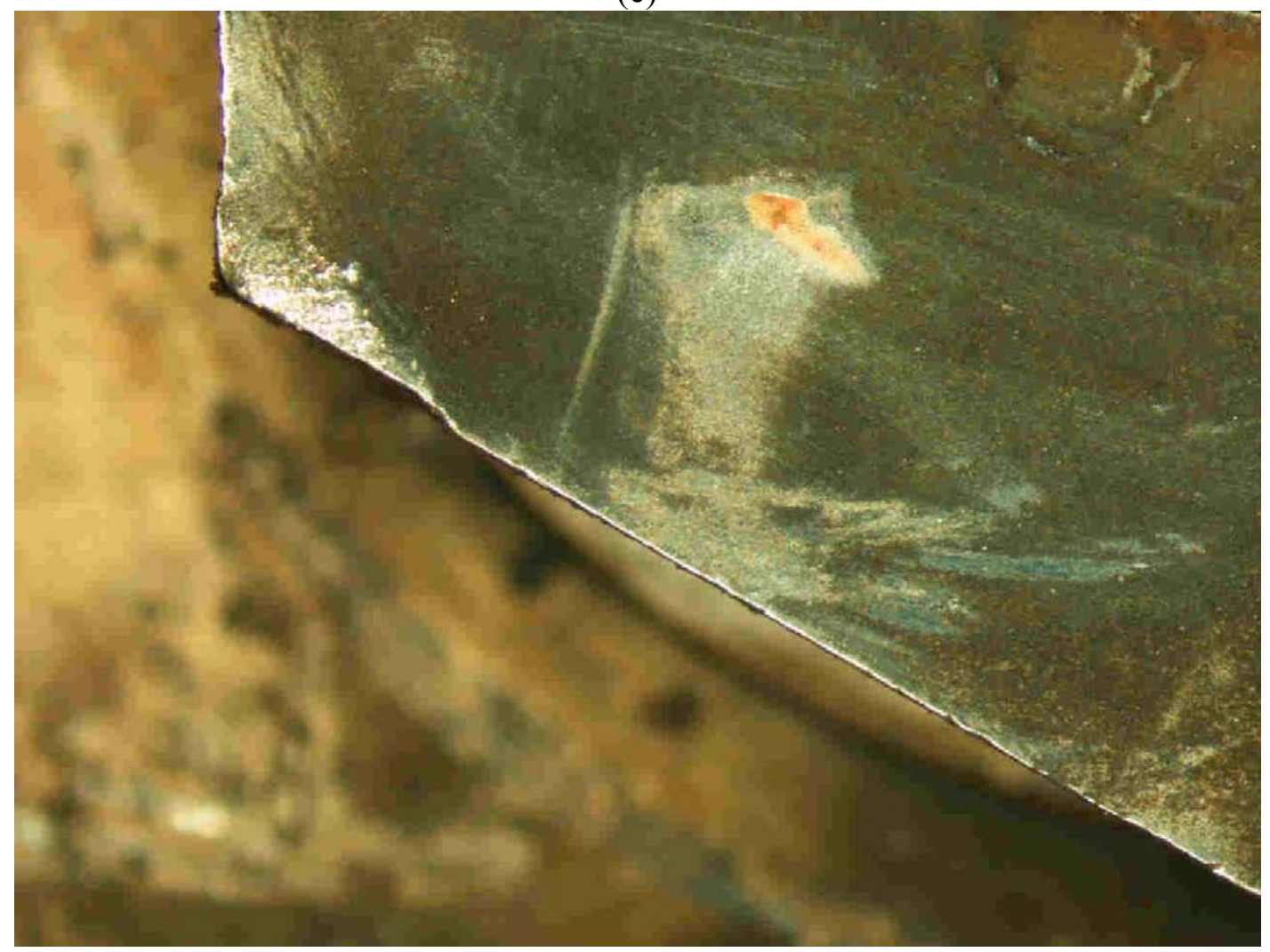

(f) 
